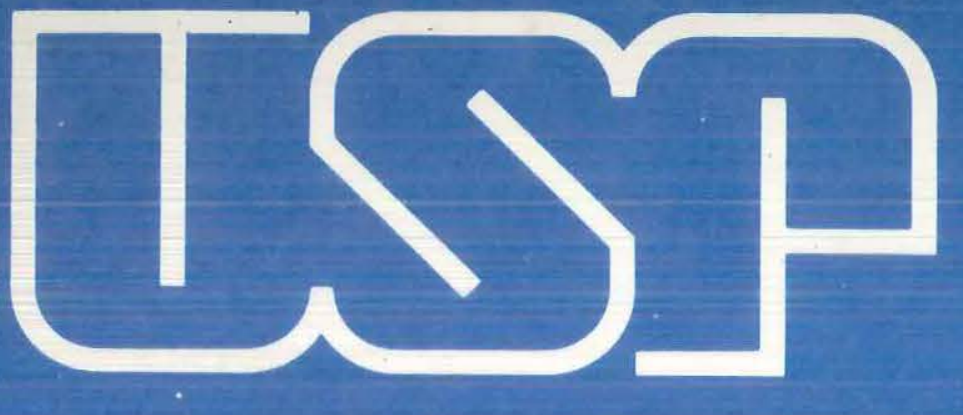

Campus de São Carlos

CÁLCULO DE ESFORÇOS E DESLOCAMENTOS EM PAVIMENTOS DE EDIFICIOS CONSIDERANDO-SE MODELOS PRÓPRIOS PARA O CONCRETO ARMADO

AUTOR: Engo. FAUSTINO SANCHES JÚNIOR ORIENTADOR: Prof. Dr. WILSON SERGIO VENTURINI

UNIVERSIDADE DE SÃO PAULO

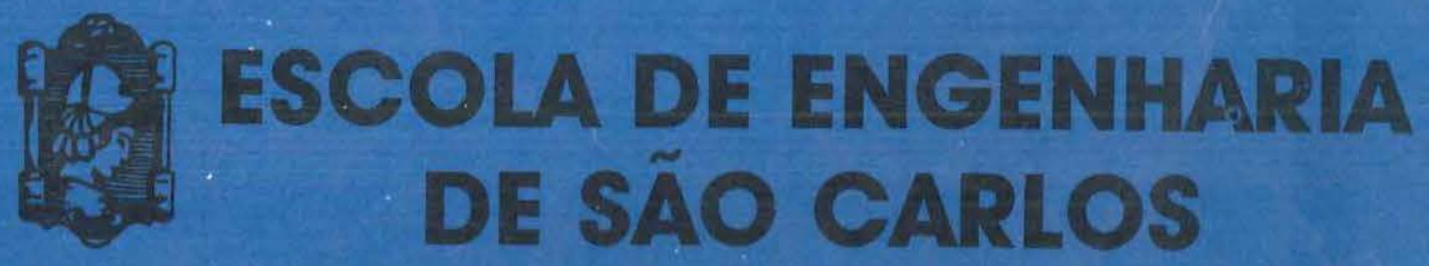




\section{CÁLCULO DE ESFORÇOS E DESLOCAMENTOS EM PAVIMENTOS DE EDIFÍCIOS CONSIDERANDO-SE MODELOS PRÓPRIOS PARA O CONCRETO ARMADO}

FAUSTINO SANCHES JÚNIOR

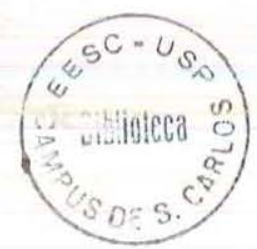

Dissertação apresentada à Escola de Engenharia de São Carlos, da Universidade de São Paulo, como parte dos requisitos para obtenção do título de

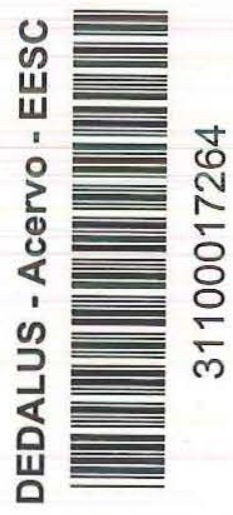
Mestre em Engenharia de Estruturas.

Orientador : Prof. Tit. Wilson Sérgio Venturini

São Carlos 


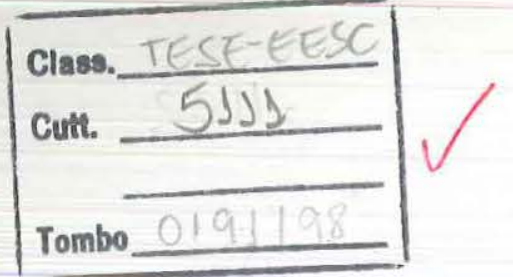

1405198

st 0984425

Ficha catalográfica preparada pela Seção de Tratamento da Informação do Serviço de Biblioteca - EESC-USP
Cálculo de esforços e deslocamentos em pavimentos de edifícios considerando-se modelos próprios para concreto armado / Faustino Sanches Júnior. -- São Carlos, 1998.

Dissertação (Mestrado) -- Escola de Engenharia de São Carlos-Universidade de São Paulo, 1998. Área: Engenharia de Estruturas.

Orientador: Prof. Dr. Wilson Sérgio Venturini.

1. Elementos finitos. 2. Análise não-linear. 3. Pavimentos. 4. Concreto armado. I. Título. 
Ofereço este trabalho aos meus pais. 


\section{AGRADECIMENTOS}

A Deus.

Ao Prof. Venturini, pelo paciente trabalho de orientação e pela amizade.

À Fundação de Amparo à Pesquisa do Estado de São Paulo - FAPESP, pelo auxílio financeiro.

A todos professores, colegas e funcionários do Departamento de Engenharia de Estruturas da EESC-USP. 
SUMÁRIO

LISTA DE FIGURAS V v

LISTA DE TABELAS viii

LISTA DE SÍMBOLOS ix

LISTA DE ABREVIATURAS E SIGLAS xii

RESUMO Xiii

ABSTRACT Xiiv

1-INTRODUÇÃO

1.1-GENERALIDADES

1.2-OBJETIVOS 3

1.3-METODOLOGIA

1.4- ORGANIZAÇÃO DO TEXTO 5

2-COMPORTAMENTO EMI SERVIÇO DAS ESTRUTURAS DE $\begin{array}{ll}\text { CONCRETO ARMADO } & 7\end{array}$

2.1-INTRODUÇÃo

2.2-ESTADOS LIMITES $\quad \mathbf{8}$

2.2.1-ESTADOS LIMITES DE UTILIZAÇÃO

2.2.2-ESTADO LIMITE ÚLTIMO 9

2.3-ESTÁDIOS DE SOLICITAÇÃO

2.3.1-CÁLCULO CLÁSSICO NO ESTÁDIO 1 PARA A FLEXÃO SIMPLES 14 
2.4-CONTRIBUIÇÃO DO CONCRETO INTACTO ENTRE FISSURAS - "TENSION STIFFENING"

2.4.1-TIRANTE DE CONCRETO ARMADO 22

3-FENÔMENOS REOLÓGICOS DO CONCRETO ARMADO 27

$\begin{array}{ll}\text { 3.1-INTRODUÇÃO } & 27\end{array}$

3.2-FLUÊNCIA DO CONCRETO

3.3-RETRAÇÃo DO CONCRETO

3.4-RELAXAÇ̃̃O DO CONCRETO

3.5-CÁLCULO DA RETRAÇ̃̃o E FLUÊNCIA DE ACORDO COM O CÓDIGO - MODELO DE 1990 DO CEB 36

3.5.1-APLICABILIDADE DO MODELO 36

3.5.2-PARÂMETROS DE CÁLCULO 36

3.5.3-CÁlCULO DA RETRAÇÃO 38

3.5.4-CÁLCULO DA FLUÊNCIA DO CONCRETO 40

3.6-VARIAÇÃo DO MÓDULO DE DEFORMAÇÃO LONGITUDINAL DO CONCRETO 43

3.7-DESENVOLVIMENTO DA RESISTÊNCIA COM O TEMPO 44

3.7.1-RESSITÊNCIA À COMPRESSÃO 44

3.7.2-RESISTÊNCIA À TRAÇĀO

3.8-CÁLCULO DO COEFICIENTE DE ENVELHECIMENTO DO CONCRETO 46

3.8.1-RELAÇÕES BÁSICAS 46

3.8.2-ALGORITMO "PASSO A PASSO" PARA O CÁLCULO DA RELAXAÇ̃̃O DO

CONCRETO. 48

3.9-MODIFICAÇÕES NOS ESFORÇOS SOLICITANTES DEVIDO À FLUÊNCIA 
4.2-MODELO DE GHALI \& FAVRE - FLEXÃO SIMPLES

4.2.1-INSTANTE DA APLICAÇÃO DO CARREGAMENTO 57

4.2.2-INSTANTE GENÉRICO DE TEMPO $\quad 60$

4.3-MODELO DE DEBERNARDI - FLEXÃO SIMPLES 66

4.3.1-INTRODUÇÃOO 66

4.3.2-HIPÓTESES BÁSICAS

4.3.3-EQUAÇÕES CONSTITUTIVAS

4.3.4-TENSÕES E DEFORMAÇÕES: SEÇÃO NÃO FISSURADA DE CONCRETO ARMADO

69

4.3.5-TENSÕES E DEFORMAÇÕES: SEÇÃO FISSURADA DE CONCRETO ARMADO 76

5-ANÁLISE LINEAR E NÃO-LINEAR DE ESTRUTURAS 93

5.1-GENERALIDADES 93

5.1.1 - PRINCÍPIO DA MÍNIMA ENERGIA POTENCIAL 94

5.1.2-CASO NÃO-LINEAR 95

5.2-ELEMENTO FINITO DE BARRA

5.2.1-MATRIZ DE RIGIDEZ : PARCELA DA FLEXÃO 97

5.2.2 - MATRIZ DE RIGIDEZ - PARCELA DA TORÇÃO 99

5.3-CÁlCULO DOS RESÍDUOS DE CARREGAMENTO NO ELEMENTO 100

5.4-SOLUÇÃO NUMÉRICA 101

5.4.1-INTRODUÇÃO 101

5.4.2-FORMULAÇÃO INCREMENTAL 102

5.4.3-FORMULAÇÃO ITERATIVA : Método de Newton-Raphson: 103

6-PROGRAMA PARA ANÁLISE DE GRELHAS 106

$\begin{array}{lr}\text { 6.1-INTRODUÇÃO } & 106\end{array}$

6.2-NÃO-LINEARIDADE FÍSICA - INSTANTE DE APLICAÇÃO DO CARREGAMENTO 
7.2-EXEMPLOS DO BULLETIN-158 DO CEB

7.2.1-VIGA BI-ENGASTADA

7.2.2-VIGA SIMPLESMENTE APOIADA

7.2.3-VIGA BI-APOIADA COM SEÇÃO "T"

7.3-COMPARAÇÃO COM DADOS EXPERIMENTAIS

7.3.1-LABORATÓRIO DE ESTRUTURAS DAS EESC-USP

7.3.2-ENSAIO DE BRESLER e SCORDELIS

7.4-PAVIMENTOS DE EDÍFICIOS

7.4.2-PAVIMENTO FICTÍCIO

7.4.3-PAVIMENTO REAL 


\section{LISTA DE FIGURAS}

Figura 2.1: Estádios de solicitação de uma seção de concreto armado 13

Figura 2.2: Seção transversal e deformações para o estádio 1

Figura 2.3: Seção transversal e deformações para o estádio 2

Figura 2.4 : Tensőes em um tirante fissurado de concreto armado 23

Figura 3.1 : Barra de concreto carregada axialmente 29

Figura 3.2: Deformações ao longo do tempo 32

Figura 3.3 : Retração e expansão ao longo do tempo 33

Figura 3.4 : Deformação de barra prismática 35

Figura 3.5 : Relaxação do concreto 35

Figura 3.6 : Módulos de deformação longitudinal tangente e secante para o concreto 43

Figura 3.7 : Divisão de tensőes com o tempo para a análise "passo a passo" da relaxação do concreto $\quad 49$

Figura 3.8: Aplicação do processo dos deslocamentos 54

Figura 3.9 : Momentos isostáticos 54

Figura 4.1 : Peça fissurada de concreto armado 57

Figura 4.2: Diagrama Momento-Curvatura - Flexão Simples 60

Figura 4.3 : Efeitos da fluência e retração numa seção não fissurada de concreto armado 63

Figura 4.4 : Efeitos da fluência e retração numa seção fissurada de concreto armado 64

Figura 4.5 : Tensőes e deformaçőes nos tempos "to" e " $t$ " para uma seção não-fissurada de concreto armado 
Figura 4.6 : Tensões e Deformações Nos Tempos " $t_{0}$ " e " $t$ " Para Uma Seção Fissurada De Concreto Armado

Figura 4.7 : Contribuição do concreto intacto entre fissuras - "tension stiffening" - na flexão simples

Figura 5.1 : Viga com carregamento qualquer 94

Figura 5.2: Elemento de barra 97

Figura 5.3 : Métodos de Newton-Raphson 105

Figura 6.1 : Seção transversal típica 107

Figura 6.2: Elemento de barra 108

Figura 6.3 : llustração do cálculo das curvaturas $\quad 110$

Figura 6.4 : Resíduos de momento para uma seção 110

Figura 6.5 : Determinação do modulo de deformação por flexão secante 112

Figura 6.6: Apresentação de fluxograma de procedimento incrementaliterativo

Figura 6.8 : Diagrama momento curvatura, com a consideração da fluência

Figura 6.9 : Resíduo de momento devido a fluência para o instante de tempo "to $+\Delta t "$

Figura 6.10 : Fluxograma de procedimento incremental-iterativo para o instante de aplicaçäo das cargas e incremental para a consideraçăo das deformaçőes ao longo do tempo

Figura 6.11: Novo carregamento na estrutura

Figura 6.12: Fluxograma para análise considerando carregamentos em instantes de tempo distintos

Figura 6.13: Descarregamento

Figura 7.1: Exemplo 7.2.1- viga bi-engastada de concreto armado

Figura 7.2 : Diagrama de momentos para exemplo 7.2.1. (kN.cm) 122

Figura 7.3: Curva de Deslocamentos Para o Ponto Central da Viga 123

Figura 7.4 : Viga bi-apoiada do exemplo 7.2.2. 
Figura 7.5: Viga do exemplo 7.2.3

Figura 7.7: Resultados numéricos para viga pouco armada

Figura 7.8: Resultados numéricos para viga normalmente armada

Figura 7.9 : Resultados numéricos para viga muito armada

Figura 7.10 : Viga ensaiada por Bresler \& Scordelis

Figura 7.11 : Resultados numéricos para viga ensaiada por BRESLER \& SCORDELIS

Figura 7.12: Resultados para viga V01 136

Figura 7.13: Pavimento fictício 137

Figura 7.14 : Pavimento : Pilotis de Edifício 139

Figura 7.15: Simetria no pavimento 140

Figura 7.16: Discretização em elementos finitos 141

Figura 7.17: Carregamentos no pavimento 142

Figura 7.18 : Diagramas de momento fletor - exemplo 7.4

Figura A.1 : Seção em forma de "I " 148

Figura A.2 : Estádio 2 : a) seção transversal; b) comportamento de seção retangular; c) comportamento de seção " I" 


\section{LISTA DE TABELAS}

Tabela 7.1: Taxas de armadura e carregamento para a viga Fig.(7.4)

124

Tabela 7.2 : Deslocamento vertical do ponto médio do vão da viga do exemplo 7.2.2 para os instantes "to"

Tabela 7.3 : Deslocamento vertical do ponto médio do vão da viga do exemplo 7.2.2 "t"

Tabela 7.4 : Viga do exemplo 7.3.1

Tabela 7.5: Deslocamentos em pontos nodais

Tabela A.1 : Coordenadas do exemplo 7.4.2

Tabela A.2 : Incidência das barras do exemplo 7.4.2

Tabela A.3 : Seções transversais das barras do exemplo 7.4.2 


\section{LISTA DE SÍMBOLOS}

\section{letras romanas maiúsculas}

$\begin{array}{ll}A & \text { - área } \\ A_{s} & \text {-área da armadura longitudinal tracionada } \\ A_{S}^{\prime} & \text { - área da armadura longitudinal comprimida } \\ E_{c} & \text { - módulo de elasticidade longitudinal do concreto } \\ E_{s} & \text { - módulo de elasticidade longitudinal do aço } \\ F & \text { - vetor de esforços nodais na estrutura } \\ G & \text { - módulo de elasticidade transversal } \\ K & \text { - matriz de rigidez da estrutura } \\ K_{e} & \text { - matriz de rigidez de um elemento } \\ L & \text { - comprimento } \\ M & - \text { momento fletor } \\ M_{\mathrm{r}} & \text { - momento de fissuração } \\ M_{r, k} & \text { - momento resistente - função do modelo constitutivo } \\ N & \text { - esforço normal } \\ S & \text { - momento estático da seção } \\ U & \text { - energia de deformação } \\ W & \text { - energia potencial das ações externas }\end{array}$

letras romanas minúsculas

e

- excentricidade da carga axial

$f_{c k}$

- resistência característica do concreto à compressão

$f_{c m}$

- resistência média do concreto à compressão 


$\begin{array}{ll}f_{c t k} & \text { - resistência característica do concreto à tração } \\ f_{c t m} & \text { - resistência média do concreto à tração } \\ f_{y k} & \text { - resistência característica do aço à tração } \\ p & \text { - carregamento uniformemente distribuído no elemento } \\ t & \text { - instante de tempo qualquer, porém maio que to } \\ t_{0} & \text { - instante de aplicação do carregamento } \\ 1 / r & - \text { curvatura da seção } \\ u & - \text { vetor de deslocamentos nodais da estrutura } \\ v & - \text { deslocamento vertical } \\ x & - \text { posição da linha neutra } \\ x_{1} & - \text { posição da linha neutra no estádio } 1 \\ x_{2} & - \text { posição da linha neutra no estádio } 2\end{array}$

letras gregas maiúsculas

$\begin{array}{ll}\Delta & \text { - variação } \\ \Delta f & \text { - incremento de carga } \\ \Delta M & - \text { resíduo de momento } \\ \Phi & - \text { função de fluência } \\ I_{1} & \text { - momento de inércia da seção - estádio } 1 \\ I_{2} & \text { - momento de inércia da seção - estádio } 2 \\ \Pi & - \text { funcional de energia } \\ \Theta_{x} & - \text { rotação em torno do eixo } X \\ \Theta_{y} & - \text { rotação em torno do eixo } Y\end{array}$

letras gregas minúsculas

$\alpha \quad$ - coeficiente de homogeneização da seção

$\beta \quad$ - matriz que relaciona as deformações aos deslocamentos nodais 
X

$\delta_{\mathrm{e}}$

$\varepsilon$

$\varepsilon_{\text {CS }}$

$\varphi$

v

$\zeta$

$x$

$v$

$p$

$\sigma$

$T$

$\psi$

- coeficiente de envelhecimento do concreto

- vetor de deslocamentos nodais do elemento

- deformação

- deformação por retração

- coeficiente de fluência

- coeficiente de Poisson

- coeficiente de ponderação entre os estádios 1 e 2

- coeficiente de envelhecimento do concreto

- coeficiente de Poisson

- taxa de armadura

- tensor das tensões

- tensão de aderência

- vetor esforços residuais na estrutura 


\section{LISTA DE ABREVIATURAS E SIGLAS}

$\begin{array}{ll}\text { AAEM } & \text { - "Age adjusted effective modullus" } \\ \text { CEB } & \text { - Comité Euro-international du Béton } \\ \text { EESC } & \text { - Escola de Engenharia de São Carlos } \\ \text { MC } & \text { - Model Code } \\ \text { NB } & \text { - Norma Brasileira } \\ \text { NBR } & \text { - Norma Brasileira Regulamentada } \\ \text { USP } & \text { - Universidade de São Paulo }\end{array}$




\section{Resumo}

SANCHES JR, F. Cálculo de esforços e deslocamentos em pavimentos de edifícios considerando-se modelos próprios para o concreto armado. São Carlos, 1998. 159p. Dissertação (Mestrado) - Escola de Engenharia de São Carlos, Universidade de Säo Paulo.

O objetivo deste trabalho é fornecer uma contribuição à análise estrutural de pavimentos de edifícios de concreto armado. Com esse fim, foram implementados os modelos de DEBERNARDI e de GHALI \& FAVRE, próprios para barras de concreto armado. Os resultados são obtidos para o instante de aplicação de um carregamento e para um instante qualquer de tempo, considerando-se a fluência.

Apresenta-se, no decorrer do trabalho, o equacionamento dos modelos e das variáveis envolvidas no processo. São mostrados exemplos práticos de aplicação dos algoritmos desenvolvidos e discute-se, nos capítulos finais, a redistribuição de momentos que ocorre em estruturas reticulares de concreto armado.

Palavras-chave: não-linearidade física, concreto armado, estruturas reticuladas, elementos finitos. 


\section{ABSTRACT}

SANCHES JR, F. Calculation of stresses and displacements in building floors with proper models for reinforced concrete. São Carlos, 1998. 159p. Dissertação (Mestrado) - Escola de Engenharia de São Carlos, Universidade de São Paulo.

The aim of this work is to give a contribution to structural analysis of reinforced concrete building floors. Therefore, DEBERNARDI's and GHALI \& FAVRE's models for reinforced concrete were implemented. The results are obtained at the loading application instant and at any instant of time, considering therefore the creep.

In this work, it is presented the formulations of the adopted models and the variables used in the process. Some practical examples of application for the developed algorithms are shown. Finally, it is discussed the redistribution of bending moments that may occur in reinforced concrete grid structures.

Keywords: physical nonlinearly, reinforced concrete, grid structures, finite elements. 


\section{1-INTRODUÇÃO}

\section{1-GENERALIDADES}

A análise de esforços e deslocamentos em estruturas de concreto armado tem como principal objetivo reproduzir matematicamente o comportamento deste material. As clássicas hipóteses fundamentadas na Lei de Hooke para a modelagem do concreto armado, onde é assumida a relação linear entre tensões e deformações, são de largo uso tanto no meio técnico quanto científico. Isso se dá desde o surgimento desse material até os dias atuais, constituindo-se na forma mais simples e freqüente de se analisar um sistema estrutural.

Os modelos elástico-lineares são, certamente, os de mais fácil compreensão e de maior utilização pelo meio técnico, pois dentre outros fatores admitem a superposição de efeitos, evidentemente onde a linearidade geométrica pode ser assumida. Entretanto, há de se questionar a validade de tais hipóteses para o concreto armado, cujo comportamento é bastante complexo devido ao trabalho em conjunto dos materiais que o constituem - concreto e armadura passiva - e, também, ao caráter näolinear de cada um dos seus constituintes.

O concreto armado apresenta um comportamento que se desvia das hipóteses elástico-lineares, mesmo quanto submetido a níveis baixos de tensão. Sua resistência à tração é esgotada para níveis de tensäo cerca de dez vezes menor que aqueles que causariam a ruptura na compressão. Quando submetido à flexão simples, a região tracionada sofrerá um processo de danificação, dando início à formação de fissuras, exigindo armadura passiva para que obtenha-se uma configuração de equilíbrio. 
Para um elemento de concreto armado submetido à flexão simples, fissuras espaçadas entre si deverão ocorrer. O alongamento máximo do aço tracionado se dará na localização da fissura, diminuindo à medida que se caminha para o ponto médio entre fissuras sucessivas. Esse fato exemplifica a contribuição do concreto íntegro entre fissuras, conhecido no meio técnico por "tension stiffening".

O comportamento que foi brevemente descrito é marcadamente nãolinear. Uma maneira apropriada e simples para representar esse comportamento é através das relações momento-curvatura. Outro caráter

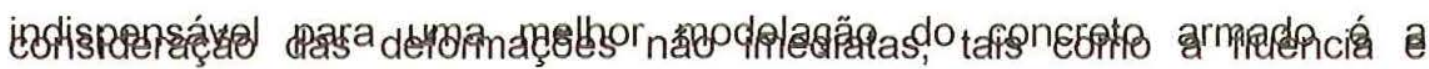
retração. O efeito desses fenômenos também pode ser acoplado aos diagramas momento-curvatura.

Como pode ser visto, uma melhor modelação das estruturas de concreto armado deve ser baseada em critérios que considerem a danificação do concreto armado e as deformaçōes não-imediatas. A formulação deste problema não-linear conduz à sistemas matemáticos extremamente complexos que não podem ser resolvidos analiticamente, mas sim numericamente. Tais soluções numéricas somente são viáveis na prática quando rotinas computacionais devidamente implementadas em equipamento programável são disponíveis.

A partir da década de 1960 surgiram os primeiros programas para análise estrutural via computador, empregando-se técnicas matriciais e discretizações pelo método dos elementos finitos (MEF). O forte impulso que a microinformática vem apresentando, essencialmente nas duas últimas décadas, permite uma evolução nos processos de cálculo e os modelos baseados na Lei de Hooke vão sendo substituídos por outros onde a nãolinearidade é acoplada, visando representar de maneira mais realista o comportamento das estruturas em geral e dos materiais que as constituem.

À medida que os estudos sobre modelos mais apropriados para a modelação do concreto armado avançam, e também que o uso de computadores se torna cada vez mais freqüente, é extremamente 
interessante que se passe a agregar estes progressos ao cálculo de estruturas correntes de concreto armado, tais como os pavimentos de edifícios.

\section{2-OBJETIVOS}

O projeto de estruturas de concreto armado deve satisfazer as condições de segurança a uma possível ruína, quer seja de um elemento estrutural isolado ou desta como um todo; além de garantir que durante a sua vida útil apresente condições adequadas à utilização para cargas de serviço.

No passado as verificações pertinentes aos "Estados Limites de Utilização" não recebiam por parte dos projetistas o mesmo tratamento dispensado ao cálculo na ruína - "Estado Limite Último". Esse fato era, até certo ponto, compreensivel haja visto que as dimensöes dos elementos estruturais resultavam avantajadas. À medida que as técnicas de cálculo foram evoluindo, aliado ao emprego de materiais de maior resistência, as dimensões de peças de uma estrutura de concreto armado foram tornandose cada vez mais esbeltas, o que exige uma verificação em serviço mais rigorosa.

Nesse sentido pretende-se fornecer uma pequena contribuição para a análise em serviço de esforços e deslocamentos em pavimentos de edifícios de concreto armado. O fenômeno da fluência também será tratado. Assim sendo, cria-se uma ferramenta computacional - "software" - que possibilita ao projetista de estruturas uma determinação mais rigorosa de flechas; além de proporcionar um cálculo de esforços solicitantes mais realista uma vez que a diminuição da rigidez da estrutura é considerada. É possivel, também, manipular as taxas de armadura visando uma distribuição de esforços mais adequada à forma estrutural.

Em se tratando do meio científico procuram-se efetuar comparações entre modelos para barras de concreto armado, baseados em relações 
momento x curvatura, tanto para o instante inicial de carregamento quanto da consideração da deformação lenta. Estudos futuros e mais completos podem sugerir diretrizes sobre a escolha de um modelo mais apropriado a ser empregado para os casos de interesse prático.

A ferramenta computacional desenvolvida permite simular a aplicação de diversas etapas de carregamento num piso de edifício, levando-se em conta o instante de tempo de cada etapa. Para esse caso a perda de rigidez devida a deformação lenta será considerada. Desse modo, pode-se, a título de exemplo, dizer que o peso próprio da estrutura é aplicado na ocasião da desforma, a alvenaria após tempo específico conhecido porém curto; idem para as ações acidentais etc...

As finalidades a que se destinam as implementações referidas neste trabalho são de emprego perfeitamente viável à rotina de escritórios de cálculo pois os tempos de processamento requeridos mostram-se reduzidos. Objetiva-se também que a nível educacional seja possível a utilização do programa desenvolvido para uma melhor exemplificação do comportamento em serviço das estruturas de concreto armado, através da manipulação com taxas de armadura, por exemplo.

\section{3-METODOLOGIA}

O pavimento será analisado como grelha, dessa forma trabalha-se apenas com elementos lineares. As reações de apoio das lajes sobre as vigas devem ser determinadas a priori empregando-se um procedimento adequado para tal fim. O Método dos Elementos Finitos (MEF) é empregado para a resolução do subsistema estrutural.

Emprega-se para a consideração da não-linearidade física e dos fenômenos reológicos os modelos propostos pelos autores Ghali \& Favre (1986) e Debernardi (1983). Os parâmetros necessários aos cálculos seguem as indicações do CEB-90. O sistema de equações não-lineares resultantes é resolvido numericamente através de algoritmos do tipo 
Newton-Raphson. Comparações com os resultados obtidos, quando consideram-se os métodos clássicos também são abordadas através de exemplos.

Todas implementações necessárias foram executadas na linguagem de programação FORTRAN com a utilização do compilador Power StationMicrosoft. Os processamentos dos exemplos deram-se em microcomputador equipado com processador Pentium de 200 Mhz, 32Mb de memória.

\section{4- ORGANIZACEÃO DO TEXTO}

O segundo capítulo deste texto aborda alguns aspectos sobre o comportamento em serviço do concreto armado; visando, principalmente a introdução de conceitos e definições que serão necessários para os capítulos seguintes. Algumas noçōes sobre os efeitos dependentes do tempo nas estruturas de concreto armado serão estudadas no capítulo 3 . É desenvolvido um conjunto de tópicos que são necessários para a implementação numérica dos modelos de comportamento do concreto armado.

Definidos os conceitos de estádios de solicitação do concreto armado e introduzidas as noções básicas relativamente às deformações nãoimediatas, pode-se apresentar os modelos de comportamento em serviço no capítulo 4. Serão descritos os modelos de GHALI \& FAVRE e de DEBERNARDI.

Noções elementares sobre a análise linear e não-linear de estruturas serão apresentadas no capítulo 5, com ênfase para a determinação do vetor de esforços residuais a ser reaplicado numa estrutura, quando da consideração da não-lineridade física. Nesse capítulo também é apresentado o elemento finito usado neste trabalho.

No capítulo 6 são apresentados fluxogramas dos programas desenvolvidos e, também, as consideração adotadas para a implementação numérica dos algoritmos. 
Nos capítulos finais são apresentados vários exemplos de resultados obtidos para estruturas de pavimentos de edifícios. São efetuadas comparações entre os resultados numéricos e dados experimentais que constam da literatura. 


\section{2-COMPORTAMENTO EM SERVIÇO DAS ESTRUTURAS DE CONCRETO ARMADO}

\section{1-INTRODUÇÃO}

Denominam-se ações de serviço aquelas que efetivamente ocorrerão numa estrutura de concreto armado sem que a ruína seja atingida. As verificações nesse estado de solicitação visam garantir condições de utilização satisfatórias para uma edificação. A grande preocupação dos projetistas de estruturas é garantir a segurança quanto à ruína. Apenas recentemente é que as verificações em serviço vêm assumindo um papel de importância no meio técnico.

As deformações excessivas em lajes ou vigas de um pavimento podem causar danos irreparáveis a uma edificação tais como: fissuras nas alvenarias que nelas se apoiam ou rompimento e inutilização de caixilhos e canalizações. De outro modo avaliações superestimadas da magnitude das flechas podem induzir ao uso de contra-f́lechas exageradas causando um mau aspecto arquitetônico. Ainda a não verificação dos estados limites de aberturas de fissuras ou fissuração inadmissível (ver próxima seção) podem fazer, por exemplo no caso de um reservatório, que estes percam a sua capacidade de armazenamento de água. Além disso, a durabilidade de uma estrutura qualquer, e não somente um reservatório, pode ficar comprometida pela exposição da armadura - estado limite de fissuração inaceitável - a agentes externos nocivos. Ressalta-se que a nova NB1 traz recomendações amplas quanto às verificaçőes nos estados limites de utilização. 
Capítulo 2 : COMPORTAMENTO EM SERVIÇO DAS ESTRUTURAS DE CONCRETO ARMADO

Com o emprego de materiais - concreto e aço - mais resistentes nas estruturas correntes, as dimensōes dos elementos estruturais tornam-se cada vez menos robustas aumentando a probabilidade de flechas inadmissíveis, por exemplo. Além disso, existe uma tendência de aproximar os cálculos em ruína e em serviço visando uma maior economia sem comprometer a segurança e a funcionalidade de uma edificação. Desse modo o projetista pode conduzir à uma distribuição de esforços que seja mais adequada à forma estrutural.

A forma mais tradicional e antiga de se proceder à análise em serviço de uma estrutura de concreto armado é aquela baseada nas hipóteses clássicas de estádios de tensão onde considera-se a seção fissurada ou não dependendo do nível de solicitação ao qual estiver submetida. As situações intermediárias entre um e outro estádio são as que melhor representam o comportamento de uma peça estrutural.

\section{2-ESTADOS LIMITES}

Uma estrutura de concreto armado atinge um "estado limite" quando em parte ou como um todo, não mais desempenha as principais finalidades para as quais foi projetada e construida. Dessa forma existem dois tipos de estados limites a serem considerados: os "estados limites de utilização "e os "estados limites últimos", que serão descritos a seguir. Para este texto e para os programas que foram desenvolvidos, deve-se ressaltar que todas as análises são efetuadas em serviço, ou seja, visando as condiçōes limites de utilização.

\subsection{1-ESTADOS LIMITES DE UTILIZAÇÃO}

Os estados limites de utilização são aqueles que ocorrem sem que a capacidade resistente da estrutura tenha-se esgotado; dessa forma, fica caracterizado pelo sistema estrutural não mais oferecer condições de 
Capitulo 2 : COMPORTAMENTO EM SERVIÇO DAS ESTRUTURAS DE CONCRETO ARMADO

durabilidade, conforto, estética ou funcionalidade devido a presença de grandes deslocamentos ou fissuração em toda a estrutura ou até mesmo em parte dela.

Para os projetos mais comuns os principais itens que devem ser verificados são os seguintes :

a) abertura de fissuras,

b) fissuração inaceitável,

c) deformaçäo excessiva,

d) vibraçōes de grande amplitude,

e) outros, de acordo com critério apropriado do projetista.

Maiores detalhes devem ser procurados em literatura apropriada, podendo-se sugerir FUSCO (1986), LEONHARDT (1977). Neste trabalho terão particular interesse a determinação das flechas em vigas solicitadas a flexäo simples (momento fletor e força cortante), para tanto serão calculados tensőes e deformaçőes para as solicitações em serviço.

\subsection{2-ESTADO LIMITE ÚLTIMO}

Como o próprio nome sugere, o estado limite último fica definido pelo esgotamento da capacidade resistente da estrutura quer seja desta como um todo ou em parte. Segundo o CEB-90 os mesmos podem ocorrer devido as seguintes causas: transformação da estrutura em um mecanismo ruptura após plastificação; perda da estabilidade quando o elemento for considerado como um corpo rígido; instabilidade por excesso de deformação e deterioraçäo por fadiga. Ainda, segundo FUSCO (1986) também devem ser consideradas as deformações elásticas ou plásticas, deformação lenta ou fissuração que provoquem uma mudança da geometria da estrutura, tornando necessária a sua substituição.

Para o caso do dimensionamento de uma seção de concreto armado, de um modo geral, a ruína fica configurada quando a deformação máxima da armadura tracionada atingir um alongamento plástica excessivo, ou quando a fibra mais comprimida de concreto atingir determinado encurtamento limite. 
Capítulo 2 : COMPORTAMENTO EM SERVIÇO DAS ESTRUTURAS DE CONCRETO ARMADO

O estudo destes não compete ao escopo deste trabalho; sugere-se para tanto que sejam consultadas as referências citadas na bibliografia.

\section{3-ESTÁDIOS DE SOLICITAÇÃO}

Denomina-se estádios de solicitação às diversas fases de comportamento em termos de tensões pelas quais passa uma peça de concreto armado quando submetida a um carregamento externo que varia desde zero até provocar a ruptura. Imagine-se uma seção de forma em forma qualquer, como mostrada pela figura (2.1-a) solicita à flexão simples por um momento fletor M crescente.

Ainda nesta mesma figura são ilustrados os diagramas de deformações e tensões da seção para quatro níveis distintos de solicitação sendo que todos estes se devem à aplicação de cargas de serviço. Cada uma dessas fases de solicitação é denominada "estádio". Será empregada neste trabalho a mesma nomenclatura utilizada por FUSCO (1986) e GHALI \& FAVRE (1986). No primeiro estádio, as solicitaçőes são bastante pequenas e designa-se a nomenclatura de estádio 1-a, a medida que crescem os esforços se definem os demais estádios, a saber, respectivamente : estádio 1-ôs, estádio 2 e estádio 3.

Para as cargas de utilização, pode-se admitir com razoável precisão que as relações tensão $x$ deformação para o concreto comprimido e para o aço podem ser admitidas lineares. Em se tratando do concreto, a proporcionalidade pode ser considerada para tensöes da ordem de $40 \%$ a $50 \%$ de sua resistência f́c $_{\mathrm{c}}$.

Define-se o estádio 1-a como sendo aquele onde a seção permanece íntegra (sem fissuração) e as tensőes no concreto são de pequena magnitude de forma que pode ser aplicada a proporcionalidade entre tensão e deformação para qualquer fibra da seção transversal, conforme ilustrado pela figura (2.1-b). Tal fato somente ocorre para valores de $\mathbf{M}$ bastante pequenos. 
Capitulo 2: COMPORTAMENTO EM SERVIÇO DAS ESTRUTURAS DE CONCRETO ARMADO

Com um pequeno aumento nos esforços solicitantes, o concreto ainda permanece íntegro, entretanto o diagrama de tensöes não é mais linear na região tracionada; novos incrementos nos esforços aumentariam as deformaçöes ao longo da altura da seção, entretanto as tensöes de tração no concreto não cresceriam mais na mesma proporção, caracterizando assim a plastificação da zona tracionada. $\mathrm{Na}$ iminência da fissuração o diagrama de tensões para abaixo da linha neutra será aproximadamente retangular.

No instante em que o módulo da tensão na fibra de concreto mais tracionada atingir a sua resistência à tração, $f_{\mathrm{ct}}$, tem início o estádio 1-b. Esse estádio fica caracterizado pelo crescimento da fissura, ou fratura, em direção à linha neutra a medida que o módulo do carregamento aplicado cresce. Define-se estádio 2 como sendo aquele em que o concreto abaixo da linha neutra não mais resiste à tração. Conforme pode-se observar pela figura (2.1-d) existe um trecho abaixo da linha neutra ainda resistindo à traçäo, entretanto sua contribuição será desprezada e admitir-se-á que toda região abaixo da linha neutra de tensőes está fissurada.

Com o crescimento das cargas até se tornarem exiremamente elevadas, a seção atinge o estádio 3 que é o estado limite de ruptura do concreto na compressão. Deve-se distinguir este estádio do estado limite de ruptura do concreto ou deformação plástica excessiva da armadura tracionada (cálculo na ruína), visto que este último é mais genérico e pode ser caracterizado pelo estádio $3 \mathrm{ou}$, como já foi citado, pelo alongamento excessivo da armadura, ou, ainda, por ambos simultaneamente. Tal fato leva a constantes confusőes entre os leitores mais distraídos, entretanto referência a este foram extraídas de FUSCO (1986) e MACHADO (1989).

Atualmente as verificações não são mais efetuadas considerando-se os estádios 1 ou $\mathbf{2}$ isoladamente, mas sim através de valores intermediários obtidos por meio de apropriadas interpolaçöes entre estes visando a consideração da contribuição do concreto íntegro entre fissuras.

De maneira resumida, os estádios de solicitação ficam definidos da seguinte forma, em relação as tensões : 
a) estádio 1-a :

$$
\begin{aligned}
& \sigma_{\text {ct }} \leq \mathrm{f}_{\text {cte }} \\
& \mathrm{e} \\
& \left|\bar{\sigma}_{\mathrm{c}}\right| \leq \mathrm{f}_{\mathrm{ce}}
\end{aligned}
$$

b) estádio 1-b :

$$
\left|\bar{\sigma}_{\mathrm{c}}\right| \leq \mathrm{f}_{\mathrm{ce}}
$$

e

$$
\sigma_{\mathrm{ct}}=\mathrm{f}_{\mathrm{ct}}
$$

c) estádio 2 :

$$
\left|\bar{\sigma}_{\mathrm{c}}\right| \leq \mathrm{f}_{\mathrm{ce}}
$$

e

$$
\varepsilon_{\mathrm{ct}} \geq \varepsilon_{\mathrm{ctu}}
$$

d) estádio 3 :

$$
\left|\bar{\sigma}_{c}\right|=f_{c c}
$$

e

$$
\varepsilon_{\mathrm{ct}} \gg \varepsilon_{\mathrm{ctu}}
$$

onde $\sigma_{\mathrm{ct}}$ é a tensão na fibra mais tracionada; $f_{\text {cte }}$ e $f_{c t}$ são, respectivamente, a tensão de proporcionalidade na tração e tensão que provoca ruptura no concreto; $f_{c e}$ e $f_{c c}$ têm o mesmo significado para a compressão; $\bar{\sigma}_{\mathrm{c}}$ é a maior tensão de compressão; $\varepsilon_{\mathrm{ct}}$ é o alongamento da fibra mais tracionada e $\varepsilon_{\text {ctu }}$ o valor limite para essa deformação. 
Capítulo 2 : COMPORTAMENTO EM SERVIÇO DAS ESTRUTURAS DE CONCRETO ARMADO

a)
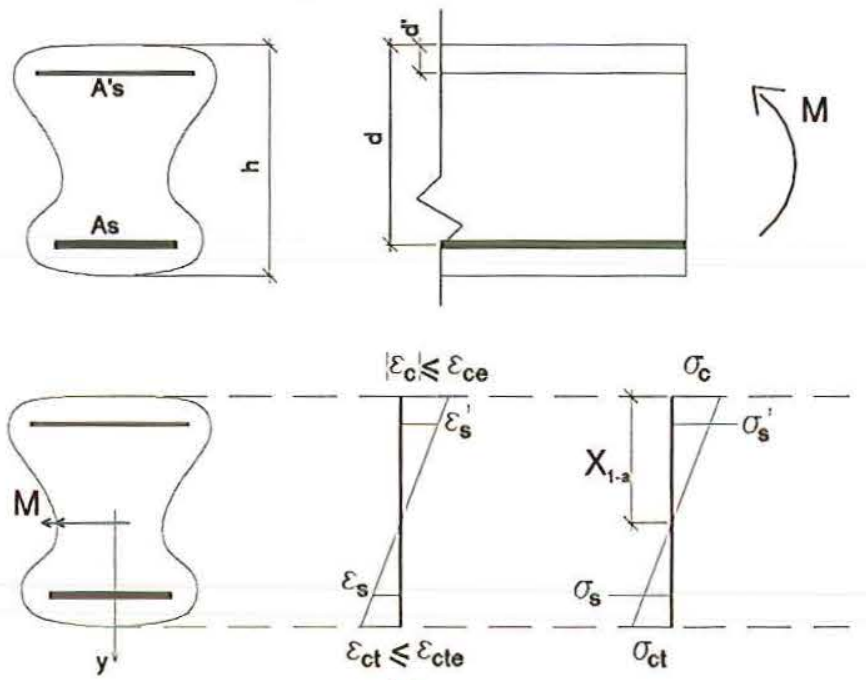

b)

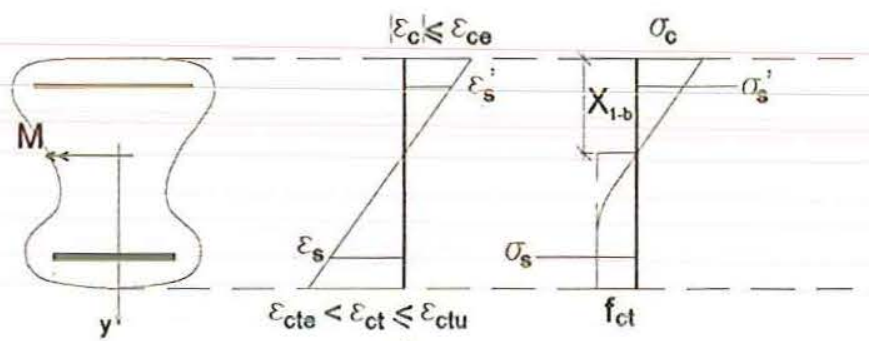

c)

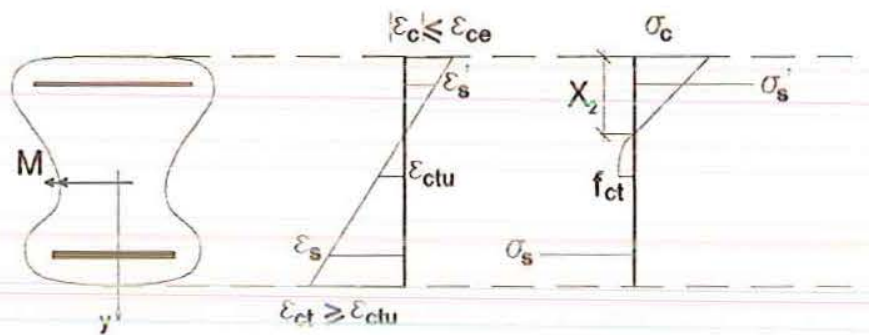

d)

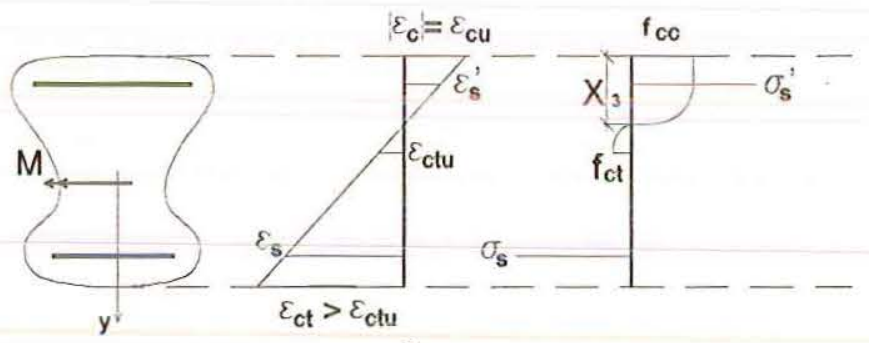

e)

Figura 2.1 : Estádios de solicitação de uma seção de concreto armado solicitada à f́lexão simples: a) geometria; b) estádio 1-a; c) estádio 1-b; d) estádio 2; e) estádio 3. 
Capítulo 2 : COMPORTAMENTO EM SERVIÇO DAS ESTRUTURAS DE CONCRETO ARMADO

\section{2,3.1-CÁLCULO CLÁSSICO NO ESTÁdIO 1 PARA A FLEXÃO SIMPLES}

O cálculo no estádio 1 é aplicado às estruturas não fissuradas de concreto armado. Na prática isto deverá ocorrer para as seguintes situaçōes: lajes onde a solicitação é de pequena intensidade, peças onde é aplicado um esforço de protensão tal que a seção transversal esteja totalmente comprimida, além de regiőes íntegras entre fissuras sucessivas de vigas. Os dois primeiros casos näo seräo tratados neste trabalho, entretanto o último terá grande importância para o estudo da contribuição do concreto intacto entre fissuras.

Pretende-se, no decorrer desta seçäo, apresentar as hipóteses de cálculo e desenvolver expressões que possam ser utilizadas na prática por meio de algoritmos bastante simples possíveis de serem implementados em qualquer computador, ou até mesmo resolvidos manualmente sem grande trabalho.

\section{HIPÓTESES BÁSICAS :}

O diagrama de deformaçöes para a seção transversal de um elemento de concreto armado solicitado à flexão simples por um momento M. atuando no plano do eixo oy que passa pelo seu eixo de simetria, é mostrado pela figura (2.2). As hipóteses fundamentais para a consideração e o equacionamento do cálculo no estádio 1 serão apresentadas, item a item, como segue :

a) A resistência à tração do concreto, $f_{\mathrm{ct}}$, não será atingida, dessa forma não haverá formação de fissuras na seção.

b) Existe um eixo de simetria pertencente ao plano do esforço atuante.

c) É suposta a perfeita aderência entre as barras da armadura e o concreto que as envolve. Dessa forma, é válida a seguinte relação :

$$
\varepsilon_{\mathrm{si}}=\varepsilon_{\mathrm{c}, \mathrm{y}}\left(\mathrm{p} / \mathrm{y}=\mathrm{d}_{\mathrm{i}}-\mathrm{X}_{1}\right)
$$




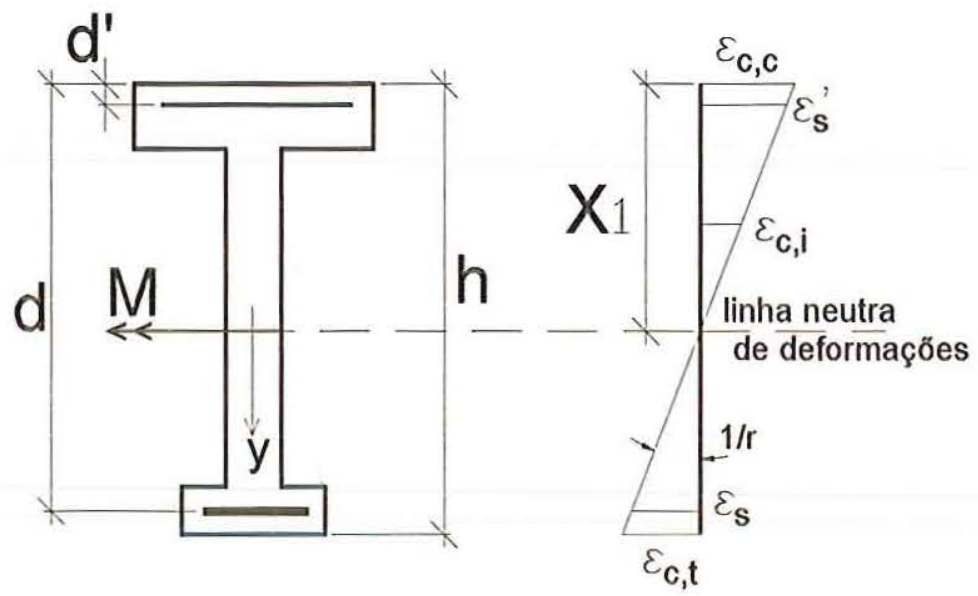

Figura 2.2 : Seção transversal e deformações para o estádio 1.

d) A clássica hipótese de Bernoulli da manutenção das seções planas à configuração deformada, para materiais homogêneos é estendida às seções armadas. Portanto, o digrama de deformações será linear ao longo da altura da seção e serão válidas as seguintes relações :

$$
\begin{gathered}
\frac{\left|\varepsilon_{\mathrm{c}, \mathrm{y}}\right|}{\mathrm{y}}=-\frac{1}{\mathrm{r}} \\
\frac{\varepsilon_{\mathrm{si}}}{\mathrm{d}_{\mathrm{i}}-\mathrm{x}_{1}}=\frac{1}{\mathrm{r}}
\end{gathered}
$$

e) A seção gira em torno de um eixo perpendicular ao seu plano de simetria. A este denomina-se "linha neutra de deformaçōes", que na ausência de deformaçōes impostas coincide com a "linha neutra de tensões".

f) A relação entre tensões e deformação será linear tanto para o concreto quanto para o aço, permitindo-se escrever as tensöes no concreto e no aço, respectivamente, pelas expressőes para uma fibra genérica descritas abaixo :

$$
\begin{aligned}
& \sigma_{\mathrm{c}, \mathrm{y}}=\mathrm{E}_{\mathrm{c}} \cdot \varepsilon_{\mathrm{c}, \mathrm{y}} \\
& \sigma_{\mathrm{si}}=\mathrm{E}_{\mathrm{s}} \cdot \varepsilon_{\mathrm{si}}
\end{aligned}
$$

onde $E_{c}$ é o módulo de elasticidade longitudinal do concreto e $E_{s}$ tem o mesmo significado para o aço. 


\section{HOMOGENEIZAÇÃO DA SEÇÃO :}

Para a aplicação do método clássico de cálculo é necessário que a seção do elemento em análise seja composta por uma material homogêneo. Isto pode ser obtido transformando-se uma seção de concreto armado em outra, fictícia, tomando o concreto como material de referência. Para tanto é definido o coeficiente de homogeneização, $\alpha_{\mathbf{s}}$, da seguinte forma :

$$
\alpha_{\mathrm{s}}=\frac{\mathrm{E}_{\mathrm{s}}}{\mathrm{E}_{\mathrm{c}}}
$$

A obtenção desse coeficiente pode ser facilmente demonstrada a partir das hipóteses de perfeita aderência entre o aço e o concreto e linearidade física dos materiais, ambas anteriormente descritas. Desse modo o que se busca é escrever a tensão numa camada genérica de armadura, localizada na fibra $d_{1}$, em função da tensão na mesma se esta fosse composta efetivamente de concreto, que é o material de referência. Assim, com o emprego das expressões (2.12) e (2.13) pode-se escrever:

$$
\sigma_{\mathrm{si}}=\frac{\mathrm{E}_{\mathrm{s}}}{\mathrm{E}_{\mathrm{c}}} \sigma_{\mathrm{c}, \mathrm{y}}=\alpha_{\mathrm{s}} \cdot \sigma_{\mathrm{c}, \mathrm{y}} \quad\left(\mathrm{c} / \mathrm{y}=\mathrm{d}_{\mathrm{i}}\right)
$$

Assim, a área da seção homogeneizada no estádio $1, A_{1}$, pode ser escrita da seguinte forma, descontando-se os espaços ocupados pela armadura:

$$
\mathrm{A}_{1}=\mathrm{Ac}_{\mathrm{n}}+\sum_{\mathrm{i}=1}^{\mathrm{n}}\left(\alpha_{\mathrm{s}}-1\right) \mathrm{As}_{\mathrm{i}}
$$

Onde $A c_{n}$ é a área total da seção transversal, $n$ é o número de camadas de armadura e $\mathbf{A} \mathbf{s}_{1}$ é a área de cada uma dessas camadas. 


\section{CÁLCULO NA FLEXÃO SIMPLES :}

Considere-se a seção de concreto armado apresentada na figura (2.2); a seu respeito podem ser escritas as seguintes equaçöes de equilíbrio em termos de força e de momento, respectivamente :

$$
\begin{aligned}
& \int_{A_{c}} \sigma_{c, y^{\prime}} d A_{c}+\sum_{i=1}^{n}\left(\alpha_{s}-1\right) A_{s i}\left(\frac{\sigma_{s i}}{\alpha_{s}}\right)=0 \\
& \int_{A_{c}} \sigma_{c, y^{\prime}} y^{\prime} d A_{c}+\sum_{i=1}^{n}\left(\alpha_{s}-1\right) A_{s i}\left(\frac{\sigma_{s i}}{\alpha_{s}}\right)\left(x_{1}-d_{i}\right)=M
\end{aligned}
$$

Os significados de todas as variáveis empregadas nas equaçöes (2.17) e (2.18) já foram anteriormente descrito.

A partir do diagrama de tensões da figura (2.1-b) podem ser escritas as seguintes relaçöes :

$$
-\frac{\sigma_{c}}{x_{I}}=-\frac{\sigma_{c, y^{\prime}}}{y^{\prime}}=\frac{\sigma_{s i}}{\alpha_{s}\left(d_{i}-x\right)}
$$

Fazendo-se transformaçőes nas equaçőes de equilibrio de esforços (2.17) e (2.18), de maneira a não alterá-las o significado, são obtidas as seguintes expressöes :

$$
\int_{\Lambda_{c}} \frac{\sigma_{c, y^{\prime}}}{y^{\prime}} y^{\prime} \sigma_{c, y^{\prime}} d A_{c}+\sum_{i=1}^{n}\left(\alpha_{s}-1\right) A_{s i}\left(\frac{\sigma_{s i}}{\alpha_{s}\left(x_{1}-d_{i}\right)}\right)\left(x_{1}-d_{i}\right)=0
$$

e :

$$
\int_{A_{c}} \frac{\sigma_{c, y^{\prime}}}{y^{\prime}}\left(y^{\prime}\right)^{2} d A_{c}+\sum_{i=1}^{n}\left(\alpha_{s}-1\right) A_{s i}\left(\frac{\sigma_{s i}}{\alpha_{s}\left(x_{1}-d_{i}\right)}\right)\left(x_{1}-d_{i}\right)^{2}=M
$$


Capítulo 2 : COMPORTAMENTO EM SERVICYO DAS ESTRUTURAS DE CONCRETO ARMADO

Os momentos estático e de inércia, no estádio 1, para a seção homogeneizada em relação à linha neutra valem, respectivamente:

$$
\begin{aligned}
& S_{n, 1}=\int_{A_{c}} y^{\prime} d A_{c}+\sum_{i=1}^{n}\left(\alpha_{s}-1\right) A_{s i}\left(x_{1}-d_{i}\right) \\
& I_{n, 1}=\int_{A_{c}}\left(y^{\prime}\right)^{2} d A_{c}+\sum_{i=1}^{n}\left(\alpha_{s}-1\right) A_{s i}\left(x_{1}-d_{i}\right)^{2}
\end{aligned}
$$

A partir das equaçöes acima descritas, é possível escrever as equação de equilíbrio de esforços de forma resumida empregando-se para tanto as condições de compatibilidade de tensões expressas pela relação (2.19). Assim :

$$
\begin{aligned}
& \frac{\sigma_{c}}{x} S_{n, 1}=0 \\
& e: \\
& \frac{\sigma_{c}}{x} I_{n, 1}=M
\end{aligned}
$$

Para a determinação da linha neutra em seçöes de concreto armado não fissuradas submetidas à flexão simples, será imposta a condição de momento estático nulo como pode ser observado pela expressão (2.24). Após a determinação do valor de $X_{1}$, o momento de inércia será calculo através da expressão (2.23).

\subsection{2 - CÁLCỤLO CLÁSSICO NO ESTTÁDIO 2 PARA FLEXÃO SIMPLES}

O cálculo de deformações e tensões no estádio 2 tem aplicação às estruturas fissuradas de concreto armado. Esta situação poderá ocorrer nas regiões mais solicitadas à flexão de vigas onde, em geral, deverão aparecer 
fissuras. Nesta seção serão apresentadas as hipóteses fundamentais para o estádio 2 e desenvolvidas expressões para uma seção em forma qualquer de concreto armado, do mesmo modo que foi efetuado na seção anterior para o estádio 1.

\section{HIPÓTESES DE CÁLCULO :}

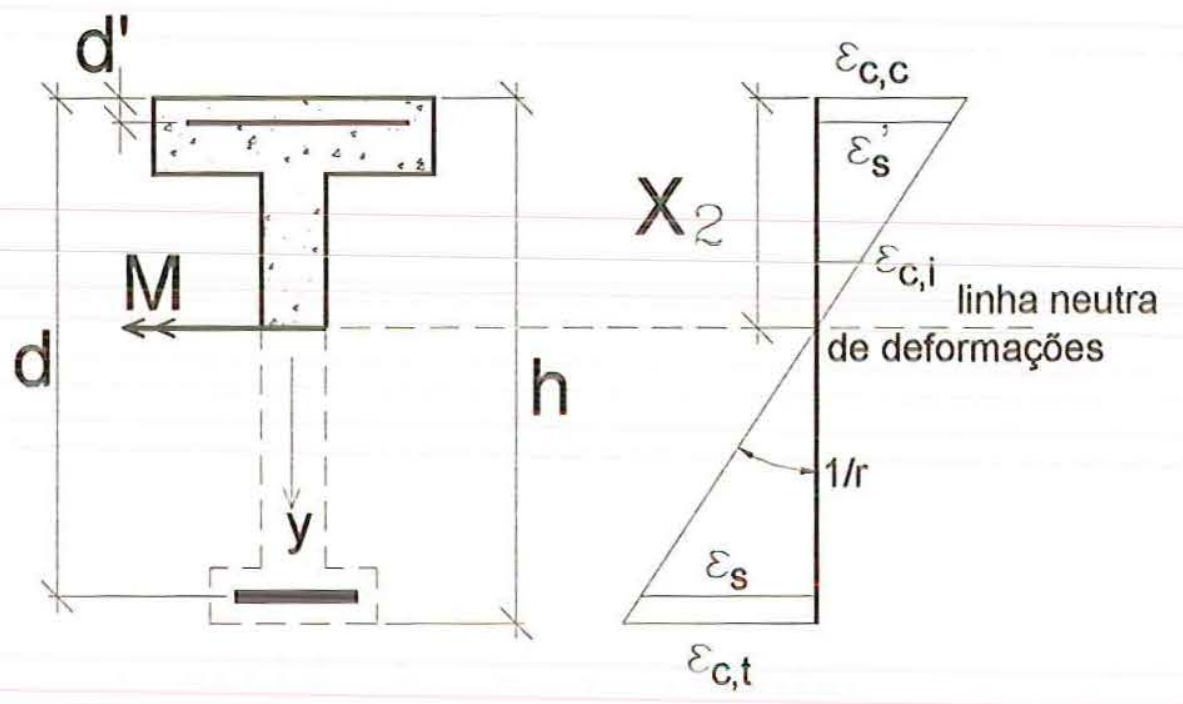

Figura 2.3: Seção transversal e deformações para o estádio 2.

Uma seção fissurada de concreto armado e seu diagrama de deformações são ilustrados pela figura (2.3). As notações utilizadas serão as mesmas da seção anterior. As hipóteses básicas são relacionadas a seguir :

a) $\mathrm{O}$ momento fletor atuante, $\mathbf{M}$, tem intensidade suficiente para provocar a fissuração do concreto na fibra mais tracionada.

b) Toda a região de concreto abaixo da linha neutra será totalmente desprezada, mesmo que ainda haja um pequeno trecho resistindo à tração, como pode ser observado na figura (2.1-d).

c) As hipóteses b, c, d, e, além de f empregadas na seção anterior, onde tratava-se do cálculo no estádio 1 continuam válidas para o estádio 2. 


\section{HOMOGENEIZAÇÃO DA SEÇÃO :}

O conceito é análogo ao exposto para o estádio 1, a única diferença está no fato de que a área de concreto abaixo da linha neutra será completamente desprezada para o cálculo dos momentos estático e de inércia em relação a esta. Deve-se lembrar que as áreas ocupadas pela armadura só devem ser descontadas para fibras na região comprimida da seção. Desse modo a área da seção homogeneizada no estádio $2, A_{2}$, será calculada de acordo com a expressão (2.26).

$$
\mathrm{A}_{2}=\mathrm{A}_{\mathrm{cc}}+\sum_{\mathrm{i}=1}^{\mathrm{n}_{\mathrm{c}}} \mathrm{A}_{\mathrm{si}}\left(\alpha_{\mathrm{s}}-1\right)+\sum_{\mathrm{i}=\mathrm{n}_{\mathrm{c}}+1}^{\mathrm{n}} \mathrm{A}_{\mathrm{si}} \alpha_{\mathrm{s}}
$$

onde $A_{c c}$ é a área de concreto comprimido; $\boldsymbol{n}_{\mathrm{c}}$ e $\mathbf{n}$ säo, respectivamente, $\mathrm{o}$ número de barras de aço na região acima da linha neutra, devendo o espaço ocupado pelas barras ser descontado e o número total de barras na seção.

\section{CÁLCULO NA FLEXÃO SIMPLES :}

Do mesmo modo que foi desenvolvido para o estádio 1, são escritas as equaçőes de equilíbrio em termos de esforço normal e de momento para uma seção de concreto armado semelhante aquela da figura (2.3), com seção de forma qualquer, tom-se :

$$
\int_{A_{c c}} \sigma_{c, y^{\prime}} d A_{c c}-\sum_{i=1}^{n_{c}} A_{s i}\left(\frac{\sigma_{s i}}{\alpha_{s}}\right)+\sum_{i=1}^{n}\left(A_{s i} \sigma_{s i}\right)=0
$$

e:

$$
\begin{gathered}
\int_{A_{c c}} \sigma_{c, y^{\prime}} y^{\prime} d A_{c c}-\sum_{i=1}^{n_{c}} A_{s i}\left(\frac{\sigma_{s i}}{\alpha_{s}}\right)\left(x_{2}-d_{i}\right)+ \\
\sum_{i=1}^{n} A_{s i} \sigma_{s i}\left(x_{2}-d_{i}\right)=M
\end{gathered}
$$

Transformando-se as expressões acima, de modo que as relaçöes expressas em (2.19) possam ser utilizadas tem-se : 


$$
\begin{aligned}
\int_{A_{c c}} \frac{\sigma_{c, y^{\prime}}}{y^{\prime}} y^{\prime} d A_{c c} & -\sum_{i=1}^{n_{c}}\left(\alpha_{s}-1\right) A_{s i}\left(\frac{\sigma_{s i}}{\alpha_{s}\left(x_{2}-d_{i}\right)}\right)\left(x_{2}-d_{i}\right)+ \\
& +\sum_{i=n_{c}+1}^{n} A_{s i}\left(\frac{\sigma_{s i}}{\alpha_{s}\left(x_{2}-d_{i}\right)}\right) \alpha_{s}\left(x_{2}-d_{i}\right)=0
\end{aligned}
$$

e:

$$
\begin{array}{r}
\int_{A_{c c}} \frac{\sigma_{c, y^{\prime}}}{y^{\prime}}\left(y^{\prime}\right)^{2} \mathrm{dA}_{\mathrm{cc}}-\sum_{\mathrm{i}=1}^{\mathrm{n}_{\mathrm{c}}}\left(\alpha_{\mathrm{s}}-1\right) \mathrm{A}_{\mathrm{si}}\left(\frac{\sigma_{\mathrm{si}}}{\alpha_{\mathrm{s}}\left(\mathrm{x}_{2}-\mathrm{d}_{\mathrm{i}}\right)}\right)\left(\mathrm{x}_{2}-\mathrm{d}_{\mathrm{i}}\right)^{2}+ \\
+\sum_{\mathrm{i}=\mathrm{n}_{\mathrm{c}}+1}^{\mathrm{n}} \mathrm{A}_{\mathrm{si}}\left(\frac{\sigma_{\mathrm{si}}}{\alpha_{\mathrm{s}}\left(\mathrm{x}_{2}-\mathrm{d}_{\mathrm{i}}\right)}\right) \alpha_{\mathrm{s}}\left(\mathrm{x}_{2}-\mathrm{d}_{\mathrm{i}}\right)^{2}=\mathrm{M}
\end{array}
$$

Desenvolvendo-se as expressöes (2.29) e (2.30) da mesma forma que foi efetuado para o estádio 1 chega-se às equações dos momentos estático e de inércia em relação a linha neutra para o estádio 2 , a saber :

$$
\mathrm{S}_{\mathrm{n}, 2}=\int_{\mathrm{A}_{\mathrm{cc}}} \mathrm{y}^{\prime} \mathrm{dA}_{\mathrm{cc}}+\sum_{\mathrm{i}=1}^{\mathrm{n}_{\mathrm{c}}}\left(\alpha_{\mathrm{s}}-1\right) \mathrm{A}_{\mathrm{si}}\left(\mathrm{x}_{2}-\mathrm{d}_{\mathrm{i}}\right)+\sum_{\mathrm{i}=\mathrm{n}_{\mathrm{c}}+1}^{\mathrm{n}} \alpha_{\mathrm{s}} \mathrm{A}_{\mathrm{si}}\left(\mathrm{x}_{2}-\mathrm{d}_{\mathrm{i}}\right)
$$

e:

$$
I_{n, 2}=\int_{A_{c c}}\left(y^{\prime}\right)^{2} d A_{c c}+\sum_{i=1}^{n_{c}}\left(\alpha_{s}-1\right) A_{s i}\left(x_{2}-d_{i}\right)^{2}+\sum_{i=n_{c}+1}^{n} \alpha_{s} A_{s i}\left(x_{2}-d_{i}\right)^{2}
$$

\section{4-CONTRIBUIÇÃO DO CONCRETO INTACTO ENTRE}

\section{FISSURAS - "TENSION STIFFENING"}

Conforme foi anteriormente citado, um elemento estrutural de concreto armado pode ter seu comportamento melhor descrito por uma situação intermediária entre os estádios de tensão abordados. Tal fato se justifica pela presença de armadura na região tracionada de uma seção transversal. Diversos autores trataram desse assunto. Neste trabalho, serão apresentados os modelos propostos por DEBERNARDI (1983) e GHALI \& 
Capítulo 2 : COMPORTAMENTO EM SERVIÇO DAS ESTRUTURAS DE CONCRETO ARMADO

FAVRE (1986), que foram empregados nas implementaçőes computacionais necessárias.

A diferença básica entre estes modelos é caracterizada pela utilização, por GHALI \& FAVRE, de uma apropriada interpolação entre os resultados obtidos pelos estádios 1 e 2; enquanto DEBERNARDI, por sua vez, faz um equacionamento relativo à configuração média deformada. Estes métodos serão descritos para a flexão simples no capítulo 4 .

Nesta seção será exemplificado o caso de um tirante de concreto armado onde emprega-se o modelo de GHALI \& FAVRE visando unicamente uma melhor elucidação de como o concreto intacto entre fissuras contribui para a diminuição dos níveis de deformação da armadura tracionada.

\section{2,4.1-TIRANTE DE CONCRETO ARMADO}

Seja um tirante de concreto armado submetido a um esforço axial $\mathrm{N}$ conforme a figura (2.4); a primeira fissura ocorrerá quando tomarmos para $\mathrm{N}$ um valor igual a $\mathrm{N}_{\mathrm{r}}$ ( esforço normal de fissuração) dado pela expressäo seguinte:

$$
N_{r}=f_{c t}\left[A_{c}+\left(\alpha_{s}-1\right) A_{s}\right] \cong f_{c t} \cdot A_{c}
$$

Pouco antes de ocorrer a primeira fissura, a seção se comporta de acordo com as hipóteses do estádio 1 , sendo a tensão no concreto igual a $\mathbf{f}_{\mathrm{ct}}$ e no aço $\alpha$ s.f́t . Imediatamente após a fissuração, a seção onde esta ocorreu terá comportamento típico do estádio 2, a tensão no concreto será nula, com toda a tração sendo absorvida pela armadura, desse modo para a armadura nesta seção:

$$
\sigma_{\mathrm{sr}}=\frac{N_{\mathrm{r}}}{A_{\mathrm{s}}}=\mathrm{f}_{\mathrm{ct}}\left[\frac{\mathrm{A}_{\mathrm{c}}}{\mathrm{A}_{\mathrm{s}}}+\alpha_{\mathrm{s}}-1\right]
$$




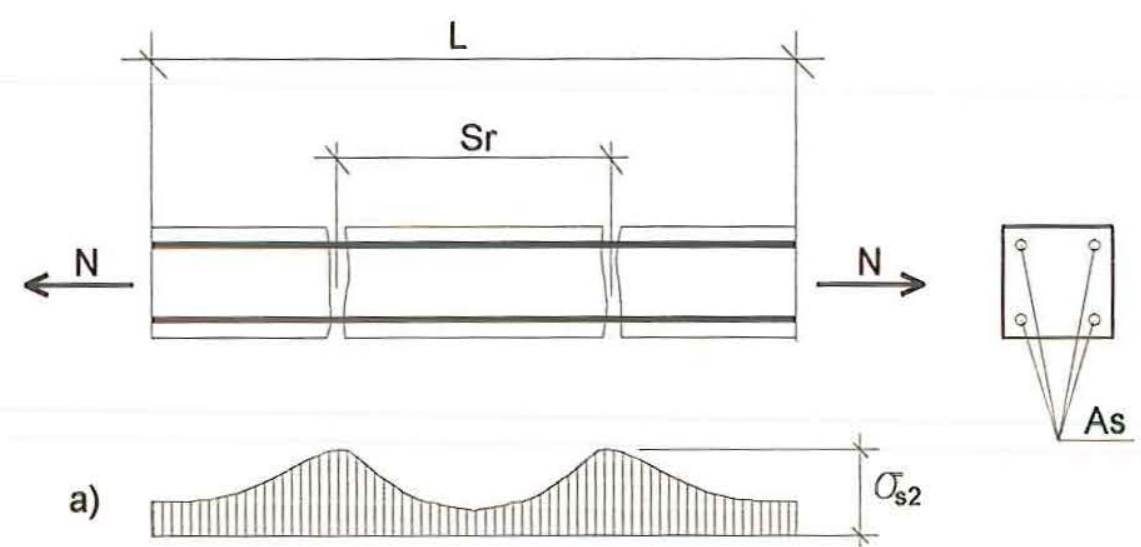

b)

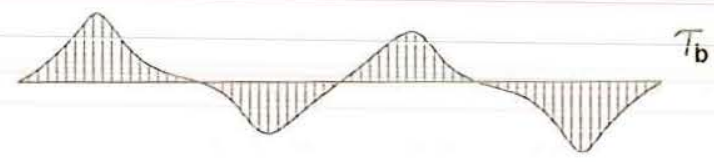

c)

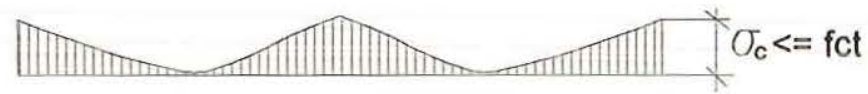

Figura 2.4 - Tensões em um tirante físsurado de concreto armado: a) tensões na armadura; b) tensões de aderência; c) tensōes no concreto.

A tensão no aço aumenta repentinamente (após a físsuração) devidio à transferência da tração que antes era absorvida pelo concreto, produzindo uma deformação da armadura incompativel com a deformação do concreto adjacente o que resulta num aumento na abertura da fissura. A contribuição do concreto intacto entre fissuras tende a diminuir a deformação do aço (ver fig. (2.4)), e a uma distância $\mathbf{s}_{\mathbf{r}}$ ocorre uma nova fissura. É interessante lembrar que numa região vizinha às fissuras o comportamento do concreto não é governado pelo estádio 1 e nem pelo estádio 2. Ocorre que esta é uma região de transição e o estádio de tensões pode ser definido pelo aparecimento de um estádio intermediário causado pelo escorregamento da armadura. 
Nas seções fissuradas, as tensões e as deformações no aço serão determinadas pelas expressões (2.35) e (2.36), respectivamente.

$$
\begin{aligned}
& \sigma_{s 2}=\frac{N}{A_{s}} \\
& \varepsilon_{s 2}=\frac{\sigma_{s 2}}{E_{s}}=\frac{N}{E_{s} A_{s}}
\end{aligned}
$$

Quando $\mathbf{N}=\mathrm{N}_{\mathbf{r}}$ a deformação na armadura correspondente à tensão de fissuração $\sigma_{\text {sr }}$ pode ser escrita conforme a expressão seguinte:

$$
\varepsilon_{\mathrm{sr} 2}=\frac{\sigma_{\mathrm{sr}}}{\mathrm{E}_{\mathrm{s}}}=\frac{\mathrm{N}_{\mathrm{r}}}{\mathrm{E}_{\mathrm{s}} \mathrm{A}_{\mathrm{s}}}
$$

Entre duas fissuras consecutivas a tensão de tração no aço terá valor menor que $\sigma_{\mathrm{s} 2}$, enquanto que a tensão de tração no concreto é máxima na seção média entre duas fissuras. O fato de haver uma redução da tensão no aço, deixa claro que esta foi provocada pela colaboração do concreto não fissurado. Uma conseqüência imediata é que a deformação da armadura varia ao longo do comprimento do elemento, podendo-se definir uma deformação média dada por:

$$
\varepsilon_{\mathrm{sm}}=\frac{\Delta \mathrm{L}}{\mathrm{L}}
$$

onde $\mathrm{L}$ é o comprimento total do elemento, e $\Delta \mathrm{L}$ é o alongamento deste. Pode-se dizer que há uma redução da deformação do aço $\left(\Delta_{\mathrm{\varepsilon s}}\right)$ causada pela contribuição do concreto. Assim, escreve-se (2.38) na forma:

$$
\varepsilon_{\mathrm{sm}}=\varepsilon_{\mathrm{s} 2}-\Delta \varepsilon_{\mathrm{s}}
$$


Capítulo 2: COMPORTAMENTO EM SERVIÇO DAS ESTRUTURAS DE

O valor de $\varepsilon_{s m}$ está compreendido entre $\varepsilon_{s 2}$ e $\varepsilon_{s 1}$, onde este último é uma deformação hipotética do aço admitindo estádio 1 , dada por:

$$
\varepsilon_{\mathrm{sl}}=\varepsilon_{\mathrm{cl}}=\frac{\mathrm{N}}{\mathrm{E}_{\mathrm{c}}\left(\mathrm{A}_{\mathrm{c}}+\alpha_{\mathrm{s}} \mathrm{A}_{\mathrm{s}}\right)}=\frac{\mathrm{N}}{\mathrm{E}_{\mathrm{c}} \mathrm{A}_{1}}
$$

O módulo de $\Delta_{\mathrm{gs}}$ representa a diferença numérica entre a deformação média $\varepsilon_{s m}$ e a deformação do aço na seção fissurada. Esta diferença assume um valor máximo $\Delta_{\varepsilon s, m a x}$ no início da fissuração, quando $N=N_{r}$, segundo GHALI e FAVRE (1986) $\Delta_{\mathrm{ss}}$ varia parabolicamente com $\sigma_{\mathrm{s} 2}$ conforme as equações que seguem.

$$
\Delta_{\varepsilon \mathrm{s}}=\Delta_{\varepsilon s, \max } \frac{\sigma_{\mathrm{sr}}}{\sigma_{\mathrm{s} 2}}
$$

com:

$$
\Delta_{\varepsilon s, \max }=\left(\varepsilon_{\mathrm{s} 2}-\varepsilon_{\mathrm{s} 1}\right) \frac{\sigma_{\mathrm{sr}}}{\sigma_{\mathrm{s} 2}}
$$

Substituindo-se (2.41) e (2.42) em (2.39), obtém-se a expressão da deformação média no aço:

$$
\varepsilon_{\mathrm{sm}}=(1-\zeta) \varepsilon_{\mathrm{s} 1}+\zeta \varepsilon_{\mathrm{s} 2}
$$

Onde $\zeta$ é um coeficiente de ponderação compreendido entre 0 e 1. Para seçőes não fissuradas $\left(N<N_{r}\right) \zeta$ assume o valor zero, quando $N>N_{r}$, o valor de $\zeta$ é dado pelas expressões seguintes:

$$
\zeta=1-\left(\frac{\sigma_{\mathrm{sr}}}{\sigma_{\mathrm{s} 2}}\right)^{2}, \sigma_{\mathrm{s} 2}>\sigma_{\mathrm{sr}}
$$

ou ainda: 


$$
\zeta=1-\left(\frac{\mathrm{N}_{\mathrm{r}}}{\mathrm{N}}\right)^{2}, \mathrm{~N}>\mathrm{N}_{\mathrm{r}}
$$

Para levarem-se em conta as condiçöes de aderência da armadura e a duração de aplicação ou a repetição dos carregamentos o CEB-FIP (MC90) faz um ajuste na expressäo de $\zeta$, introduzindo os coeficientes $\beta_{1}$ e $\beta_{2}$ nas expressões acima, resultando em:

$$
\zeta=1-\beta_{1} \beta_{2}\left(\frac{\sigma_{\mathrm{sr}}}{\sigma_{\mathrm{s} 2}}\right)^{2}, \sigma_{\mathrm{s} 2}>\sigma_{\mathrm{sr}}
$$

e:

$$
\zeta=1-\beta_{1} \beta_{2}\left(\frac{N_{\mathrm{r}}}{N}\right)^{2}, N>N_{r}
$$

onde:

- considerando-se as condiçöes de aderência:

$$
\begin{aligned}
& \beta_{1}=1,0 \text { para barras de alta aderência }\left(\eta_{b} \geq 1,5\right) \\
& \beta_{1}=0,5 \text { para barras lisas }\left(\eta_{b}=1,0\right)
\end{aligned}
$$

- considerando-se as condições de carregamento:

$$
\beta_{2}=1,0 \text { para o primeiro carregamento, ou para cargas pouco }
$$
repetitivas, näo permanentes.

$\beta_{2}=0,5$ para cargas permanentes ou com grande número de ciclos. 


\section{3-FENÔMENOS REOLÓGICOS DO CONCRETO}

\section{ARMADO}

\section{1-INTRODUÇÃO}

As estruturas de concreto armado estão, de uma maneira geral, sujeitas a sofrerem uma série de mudanças em seu estado de tensões e deformações desde o instante em que um carregamento é aplicado, aqui denominado " $\hat{t}_{0}$ ", até outro instante de tempo genérico, " $\mathbf{t}$ " maior que $\mathbf{t}_{\mathbf{0}}$. Estas mudanças têm sido objeto de estudo de diversos autores, dentre os quais pode-se destacar NEVILLE (1983) e BAZANT (1972).

As modificações nos estados de tensões e deformações dos elementos de concreto armado estão relacionadas a diversos fatores dentre os quais assume grande importância a fluência $e$ a retração do concreto, itens estes que serão sucintamente estudados no transcorrer deste capítulo. Para avaliar as mudanças nas deformações causadas por esses fenômenos torna-se necessário o emprego de funçőes de tempo apropriadas, recorrendo-se às formulações empregadas por normas internacionais conceituadas dentre elas o $\mathrm{ACl}$ e os Códigos-modelo do $\mathrm{CEB}$. Aqui optouse pelo MC-90 do CEB por apresentar uma formulação atual e facilmente programável.

Ao longo do tempo o módulo de elasticidade do concreto sofre sucessivos acréscimos em relação ao seu valor inicial; do mesmo modo ocorre com a resistência a compressão e a resistência a tração; para tais casos será aqui utilizada novamente a formulação do Código-modelo de 1990 do CEB. Nessas recomendações utiliza-se na formulação um fator denominado " $\beta_{2}$ " que DEBERNARDI (1983) em seu trabalho diz parecer 
uma tentativa de avaliar a fluência na aderência entre a armadura e o concreto que o envolve, marcando aí mais um efeito dependente do tempo.

Nas estruturas isostáticas tanto a fluência quanto a retração, alteramse somente os deslocamentos destas, pois os esforços solicitantes dependem apenas de equações de equilíbrio externo. Entretanto, em se tratando de vigas, grelhas, pórticos etc... hiperestáticos é possível que ocorra também uma redistribuição de esforços; este fato será visto mais adiante e pode também ser encontrado em NEVILLE (1983).

As deformações que irão ocorrer internamente numa estrutura devido ao efeito da fluência do concreto implicarão num aumento da magnitude dos seus deslocamentos ao longo do tempo. Para os casos onde o efeito de segunda ordem não for desprezivel, a deformação lenta também deve ser considerada.

Outro fato importante a ser citado é que as estruturas de pavimentos de edifícios sofrem ao longo do tempo mudanças em suas condiçőes de apoio, isto se deve à presença do cimbramento até a estrutura adquirir certa resistência mínima necessária para a sua retirada. Desta maneira fica evidenciado que deverão ocorrer grandes mudanças tanto em termos de deformaçöes e deslocamentos quanto em termos de tensões internas e esforços solicitantes.

O concreto é um material de comporiamento difícil de ser analisado com rigor, ainda mais quando o efeito do tempo é envolvido. Procura-se reunir subsídios necessários para as implementações de fenômenos reológicos no programas desenvolvido e também para futuras implementaçöes nessa linha.

\section{2-FLUENNCIA DO CONCRETO}

Considere-se uma barra prismática de concreto tal que a área de sua seçäo transversal seja igual a "A" constante ao longo de todo o seu comprimento e esteja apoiada continuamente sobre um plano ao longo de 
toda sua base, conforme mostrado pela figura (3.1). Se for aplicado em seu extremo superior, num instante de tempo denominado inicial " $\mathbf{t}_{0}$ ", uma ação uniformemente distribuída de módulo igual a "p" por unidade de área a tensão atuante num plano qualquer paralelo aquele que define o extremo superior da barra terá o valor em módulo conforme a equação (3.1).

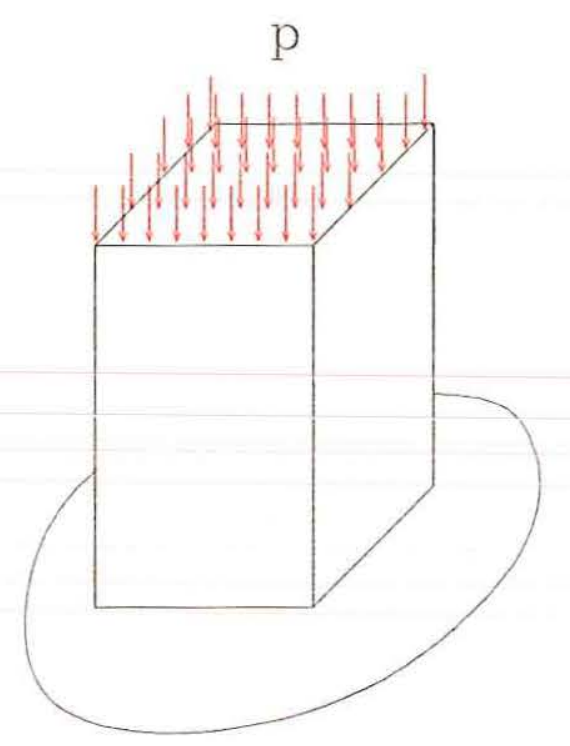

Figura 3.1 : Barra de concreto carregada axialmente.

$$
\sigma=\frac{\mathrm{pA}}{\mathrm{A}}=\mathrm{p}
$$

Neste caso a deformação elástica no instante " $\hat{\imath}_{0}$ " assumirá o seguinte valor :

$$
\varepsilon_{\mathrm{ce}}\left(\mathrm{t}_{0}\right)=\frac{\sigma}{\mathrm{E}_{\mathrm{c}}\left(\mathrm{t}_{0}\right)}
$$

onde $\mathbf{E}_{\mathrm{c}}\left(\mathrm{t}_{0}\right)$ é o módulo de elasticidade longitudinal do concreto para o instante de tempo igual a " $\mathfrak{t}_{0}$ ".

Supondo-se que o carregamento externo aplicado seja mantido constante ao longo de um intervalo de tempo que varie de " $\mathbf{t}_{0}$ " até " $\mathrm{t}$ ", as tensões permanecerão constantes ao longo do tempo; entretanto devido a 
um re-arranjo da estrutura interna do concreto, as deformaçōes sofrerão acréscimos em seus valores. Dessa maneira a fluência é definida como sendo o acréscimo de deformações sob tensão constante. A deformação total num instante genérico de tempo será obtida por :

$$
\varepsilon_{c, t o t}(t)=\varepsilon_{c}\left(t_{0}\right)+\varepsilon_{c c}\left(t, t_{0}\right)
$$

onde $\varepsilon_{\mathrm{cc}}\left(\mathbf{t}, \mathrm{t}_{0}\right)$ é a deformação no concreto por fluência. A expressão (3.3) também pode ser escrita da seguinte forma :

$$
\varepsilon_{\mathrm{c}, \text { tot }}(\mathrm{t})=\varepsilon_{\mathrm{c}}\left(\mathrm{t}_{0}\right)\left(1+\varphi\left(\mathrm{t}, \mathrm{t}_{0}\right)\right)
$$

onde o termo $\varphi\left(t, t_{0}\right)$ é relação entre a deformaçäo no concreto por fluência e deformação elástica inicial, também denominado coeficiente de fluência. Ao se relacionar a deformação total com a tensão inicial do concreto pode-se definir uma função de fluência na seguinte forma :

$$
\phi\left(\mathrm{t}, \mathrm{t}_{0}\right)=\frac{\varepsilon_{\mathrm{c}, \mathrm{tot}}(\mathrm{t})}{\sigma}=\frac{1}{\mathrm{E}_{\mathrm{c}}\left(\mathrm{t}_{0}\right)}\left[1+\varphi\left(\mathrm{t}, \mathrm{t}_{0}\right)\right]
$$

Suponha-se agora que açäo exierna seja abruptamente retirada no instante de tempo igual a " $\ell$ ". Logo de início existe uma diminuição no nível de deformaçöes devida a recuperação elástica. Esta deformação pode ser determinada de maneira semelhante à equação (3.2), no entanto o sinal é invertido por se tratar de descarregamento e, ainda, o módulo é menor devido ao ganho de resistência e a diminuição da deformabilidade do concreto. Assim :

$$
\varepsilon_{\text {ce }}(t)=-1 \frac{\sigma}{E_{c}(t)} \quad c / E_{c}(t)>E_{c}\left(t_{0}\right)
$$


No caso do descarregamento parte da deformação devida à fluência será recuperada ao longo do tempo, a esta denomina-se de acordo com NEVILLE (1983), "fluência recuperável" ou "reversível". Por outro lado, a parcela de deformação que não pode ser recuperada é divida em duas partes, a saber: "deformação lenta irreversivel" e "fluência rápida" que é aquela que ocorre nas primeiras 24 horas após o carregamento.

A evolução das deformaçőes ao longo do tempo de uma barra do tipo daquela da figura (3.1) sujeita a um estado de tensöes constante durante um intervalo que varia de " $\boldsymbol{t}_{0}$ " até " $\boldsymbol{t}$ " pode ser ilustrado pela figura (3.2) onde $\varepsilon_{\mathrm{ce}}\left(\mathbf{t}_{0}\right)$ é a deformação elástica inicial; $\varepsilon_{\mathrm{cc}}\left(\mathbf{t}, \mathrm{t}_{0}\right)$ é o acréscimo de deformaçőes no concreto devido a fluência; $\varepsilon_{\mathrm{ce}}(t)$ é a recuperação elástica no tempo " $\mathrm{t}$ "; $\varepsilon_{\text {ccd }}$ é a fluência recuperável; $\varepsilon_{\text {cer }}$ é a parcela irreversível desta e $\varepsilon_{\text {cca }}$ é fluência rápida. Será apresentada neste capítulo a formulação para o cálculo do coeficiente de fluência de acordo o MC-90 do CEB.

Quando se efetua a análise de estruturas de concreto armado sujeitas à flexão, as tensöes acabam por sofrer variaçőes ao longo do tempo e não existe mais fluência pura como no caso da barra da figura (3.1). Embora não se pretenda neste capítulo aprofundar-se nesse fenômeno deve-se ao menos ser citado que para tais casos existe um equacionamento através de uma integração ao longo do tempo e a deformação total passa a ser dada por :

$$
\varepsilon_{c, t o t}(t)=\sigma_{c\left(t_{0}\right)} \cdot \phi_{\left(t, t_{0}\right)}+\int_{t_{0}}^{t} \phi_{(t, \tau)} \cdot d \sigma_{c(\tau)}
$$

A equação acima pode ser resolvida através do emprego do método AAEM ("Age Adjusted Effective Modulus") e mais detalhes sobre esse assunto podem ser encontrados na bibliografia citada. 


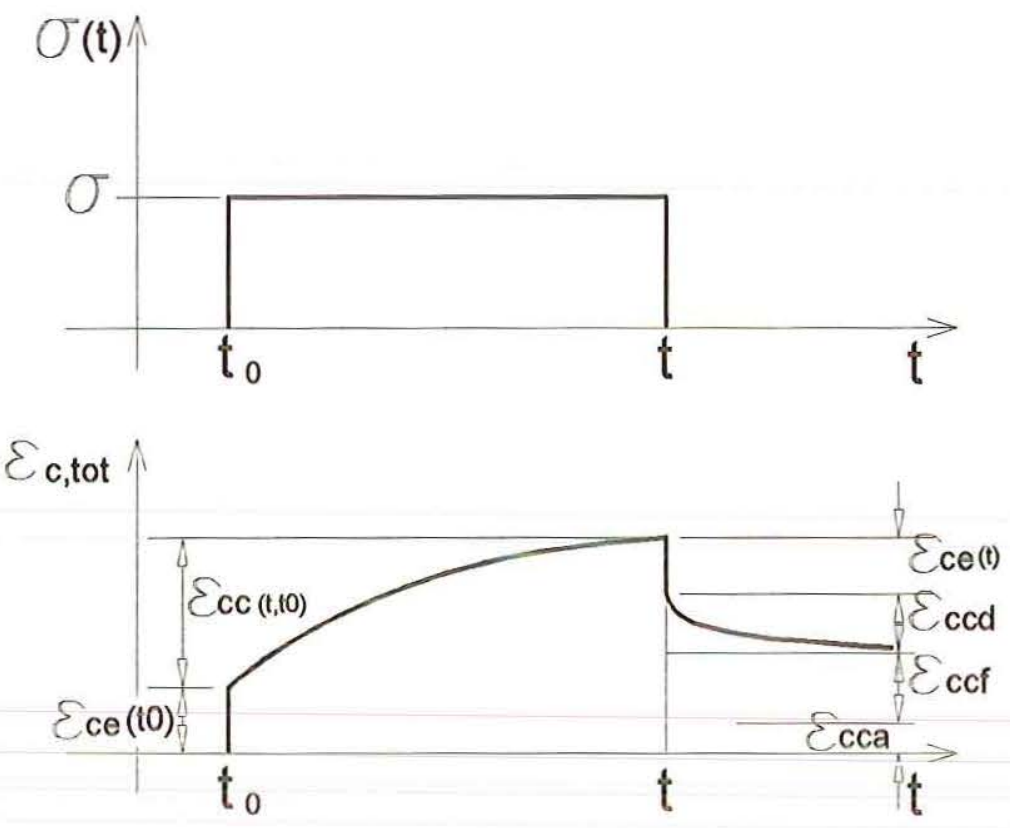

Figura 3.2 : Deformações ao longo do tempo para barra comprimida de concreto armado.

\section{3-RETRAÇÃO DO CONCRETO}

Denomina-se retração à redução expontânea de volume que ocorre em uma barra de concreto, mesmo na ausência de carregamento externo causando tensões mecânicas ou de variação de temperatura. Pode também ocorrer o inverso, ou seja, o aumento de volume quando a peça estiver em ambiente extremamente úmido ou submersa; tais fatos são ilustrados pela figura (3.3) que mostra ainda que a retração é maior no início tendendo a um valor constante com o envelhecimento do concreto. 


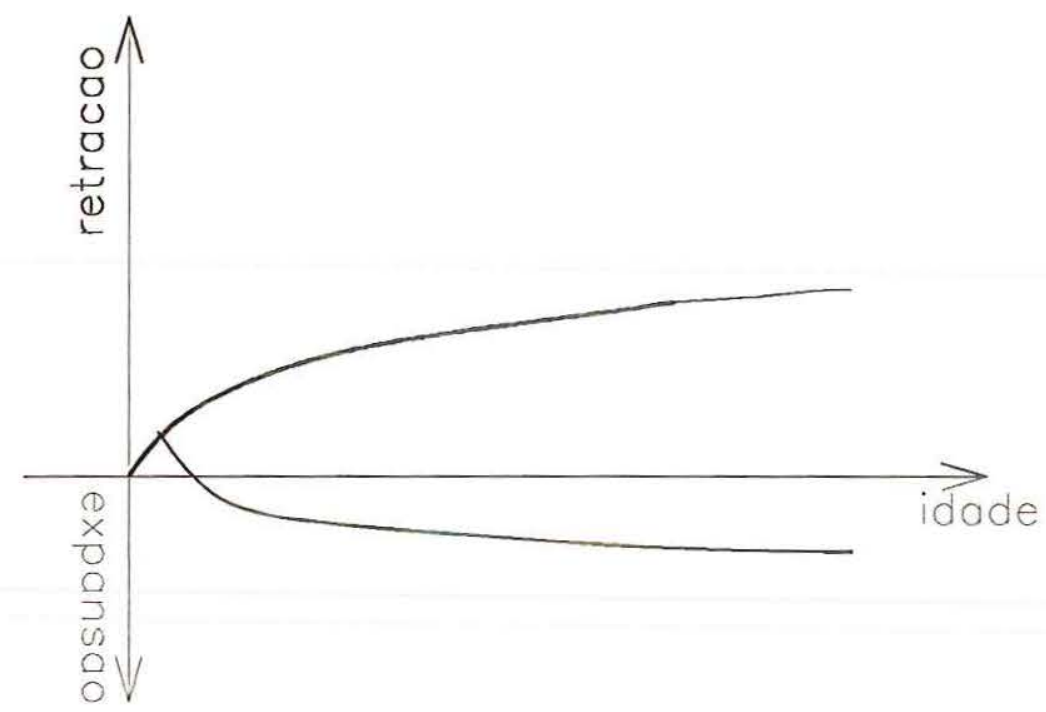

Figura 3.3 : Retração e expansão ao longo do tempo.

As causas da retração e da expansão estão relacionadas basicamente com a estrutura interna do concreto e, enumeradas em PINHEIRO (1992), estão as três principais: química, evaporação da água dos capilares do concreto e carbonatação. Como o estudo mais aprofundado destes fenômenos implicaria na elaboração de uma pesquisa muito mais abrangente sobre a estrutura interna do concreto, indica-se o trabalho de SMERDA (1988) além dos demais já citados anteriormente.

Os fatores principais que influem na retração do concreto estão relacionados basicamente com :

a) tipo do cimento: cimentos mais resistentes e de endurecimento mais rápido apresentam maior retração; a finura das partículas também faz com que a retração aumente pois quanto mais fino for o grão mais água de amassamento é necessária .

b) quantidade de cimento: quanto maior mais retração química haverá.

c) água de amassamento: quando maior a relação água/cimento maior será o número de capilares resultando maior diminuição expontânea de volume.

d) tamanho dos agregados: quanto menor mais água será necessária à mistura. 
e) umidade ambiente: assume grande influência no processo de cura do concreto, dificultando a retração.

f) temperatura: seu aumento favorece a evaporação da água, aumentando a retração.

g) espessura dos elementos: quando menor, maior será a superfície relativa em contato com o ambiente provocando o aumento da evaporação.

h) idade do concreto: o aumento de sua resistência com o tempo dificulta a retração.

i) presença de armadura: influencia na deformabilidade da peça dificultando inclusive a deformação expontânea.

\section{4-RELAXAÇÃO DO CONCRETO}

Para a análise do comportamento do concreto sob o efeito de açőes de longa duração, além da deformação lenta, como já tratado, deve-se também ser considerado outro fenômeno denominado " relaxação ".

Considere-se, para tanto, uma barra prismática de comprimento $\mathrm{L}$ como mostrado pela figura (3.4-a). Se num instante qualquer for imposto um deslocamento $\Delta \mathrm{L}$ (figura 3.4-b) a deformação correspondente será :

$$
\varepsilon=\frac{\Delta \mathrm{L}}{\mathrm{L}}
$$

Se o módulo de elasticidade da barra para esse instante for igual a $E$, o valor da tensäo correspondente será $\sigma\left(\hat{t}_{0}\right)=\mathbf{E} \varepsilon$. Suponha-se, agora, que $\Delta \mathrm{L}$ e, consequentemente, $\varepsilon$ sejam mantidos constantes ao longo do tempo com o auxílio de algum instrumento de controle apropriado; a tensão que inicialmente valia $\sigma_{\text {। }}$ vai sofrendo uma diminuição em seu módulo ao longo do tempo até se estabilizar atingindo o valor $\sigma\left(t_{f}\right)$ num tempo infinito conforme ilustrado pela figura (3.5). 
Pode-se dizer, então, que relaxação de um material é a "diminuição de tensão sob deformação constante"; entretanto em estruturas de concreto este fenômeno se dá juntamente com a deformação lenta, não existindo dessa forma a relaxação pura para o concreto.

A relação entre a tensão num instante de tempo $t$ qualquer, desde que maior que $t_{0}$, e a deformação inicial de uma fibra do concreto é denominada função de relaxação, $r\left(t, t_{0}\right)$; esta função será de importância no cálculo do "coeficiente de envelhecimento do concreto", $\chi\left(\mathbf{t}, \mathbf{t}_{0}\right)$, como será visto no item (3.8). Assim :

$$
\sigma(\mathrm{t})=\varepsilon \mathrm{r}\left(\mathrm{t}, \mathrm{t}_{0}\right)
$$

a)

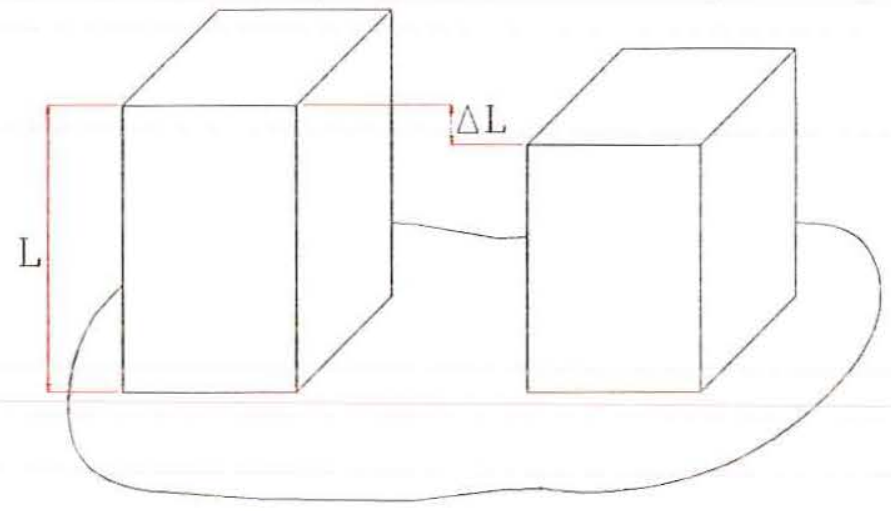

Figura 3.4 : Deformaçăo de barra prismática.
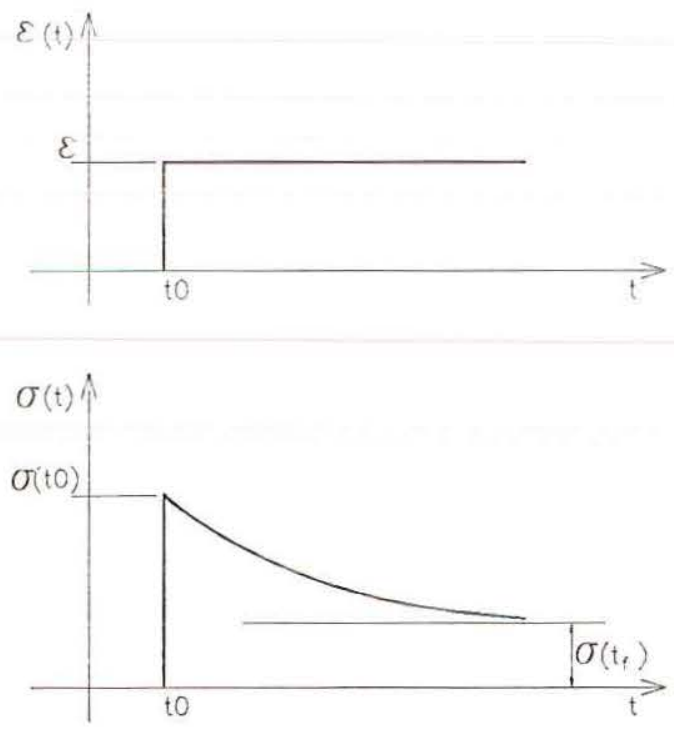

Figura 3.5 : Relaxação do concreto. 


\section{5-CÁlCULO DA RETRAÇÃO E FLUÊNCIA DE ACORDO COM O CÓDIGO - MODELO DE 1990 DO CEB}

\section{3,5.17APLICABILIDADE DO MODELO}

Segundo o CEB (1990), o equacionamento apresentado é válido para os concretos estruturais correntemente usados na prática podendo sua resistência característica à compressão, $\mathbf{f}_{\mathrm{ck}}$, assumir valores que variam desde $12 \mathrm{MPa}$ até o máximo de $80 \mathrm{MPa}$. As tensões de compressão não devem exceder 40 por cento da resistência média à compressão do dia correspondente ao carregamento, ou seja $\left|\sigma_{\mathrm{c}}\right|<\boldsymbol{f}_{\mathrm{cm}}\left(\boldsymbol{t}_{0}\right)$. A umidade ambiente deve estar compreendida entre 40 e $\mathbf{1 0 0} \%$ e a temperatura entre $5^{\circ} \mathrm{C}$ e $30^{\circ} \mathrm{C}$. O modelo também é válido para as solicitações de tração.

\subsection{2-PARÂMETROS DE CÁLCULO}

O cálculo das deformações devido a fluência e retração do concreto depende de vários fatores sendo que os principais são a resistência a compressão, a espessura equivalente, a idade do concreto, a temperatura ambiente, a umidade e o tipo do cimento dentre outros. Todos estes parâmetros são considerados no equacionamento como será descrito a seguir.

a) resistência à compressão :

O valor da resistência média à compressão aos 28 dias é dado pela expressão (3.10). Onde $\mathbf{f}_{c k}$ é resistência característica à compressão tomada aos 28 dias.

$$
\mathrm{f}_{\mathrm{cm}}=\mathrm{f}_{\mathrm{ck}}+8 \mathrm{MPa}
$$




\section{b) espessura equivalente :}

A espessura equivalente $h_{0}(\mathrm{~cm})$ é determinada por :

$$
\mathrm{h}_{0}=\frac{2 \mathrm{~A}_{\mathrm{c}}}{\mu}
$$

onde $A_{c}$ é a área da seção transversal $\left(\mathrm{cm}^{2}\right)$ e $\mu(\mathrm{cm})$ é o perímetro exposto ao ambiente. Pode-se notar que peças muitos esbeltas terão uma grande espessura equivalente e sofrerão maiores deformações por retração.

\section{c) maturidade do concreto :}

A temperatura média ambiente tem um efeito sobre a maturidade do concreto que é levado em conta de modo a substituir a idade real deste por outra, denominada "idade fictícia ", t̂ T , que será exatamente igual a real se a temperatura média ambiente for de $20^{\circ} \mathrm{C}$. Dessa forma o intervalo total de tempo deve ser dividido em sub-intervalos que caracterizem a predominância de determinada temperatura média, assim sendo:

$$
\mathrm{t}_{\mathrm{T}}=\sum_{\mathrm{i}=\mathrm{i}}^{\mathrm{n}} \Delta \mathrm{t}_{\mathrm{i}} \cdot \exp -\left[\frac{4000}{273+\frac{\mathrm{T}\left(\Delta \mathrm{t}_{1}\right)}{\mathrm{T}_{0}}-13.65}\right]
$$

onde $T\left(\Delta \hat{t}_{i}\right)$ é a temperatura média $\left[{ }^{\circ} \mathrm{C}\right]$ durante um intervalo de tempo igual a $\Delta \hat{t}_{i}$ em dias e $T_{0}$ assume o valor de $1^{\circ} \mathrm{C}$.

\section{d) tipo do cimento :}

O efeito do tipo de cimento no cálculo da fluência do concreto é considerado por meio da correção da sua idade por ocasião do carregamento ou seja, da idade inicial ou " to". Isto é feito por meio da aplicação da equação (3.13). 


$$
\mathrm{t}_{0 \mathrm{f}}=\mathrm{t}_{0 \mathrm{~T}} \cdot\left[\frac{9}{2+\left(\mathrm{t}_{0 \mathrm{~T}} / \mathrm{t}_{01}\right)^{0.50}}\right]^{\alpha} \geq 0,5 \mathrm{dia}
$$

onde $\mathbf{t}_{01}$ é igual a 1 dia, $\mathbf{t}_{0 \mathrm{~T}}$ é a idade inicial do concreto, corrigida de acordo com a expressão (3.12) e a potência $\alpha$ é função do tipo de cimento e assume os seguintes valores :

$\alpha=-1$ para cimentos de endurecimento lento tipos ( $A F, P O Z$, MRS,ARS );

$\alpha=0$ para cimento portland comum ( CP );

$\alpha=+1$ para alta resistência inicial e rápido endurecimento ( $A R I$ ).

\subsection{3-CÁLCULO DA RETRAÇÄO}

O valor total da retração do concreto que se desenvolve desde um instante de referência, $\boldsymbol{t}_{\mathrm{s}}$ até outro aqui denominado $\boldsymbol{t}$ é dado pela seguinte expressão :

$$
\varepsilon_{\mathrm{cs}}\left(\mathrm{t}, \mathrm{t}_{\mathrm{s}}\right)=\varepsilon_{\mathrm{cs} 0} \beta_{\mathrm{s}}\left(\mathrm{t}-\mathrm{t}_{\mathrm{s}}\right)
$$

onde $\mathbf{t}$ é idade real no instante em que se calculam as deformaçöes; $t_{\mathrm{s}}$ é a idade real do concreto no dia a partir do qual a retração interessa a ser considerada; $\varepsilon_{\mathrm{cs} 0}$ é o valor de referência da retração dado pela expressão (3.15); $\beta_{s}$ é função da evolução da retração com o tempo e tem seu valor dado pela equação (3.19).

O valor da retração de referência é dado por :

$$
\varepsilon_{\mathrm{cs} 0}=\varepsilon_{\mathrm{c}}\left(\mathrm{f}_{\mathrm{cm}}\right) \beta_{\mathrm{UR}}
$$

com :

$$
\varepsilon_{\mathrm{c}}\left(\mathrm{f}_{\mathrm{cm}}\right)=\left[160+10 \beta_{\mathrm{sc}}\left(9-\mathrm{f}_{\mathrm{cm}} / \mathrm{f}_{\mathrm{cm} 0}\right)\right] \cdot 10^{-6}
$$


onde $f_{\mathrm{cm}}$ é a resistência média à compressão do concreto aos 28 dias conforme a expressão (3.10); $\mathbf{f}_{\mathrm{cm} 0}$ é igual a $10 \mathrm{MPa}$ e $\beta_{\mathrm{sc}}$ é o coeficiente para levar em consideração o tipo do cimento e pode assumir um dos seguintes valores abaixo :

$\beta_{\mathrm{sc}}=4$ para cimentos de endurecimento lento tipos (AF, POZ, MRS,ARS);

$$
\begin{aligned}
& \beta_{\mathrm{sc}}=\mathbf{5} \text { para cimento portland comum (CP); } \\
& \beta_{\mathrm{sc}}=\mathbf{8} \text { para alta resistência inicial e rápido endurecimento (ARI). }
\end{aligned}
$$

$\mathrm{O}$ termo $\beta_{\mathrm{UR}}$, que aparece na equação (3.15), tem como função levar em conta a umidade do meio ambiente, sendo calculado pela expressão (3.17) ou pela (3.18)- conforme a umidade relativa do ambiente. Vaiores negativos deste significam que houve diminuição de volume na peça, ao passo que o sinal positivo para o módulo de $\beta_{\mathrm{UR}}$ indicariam uma possível expansão.

$$
\begin{gathered}
\beta_{\mathrm{UR}}=-1,55\left[1-\left(\frac{\mathrm{UR}}{100}\right)^{3}\right] \text { para } 40 \% \leq \mathrm{UR}<99 \% \\
\beta_{\mathrm{UR}}=+0,25 \quad \text { para UR } \geq 99 \%
\end{gathered}
$$

O desenvolvimento da retraçäo com o tempo depende do intervalo considerado e da espessura fictícia. Dessa forma o valor de $\beta_{\mathrm{s}}\left(\hat{t}, \hat{t}_{\mathrm{s}}\right)$ é dado por (3.19):

$$
\beta_{\mathrm{s}}\left(\mathrm{t}-\mathrm{t}_{\mathrm{s}}\right)=\left(\frac{\mathrm{t}-\mathrm{t}_{\mathrm{s}}}{350\left(\mathrm{~h}_{0} / \mathrm{h}_{\mathrm{ref}}\right)^{2}+\left(\mathrm{t}-\mathrm{t}_{\mathrm{s}}\right) / \mathrm{t}_{1}}\right)^{0,5}
$$

onde $\hat{t}_{1}$ é igual a 1 dia e $\mathbf{h}_{\text {ref }}$ vale $10 \mathrm{~cm}$. 


\subsection{4-CÁLCULO DA FLUÊNCIA DO CONCRETO}

O valor da deformação devido a fluência no concreto, quando submetido a uma tensão constante, pode ser calculado pela expressão (3.20) desde que as condições de aplicabilidade expressas pelo item (3.5.1) deste texto sejam satisfeitas.

$$
\varepsilon_{\mathrm{cc}}\left(\mathrm{t}, \mathrm{t}_{0}\right)=\frac{\sigma_{\mathrm{c}}\left(\mathrm{t}_{0}\right)}{\mathrm{E}_{\mathrm{c}}(28)} \cdot \varphi_{28}\left(\mathrm{t}, \mathrm{t}_{0}\right)
$$

onde $\sigma_{\mathrm{c}}\left(\mathrm{t}_{0}\right)$ é a tensão no concreto; $\boldsymbol{E}_{\mathrm{c}}(\mathbf{2 8})$ é o módulo de elasticidade longitudinal que tem seu valor de acordo com o item (3.6) e $\varphi_{28}\left(t, t_{0}\right)$ é o coeficiente de fluência em relação à deformação aos 28 dias.

A deformação total num instante de tempo qualquer, devida a uma tensão constante aplicada numa fibra do concreto pode ser relacionada com esta tensão através de uma "função de fluência" como já foi comentado no item (3.2). Dessa forma :

$$
\varepsilon_{\mathrm{c}, \text { tot }}(\mathrm{t})=\sigma_{\mathrm{c}}\left(\mathrm{t}_{0}\right) \cdot \phi\left(\mathrm{t}, \mathrm{t}_{0}\right)
$$

onde a função de fluência pode ser escrita na seguinte forma:

$$
\phi\left(t, t_{0}\right)=\frac{1}{E_{c}\left(t_{0}\right)}+\frac{\varphi_{28}\left(t, t_{0}\right)}{E_{c}(28)}
$$

\section{CÁLCULO DO COEFICIENTE DE FLUÊNCIA:}

O coeficiente de fluência é calculado da seguinte forma :

$$
\varphi_{28}\left(\mathbf{t}, \mathbf{t}_{0}\right)=\varphi_{0} \beta_{\mathrm{c}}\left(\mathbf{t}-\mathbf{t}_{0}\right)
$$


onde $\varphi_{0}$ é o valor de referência do coeficiente de fluência para a idade $\mathbf{t}_{0} \mathrm{e}$ $\beta_{c}\left(t-t_{0}\right)$ é um coeficiente que mede o desenvolvimento da fluência ao longo do tempo.

A umidade relativa do ambiente, a espessura equivalente, a resistência do concreto, o tipo do cimento e o instante da aplicação do carregamento são os fatores que influem no valor do coeficiente de referência que é determinado conforme as expressões seguintes :

$$
\varphi_{0}=\varphi_{\mathrm{UR}} \cdot \beta\left(\mathrm{f}_{\mathrm{cm}}\right) \cdot \beta\left(\mathrm{t}_{0}\right)
$$

com :

$$
\begin{aligned}
& \varphi_{\mathrm{UR}}=1+\frac{1-\mathrm{UR} / 100}{0.215\left(\mathrm{~h}_{0}\right)^{1 / 3}} \\
& \beta\left(\mathrm{f}_{\mathrm{cm}}\right)=\frac{16,8}{\left(\mathrm{f}_{\mathrm{cm}}\right)^{0.5}} \\
& \beta\left(\mathrm{t}_{0}\right)=\frac{1}{0,1+\left(\mathrm{t}_{0 \mathrm{f}}\right)^{0.2}}
\end{aligned}
$$

onde UR é a umidade relativa em \%; $\boldsymbol{h}_{0}$ é a espessura fictícia calculada conforme a expressão (3.11); $\hat{f}_{\mathrm{cm}}$ dado por (3.10) e $\hat{t}_{0 f}$ é a idade inicial corrigida pelas equaçöes (3.12) e (3.13), respectivamente.

O desenvolvimento da fluência com o tempo é dado por :

$$
\beta_{c}\left(t, t_{0}\right)=\left[\frac{\left(t-t_{0}\right) / t_{1}}{\beta_{H}+\left(t-t_{0}\right) / t_{1}}\right]^{0,3}
$$

com :

$$
\beta_{\mathrm{H}}=150\left\{1+\left(1.2 \frac{\mathrm{UR}}{100}\right)^{18}\right\} \frac{\mathrm{h}_{0}}{\mathrm{~h}_{\mathrm{ref}}}+250 \leq 1500
$$

onde $\left(\mathbf{t}-\hat{t}_{0}\right)$ é o intervalo real em dias, não corrigido; $\mathbf{h}_{\text {ref }}$ é a espessura de referência que é tomada como valendo $10 \mathrm{~cm} ; \mathbf{t}_{1}$ vale 1 dia. 


\section{OBSERVAÇÕES:}

De acordo com as indicaçöes do CEB, o cálculo do coeficiente de fluência é proposto como sendo a relação entre a deformação por fluência no instante " $\boldsymbol{~ "}$ " e a deformação instantânea para uma tensão aplicada aos 28 dias, daí o fato de estar sendo usado na nomenclatura o símbolo $\varphi_{28}$. Assim a partir da equação (3.20) resulta :

$$
\varphi_{28}\left(\mathrm{t}, \mathrm{t}_{0}\right)=\frac{\varepsilon_{\mathrm{cc}}\left(\mathrm{t}, \mathrm{t}_{0}\right)}{\sigma_{\mathrm{c}}\left(\mathrm{t}_{0}\right) / \mathrm{E}_{\mathrm{c}}(28)}
$$

Pode também ser interessante definir o coeficiente de fluência como a relaçäo entre a deformação por f́luência no instante " $\mathrm{\imath}$ " e a deformaçäo elástica para o instante inicial " $\mathbf{t}_{0}$ ". Desse modo resulta uma expressão semelhante a (3.30) descrita a seguir :

$$
\varphi_{0}\left(\mathrm{t}, \mathrm{t}_{0}\right)=\frac{\varepsilon_{c c}\left(t, t_{0}\right)}{\sigma_{c}\left(t_{0}\right) / E_{c}\left(t_{0}\right)}
$$

O coeficiente de fluência em relação ao tempo inicial pode ser obtido a partir do valor calculado pelas recomendaçöes do CEB, bastando para Isso isoiar o termo correspondente a deformação por fluência nas expressőes (3.30) e (3.31) e depois igualar as equaçöes resultantes. Assim :

$$
\varepsilon_{c c}\left(t, t_{0}\right)=\frac{\sigma_{c}\left(t_{0}\right)}{E_{c}(28)} \cdot \varphi_{28}\left(t, t_{0}\right)=\frac{\sigma_{c}\left(t_{0}\right)}{E_{c}\left(t_{0}\right)} \cdot \varphi_{0}\left(t, t_{0}\right)
$$

portanto:

$$
\varphi_{0}\left(t, t_{0}\right)=\varphi_{28}\left(t, t_{0}\right) \cdot \frac{E_{c}\left(t_{0}\right)}{E_{c}(28)}
$$

e, analogamente :

$$
\varphi_{28}\left(t, t_{0}\right)=\varphi_{0}\left(t, t_{0}\right) \cdot \frac{E_{c}(28)}{E_{c}\left(t_{0}\right)}
$$


3.6-VARIAÇÃO DO MÓDULO DE DEFORMAÇÃO LONGITUDINAL DO CONCRETO

O módulo de elasticidade longitudinal, tangente na origem do diagrama tensão $x$ deformação, para concretos de peso específico normal, pode ser estimado da seguinte forma, de acordo com as indicaçöes do CEB de 1990:

$$
E_{c}(28)=21500\left[\left(f_{c k}+\Delta f\right) / f_{c m 0}\right]^{\frac{1}{3}}
$$

onde $E_{c}$ (28) tem seu valor em MPa e se refere a idade de 28 dias; î́ck é a resistência característica do concreto à compressão; $\mathbf{f}_{\mathrm{cm} 0}$ é igual a $10 \mathrm{MPa} \mathrm{e}$ $\Delta$ f́ é tomado como sendo igual a $8 \mathrm{MPa}$.

Para o caso de análise em regime de elasticidade linear, com a consideração da fluência e níveis de tensão maiores é definido um módulo secante, $E_{\mathrm{cs}}(28)$, que é na realidade uma minoração do módulo tangente; estes fatos podem ser ilustrados pela figura (3.6) .

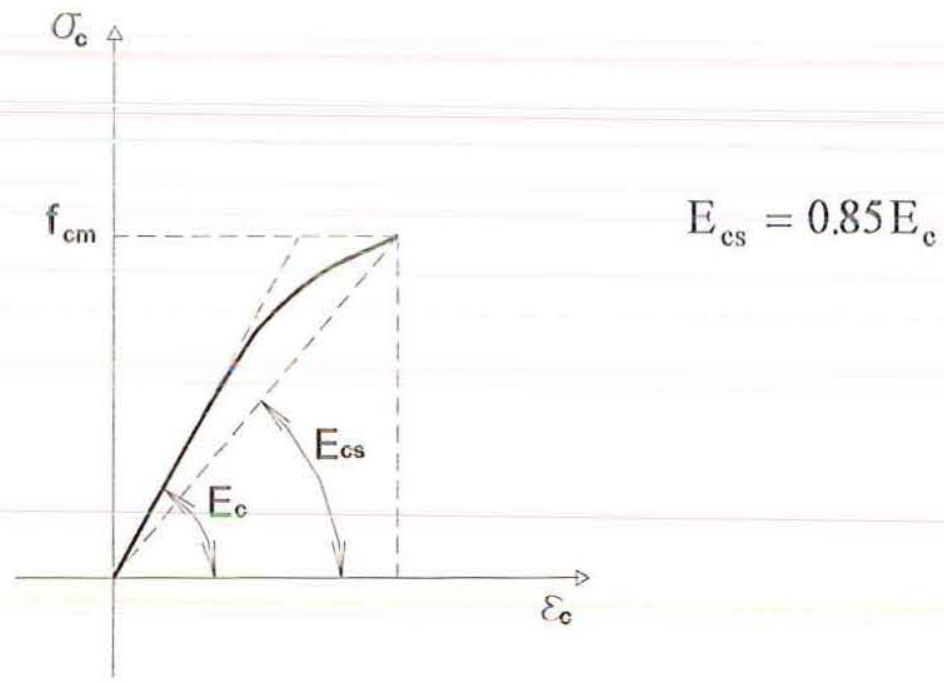

Figura 3.6 : Módulos de deformação longitudinal tangente e secante para o concreto. 
Para uma idade qualquer do concreto, diferente de 28 dias, o CEB-90 apresenta uma formulação para a avaliação do valor do módulo elástico como será apresentado a seguir :

$$
E_{c}(t)=\beta_{E}(t) \cdot E_{c}(28)
$$

Com :

$$
\beta_{\mathrm{E}}(\mathrm{t})=\sqrt{\beta_{\mathrm{cc}}(\mathrm{t})}
$$

e :

$$
\beta_{c c}(t)=\exp [s(1-\sqrt{28 / t})]
$$

O termo "s" é um coeficiente que é funçäo do tipo de cimento; seus valores possíveis são os seguintes :

$s=0,20$ para cimentos de endurecimento lento tipos (AF, POZ, MRS, ARS);

$s=0,25$ para cimento portland comum (CP);

$s=\mathbf{0 , 3 8}$ para alta resistência inicial e rápido endurecimento (ARI).

\section{7-DESENVOLVIMENTO DA RESISTÊNCIA COM O TEMPO}

\subsection{1-RESISTÊNCIA À COMPRESSÄO}

O valor da resistência média à compressão, $\hat{f}_{\mathrm{cm}}$, já foi estudado no item (3.5.2), pois seu conhecimento era de interesse para os cálculos relativos à fluência e à retração. Naquela ocasião o valor calculado referia-se aos 28 dias após a concretagem, neste item pretende-se expor a formulação para avaliação das mudanças devido ao tempo na resistência do concreto. Novamente, as equaçöes apresentadas serão relativas ao MC-90 do CEB. Assim, para um instante genérico de tempo:

$$
\mathrm{f}_{\mathrm{cm}}(\mathrm{t})=\beta_{\mathrm{cc}}(\mathrm{t}) \cdot \mathrm{f}_{\mathrm{cm}}
$$


onde $\beta_{c c}(t)$ e $\boldsymbol{f}_{\mathrm{cm}}$ são calculados de acordo com as equações (3.38) e (3.10), respectivamente.

\subsection{2-RESISTÊNECIA À TRAÇÃO}

A resistência à tração do concreto tem uma variabilidade maior que aquela à compressão, por isso o CEB indica um valor inferior e outro superior para o seu cálculo, sendo que também estabelece uma média entre ambos. Indica, ainda, que estes podem ser adotados na ausência de outro valor mais acuradamente determinado. Para os cálculos a que este trabalho se interessa será adotado o valor médio obtido por (3.42). Assim :

$$
\begin{aligned}
& \mathrm{f}_{\text {ctk, min }}=0,95\left(\mathrm{f}_{\mathrm{ck}} / \mathrm{f}_{\mathrm{ck} 0}\right)^{\frac{2}{3}} \\
& \mathrm{f}_{\mathrm{ctk}, \max }=1,80\left(\mathrm{f}_{\mathrm{ck}} / \mathrm{f}_{\mathrm{ck} 0}\right)^{\frac{2}{3}} \\
& \mathrm{f}_{\mathrm{ctm}}=1,40\left(\mathrm{f}_{\mathrm{ck}} / \mathrm{f}_{\mathrm{ck} 0}\right)^{\frac{2}{3}}
\end{aligned}
$$

onde $f_{\mathrm{ck}}$ é a resistência característica do concreto à compressão para 28 dias e $\hat{f}_{c k n}$ é igual a $10 \mathrm{MPa}$.

Segundo as recomendações do CEB, o desenvolvimento da resistência à tração com o tempo é largamente influenciado pelo processo de cura e pelas dimensões da peça. Este código-modelo indica, como uma primeira aproximação, que se pode assumir que o desenvolvimento da resistência à tração seja semelhante à evolução da resistência à compressão para caos onde houve cura adequada e idade do concreto $\geq 28$ dias. 


\section{8-CÁLCULO DO COEFICIENTE DE ENVELHECIMENTO DO CONCRETO}

\section{3,8.1-RELAÇÕES BÁSICAS}

Conforme já foi dito em seçöes anteriores, dificilmente existe a fluência pura nas estruturas de concreto. Assim sendo, a deformação total de uma fibra num instante qualquer de tempo $(\boldsymbol{t})$ será determinada pela expressão abaixo :

$$
\varepsilon_{\mathrm{c}\left(\mathrm{t}, \mathrm{t}_{0}\right)}=\sigma_{\mathrm{c}\left(\mathrm{t}_{0}\right)} \cdot \phi_{\left(\mathrm{t}, \mathrm{t}_{0}\right)}+\int_{\mathrm{t}_{0}}^{\mathrm{t}} \phi_{(\mathrm{t}, \tau)} \cdot d \sigma_{\mathrm{c}(\tau)}+\varepsilon_{\mathrm{cs}\left(\mathrm{t}, \mathrm{t}_{0}\right)}
$$

onde $\tau$ é um instante genérico entre $\hat{t}_{0}$ e $\hat{t}$, do $(\tau)$ é um incremento infinitesimal de tensão aplicado na idade $\tau, \varepsilon_{\mathrm{cs}}\left(t, t_{0}\right)$ é a retração no período e $\phi$ são as funçőes de fluência definidas a seguir:

$$
\begin{gathered}
\phi\left(t, t_{0}\right)=\frac{1+\varphi_{0}\left(t, t_{0}\right)}{E_{c}\left(t_{0}\right)} \\
\phi(t, \tau)=\frac{1+\varphi_{0}(t, \tau)}{E_{c}(\tau)}
\end{gathered}
$$

onde $\varphi$ é o coeficiente de fluência conforme definido na seçäo $(3.5 .2), E_{c}\left(\hat{t}_{0}\right)$ e $E_{c}(\tau)$ são os módulos elásticos dependentes do tempo determinados conforme o item (3.6) deste capítulo.

Analisando-se a expressão (3.43) pode-se pensar na fluência total da seguinte forma: primeiramente a tensão inicial $\sigma_{\mathbf{c}}\left(\hat{t}_{0}\right)$, se permanecesse constante ao longo do tempo, causaria uma deformação total no tempo $\mathfrak{t}$ de valor igual ao primeiro termo do lado direito da equação (3.43); como na realidade a tensão é variável com o tempo, existindo um incremento de tensőes, $\Delta \sigma_{\mathbf{c}}(\mathbf{t})$, existe outra parcela de deformação (tanto elástica, quanto 
por fluência), cujo valor é dado pela integração que aparece na expressão (3.43).

Como pode-se supor, $\Delta \sigma_{c}$ (t) não é introduzido de uma só vez no instante inicial e sim gradualmente variando de zero para o tempo $t_{0}$ até $\Delta \sigma_{c}(\hat{t})$ para $t$. Seja um intervalo $\tau$ de tempo, um incremento $\Delta \sigma_{c}(\tau)$ introduzido gradualmente no decorrer deste provocaria menor deformação por fluência do que se fosse introduzido integralmente no início do intervalo. Através de um coeficiente apropriado, adimensional, positivo e menor que a unidade, $\chi$, é possível supor que todo o incremento $\Delta \sigma_{c}(t)$ seja aplicado no instante inicial do intervalo e mantido constante, simplificando bastante a expressão (3.43). A este denomina-se "coeficiente de envelhecimento do concreto". Assim, a deformação total no tempo $\hat{\imath}$ devida a $\Delta \sigma_{c}(\hat{\imath})$ é calculada de maneira semelhante ao que se faz para $\sigma_{c}\left(t_{0}\right)$, com o coeficiente de fluência $\varphi_{0}\left(\mathfrak{t}, \mathfrak{t}_{0}\right)$ multiplicado por $\chi$. Desse modo, a equação (3.43) pode ser reescrita da seguinte forma:

$$
\varepsilon_{\mathrm{c}\left(\mathrm{t}, \mathrm{t}_{0}\right)}=\sigma_{\mathrm{c}\left(\mathrm{t}_{0}\right)} \cdot \phi_{\left(\mathrm{t}, \mathrm{t}_{0}\right)}+\Delta \sigma_{\mathrm{c}(\mathrm{t})} \cdot \phi *{ }_{\left(\mathrm{t}, \mathrm{t}_{0}\right)}
$$

com :

$$
\phi *\left(t, t_{0}\right)=\frac{1+\chi \varphi_{0}\left(t, t_{0}\right)}{E_{c}\left(t_{0}\right)}
$$

O valor do coeficiente de envelhecimento é função basicamente dos instantes inicial e final do intervalo de tempo, podendo-se afirmar que $\chi=\chi\left(t, t_{0}\right)$. GHALI \& FAVRE (1986) demonstram que é possível relacionar $x$ com a relaxação e a fluência do concreto, resultando na expressão (3.48) que é bastante simples de ser empregada.

$$
\chi\left(t, t_{0}\right)=\frac{1}{1-r\left(t, t_{0}\right) / E_{c}\left(t_{0}\right)}-\frac{1}{\varphi_{0}\left(t, t_{0}\right)}
$$


As determinações do coeficiente de fluência e do módulo de elasticidade do concreto, empregados pela expressão (3.48), já foram definidas em seções anteriores restando apenas a definição do valor de $r\left(t, t_{0}\right)$ para o cálculo de $\chi$. A função de relaxação pode ser encontrada em ábacos propostos por GHALI \& FAVRE (1986), onde também é apresentado um algoritmo programável para a sua determinação. Este último foi implementado no decorrer deste trabalho de mestrado e será descrito resumidamente a seguir. Maiores detalhes e a dedução completa do algoritmo, podem ser encontrados também em BAZANT (1972) e MACHADO (1989).

\subsection{2-ALGORITMO "PASSO A PASSO" PARA O CÁLCULO DA RELAXAÇÃO DO CONCRETO,}

O diagrama que expressa a variação das tensöes ao longo do tempo para uma fibra (de concreto) da seção transversal de um elemento de concreto armado tem o aspecto da figura (3.7). Supöe-se que uma tensäo inicial, $\Delta \sigma_{\mathrm{c}} 1$, é introduzida nessa fibra no instante de tempo $\hat{t}_{0}$; esta tensão vai aumentando gradualmente no intervalo de tempo $\left(\hat{t}_{0}, \hat{t}\right)$. O acréscimo de tensão $\Delta \sigma_{c}$ j é suposto no ponto médio do j-ésimo intervalo, no caso de acréscimos bruscos de tensão como ocorrem nos intervalos 1 e k o comprimento da variação de tempo é considerado nulo. Ainda para o intervalo genérico $j$, o tempo $t_{j-1 / 2}$ define o seu extremo inferior, $t_{j}$ o ponto médio e $t_{i+1 / 2}$ o extremo superior.

A partir do emprego das equaçöes (3.46) e (3.47) é possível escrever-se a deformação total no final do i-ésimo intervalo conforme as expressäo (3.49) e (3.50). 


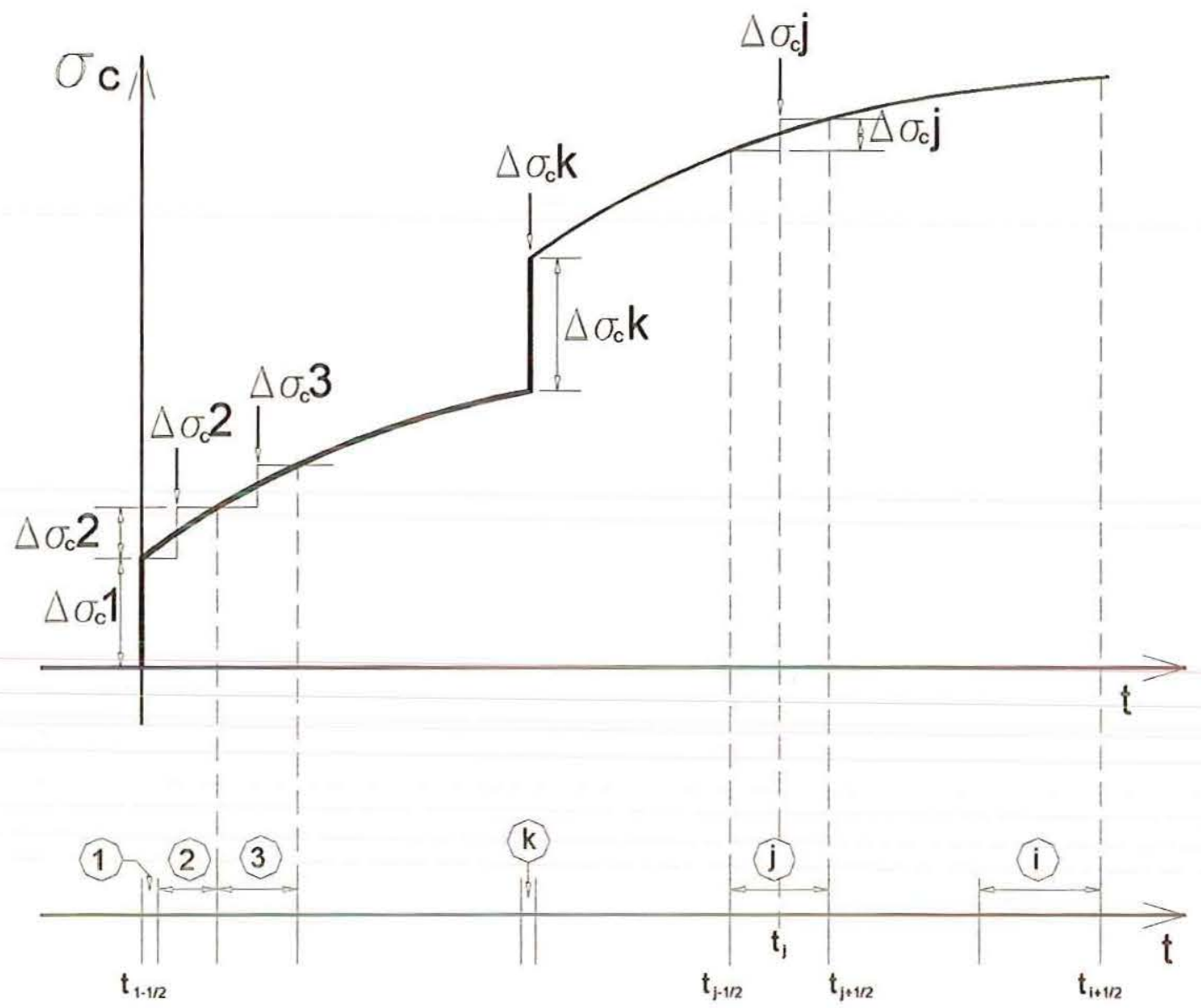

Figura 3.7 : Divisão de tensões com o tempo para a análise "passo a passo" da relaxaçăo do concreto.

$$
\begin{aligned}
& \varepsilon_{c}\left(t_{i+1 / 2}\right)=\left(\Delta \sigma_{c}\right)_{1} \frac{1+\varphi_{0}\left(t_{i+1 / 2}, t_{1}=t_{0}\right)}{E_{c}\left(t_{1}\right)}+\left(\Delta \sigma_{c}\right)_{2} \frac{1+\varphi_{0}\left(t_{i+1 / 2}, t_{2}\right)}{E_{c}\left(t_{2}\right)}+ \\
&\left(\Delta \sigma_{c}\right)_{j} \frac{1+\varphi_{0}\left(t_{i+1 / 2}, t_{j}\right)}{E_{c}\left(t_{j}\right)}+\left(\Delta \sigma_{c}\right)_{i} \frac{1+\varphi_{0}\left(t_{i+1 / 2}, t_{i}\right)}{E_{c}\left(t_{i}\right)}+\varepsilon_{c s}\left(t_{i+1 / 2}, t_{0}\right)
\end{aligned}
$$

A expressão acima pode ser escrita na forma compacta :

$\varepsilon_{c}\left(t_{i+1 / 2}\right)=\sum_{j=1}^{i}\left[\left(\Delta \sigma_{c}\right)_{j} \frac{1+\varphi_{0}\left(t_{i+1 / 2}, t_{j}\right)}{E_{c}\left(t_{j}\right)}\right]+\varepsilon_{c s}\left(t_{i+1 / 2}, t_{0}\right)$ 
Para o caso em que todos os incrementos de tensão são conhecidos, a equação acima fornece a deformação total para o instante $t_{i+1 / 2}$. No entanto, para o problema do cálculo da relaxação, o que se conhece é a deformação total, $\varepsilon_{c}$, que é imposta no instante to e mantida constante provocando uma tensão inicial igual que vai sendo relaxada ao longo do tempo; nesse caso, os valores dos incrementos $\Delta \sigma_{c}$ j devem ser calculados passo a passo e a tensão total ao término do último intervalo de tempo será determinada por:

$$
\begin{aligned}
\sigma_{c}\left(t_{i+1 / 2}\right) & =\left(\Delta \sigma_{c}\right)_{1}+\left(\Delta \sigma_{c}\right)_{2}+\ldots . .+\left(\Delta \sigma_{c}\right)_{j}+\ldots . .+\left(\Delta \sigma_{c}\right)_{i} \\
& =\sum_{j=1}^{i}\left(\Delta \sigma_{c}\right)_{j}
\end{aligned}
$$

As tensöes inicial e final seräo calculadas pelas expressőes (3.52) e (3.53), respectivamente, onde $\boldsymbol{r}\left(\boldsymbol{t}, \mathbf{t}_{0}\right)$ é a função de relaxação do concreto no período.

$$
\begin{aligned}
& \sigma_{\mathrm{c}}\left(\mathrm{t}_{0}\right)=\mathrm{E}_{\mathrm{c}}\left(\mathrm{t}_{0}\right) \cdot \varepsilon_{\mathrm{c}} \\
& \sigma_{\mathrm{c}}\left(\mathrm{t}_{0}\right)=\mathrm{r}\left(\mathrm{t}_{\mathrm{i}+1 / 2}, \mathrm{t}_{0}\right) \cdot \varepsilon_{\mathrm{c}}
\end{aligned}
$$

O valor da relaxação no final do último intervalo pode ser determinado igualando-se as expressões (3.51) e (3.53), assim :

$$
r\left(t_{i+1 / 2}, t_{0}\right)=\frac{1}{\varepsilon_{c}} \sum_{j=1}^{i}\left(\Delta \sigma_{c}\right)_{j}
$$

Tomando-se o valor unitário para a deformação imposta $\varepsilon_{\mathfrak{c}}$, o valor da relaxaçäo fica definido como sendo a soma de todos os incrementos de tensão que ocorreram durante to e t. Para a dedução do algoritmo é conveniente rescrever (3.50) isolando o último termo da somatória o que resulta na expressão (3.55). 


$$
\begin{aligned}
\varepsilon_{c}\left(t_{i+1 / 2}\right)= & \sum_{j=1}^{i-1}\left[\left(\Delta \sigma_{c}\right)_{j} \frac{1+\varphi_{0}\left(t_{i+1 / 2}, t_{j}\right)}{E_{c}\left(t_{j}\right)}\right]+ \\
& \left(\Delta \sigma_{c}\right)_{i} \frac{1+\varphi_{0}\left(t_{i+1 / 2}, t_{i}\right)}{E_{c}\left(t_{i}\right)}+\varepsilon_{c s}\left(t_{i+1 / 2}, t_{0}\right)
\end{aligned}
$$

Conforme já foi dito, a deformação imposta inicialmente é mantida constante ao longo do tempo, portanto $\varepsilon_{c}\left(\hat{t}_{1}\right)$ será constante e igual à unidade. Dessa forma é possível escrever um incremento genérico de tensões $\left(\Delta \sigma_{\mathrm{c}}\right)_{\text {I }}$ em função do módulo de elasticidade e dos coeficientes de fluência dos intervalos precedentes, assim :

$$
\begin{gathered}
\left(\Delta \sigma_{c}\right)_{i}=\frac{E_{c}\left(t_{i}\right)}{1+\varphi_{0}\left(t_{i+1 / 2}, t_{i}\right)}\left\{\varepsilon_{c}\left(t_{i+1 / 2}\right)-\varepsilon_{c s}\left(t, t_{0}\right)-\right. \\
\left.\sum_{j=1}^{i-1}\left[\left(\Delta \sigma_{c}\right)_{j} \frac{1+\varphi_{0}\left(t_{i+1 / 2}, t_{j}\right)}{E_{c}\left(t_{j}\right)}\right]\right\}
\end{gathered}
$$

A expressão acima dever ser aplicada sucessivamente para $i=1,2 \ldots n$, onde $\mathrm{n}$ é o número de intervalos em que o tempo total foi dividido. Dessa forma ao se aplicar (3.56) para o cálculo do incremento no i-ésimo intervalo todos os incrementos precedentes, $\left(\dot{\Delta} \sigma_{c}\right)_{i}$, necessários para a sua resolução já estarão previamente determinados. Assim a relaxação total será :

$$
r\left(t_{i+1 / 2}, t_{0}\right)=\sum_{j=1}^{i}\left(\Delta \sigma_{c}\right)_{j}
$$

O coeficiente de envelhecimento do concreto será calculado de acordo com a expressão (3.48) aqui repetida por comodidade.

$$
\chi\left(\mathrm{t}, \mathrm{t}_{0}\right)=\frac{1}{1-\mathrm{r}\left(\mathrm{t}, \mathrm{t}_{0}\right) / \mathrm{E}_{\mathrm{c}}\left(\mathrm{t}_{0}\right)}-\frac{1}{\varphi_{0}\left(\mathrm{t}, \mathrm{t}_{0}\right)}
$$

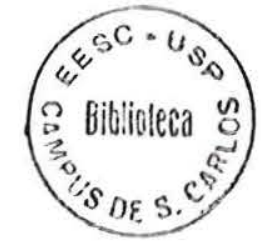


O número total de sub-intervalos ( $\mathbf{n}$ ) em que o intervalo principal (to t) deve ser dividido influi na precisão dos resultados, dessa forma se $\mathbf{n}$ for um valor suficientemente grande conduzirá, evidentemente, a melhores resultados, entretanto a grande custo computacional. Por outro lado quando o número de subintervalos for pequeno, o resultado será impreciso, apesar da facilidade computacional. BAZANT (1972) sugere que o tempo total seja repartido em torno de 5 ou 6 parcelas. Através do programa computacional efetuado para a análise "passo a passo" da relaxação do concreto pode-se perceber que para $n>10$ o valor obtido praticamente não se alterava, por isso neste trabalho, indica-se que o intervalo total de tempo seja dividido em 10 partes.

Ainda de acordo com BAZANT, a forma como os subintervalos são tomados influi significativamente nos resultados. Esse autor indica que melhores resultados são obtidos quando os comprimentos $\Delta \hat{t}_{i}$ dos intervalos são aproximadamente iguais quando colocados sobre uma escala logarítmica. Sugere-se, neste trabalho, que estes sejam tomados da seguinte forma :

$$
\Delta \mathrm{t}^{\prime}=\frac{\log (\mathrm{t})-\log \left(\mathrm{t}_{0}\right)}{\mathrm{n}}
$$

Assim, o extremo inferior de um intervalo $\mathbf{i}, \hat{\mathbf{t}}_{\mathbf{i}-1 / 2}$, será igual ao extremo superior do intervalo i-1, que já foi previamente determinado. Por outro lado, $\hat{\imath}_{i+1 / 2}$ deverá ser avaliado da seguinte forma:

$$
\log \left(t_{i+1 / 2}\right)=\log \left(t_{i-1 / 2}\right)+\Delta t^{\prime}
$$




\section{9-MODIFICAÇÕES NOS ESFORÇOS SOLICITANTES DEVIDAS À FLUÊNCIA}

Conforme já foi citado no início deste capítulo a fluência pode, ao longo do tempo, causar uma redistribuição de esforços solicitantes nas estruturas hiperestáticas. Pretende-se nesta seçäo analisar as circunstâncias em que este fato irá ocorrer; para tanto será aqui empregado o processo dos esforços. Deve-se esclarecer que as demonstraçőes que serão efetuadas a seguir podem ser encontradas em BAZANT (1972).

A determinação do momento hiperestático sobre o apoio intermediário de uma viga composta por dois tramos, conforme mostra a figura (3.8), é tratado agora. Pode-se afirmar que a rotação relativa do eixo da viga em relação a um ponto fixo sobre o apoio intermediário $\left(\delta_{\text {ir }}\right)$ é nulo. $\mathrm{O}$ vínculo que transmite momentos fletores entre os dois tramos será liberado e, em seu lugar, será imposto um momento fletor F1 com o objetivo de restituir a condição real da viga. A questäo então passa a ser determinar o valor de $\mathrm{F}$ para que $\delta_{1 \text { r }}$ seja nulo; o problema original hiperestático passa a ser representado por dois problemas isostáticos. Com o emprego do processo dos esforços pode-se escrever a seguinte equação de compatibilidade entre deslocamentos:

$$
\delta_{1 \mathrm{r}}=\delta_{10}+\mathrm{F}_{1} \delta_{11}=0
$$

Assim :

$$
\mathrm{M}=\mathrm{F}_{1}=-\frac{\delta_{10}}{\delta_{11}}
$$

Aplicando-se o princípio do trabalhos virtuais, PTV obtém-se (3.63) e (3.64).

$$
\delta_{10}=\int_{\text {est }} \frac{M_{0} M_{1}}{E_{c} I_{c}} d s
$$


e :

$$
\delta_{11}=\int_{\text {est }} \frac{M_{1}^{2}}{E_{c} I_{c}} d s
$$

onde $\mathrm{M}_{0}$ corresponde ao diagrama de momentos para o problema " 0 " conforme a figura (3.9), e $\mathbf{M}_{1}$ tem o mesmo significado para o problema "1" e M será o momento final sobre o apoio intermediário.

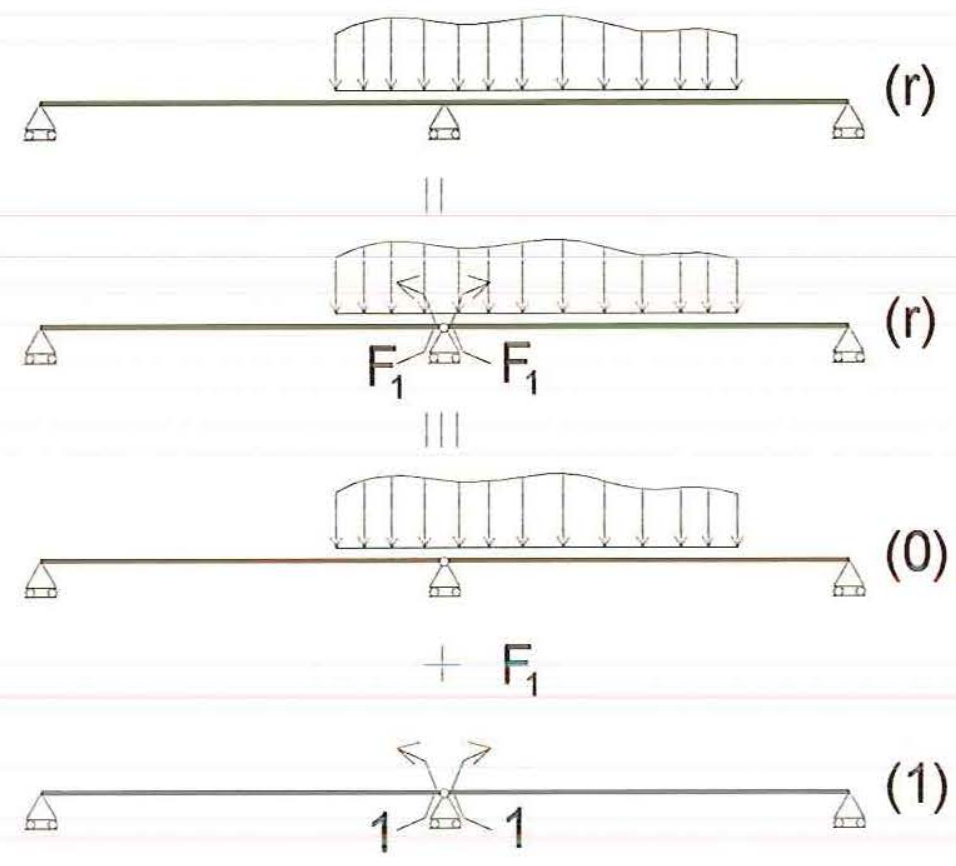

Figura 3.8 : Aplicaçáo do processo dos desiocamentos.

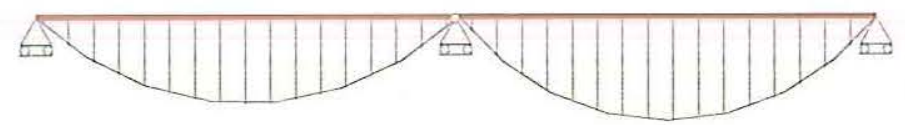

(M0)

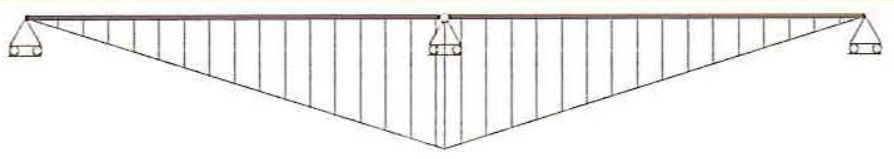

(M1)

Figura 3.9 : Momentos isostáticos. 
Supõe-se que ambos os tramos da viga tenham as mesmas propriedades físicas e geométricas e foram concretados no mesmo instante. Transcorrido um intervalo de tempo $\left(\mathfrak{t}_{-}-\hat{t}_{0}\right)$ novos deslocamentos devidos à fluência irão ocorrer na viga da figura (3.8). Para o caso das estruturas isostáticas basta multiplicar o deslocamento inicial pelo já definido coeficiente de fluência. Pode ser escrita um equação de compatibilidade semelhante à (3.61) em termos dos acréscimos de deslocamentos com o tempo.

$$
0 . \varphi=\delta_{10} \varphi+M \delta_{11} \varphi+\Delta M \delta_{11}(1+\varphi)
$$

onde $\varphi=\varphi\left(\hat{t}, \hat{t}_{0}\right)$ é o coeficiente de fluência e $\Delta M$ é a variação de esforços solicitantes.

Como os valores de $\delta_{10}, \delta_{11}$ e M são não-nulos, a equação (3.65) só pode ser satisfeita de $\Delta M$ for zero. Isso significa que para as estruturas hiperestáticas com o mesmo coeficiente de fluência em todos os seus membros a fluência não causa uma redistribuição de esforços.

Em se tratando de estruturas de concreto armado, além da condição anterior, os membros da estrutura devem ter idênticas taxas de armadura positiva e negativa para que a redistribuiçäo de esforços devida à fluência seja nula. Segundo BAZANT (1972) essa conclusão se estende a todas as estruturas hiperestáticas onde não se considera efeitos de segunda ordem e não somente ao caso particular acima descrito.

Dessa forma, para as estruturas de concreto armado, a grande responsável pela redistribuiçáo de esforcos solicitantes é a presenca de armadura. Deve ser efetuado um adequado equacionamento do equilibrio nos instantes inicial e final de tempo e este obrigatoriamente deve considerar a presença da armadura, que de certo modo tendem a diminuir a fluência e a retração. 


\section{4-MODELOS DE COMPORTAMENTO DO CONCRETO} ARMADO

\section{1-INTRODUÇÃO}

A modelagem do comportamento em serviço do concreto armado, através do método dos elementos finitos com a incorporação da nãolinearidade física, pode ser feita através de duas maneiras distintas, a saber:

1. modelagem das relaçöes entre tensőes e deformaçöes dos materiais constituintes: concreto e aço;

2. modelagem via diagramas momento $x$ curvatura de uma seção transversal.

Os modelos do tipo 1 têm um campo de aplicação mais amplo do que os do tipo 2 - podem ser empregados em qualquer tipo de elemento finito Os modelos do tipo 2 têm a virtude de considerar facilmente, através de um modelo adequado, a contribuição do concreto intacto entre fissuras. Ambos devem ter seus parâmetros aferidos experimentalmente.

Os resultados obtidos em estruturas de concreto armado empregando-se as relaçöes momento $x$ curvatura são bastante satisfatórios e não encontra-se na literatura justificativa fundamentada que mostre serem os modelos do tipo 1 melhores do que os do tipo 2. Neste trabalho seräo empregados modelos baseados nas relações momento $\mathrm{x}$ curvatura.

Serão descritos neste capítulo os algoritmos propostos por GHALI \& FAVRE (1986) e DEBERNARDI (1983). A diferença básica entre eles é que os primeiros autores efetuam uma interpolação direta entre os estádios 1 e 2 
enquanto DEBERNARDI equaciona o equilíbrio em relação a uma configuração média deformada.

\section{2-MODELO DE GHALI \& FAVRE - FLEXÃO SIMPLES}

\section{4,2,1-INSTANTE DA APLICAÇÃO DO CARREGAMENTO}

Para uma seção näo fissurada de concreto armado são admitidas todas as hipóteses do estádio 1 , sendo que o cálculo das propriedades geométricas e da curvatura correspondente à seção íntegra são efetuados conforme o capítulo 2 deste trabalho. Da mesma maneira procede-se para seçöes totalmente fissuradas - estádio 2, com as mesmas hipóteses e consideraçőes do cap. 2. Descreve-se a seguir a formulação desenvolvida por GHALI \& FAVRE para uma configuração média entre os estádios 1 e 2.

Considere-se que uma barra de concreto armado solicitada à flexão simples conforme ilustrada na figura (4.1). Esta apresentará uma primeira fissura quando o momento máximo ao longo da sua extensão atingir um valor tal que a tensäo na fibra mais tracionada da seção supere a resistência média à tração do concreto, $\boldsymbol{f}_{\mathrm{ctm}}$. Este momento é denominado momento de fissuração, $\mathrm{M}_{\mathrm{r}}$ e pode ser calculado de acordo com a expressäo (4.1) proposta pelo CEB-90.

$$
M_{r}=\frac{f_{c t m} I_{1}}{\left(h-x_{1}\right)}
$$

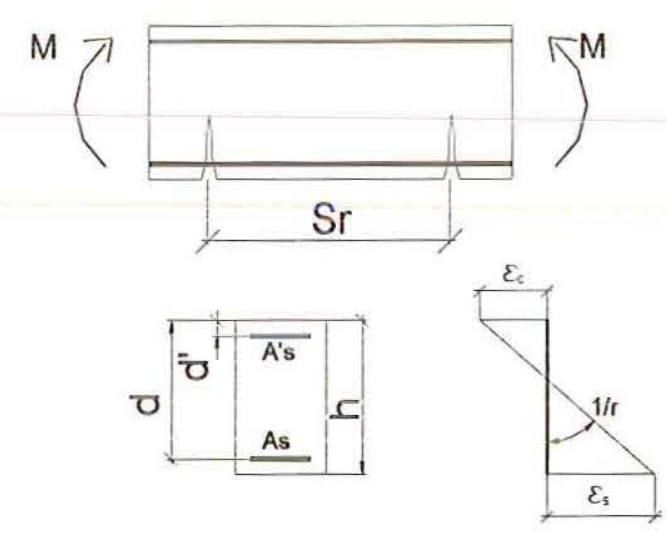

Figura 4.1 - Peça fissurada de concreto armado. 
onde $I_{1}$ e $x_{1}$ são, respectivamente, o momento de inércia da seção homogeneizada e a posição da linha neutra no estádio 1.

Para a atuação de um momento fletor $M>M_{r}$, as tensões na armadura de tração variam de um valor máximo nas seçöes das fissuras para um mínimo num ponto médio entre fissuras sucessivas. Assumindo-se que a contribuição do concreto entre fissuras - "tension stiffening"- causa um efeito equivalente ao descrito para a tração simples (vide seção 2.4) para a determinação da deformação média no aço, podemos escrever a deformação média na fibra correspondente à armadura tracionada na seguinte forma :

$$
\varepsilon_{\mathrm{sm}}=(1-\zeta) \varepsilon_{\mathrm{sl}}+\zeta \varepsilon_{\mathrm{s} 2}
$$

onde $\varepsilon_{\mathbf{s} 1}$ é a deformação da armadura tracionada quando supõe-se estádio $1, \varepsilon_{\mathbf{s} 2}$ tem o mesmo significado para o estádio $2, \zeta$ é um coeficiente de ponderaçäo definido por GHALI \& FAVRE pela expressão que segue :

$$
\zeta=1-\beta_{1} \beta_{2}\left(\frac{\sigma_{\mathrm{sr}}}{\sigma_{\mathrm{s} 2}}\right)^{2}=1-\beta_{1} \beta_{2}\left(\frac{\mathrm{M}_{\mathrm{r}}}{\mathrm{M}}\right)^{2}
$$

onde $\beta_{1}$ e $\beta_{2}$ são coeficientes que levam em contas as condiçôes de aderência e o tipo do carregamento, respectivamente. Assim :

a) condiçőes de aderência:

$$
\begin{aligned}
& \beta_{1}=1,0 \text { para barras de alta aderência }\left(\eta_{b} \geq 1,5\right) \\
& \beta_{1}=0,5 \text { para barras lisas }\left(\eta_{b}=1,0\right)
\end{aligned}
$$

b) condiçöes de carregamento:

$\beta_{2}=1,0$ para o primeiro carregamento, ou para cargas pouco repetitivas, não permanentes.

$\beta_{2}=0,5$ para cargas permanentes ou com grande número de ciclos. 
No caso de uma análise estrutural onde os efeitos dependentes do tempo foram considerados, ou seja com a consideração da deformação lenta, sugere-se que $\beta_{2}$ seja tomado igual a 1,0 para o instante inicial da análise e igual a 0,5 para um instante genérico de tempo.

Para um espaçamento médio entre fissuras $\mathbf{s}_{\mathrm{m}}$, pode-se calcular a abertura destas por:

$$
\mathrm{w}=\mathrm{s}_{\mathrm{mm}} \zeta \varepsilon_{\mathrm{s} 2}
$$

A curvatura $1 / \mathrm{r}$ para uma seção transversal fissurada ou näo, admitindo-se as hipóteses da seção plana assim permanecer após a deformaçäo e da proporcionalidade entre tensōes e deformaçōes, pode ser expressa para a flexão simples por :

$$
\frac{1}{\mathrm{r}}=\frac{\mathrm{M}}{\mathrm{E}_{\mathrm{c}} \mathrm{I}}
$$

ou, ainda:

$$
\frac{1}{\mathrm{r}}=\frac{\varepsilon_{\mathrm{s}}+\varepsilon_{\mathrm{c}}}{\mathrm{d}}
$$

onde $E_{c}$ é módulo de elasticidade do concreto (coníorme seção 3.5), i é o momento de inércia da seção, $\varepsilon_{\mathrm{c}} \mathrm{e} \quad \varepsilon_{\mathrm{c}}$ são respectivamente a deformação na fibra mais comprimida de concreto e na fibra correspondente à armadura tracionada e d é a distância entre a fibra mais comprimida e a armadura tracionada.

Assumindo-se a contribuição do concreto íntegro entre fissuras, podese escrever a expressão da curvatura média - que é ilustrada na figura (4.2) - por:

$$
\frac{1}{\mathrm{r}_{\mathrm{m}}}=(1-\zeta) \frac{1}{\mathrm{r}_{1}}+\zeta \frac{1}{\mathrm{r}_{2}}
$$


onde $1 / r_{1}$ e $1 / r_{2}$ säo as curvaturas correspondentes a um momento fletor $M$, calculadas conforme a expressão (4.5) assumindo-se estádio 1 e estádio 2 respectivamente. $\mathrm{O}$ coeficiente $\zeta$ tem função de interpolar as curvaturas do estádio 1 e do estádio 2 . Uma vez obtido o valor de $1 / \mathrm{r}_{\mathrm{m}}$ é possível determinar um módulo de deformação por flexão médio $-\left(E_{c} I\right)_{m}$, que na verdade corresponde a uma rigidez secante para a seção, assim :

$$
(\mathrm{EI})_{\mathrm{m}}=\frac{\mathrm{M}}{1 / \mathrm{r}_{\mathrm{m}}}
$$

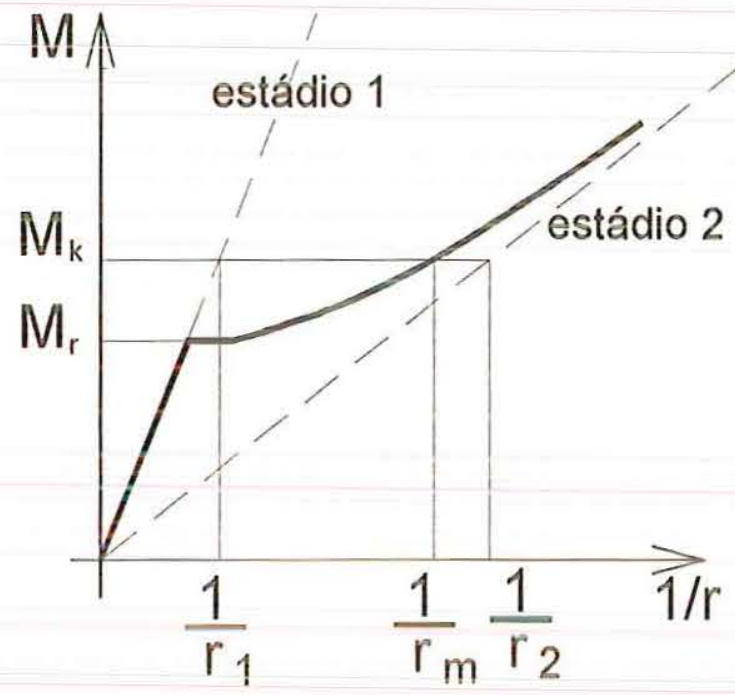

Figura 4.2 - Diagrama Mlomento-Curvatura - Flexão Simples.

\subsection{2-INSTANTE GENÉRICO DE TEMPO}

Uma fibra genérica de concreto está sujeita a sofrer uma mudança em seu estado de tensöes que vai ocorrer entre o instante em que o carregamento é aplicado até outro instante de tempo qualquer. Isto se deve à presença da armadura que restringe a deformaçäo lenta nas fibras de concreto adjacentes a ela, supondo-se a inexistência de armadura pode-se 
afirmar que as tensōes não sofrem alterações. $A$ tensão total e a deformação para o instante de tempo " $t$ ", desprezando-se a retraçäo säo dadas respectivamente por :

$$
\begin{aligned}
& \sigma_{c}(t)=\sigma_{c}\left(t_{0}\right)+\Delta \sigma_{c}\left(t, t_{0}\right) \\
& \varepsilon_{c}(t)=\frac{\sigma_{c}\left(t_{0}\right)}{E_{c}\left(t_{0}\right)} \cdot\left(1+\varphi\left(t, t_{0}\right)\right)+\frac{\Delta \sigma_{c}\left(t, t_{0}\right)}{\bar{E}_{c}\left(t, t_{0}\right)}
\end{aligned}
$$

onde:

$$
\overline{\mathrm{E}}_{\mathrm{c}}\left(\mathrm{t}, \mathrm{t}_{0}\right)=\frac{\mathrm{E}_{\mathrm{c}}\left(\mathrm{t}_{0}\right)}{1+\chi \varphi\left(\mathrm{t}, \mathrm{t}_{0}\right)}
$$

$\overline{\mathbf{E}}_{\mathrm{c}}\left(\mathrm{t}, \mathrm{t}_{0}\right)$ é chamado de módulo elástico ajusłado . GHALI \& FAVRE (1986) também apresentam em seu trabalho a seguinte relação que deve ser atendida :

$$
\Delta \varepsilon_{\mathrm{c}}\left(\mathrm{t}, \mathrm{t}_{0}\right)=\frac{\Delta \sigma_{\mathrm{c}}\left(\mathrm{t}, \mathrm{t}_{0}\right)}{\overline{\mathrm{E}}_{\mathrm{c}}\left(\mathrm{t}, \mathrm{t}_{0}\right)}
$$

Da expressão acima pode-se concluir que o módulo elástico ajustado somente tem sentido para as seçöes com a presença de armadura. Para o caso de uma seção de concreto simples haveria variação de deformação e a mudança no estado de tensöes seria nula tornando impossivel atender à equação (4.12).

\section{SEÇÃO TRANSFORMADA:}

Uma seção transversal composta de concreto e armadura passiva pode ser substituída por outra, homogênea, transformando a área de aço numa área equivalente de concreto, ou qualquer outro material de referência. Para esse fim define-se um coeficiente de homegeneização $\propto$. Em se tratando da análise de esforços que variam ao longo do tempo definese um coeficiente de homogeneização $\bar{\alpha}\left(\mathbf{t}, \mathbf{t}_{0}\right)$ tal que a expressäo (4.13) seja atendida. 


$$
\bar{\alpha}\left(\mathrm{t}, \mathrm{t}_{0}\right)=\frac{\mathrm{E}_{\mathrm{s}}}{\overline{\mathrm{E}}_{\mathrm{c}}\left(\mathrm{t}, \mathrm{t}_{0}\right)}
$$

A seção ajustada, ou transformada, será aquela onde a área e o momento de inércia são calculados considerando-se que a área da armadura será multiplicada por $\bar{\alpha}\left(\mathbf{t}, \mathbf{t}_{0}\right)$ na homogeneização da seção.

\section{EFEITOS DA FLUÊNCIA E RETRAÇÃO PARA SEÇÕES NÃO- FISSURADAS DE CONCRETO ARMADO:}

Considere-se uma seção transversal de uma peça de concreto armado como ilustrado na figura (4.3), a deformação numa fibra $\mathbf{O}$ (centro da seção transformada) e respectiva curvatura da seção sofrerão mudanças devidas à retração e à fluência. GHALI \& FAVRE (1986) fornecem as seguintes expressões para a avaliação dessas mudanças :

$$
\begin{aligned}
& \Delta \varepsilon_{0}=\eta\left\{\varphi\left(t, t_{0}\right)\left[\varepsilon_{0}\left(t_{0}\right)+\frac{1}{r}\left(t_{0}\right) y_{c}\right]+\varepsilon_{c s}\left(t, t_{0}\right)\right\} \\
& \Delta \frac{1}{r}=k\left[\varphi\left(t, t_{0}\right)\left(\frac{1}{r}\left(t_{0}\right)+\varepsilon_{o}\left(t_{0}\right) \frac{y_{c}}{r_{c}^{2}}\right)+\varepsilon_{c s}\left(t, t_{0}\right) \frac{y_{c}}{r_{c}^{2}}\right]
\end{aligned}
$$

onde $\varepsilon_{0}\left(t_{0}\right)$ é a deformação instantânea no ponto $O ; y_{c}$ é a distância entre os centros geométricos da seção de concreto bruto e da seção transformada; $\eta$ é a relação entre a área da seção bruta de concreto e a área da seção transformada e $\mathrm{k}$ tem o mesmo significado em relação ao momento de inércia, com $\mathrm{I}_{\mathrm{c}}$ e $\overline{\mathrm{I}}$ respectivamente os momentos de inércia da área bruta de concreto e da área transformada em relaçäo ao ponto $\mathrm{O}$. Assim :

$$
\eta=\frac{\mathrm{A}_{\mathrm{c}}}{\overline{\mathrm{A}}}
$$




$$
\mathrm{k}=\frac{\mathrm{I}_{\mathrm{c}}}{\overline{\mathrm{I}}}
$$

e

$$
r^{2}=\frac{I_{c}}{A_{c}}
$$

Os termos $\eta$ e k (equações (4.16) e (4.17)) são empregados por GHALI \& FAVRE visando considerar o efeito da armadura na diminuição dos acréscimos de deformação e curvatura devidos à deformação lenta e à retração. Para altas taxas de armadura, como pode ser observado nas expressões (4.17) e (4.18) tais variações tenderiam a zero, ao passo que para seções pouco armadas tenderiam à f́luência e retração puras.

A figura (4.3) tem por objetivo ilustrar as variáveis empregadas no equacionamento.

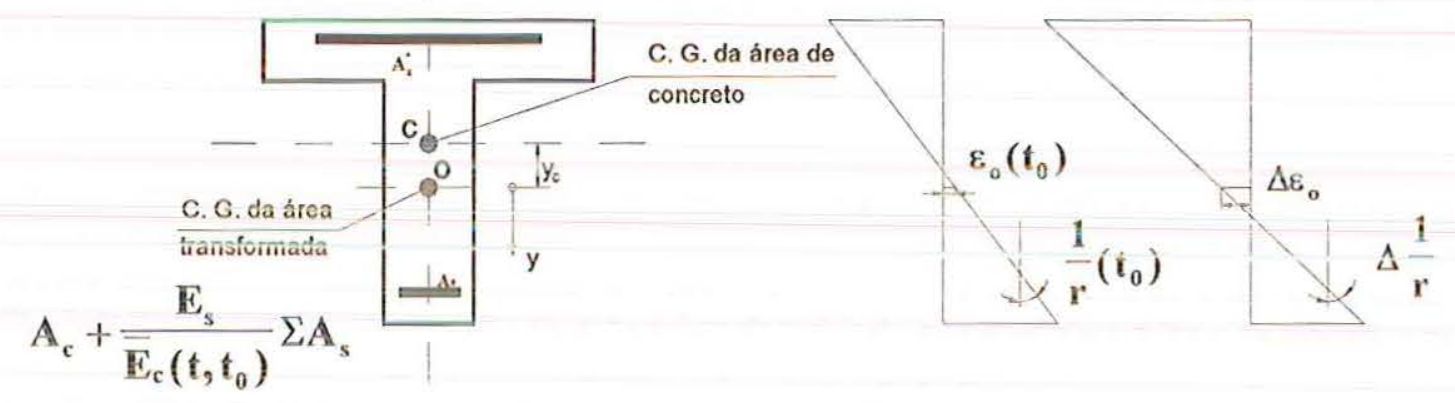

Figura 4.3 - Efeitos da îluência e retração numa seção não físsurada de concreto armado. 


\section{EFEITOS DA FLUÊNCIA E RETRAÇÃO PARA SEÇÕES FISSURADAS DE CONCRETO ARMADO:}

Numa seçäo fissurada de concreto armado (vide figura 4.4), somente parte da área de concreto estará sujeita a sofrer retração e fluência; uma consequência disto é o deslocamento da linha neutra em direção à fibra mais tracionada da seção, aumentando a área de concreto comprimido, que alteraria o equacionamento do equilíbrio em termos de esforços normal e fletor. Desprezar esse fato não constitui um erro grande, além do mais quando se comparar com os demais erros embutidos no processo.

Assumindo-se essa simplificação, os efeitos da fluência e retração para uma seção transversal de concreto armado no estádio 2 são tratados por GHALI \& FAVRE de maneira semelhante ao descrito para as seçöes não-fissuradas. Assim as equaçōes (4.14) e (4.15) permanecem válidas. $O$ significado de cada um de seus termos é ilustrado pela figura (4.4).

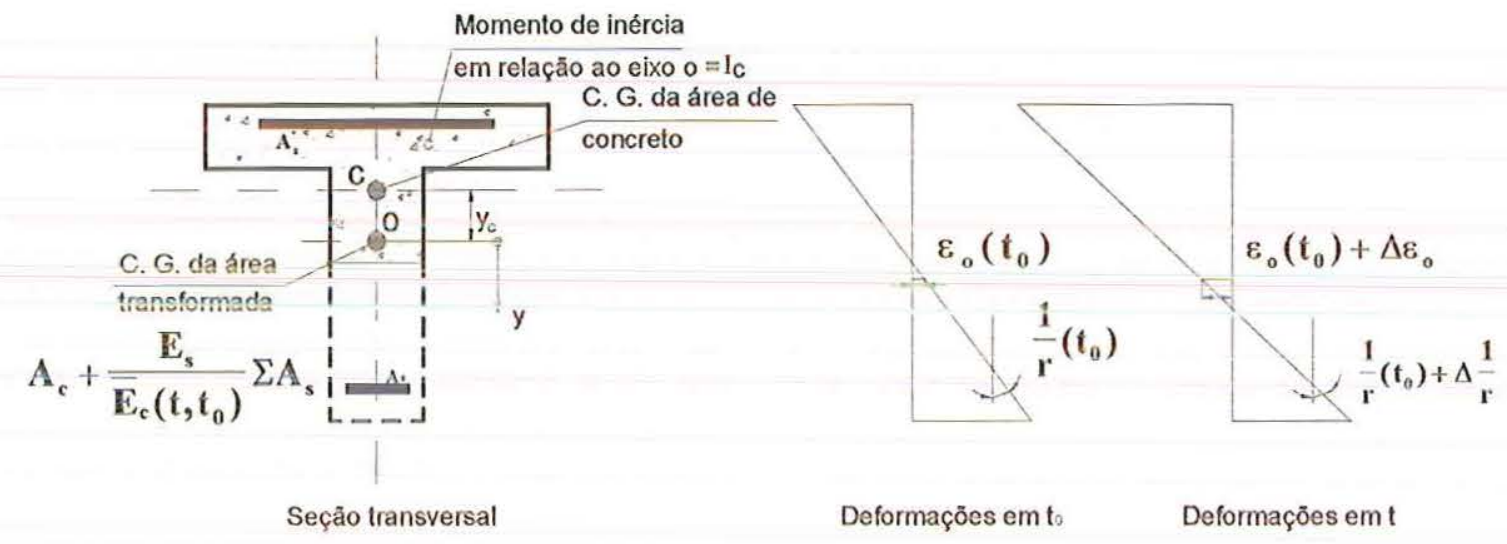

Figura 4.4 - Efeitos da fluência e retração numa seção fissurada de concreto armado. 


\section{EFEITOS DA RETRAÇÃO E DA FLUÊNCIA PARA UMA CONFIGURAÇÃO MÉDIA:}

A curvatura média num instante de tempo genérico " $t$ " será obtida efetuando-se a interpolação entre aquelas determinadas para os estádios 1 e 2, conforme já mencionado neste capítulo. Assim :

$$
\begin{aligned}
& \frac{1}{r_{m}}(t)=(1-\zeta) \frac{1}{r_{1}}(t)+\zeta \frac{1}{r_{2}}(t) \\
& \zeta=1-\beta_{1} \beta_{2}(t)\left(\frac{M_{r}}{M}\right)^{2}
\end{aligned}
$$

onde $\mathrm{M}_{\mathrm{r}}$ é calculado para o instante inicial do carregamento e $\beta_{2}(\mathrm{t})$ é igual a 0,5 . 


\section{3-MODELO DE DEBERNARDI - FLEXÃO SIMPLES}

\section{4,3,1-INTRODUÇÃO}

O método de GHALI \& FAVRE (1986), estudado na seção anterior, tem por objetivo apresentar expressōes simplificadas para o cálculo de deslocamentos e esforços em elementos de concreto armado, quer seja este fissurado ou não. Esse modelo é bastante atrativo para o uso na prática, uma vez que seu equacionamento é relativamente simples.

DEBERNARDI (1983) procura fazer uma análise bastante rigorosa para o cálculo da curvatura média. É considerado em seu modelo o efeito simultâneo da fissuração, fluência, retração, da fluência devido à aderência, da colaboração do concreto entre fissuras e é descontado o espaço ocupado pela armadura comprimida. Dessa forma o método de Debernardi torna-se bastante complexo, sendo o de maior rigor entre os diversos existentes atualmente - no campo das relaçőes momento x curvatura.

A diferença básica em relação aos outros métodos está no fato de não ser empregada uma interpolação entre os valores obtidos no estádio 1 e 2 para o cálculo da curvatura. DEBERNARDI apenas utiliza interpolação no cálculo da deformação média da armadura tracionada. Ainda, seu processo é formulado para uma seçāo de forma quaiquer.

Neste modelo é analisado primeiramente o estado de tensões e deformaçőes para um instante " $\mathbf{t}_{0}$ ". Para a consideração dos efeitos reológicos (retração e fluência) no instante genérico " $\mathrm{\imath "}$ ", Debernardi utiliza o método AAEM (Age Adjusted Effective Modulus Method), admitindo que esse procedimento seja válido independentemente da variação da posição da linha neutra com o tempo. 


\section{4,3.2-HIPÓTESES BÁSICAS}

Entre as hipóteses admitidas está a manutenção das seções planas após a deformação para uma configuração média, onde são escritas as equações de equilíbrio para a obtenção das tensōes e deformações médias. Só é empregada a interpolação para o cálculo da deformação média da armadura tracionada - hipótese do C.E.B. Vale lembrar que para outros métodos conhecidos na literatura a curvatura é obtida por meio de interpolação entre as curvaturas nos estádios 1 e 2 , esta hipótese não é utilizada por Debernardi.

Os valores de tensöes, deformações e curvaturas serão obtidos diretamente, escrevendo-se as equaçőes de equilíbrio na configuração média entre os instantes " $\hat{t}$ " e " $\hat{t}_{0}$ ". Por isso é admitida a extensão da hipótese das seçőes planas permanecerem planas à configuração média.

\section{4,3,3-EQUAÇÕES CONSTITUTIVAS}

\section{CONCRETO:}

As tensões no concreto não são constantes ao longo do tempo e, portanto, não há fluência pura. A deformação total de uma fibra comprimida de concreto, tomando em particular a que sofre maior encurtamento, é obtida a partir da superposição de efeitos, a partir de :

$$
\varepsilon_{\mathrm{c}\left(\mathrm{t}, \mathrm{t}_{0}\right)}=\sigma_{\mathrm{c}\left(\mathrm{t}_{0}\right)} \cdot \phi_{\left(\mathrm{t}, \mathrm{t}_{0}\right)}+\int_{\mathrm{t}_{0}}^{\mathrm{t}} \phi_{(\mathrm{t}, \tau)} \cdot d \sigma_{\mathrm{c}(\tau)}+\varepsilon_{\mathrm{cs}\left(\mathrm{t}, \mathrm{t}_{0}\right)}
$$

Apresenta-se, a seguir, a expressão (4.22) que é a solução da equaçäo integral (4.21) e pode ser obtida a partir do emprego do método AAEM (Age Adjusted Effective Modulus Method). Maiores detalhes podem ser encontrados em Debernardi (1983) e Machado (1989). 


$$
\varepsilon_{\mathrm{c}(\mathrm{t})}=\varepsilon_{\mathrm{c}\left(\mathrm{t}_{0}\right)}+\frac{\sigma_{\mathrm{c}\left(\mathrm{t}_{0}\right)}}{\mathrm{E}_{\mathrm{c} 28}} \cdot \varphi_{28\left(1, \mathrm{t}_{0}\right)}+\left[\sigma_{\mathrm{c}(\mathrm{t})}-\sigma_{\mathrm{c}\left(\mathrm{t}_{0}\right)}\right] \cdot\left[\frac{1}{\mathrm{E}_{\mathrm{c}\left(\mathrm{t}_{0}\right)}}+\chi_{\left(\mathrm{t}, \mathrm{t}_{0}\right)} \cdot \frac{\varphi_{28\left(\mathrm{t}, \mathrm{t}_{0}\right)}}{\mathrm{E}_{\mathrm{c} 28}}\right]+\varepsilon_{\mathrm{cs}\left(\mathrm{t}, \mathrm{t}_{0}\right)}
$$

\section{ARMADURA:}

A deformação média $\varepsilon_{s m}$ da armadura tracionada $A_{s}$ é obtida efetuando-se uma apropriada interpolação entre os estádios 1 e 2, tal que :

$$
\varepsilon_{\mathrm{sm}}=\frac{\sigma_{\mathrm{s} 2}}{\mathrm{E}_{\mathrm{s}}}-\beta_{1} \cdot \beta_{2} \cdot\left(\frac{\sigma_{\mathrm{sr}}}{\mathrm{E}_{\mathrm{s}}}-\varepsilon_{\mathrm{s} 1 \mathrm{r}}\right) \cdot \frac{\sigma_{\mathrm{sr}}}{\sigma_{\mathrm{s} 2}}
$$

onde:

$\sigma_{\mathrm{s} 1}$ - tensão na armadura no instante anterior à deformação;

$\varepsilon_{s ı r}$ - deformação da armadura imediatamente antes da fissuração, devido ao momento ou esforço normal de fissuração;

$\sigma_{\mathrm{s} 2}$ - tensão atuante na armadura na seção de fissura, após a fissuração - estádio 2;

$\sigma_{s r}$ - tensão atuante na armadura devido ao momento de fissuração;

$\varepsilon_{\mathbf{s 2}}$ - deformação da armadura no estádio 2;

$\varepsilon_{\mathrm{s} 1}$ - deformação da armadura no estádio 1 .

Os valores de $\beta_{1}$ e $\beta_{2}$ săo os mesmos anteriormente definidos.

Deve ser lembrado que, conhecendo-se o valor da deformação no centro de gravidade da armadura $\varepsilon_{s m}$, o valor da tensão na armadura não pode mais ser tomado pelo produto do seu módulo de elasticidade pela deformação pois o diagrama, para valores médios, não é mais linear. Portanto $\sigma_{s m} \neq \varepsilon_{s m} E_{s}$. Como a equação $\sigma_{s m}=f\left(\varepsilon_{s m}\right)$ não é diretamente explicitada o valor da tensão $\sigma_{\mathrm{sm}}$ será obtido por meio de tentativas a partir das equaçőes de equilíbrio. 


\section{3,4-TENSÕES E DEFORMAÇÕES: SEÇÃO NÃO FISSURADA DE CONCRETO ARMADO}

Considere-se a seção de forma qualquer mostrada pela figura (4.5), com armadura superior e inferior solicitada à flexão simples por um momento externo $\mathbf{M}$ de intensidade não suficiente para provocar a ruptura da sua fibra mais tracionada. Como a seção transversal é suposta não fissurada, ou seja $\sigma_{\mathrm{c}}<\mathbf{f}_{\mathrm{ct}}$, todas as hipóteses definidas para o cálculo clássico no estádio 1 continuam válidas.

As tensões e deformações serão calculadas para os instantes inicial e final do intervalo de tempo, onde serão escritas as equações de equilíbrio em termos de esforço de compressão, que nesse caso é nulo, e momento fletor. A figura (4.5) é bastante genérica e admite que as linhas neutra de tensão e deformação possam não ser coincidentes. Os diagramas de deformaçőes e tensőes são lineares, conforme foi estudado no cálculo de seçőes no estádio 1, dessa forma é possível escrever as seguintes relaçöes de compatibilidade de tensäo tomadas em módulo :

$$
\frac{\sigma_{c}(t)}{X_{\sigma}}=\frac{\sigma_{s}^{\prime}(t)}{\alpha_{s}\left(X_{\sigma}-d^{\prime}\right)}=\frac{\sigma(t)}{y^{\prime}}=\frac{\sigma_{G i 1}(t)}{y_{0}^{\prime}}=\frac{\sigma_{s}(t)}{\alpha_{s}\left(d-X_{\sigma}\right)}=\frac{\bar{\sigma}_{c}(t)}{h-X_{\sigma}}
$$

O ponto de referência G1, da figura (4.5), corresponde ao centro de gravidade da seção homogeneizada no estádio 1 , podendo ser obtido com a imposiçäo do momento estático igual a zero. Para o caso da flexão simples, esse ponto coincide com a profundidade da linha neutra de deformaçőes e tensöes, na ausência de deformaçöes impostas. 
Seção transversal
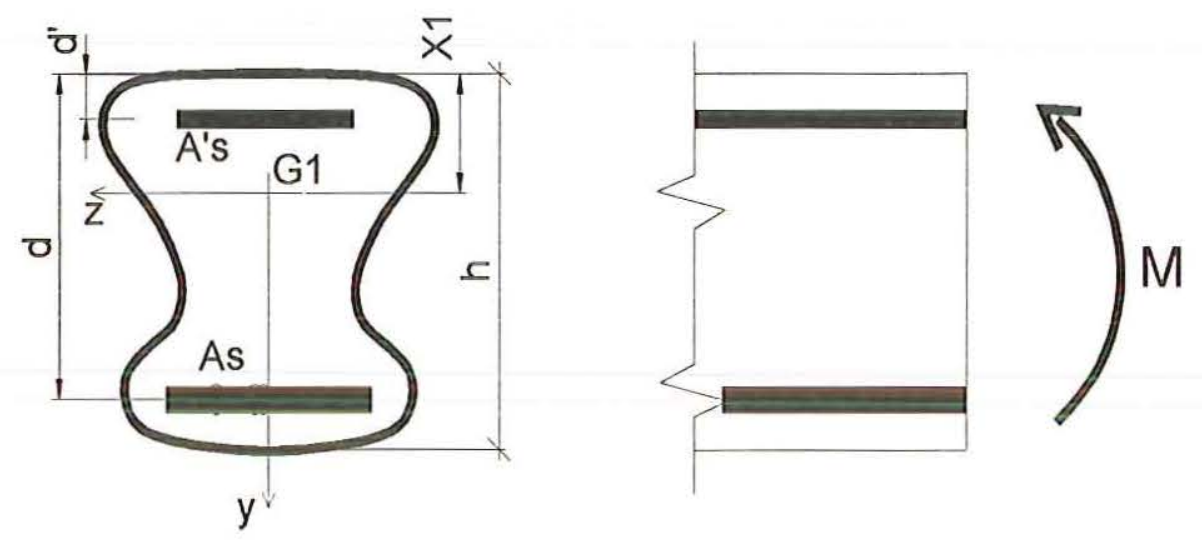

Deformações

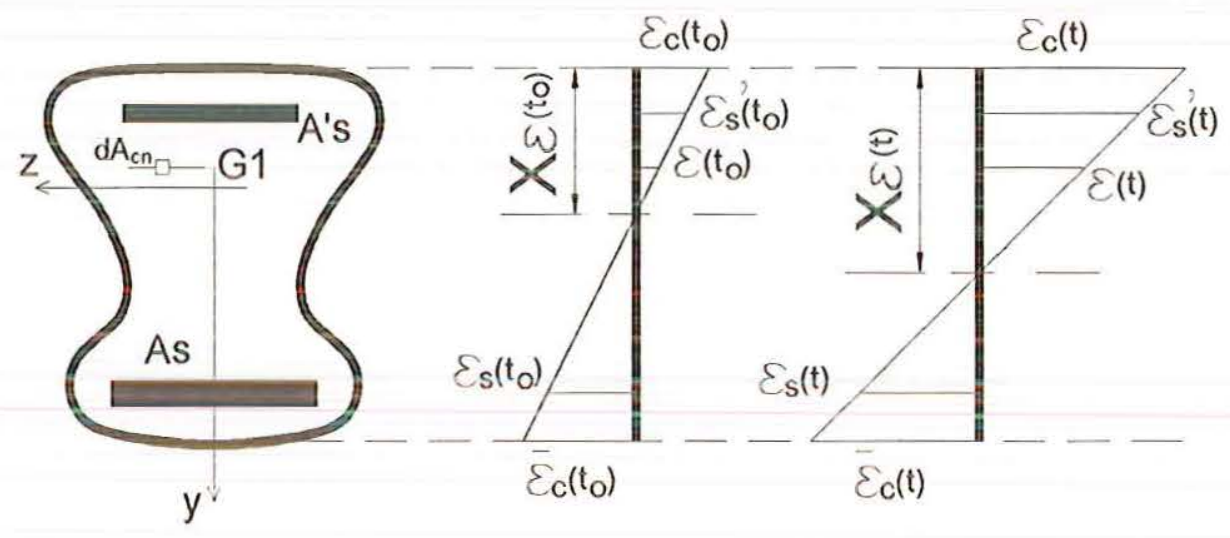

Tensões

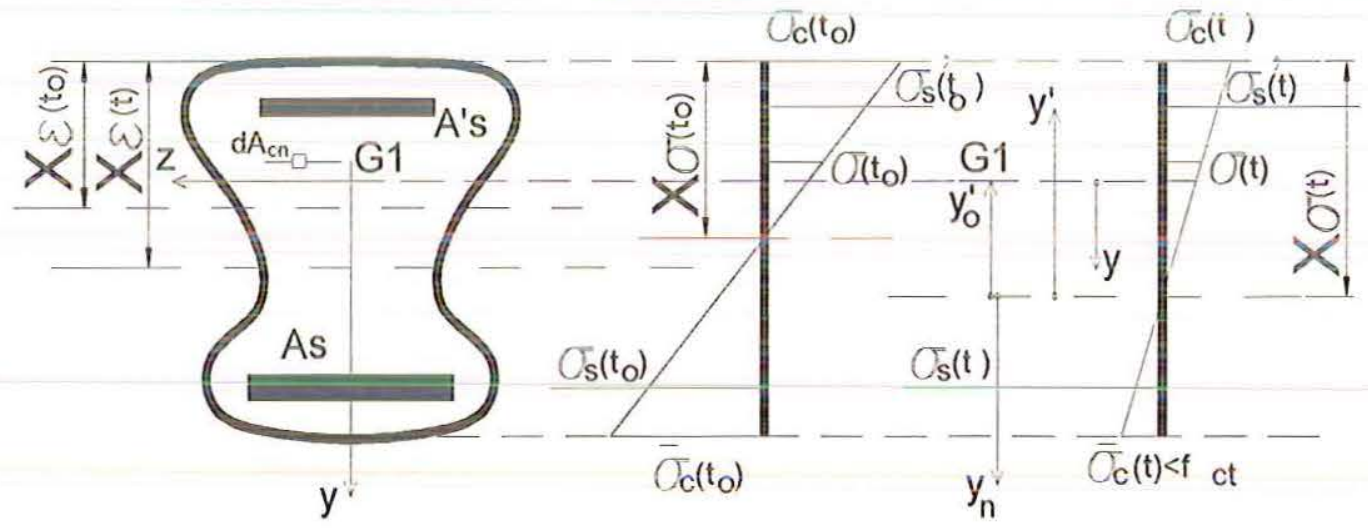

Figura 4.5 : Tensões e deformações nos tempos " $\mathrm{t}_{0}$ " e " $t$ " para uma seção não-fissurada de concreto armado. 


\section{TENSÕES E DEFORMAÇÕES INSTANTÂNEAS:}

Os diversos elementos da seção devem ser determinados, primeiramente, para o instante de aplicação do carregamento. Dessa forma, as deformações e tensões para o tempo " $\mathbf{t}_{0}$ " deverão ser obtidas aplicandose as expressões para o estádio 1 na flexão simples. Será empregado o módulo de elasticidade para o instante inicial, $E_{c}\left(\hat{t}_{0}\right)$.

Após a configuração inicial da seção de concreto armado estar completamente definida, procede-se ao cálculo no instante de tempo igual a "t $t$ ", onde são escritas equações de equilíbrio em termos de momento fletor e esforço normal, sendo que estas dependem do conhecimento das tensões iniciais ao longo da peça bem como das funções de fluência e retração.

\section{EQUAÇÕES DE EQUILÍBRIO NO INSTANTE “ $t$ ":}

Serão escritas para o tempo "t̂t" duas equações de equilíbrio, (4.26) e (4.27), sendo que a primeira leva em conta o esforço normal e a última considera o momento fletor atuante na seção. $A$ área $A_{c n}$ empregada no equacionamento se refere à área líquida de concreto, descontando-se os espaços ocupados pela armadura, ou seja :

$$
A_{c n}=A_{c}-\sum_{i=1}^{n} A_{s i}
$$

onde $A_{c}$ é a área da seção transversal bruta; $A_{s i}$ é área de cada barra de aço e n é o número total destas. As equações de equilíbrio são as seguintes:

a) equilíbrio de esforço normal:

$$
\int_{A_{c n}} \sigma(t) d A_{c n}+A_{s} \sigma_{s}(t)+A_{s}^{\prime} \sigma_{s}^{\prime}(t)=0
$$


b) equilíbrio de momento fletor (em relação ao ponto G1):

$$
\int_{A_{c n}} \sigma(t) y d A_{c n}+A_{s} \sigma_{s}(t)\left(d-X_{G 1}\right)+A_{s}^{\prime} \sigma_{s}^{\prime}(t)\left(d^{\prime}-X_{G 1}\right)=M
$$

Da figura (4.5) é possível escrever :

$$
\text { e: } \quad \begin{aligned}
& y^{\prime}=y_{0}^{\prime}-y \\
& y_{0}^{\prime}=X_{\sigma}(t)-X_{G 1}
\end{aligned}
$$

Empregando-se as relaçöes de compatibilidade de tensöes expressas em (4.24) em conjunto com as expressöes acima, pode-se modificar as equaçōes de equilíbrio transformando-as nas seguintes :

$$
\int_{A_{c n}} \frac{\sigma(t)}{y^{\prime}}\left(y_{0}^{\prime}-y\right) d A_{c n}+A_{s} \sigma_{s}(t)+A_{s}^{\prime} \sigma_{s}^{\prime}(t)=0
$$

e:

$$
\int_{A_{c}} \frac{\sigma(t)}{y^{\prime}}\left(y_{0}^{\prime}-y\right) y d A_{c n}+A_{s} \sigma_{s}(t)\left(d-X_{G 1}\right)+A_{s}^{\prime} \sigma_{s}^{\prime}(t)\left(d^{\prime}-X_{G 1}\right)=M
$$

A posição da linha neutra de tensōes pode ser expressa em função das tensöes das fibras mais extremas da seção, assim :

$$
X_{\sigma}(t)=\frac{\sigma_{c}(t)}{\sigma_{c}(t)-\sigma_{c}(t)} h
$$

As deformaçōes das armadura inferior e superior podem ser escritas em função das deformações do concreto, como segue :

$$
\varepsilon_{s}(t)=\varepsilon_{c}(t)-\frac{\varepsilon_{c}(t)-\varepsilon_{c}(t)}{h} d
$$


e: $\quad \varepsilon_{\mathrm{s}}^{\prime}(\mathrm{t})=\varepsilon_{\mathrm{c}}(\mathrm{t})-\frac{\varepsilon_{\mathrm{c}}(\mathrm{t})-\varepsilon_{\mathrm{c}}(\mathrm{t})}{\mathrm{h}} \mathrm{d}^{\prime}$

Os momentos estático e de inércia da seção líquida de concreto são determinados, respectivamente, pelas expressões (4.35) e (4.36). Deve-se lembrar que nestes cálculos, a área ocupada pelas armaduras deve ser descontada.

$$
\begin{aligned}
& S_{c n}=\int_{A_{c n}} y d A_{c n} \\
& I_{c n}=\int_{A_{c n}} y^{2} d A_{c n}
\end{aligned}
$$

As equações de equilíbrio são rescritas na seguinte forma :

a) esforço normal:

$$
\begin{aligned}
& {\left[\sigma_{c}(t)-\frac{\sigma_{c}(t)-\bar{\sigma}_{c}(t)}{h} X_{G 1}\right] A_{c n}-\frac{\sigma_{c}(t)-\sigma_{c}(t)}{h} S_{c n}+} \\
& +A_{s} E_{s}\left[\varepsilon_{c}(t)-\frac{\varepsilon_{c}(t)-\varepsilon_{c}(t)}{h} d\right]+A_{s}^{\prime} E_{s}\left[\varepsilon_{c}(t)-\frac{\varepsilon_{c}(t)-\varepsilon_{c}(t)}{h} d^{\prime}\right]=0
\end{aligned}
$$

b) momentos em relação à $\mathrm{G1}$ :

$$
\begin{aligned}
& \quad\left[\sigma_{c}(t)-\frac{\sigma_{c}(t)-\bar{\sigma}_{c}(t)}{h} X_{G 1}\right] S_{c n}-\frac{\sigma_{c}(t)-\bar{\sigma}_{c}(t)}{h} I_{c n}+ \\
& +A_{s} E_{s}\left[\varepsilon_{c}(t)-\frac{\varepsilon_{c}(t)-\varepsilon_{c}(t)}{h} d\right]\left(d-X_{G 1}\right)+ \\
& +A_{s}^{\prime} E_{s}\left[\varepsilon_{c}(t)-\frac{\varepsilon_{c}(t)-\varepsilon_{c}(t)}{h} d^{\prime}\right]\left(d^{\prime}-X_{G 1}\right)=M
\end{aligned}
$$




\section{Capítulo 4: MODELOS DE COMPORTAMENTO DO CONCRETO ARMADO}

As deformações no concreto, para o instante de tempo "t̂", serão determinadas a partir das deformações iniciais, aplicando-se o método AAEM para a resolução da equação integral da deformação ao longo do tempo. Desse modo:

a) para a fibra extrema comprimida :

$$
\begin{aligned}
& \varepsilon_{c}(t)=\varepsilon_{c}\left(t_{0}\right)+\frac{\sigma_{c}\left(t_{0}\right)}{E_{c}(28)} \varphi_{28}\left(t, t_{0}\right)+ \\
& +\left[\sigma_{c}(t)-\sigma_{c}\left(t_{0}\right)\right]\left[\frac{1}{E_{c}\left(t_{0}\right)}+\chi\left(t, t_{0}\right) \frac{\varphi_{28}\left(t, t_{0}\right)}{E_{c}(28)}\right]+\varepsilon_{c s}\left(t, t_{0}\right)
\end{aligned}
$$

b) para a fibra extrema tracionada :

$$
\begin{aligned}
& \bar{\varepsilon}_{c}(\mathrm{t})=\bar{\varepsilon}_{\mathrm{c}}\left(\mathrm{t}_{0}\right)+\frac{\bar{\sigma}_{\mathrm{c}}\left(\mathrm{t}_{0}\right)}{\mathrm{E}_{\mathrm{c}}(28)} \varphi_{28}\left(\mathrm{t}, \mathrm{t}_{0}\right)+ \\
& +\left[\overline{\sigma_{c}}(\mathrm{t})-\bar{\sigma}_{\mathrm{c}}\left(\mathrm{t}_{0}\right)\right]\left[\frac{1}{\mathrm{E}_{\mathrm{c}}\left(\mathrm{t}_{0}\right)}+\chi\left(\mathrm{t}, \mathrm{t}_{0}\right) \frac{\varphi_{28}\left(\mathrm{t}, \mathrm{t}_{0}\right)}{\mathrm{E}_{\mathrm{c}}(28)}\right]+\varepsilon_{\mathrm{cs}}\left(\mathrm{t}, \mathrm{t}_{0}\right)
\end{aligned}
$$

Define-se as variáveis $\mathbf{f}, \mathbf{q ( t _ { 0 } )}$ e $\mathbf{q}\left(\mathbf{t}_{0}\right)$ com o fim de simplificar a escrita de modo que as expressões acima possam ser modificadas para :

$$
\begin{aligned}
& \varepsilon_{c}(t)=q\left(t_{0}\right)+\sigma_{c}(t) f \\
\text { e: } \quad & \varepsilon_{c}(t)=\bar{q}\left(t_{0}\right)+\bar{\sigma}_{c}(t) f
\end{aligned}
$$

onde :

$$
\begin{aligned}
& \mathrm{f}=\frac{1}{\mathrm{E}_{\mathrm{c}}\left(\mathrm{t}_{0}\right)}+\chi\left(\mathrm{t}, \mathrm{t}_{0}\right) \frac{\varphi_{28}\left(\mathrm{t}, \mathrm{t}_{0}\right)}{\mathrm{E}_{\mathrm{c}}(28)} \\
& \mathrm{q}\left(\mathrm{t}_{0}\right)=\varepsilon_{\mathrm{c}}\left(\mathrm{t}_{0}\right)+\sigma_{\mathrm{c}}\left(\mathrm{t}_{0}\right)\left[\frac{\varphi_{28}\left(\mathrm{t}, \mathrm{t}_{0}\right)}{\mathrm{E}_{\mathrm{c}}(28)}-\mathrm{f}\right]+\varepsilon_{\mathrm{cs}}\left(\mathrm{t}, \mathrm{t}_{0}\right) \\
& \bar{q}\left(\mathrm{t}_{0}\right)=\bar{\varepsilon}_{\mathrm{c}}\left(\mathrm{t}_{0}\right)+\bar{\sigma}_{\mathrm{c}}\left(\mathrm{t}_{0}\right)\left[\frac{\varphi_{28}\left(\mathrm{t}, \mathrm{t}_{0}\right)}{\mathrm{E}_{\mathrm{c}}(28)}-\mathrm{f}\right]+\varepsilon_{\mathrm{cs}}\left(\mathrm{t}, \mathrm{t}_{0}\right)
\end{aligned}
$$


Empregando-se a notação definida por MACHADO (1989) as equaçöes de equilíbrio passam a ser expressas de maneira simplificada, gerando um sistema de duas equaçőes a duas incógnitas (eq. (4.46) e (4.47)) onde os termos não conhecidos são os valores das tensöes nas fibras extremas da seção para o tempo " $\mathrm{t}$ ". Desse modo :

$$
\begin{aligned}
& \sigma_{\mathrm{c}}(\mathrm{t}) \mathrm{E}_{1}+\bar{\sigma}_{\mathrm{c}}(\mathrm{t}) \mathrm{E}_{2}=\mathrm{N}_{1} \\
& \sigma_{\mathrm{c}}(\mathrm{t}) \mathrm{F}_{1}+\bar{\sigma}_{\mathrm{c}}(\mathrm{t}) \mathrm{F}_{2}=\mathrm{N}_{2}
\end{aligned}
$$

onde :

$$
\begin{gathered}
E_{1}=\left(h-X_{G 1}\right) A_{c n}-S_{c n}+E_{s} f\left[A_{s}^{\prime}\left(h-d^{\prime}\right)+A_{s}(h-d)\right] \\
E_{2}=X_{G 1} A_{c n}+S_{c n}+f E_{s}\left(A_{s}^{\prime} d^{\prime}+A_{s} d\right) \\
F_{1}=\left(h-X_{G 1}\right) S_{c n}-I_{c n}+E_{s} f\left[A_{s}^{\prime}\left(h-d^{\prime}\right)\left(d^{\prime}-X_{G 1}\right)+A_{s}(h-d)\left(d-X_{G 1}\right)\right] \\
F_{2}=X_{G 1} S_{c n}+I_{c n}+f E_{s}\left[A_{s}^{\prime} d^{\prime}\left(d^{\prime}-X_{G 1}\right)+A_{S} d\left(d-X_{G 1}\right)\right] \\
N_{1}=-A_{s}^{\prime} E_{s}\left[q\left(t_{0}\right)\left(h-d^{\prime}\right)+\bar{q}\left(t_{0}\right) d^{\prime}\right]-A_{s} E_{s}\left[q\left(t_{0}\right)(h-d)+\bar{q}\left(t_{0}\right) d\right]
\end{gathered}
$$

$$
\begin{aligned}
N_{2}= & \bar{M}-\dot{A}_{s}^{\prime} E_{s}\left(d^{\prime}-X_{G 1}\right)\left[q\left(i_{0}\right)\left(h-d^{\prime}\right)+q\left(\hat{t}_{0}\right) d^{\prime}\right]- \\
& A_{s} E_{s}\left(d-X_{G 1}\right)\left[q\left(t_{0}\right)(h-d)+\bar{q}\left(t_{0}\right) d\right]
\end{aligned}
$$

A partir da solução do sistema acima obtém-se as tensōes nas fibras externas da seção transversal, já as tensőes nas armaduras são obtidas por meio das relações de compatibilidade. Dessa forma :

$$
\begin{aligned}
& \sigma_{c}(t)=\frac{N_{1} F_{2}-N_{2} E_{2}}{E_{1} F_{2}-E_{2} F_{1}} \\
& \overline{\sigma_{c}}(t)=\frac{N_{2} E_{1}-N_{1} F_{1}}{E_{1} F_{2}-E_{2} F_{1}}
\end{aligned}
$$




$$
\begin{aligned}
& \sigma_{s}(t)=E_{s}\left[\varepsilon_{s}(t)-\frac{\varepsilon_{c}(t)-\overline{\varepsilon_{c}}(t)}{h} d\right] \\
& \sigma_{s}^{\prime}(t)=E_{s}\left[\varepsilon_{s}(t)-\frac{\varepsilon_{c}(t)-\overline{\varepsilon_{c}}(t)}{h} d^{\prime}\right]
\end{aligned}
$$

As deformações no concreto, para o instante de tempo genérico " $\mathrm{t}$ ", ficam determinadas a partir da aplicação das expressões (4.39) e (4.40), Para a determinação das deformaçōes nas armaduras de compressão e de tração emprega-se as relações de compatibilidade expressas por (4.34) e (4.33), respectivamente. Em hipótese alguma, para o instante genérico de tempo, pode-se supor a proporcionalidade entre tensőes e deformações, ou seja $\sigma \neq \mathrm{E} \varepsilon$.

\section{4,3.5-TENSÖES E DEFORMAÇÕES: SEÇÃO FISSURADA DE CONCRETO ARMADO}

\section{INTRODUÇÃO:}

As tensöes e deformações para uma seção fissurada de concreto armado são determinadas a partir do equacionamento do equilibrio de esforços para os instantes inicial e final de tempo para uma configuração média deformada. Os esforços solicitantes - momento fletor e esforço normal - säo admitidos constantes. A fluência e a retração são consideradas através da equação (4.22) aplicada à fibras adequadamente escolhidas. Os esforços solicitantes - momento fletor e esforço normal - são admitidos constantes. 


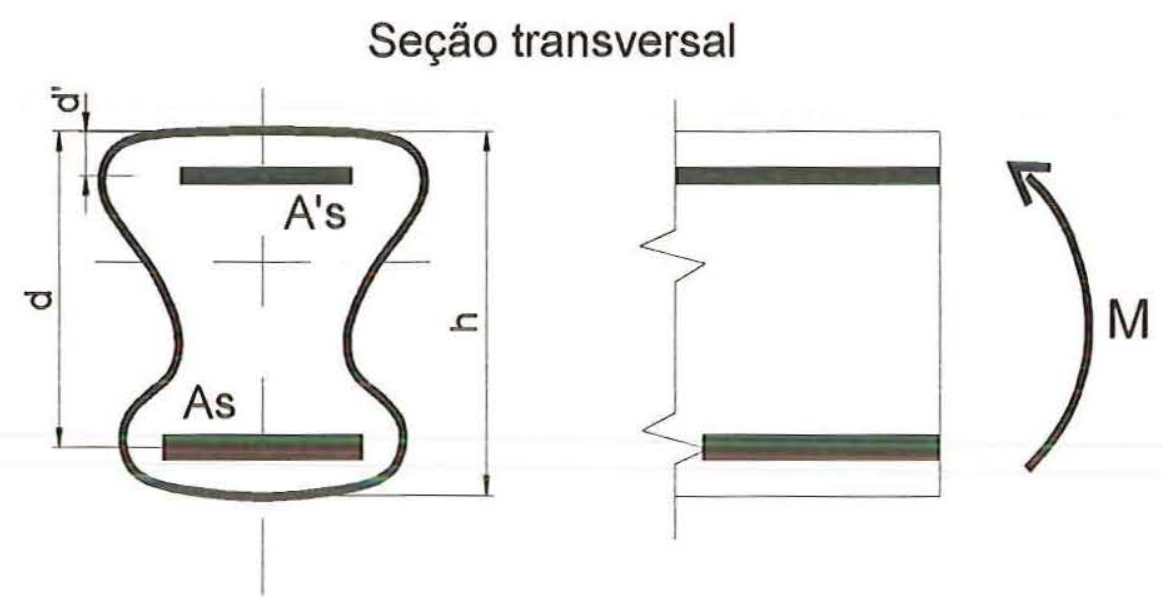

Deformações

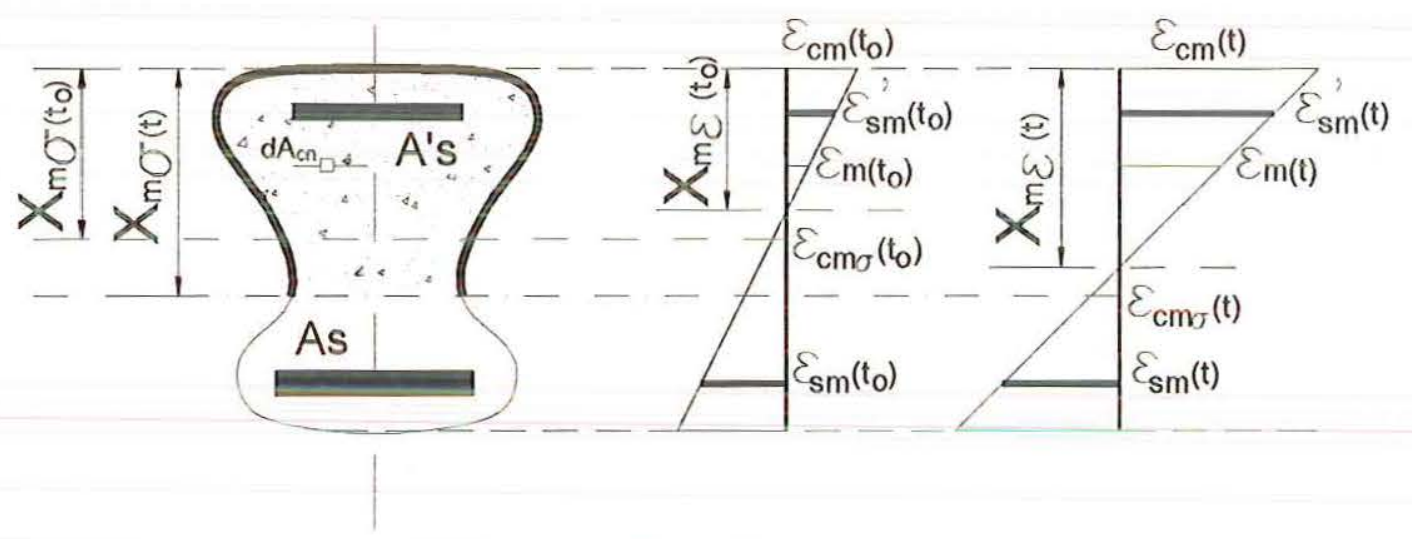

Tensöes

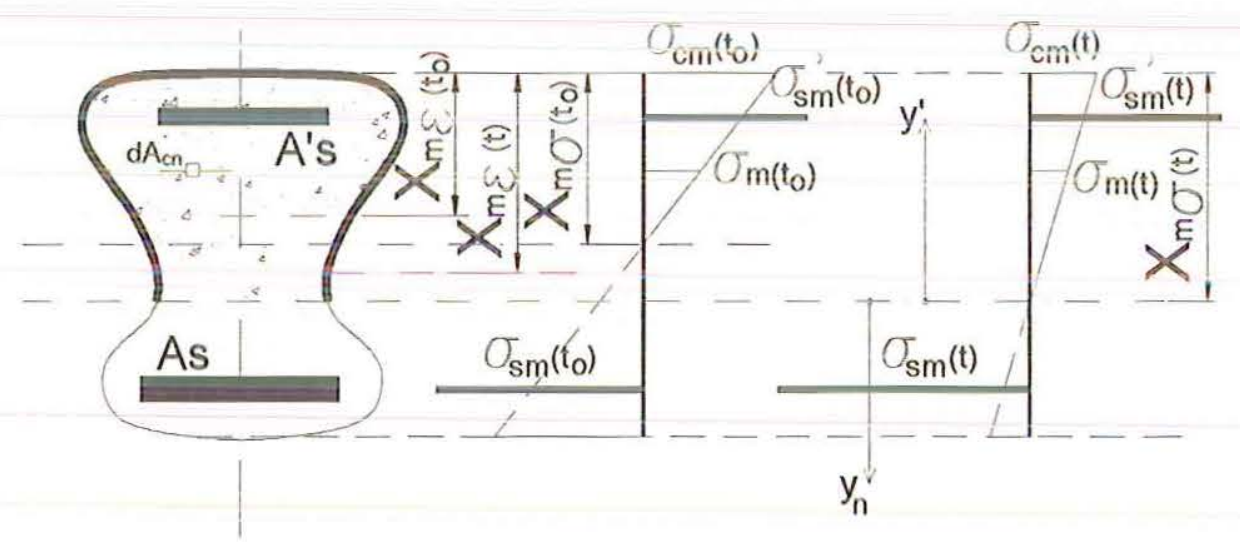

Figura 4.6 : Tensões e deformações para os instantes de tempos " $\hat{t}_{0}$ " e "t" para uma seção fissurada de concreto armado. 
O deslocamento para baixo da linha neutra ao longo do tempo e o conseqüente aumento na área de concreto comprimido são considerados no equacionamento de DEBERNARDI, ao contrário do método de GHALI \& FAVRE. É necessário que diversas configuraçōes da seção sejam verificadas. $\mathrm{O}$ equacionamento é feito supondo-se uma seção de forma qualquer com armadura dupla.

A figura (4.6) ilustra o comportamento ao longo do tempo das seçöes fissuradas de concreto - configuração média deformada. Também são definidas as principais variáveis envolvidas no equacionamento desse item. A figura (4.7) mostra o efeito da contribuição do concreto intacto entre fissuras - tension stiffening.

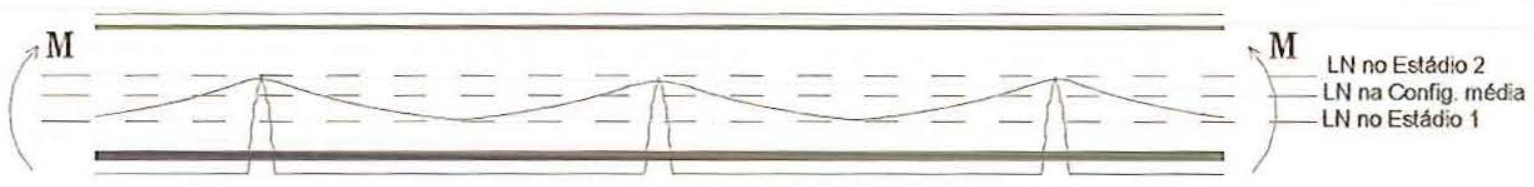

a) Elemento fissurado de concreto armado

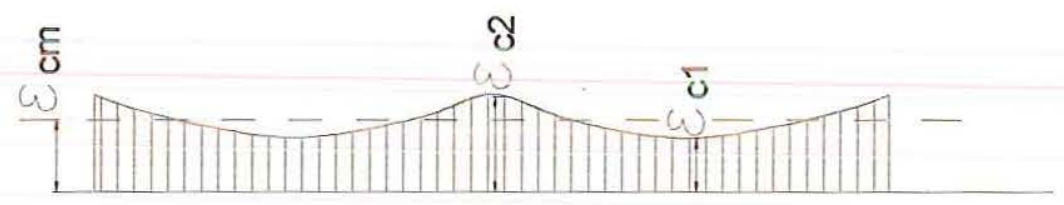

b) Deformação na fibra de concreto que sofreu o maior encurtamento

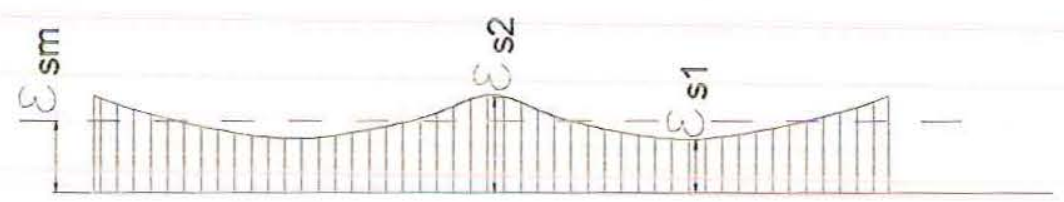

c) Deformaçäo da armadura tracionada

Figura 4.7 : Contribuição do concreto intacto entre fissuras - "tension stiffening" - na f́lexão simples. 


\section{CONFIGURAÇÕES A SEREM VERIFICADAS:}

A obtençäo das tensöes e deformaçōes na configuração média da seção para os instantes inicial " $t_{0}$ " e final " $\boldsymbol{t}$ " exige que essas grandezas sejam previamente determinadas considerando-se as hipótese do estádio 2 para ambos os instantes de análise. A deformação média da armadura de tração, $\varepsilon_{s m}$, depende dos valores de $\sigma_{s r}\left(t_{0}\right), \sigma_{s r}(t), \sigma_{s 2}\left(t_{0}\right)$ e $\sigma_{s 2}(t)$. Para atender a todas as etapas de cálculo serão consideradas as seguintes configuraçōes:

a) configuração da seção no estádio 2 para o instante $t_{0}$;

b) configuração da seção média no instante inicial to;

c) configuração da seção no estádio 2 no instante final (ou desejado) $t$;

d) configuração da seção média no instante final (ou desejado) t.

CONFIGURAÇÕES PARA O INSTANTE INICIAL $\left(\hat{t}=\hat{t}_{0}\right)$ :

Calcula-se, de início, para uma dado par de esforços $\mathrm{M}$ e $\mathrm{N}$ referidos a um ponto $\mathrm{O}$ qualquer com os módulos de elasticidade reais do aço e do concreto $E_{s}$ e $E_{c}$, respectivamente, os elementos da seção (inércia, deformaçōes e tensöes), no instante $\hat{t}=\hat{t}_{0}$ (é suposto não haver nenhuma deformação imposta no instante inicial) para os estádios de solicitação 1 e 2.

Conhecendo-se o valor de $\varepsilon_{\mathrm{sm}}\left(\hat{\varepsilon}_{0}\right)$ a partir de $\sigma_{\mathrm{sr}}\left(\hat{t}_{0}\right)$, da tensão $\sigma_{\mathrm{s} 2}\left(\hat{t}_{0}\right)$

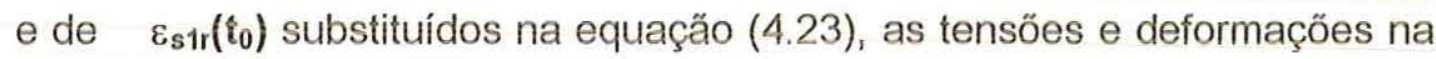
configuração média poderão ser obtidas de forma iterativa ou direta (analiticamente), conforme será mostrado a seguir.

\section{Cálculo lterativo.}

1) É atribuído, para considerar o concreto entre fissuras, uma rigidez fictícia à zona tracionada, adotando-se de início um módulo $\mathbf{E}_{\mathrm{s}}^{*}>\mathbf{E}_{\mathrm{s}}$ tal que : $\alpha^{*}=\mathbf{E}_{\mathrm{s}}^{*} / \mathbf{E}_{\mathrm{c}}\left(\mathbf{t}_{\mathbf{0}}\right)$. Para a contribuição da armadura comprimida $\mathbf{A}_{\mathrm{s}}^{*}$ e da 
área de concreto comprimida $\mathbf{A}_{\mathrm{cc}}$ são utilizados os módulos reais do aço e do concreto. Um primeiro valor para $\mathbf{E}_{\mathrm{s}}^{*}$ pode ser adotado como:

$$
\mathrm{E}_{\mathrm{s}\left(\mathrm{t}_{0}\right)}^{*}=\frac{\sigma_{\mathrm{s} 2\left(\mathrm{t}_{0}\right)}}{\varepsilon_{\mathrm{sm}\left(\mathrm{t}_{0}\right)}}
$$

2) Com os esforços $\mathrm{M}$ e $\mathrm{N}$ é efetuado o cálculo no estádio 2 , determinandose $\sigma_{s}^{*}$ e a deformação $\varepsilon_{s}^{*}$.

3) Compara-se $\varepsilon_{s}^{*}$ com o valor conhecido de $\varepsilon_{\text {sm }}\left(\mathbf{t}_{0}\right)$. Se a diferença entre esses valores estiver dentro de uma tolerância pré estabelecida, considera-se que houve convergência. A partir da última iteração obtémse os valores para a configuração média no instante $\mathfrak{t}_{0}$ : a posição da linha neutra $x_{\operatorname{mo}\left(t_{0}\right)}=x_{\operatorname{m\varepsilon }\left(t_{0}\right)}$ e os valores das tensöes e deformaçöes $\sigma_{\mathrm{cm}\left(\mathrm{t}_{0}\right)}, \sigma_{\mathrm{sm}\left(\mathrm{t}_{\mathrm{o}}\right)}=\sigma_{\mathrm{s}}^{*}$ e $\varepsilon_{\mathrm{sm}\left(\mathrm{t}_{\mathrm{o}}\right)}$.

A curvatura média no instante $\hat{t}_{0}$ é dada por :

$$
\frac{1}{r_{m\left(t_{0}\right)}}=-\frac{\varepsilon_{s m\left(t_{0}\right)}}{x_{m \varepsilon\left(t_{0}\right)}-d}
$$

e a resultante de tração na armadura para a configuraçăo média será:

$$
\mathrm{R}_{\mathrm{sm}\left(\mathrm{t}_{0}\right)}=\sigma_{\mathrm{sm}\left(\mathrm{t}_{0}\right)} \cdot \mathrm{A}_{\mathrm{s}}
$$

\section{Cálculo Analítico}

Para a obtenção da solução analítica é escrita a equação de equilíbrio de momentos fletores em relação ao centro de gravidade da armadura tracionada $\mathbf{A}_{\mathbf{s}}$, que no caso independe do módulo de elasticidade fictício $\mathbf{E}_{\mathrm{s}}^{*}$ e que simula o acréscimo de rigidez devido a contribuição do concreto entre fissuras.

Seja $A_{c c m}\left(\hat{t}_{0}\right)$ a área de concreto comprimida na configuração média para o instante $\mathfrak{t}_{0}$, a equação de equilíbrio de momentos pode ser escrita por: 


$$
\begin{aligned}
& \quad \int_{A_{c \mathrm{~cm}\left(t_{0}\right)}} \sigma_{m\left(t_{0}\right)} \cdot\left[d-x_{m \sigma\left(t_{0}\right)}-y_{n}\right] d A_{c c m\left(t_{0}\right)}-\frac{\sigma_{s m\left(t_{0}\right)}^{\prime}}{\alpha_{s}} \cdot A_{s}^{\prime} \cdot\left(d-d^{\prime}\right)+ \\
& +\sigma_{s m\left(t_{0}\right)}^{\prime} \cdot A_{s}^{\prime} \cdot\left(d-d^{\prime}\right)+N e_{s}=0
\end{aligned}
$$

onde $y_{n}$ é a distância em relação à linha neutra.

Da proporcionalidade entre tensões e deformações obtém-se :

$$
\begin{aligned}
& \sigma_{\mathrm{sm}\left(\mathrm{t}_{0}\right)}^{\prime}=\alpha_{\mathrm{s}} \cdot \sigma_{\mathrm{cm}\left(\mathrm{t}_{0}\right)} \cdot \frac{\mathrm{x}_{\mathrm{m \sigma}\left(\mathrm{t}_{0}\right)}-\mathrm{d}^{\prime}}{\mathrm{x}_{\mathrm{m \sigma}\left(\mathrm{t}_{0}\right)}} \\
& \sigma_{\mathrm{cm}\left(\mathrm{t}_{0}\right)}=\mathrm{E}_{\mathrm{c}\left(\mathrm{t}_{0}\right)} \cdot \varepsilon_{\mathrm{sm}\left(\mathrm{t}_{0}\right)} \cdot \frac{\mathrm{x}_{\mathrm{m \sigma}\left(\mathrm{t}_{0}\right)}}{\mathrm{x}_{\mathrm{m \sigma}\left(\mathrm{t}_{0}\right)}-\mathrm{d}}
\end{aligned}
$$

Substituindo-se a tensão média $\sigma_{c m}\left(\hat{t}_{0}\right)$ da expressão (4.62) pela expressão (4.63) resulta:

$$
\sigma_{\mathrm{sm}\left(\mathrm{t}_{0}\right)}^{\prime}=\alpha_{\mathrm{s}} \cdot \mathrm{E}_{\mathrm{c}\left(\mathrm{t}_{0}\right)} \cdot \varepsilon_{\mathrm{sm}\left(\mathrm{t}_{0}\right)} \cdot \frac{\mathrm{x}_{\mathrm{m \sigma}\left(\mathrm{t}_{0}\right)}-\mathrm{d}^{\prime}}{\mathrm{x}_{\mathrm{m \sigma}\left(\mathrm{t}_{0}\right)}}
$$

Da figura (4.6), pode-se escrever :

$$
\frac{\sigma_{\mathrm{m}\left(\mathrm{t}_{0}\right)}}{\mathrm{y}_{\mathrm{n}}}=\frac{\sigma_{\mathrm{cm}\left(\mathrm{t}_{0}\right)}}{-\mathrm{x}_{\mathrm{m \sigma}\left(\mathrm{t}_{0}\right)}}
$$

e:

$$
\sigma_{m\left(t_{0}\right)}=-\sigma_{c m\left(t_{0}\right)} \cdot \frac{y_{n}}{x_{m \sigma\left(t_{0}\right)}}
$$

A área elementar da zona comprimida é :

$$
\mathrm{dA}_{\operatorname{cc}\left(\mathrm{t}_{0}\right)}=\mathrm{b}_{\left(\mathrm{y}_{\mathrm{n}}\right)} \cdot \mathrm{dy} \mathrm{y}_{\mathrm{n}}
$$


Usando-se as expressőes anteriores e fazendo-se transformações na equação de equilíbrio (4.61), obtém-se :

$$
\begin{aligned}
& \left\{\begin{array}{l}
{\left[d-x_{m \sigma\left(t_{0}\right)}\right] \cdot \int_{-x_{m o\left(t_{0}\right)}}^{0} \frac{\sigma_{m\left(t_{0}\right)}}{y_{n}} \cdot y_{n} \cdot b_{\left(y_{n}\right)} \cdot d y_{n}+} \\
-\int_{-x_{\operatorname{mos}\left(t_{0}\right)}}^{0} \frac{\sigma_{m\left(t_{0}\right)}}{y_{n}} \cdot y_{n} \cdot b_{\left(y_{n}\right)} \cdot y_{n} \cdot d y_{n}
\end{array}\right\}+ \\
& +\mathrm{A}_{\mathrm{s}}^{\prime} \cdot\left(\alpha_{\mathrm{s}}-1\right) \cdot \mathrm{E}_{\mathrm{c}\left(\mathrm{t}_{0}\right)} \varepsilon_{\mathrm{sm}\left(\mathrm{t}_{0}\right)} \cdot \frac{\mathrm{x}_{\mathrm{m \sigma}\left(\mathrm{t}_{0}\right)}-\mathrm{d}^{\prime}}{\mathrm{x}_{\mathrm{m \sigma}\left(\mathrm{t}_{\mathrm{o}}\right)}-\mathrm{d}} \cdot\left(\mathrm{d}-\mathrm{d}^{\prime}\right)+\mathrm{Ne}_{\mathrm{s}}=0
\end{aligned}
$$

A relação $\frac{\sigma_{\mathrm{m}\left(\mathrm{t}_{0}\right)}}{\mathbf{y}_{\mathrm{n}}}$ é constante no tempo $\hat{t}_{0}$; portanto pode ser retirada do integrando e a expressão (4.68) pode ser reescrita por :

$$
\begin{aligned}
& {\left[\mathrm{d}-\mathrm{x}_{\mathrm{m \sigma}\left(\mathrm{t}_{0}\right)}\right] \cdot \mathrm{S}_{\mathrm{ccm}\left(\mathrm{t}_{0}\right)}-\mathrm{I}_{\mathrm{ccm}\left(\mathrm{t}_{0}\right)}-\left(\alpha_{\mathrm{s}}-1\right) \cdot \mathrm{A}_{\mathrm{s}}^{\prime} \cdot\left[\mathrm{x}_{\mathrm{m \sigma}\left(\mathrm{t}_{0}\right)}-\mathrm{d}^{\prime}\right] \cdot\left(\mathrm{d}-\mathrm{d}^{\prime}\right)=} \\
& =\mathrm{Ne}_{\mathrm{s}} \cdot \frac{\mathrm{x}_{\mathrm{m \sigma}\left(\mathrm{t}_{0}\right)}-\mathrm{d}}{\mathrm{E}_{\mathrm{c}\left(\mathrm{t}_{0}\right)} \cdot \varepsilon_{\mathrm{sm}\left(\mathrm{t}_{0}\right)}}
\end{aligned}
$$

Onde $S_{\mathrm{ccm}\left(t_{0}\right)}$ e $I_{\mathrm{ccm}\left(t_{0}\right)}$ são, respectivamente, o momenio estático e 0 momento de inércia da área bruta de concreto comprimido em relação à linha neutra de tensões. Assim:

$$
\begin{aligned}
& S_{c c m\left(t_{0}\right)}=\int_{-x_{\operatorname{mos}\left(t_{0}\right)}}^{0} b_{n}\left(y_{n}\right) \cdot y_{n} \cdot d y_{n} \\
& I_{c c m\left(t_{0}\right)}=\int_{-x_{\operatorname{mo}\left(t_{0}\right)}}^{0} b_{\left(y_{n}\right)} \cdot y_{n}^{2} \cdot d y_{n}
\end{aligned}
$$


Os momentos estático e de inércia dependem da forma da seção transversal e têm seus valores dados em função da posição da linha neutra de tensőes. Sendo $\varepsilon_{\mathrm{sm}(10)}$ conhecido, a equação (4.69) tem como incógnita $\mathbf{x}_{\mathrm{mo}}\left(\mathrm{t}_{0}\right)$, que é a posição da referida linha neutra.

$\mathbf{I}_{\mathrm{ccm}\left(\mathrm{t}_{0}\right)}$ é pelo menos uma função cúbica de $\mathbf{x}_{\mathrm{mo}\left(\mathrm{t}_{0}\right)}$, para seção retangular, e a equação (4.69) é geralmente de grau superior a dois. Para equaçöes de ordem elevada podem-se obter as soluçőes através de métodos iterativos ou analiticamente.

\section{INSTANTE GENÉRICO $($ tempo $=\hat{t})$ :}

Para um instante genérico de tempo " $\boldsymbol{t}$ ", as equaçőes que regem o equilíbrio serão, de início, escritas para uma configuração média gerando um sistema de equaçöes lineares. A deformação média $\varepsilon_{\mathrm{sm}}$ deve ser conhecida para a resolução do sistema; seu valor será calculado mais adiante para a configuração fissurada no tempo genérico $\hat{t}$.

CONFIGURAÇÃO MÉDIA - instante t́:

As equaçőes que regem o equilíbrio, tomando a configuração média num instante $\hat{\mathbf{t}}$, podem ser escritas por :

a) equilíbrio de esforço normal:

$$
\int_{A_{\operatorname{csm}(t)}} \sigma_{m(t)} d A_{\operatorname{ccmn}(t)}+\sigma_{s m(t)}^{\prime} \cdot A_{s}^{\prime}-R_{s m(t)}+N=0
$$

b) equilíbrio de momentos em relaçäo ao centro de gravidade da armadura de tração $A_{s}$ :

$\int_{A_{c \operatorname{cm}(t)}} \sigma_{m(t)} \cdot\left[y-\left(d-x_{m \sigma(t)}\right)\right] \cdot d A_{\operatorname{ccmn}(t)}+\sigma_{s m(t)}^{\prime} \cdot A_{s}^{\prime} \cdot\left(d-d^{\prime}\right)-N e_{s}=0$ 
onde $A_{\text {ccmn }}(t)$ é a área da seção líquida de concreto comprimido para a configuração média, sendo sua diferencial expressa por :

$$
\mathrm{dA}_{\operatorname{comn}(\mathrm{t})}=\mathrm{b}_{\left(\mathrm{y}_{\mathrm{n}}\right)} \cdot \mathrm{dy}_{\mathrm{n}}
$$

A partir da linearidade do diagrama de tensões pode-se escrever:

$$
\begin{aligned}
& \frac{\sigma_{m(t)}}{y_{n}}=\frac{\sigma_{c m(t)}}{-x_{m \sigma(t)}} \\
& \sigma_{m(t)}=-\sigma_{e m(t)} \cdot \frac{y_{n}}{x_{m \sigma(t)}}
\end{aligned}
$$

onde $\sigma_{\mathrm{m}(\mathrm{t})}$ é a tensão no concreto em uma fibra genérica.

Os momentos estático e de inércia da seção líquida de concreto solicitado à comprimido são, respectivamente:

$$
\begin{aligned}
& S_{c c m(t)}=\int_{-x_{\operatorname{mos}}(t)}^{0} b_{\left(y_{n}\right)} \cdot y_{n} \cdot d y_{n}-A_{s}^{\prime} \cdot\left[d^{\prime}-x_{m \sigma}(t)\right] \\
& I_{c c m(t)}=\int_{-x_{\operatorname{mos}(t)}\left(y_{n}\right)}^{0} b_{n} \cdot d y_{n}-A_{s}^{\prime} \cdot\left[d^{\prime}-x_{m \sigma(i)}\right]^{2}
\end{aligned}
$$

As equações de equilibrio podem ser modificadas de modo que o termo $\sigma_{m}(t) / y_{n}$ fique em evidência. Empregando-se as expressöes (4.77) e (4.78) obtém-se:

$$
\begin{gathered}
-\frac{\sigma_{\mathrm{cm}(t)}}{\mathrm{x}_{\mathrm{m \sigma}(\mathrm{t})}} \cdot \mathrm{S}_{\mathrm{ccm}(\mathrm{t})}+\mathrm{A}_{\mathrm{s}}^{\prime} \cdot \sigma_{\mathrm{sm}(\mathrm{t})}^{\prime}+\mathrm{R}_{\mathrm{sm}(\mathrm{t})}=\mathrm{N} \\
-\frac{\sigma_{\mathrm{cm}(\mathrm{t})}}{\mathrm{x}_{\mathrm{m} \sigma(\mathrm{t})}} \cdot\left\{\mathrm{I}_{\mathrm{ccmn}(\mathrm{t})}-\left[\mathrm{d}-\mathrm{x}_{\mathrm{m \sigma}(\mathrm{t})}\right] \cdot \mathrm{S}_{\mathrm{ccmn}(\mathrm{t})}\right\}-\mathrm{A}_{\mathrm{s}}^{\prime} \cdot \sigma_{\mathrm{sm}(\mathrm{t})}^{\prime} \cdot\left(\mathrm{d}-\mathrm{d}^{\prime}\right)=\mathrm{Ne}_{\mathrm{s}}
\end{gathered}
$$


Para que o diagrama de deformações da seção seja completamente caracterizado, devido a hipótese da manutenção das seções planas, deve-se definir duas deformaçöes correspondentes a duas fibras distintas ou a deformação de uma fibra mais a curvatura da seção. Neste trabalho optouse por determinar deformações nas seguintes fibras: a correspondente ao encurtamento máximo do concreto e aquela que passa pela linha neutra de tensões no tempo $\mathbf{t}_{0}$.

Aplicando-se o AAEM através da equação (4.22) obtém-se :

a) na fibra superior:

$$
\begin{aligned}
& \varepsilon_{\mathrm{cm}(\mathrm{t})}=\varepsilon_{\mathrm{cm}\left(\mathrm{t}_{0}\right)}+\frac{\sigma_{\mathrm{cm}\left(\mathrm{t}_{0}\right)}}{\mathrm{E}_{\mathrm{c} 28}} \cdot \varphi_{28\left(\mathrm{t}, \mathrm{t}_{0}\right)}+ \\
& +\left[\sigma_{\mathrm{cm}(\mathrm{t})}-\sigma_{\mathrm{cm}\left(\mathrm{t}_{0}\right)}\right] \cdot\left[\frac{1}{\mathrm{E}_{\mathrm{c}\left(\mathrm{t}_{0}\right)}}+\chi_{\left(\mathrm{t}, \mathrm{t}_{0}\right)} \cdot \frac{\varphi_{28\left(1, \mathrm{t}_{0}\right)}}{\mathrm{E}_{\mathrm{c} 28}}\right]+\varepsilon_{\mathrm{cs}\left(\mathrm{t}, \mathrm{t}_{0}\right)}
\end{aligned}
$$

b) na fibra da $L N$ das tensões para $\hat{t}=\hat{t}_{0}$, onde a tensão $\sigma_{\mathrm{cmo}\left(\mathfrak{t}_{0}\right)}=\mathbf{0}$ :

$$
\varepsilon_{\mathrm{cm \sigma}(\mathrm{t})}=\varepsilon_{\mathrm{cm \sigma}\left(\mathrm{t}_{0}\right)}+\sigma_{\mathrm{cm \sigma}(\mathrm{t})} \cdot\left[\frac{1}{\mathrm{E}_{\mathrm{c}\left(\mathrm{t}_{0}\right)}}+\chi_{\left(\mathrm{t}, \mathrm{t}_{0}\right)} \cdot \frac{\varphi_{28\left(\mathrm{t}, \mathrm{t}_{0}\right)}}{\mathrm{E}_{\mathrm{c} 28}}\right]+\varepsilon_{\mathrm{cs}\left(\mathrm{t}, \mathrm{t}_{0}\right)}
$$

As expressões acima são gerais, pois permitem que as linhas neutras de tensão e deformação não sejam coincidentes, nem no instante $t_{0}$, devido a existência de deformaçőes impostas.

As deformações, admitindo-se a hipótese das seçőes permanecerem planas, podem ser escritas em função da deformação na fibra mais comprimida do concreto $\varepsilon_{\mathrm{cm}}(t)$, assim :

$$
\begin{aligned}
& \varepsilon_{\mathrm{sm}(\mathrm{t})}=\frac{\mathrm{x}_{\mathrm{m \varepsilon}(\mathrm{t})}-\mathrm{d}}{\mathrm{x}_{\mathrm{m \varepsilon}(\mathrm{t})}} \cdot \varepsilon_{\mathrm{cm}(\mathrm{t})} \\
& \varepsilon_{\mathrm{sm}(\mathrm{t})}^{\prime}=\frac{\mathrm{x}_{\mathrm{m \varepsilon}(\mathrm{t})}-\mathrm{d}^{\prime}}{\mathrm{x}_{\mathrm{m \varepsilon}(\mathrm{t})}} \cdot \varepsilon_{\mathrm{cm}(\mathrm{t})}
\end{aligned}
$$




$$
\varepsilon_{\mathrm{cm \sigma}(\mathrm{t})}=\frac{\mathrm{x}_{\mathrm{m \varepsilon}(\mathrm{t})}-\mathrm{x}_{\mathrm{m \sigma}\left(\mathrm{t}_{0}\right)}}{\mathrm{x}_{\mathrm{m \varepsilon}(\mathrm{t})}} \cdot \varepsilon_{\mathrm{cm}(\mathrm{t})}
$$

Da equação (4.84) resulta :

$$
\sigma_{\mathrm{sm}(\mathrm{t})}^{\prime}=\mathrm{E}_{\mathrm{s}} \cdot \varepsilon_{\mathrm{sm}(\mathrm{t})}^{\prime}=\mathrm{E}_{\mathrm{s}} \cdot\left(1-\frac{\mathrm{d}^{\prime}}{\mathrm{x}_{\mathrm{m} \varepsilon(\mathrm{t})}}\right) \cdot \varepsilon_{\mathrm{cm}(\mathrm{t})}
$$

Para uma determinada seção, pode-se escrever:

$$
\sigma_{\mathrm{cm \sigma}(\mathrm{t})}=\left(1-\frac{\mathrm{x}_{\mathrm{m \sigma}\left(\mathrm{t}_{0}\right)}}{\mathrm{x}_{\mathrm{m \sigma}(\mathrm{t})}}\right) \cdot \sigma_{\mathrm{cm}(\mathrm{t})}
$$

Define-se um parâmetro f̂, a ser empregado na equação constitutiva do concreto; para simplificar o equacionamento, assim:

$$
f=\frac{1}{E_{c\left(t_{0}\right)}}+\chi_{\left(t, t_{0}\right)} \cdot \frac{\varphi_{28\left(t, t_{0}\right)}}{E_{c 28}}
$$

Substituindo-se (4.86) em (4.79) e (4.80); (4.85) e (4.87) em (4.82) obtém-se :

$$
\begin{aligned}
& -\frac{\sigma_{\mathrm{cm}(\mathrm{t})}}{\mathrm{x}_{\mathrm{m \sigma}(\mathrm{t})}} \cdot \mathrm{S}_{\mathrm{ccmn}(\mathrm{t})}+\mathrm{E}_{\mathrm{s}} \cdot \mathrm{A}_{\mathrm{s}}^{\prime} \cdot\left(1-\frac{\mathrm{d}^{\prime}}{\mathrm{x}_{\mathrm{m \varepsilon}(\mathrm{t})}}\right) \cdot \varepsilon_{\mathrm{cm}(\mathrm{t})}+\mathrm{R}_{\mathrm{sm}(\mathrm{t})}=\mathrm{N} \\
& -\frac{\sigma_{\mathrm{cm}(\mathrm{t})}}{\mathrm{x}_{\mathrm{m \sigma}(\mathrm{t})}} \cdot\left\{\mathrm{I}_{\mathrm{ccmn}(\mathrm{t})}-\left[\mathrm{d}-\mathrm{x}_{\mathrm{m \sigma}(\mathrm{t})}\right] \cdot \mathrm{S}_{\mathrm{ccmn}(\mathrm{t})}\right\}+ \\
& -\mathrm{A}_{\mathrm{s}}^{\prime} \cdot \mathrm{E}_{\mathrm{s}} \cdot\left(1-\frac{\mathrm{d}^{\prime}}{\mathrm{x}_{\mathrm{m} \varepsilon(\mathrm{t})}}\right) \cdot \varepsilon_{\mathrm{cm}(\mathrm{t})} \cdot\left(\mathrm{d}-\mathrm{d}^{\prime}\right)=\mathrm{Ne}_{\mathrm{s}} \\
& \varepsilon_{\mathrm{cm}(\mathrm{t})}=\varepsilon_{\mathrm{cm}\left(\mathrm{t}_{0}\right)}+\frac{\sigma_{\mathrm{cm}\left(\mathrm{t}_{0}\right)}}{\mathrm{E}_{\mathrm{c} 28}} \cdot \varphi_{28\left(\mathrm{t}, \mathrm{t}_{0}\right)}+\left(\sigma_{\mathrm{cm}(\mathrm{t})}-\sigma_{\mathrm{cm}\left(\mathrm{t}_{0}\right)}\right) \cdot \mathrm{f}+\varepsilon_{\mathrm{cs}\left(\mathrm{t}, \mathrm{t}_{0}\right)}
\end{aligned}
$$




$$
\left(1-\frac{x_{m \sigma\left(t_{0}\right)}}{x_{m \varepsilon(t)}}\right) \cdot \varepsilon_{c m(t)}=\varepsilon_{c m \sigma\left(t_{0}\right)}+\sigma_{c m(t)} \cdot f \cdot\left(1-\frac{x_{m \sigma\left(t_{0}\right)}}{x_{m \sigma(t)}}\right)+\varepsilon_{c s\left(t, t_{0}\right)}
$$

Para simplificar as expressões, define-se:

$$
\begin{aligned}
& g_{1 m(t)}=\frac{1}{x_{m \sigma(t)}} \cdot\left\{I_{\operatorname{ccmn}(t)}-\left[d-x_{m \sigma(t)}\right] \cdot S_{c c m n(t)}\right\} \\
& g_{2 m\left(t_{0}\right)}=\varepsilon_{c m\left(t_{0}\right)}+\sigma_{c m\left(t_{0}\right)} \cdot\left[\frac{\varphi_{28\left(t, t_{0}\right)}}{E_{c 28}}-f\right]+\varepsilon_{c s\left(t, t_{0}\right)}
\end{aligned}
$$

Manipulando-se as expressöes deduzidas pode-se escrever um sistema de cinco incógnitas e quatro equaçōes (4.95-4.98):

$$
\begin{aligned}
& -\frac{\sigma_{\mathrm{cm}(\mathrm{t})}}{\mathrm{x}_{\mathrm{m \sigma}(\mathrm{t})}} \cdot \mathrm{S}_{\mathrm{ccmn}(\mathrm{t})}+\mathrm{E}_{\mathrm{s}} \cdot \mathrm{A}_{\mathrm{s}}^{\prime} \cdot\left(1-\frac{\mathrm{d}^{\prime}}{\mathrm{x}_{\mathrm{mg}(\mathrm{t})}}\right) \cdot \varepsilon_{\mathrm{cm}(\mathrm{t})}+\mathrm{R}_{\mathrm{sm}(\mathrm{t})}=\mathrm{N} \\
& -\sigma_{\mathrm{cm}(\mathrm{t})} \cdot \mathrm{g}_{1 \mathrm{~m}(\mathrm{t})}-\mathrm{A}_{\mathrm{s}}^{\prime} \cdot \mathrm{E}_{\mathrm{s}} \cdot\left(1-\frac{\mathrm{d}^{\prime}}{\mathrm{x}_{\mathrm{ms}(\mathrm{t})}}\right) \cdot \varepsilon_{\mathrm{cm}(\mathrm{t})} \cdot\left(\mathrm{d}-\mathrm{d}^{\prime}\right)=\mathrm{Ne}_{\mathrm{s}} \\
& \varepsilon_{\mathrm{cm}(\mathrm{t})}=\mathrm{g}_{2 \mathrm{~m}\left(\mathrm{t}_{0}\right)}+\mathrm{f} \cdot \sigma_{\mathrm{cm}(\mathrm{t})} \\
& \frac{1}{\mathrm{x}_{\mathrm{ms}(\mathrm{t})}}=\frac{1}{\mathrm{x}_{\mathrm{m \sigma}\left(\mathrm{t}_{0}\right)}} \cdot\left\{1-\frac{1}{\varepsilon_{\mathrm{cm}(\mathrm{t})}} \cdot\left[\varepsilon_{\mathrm{cm \sigma}\left(\mathrm{t}_{0}\right)}+\left(1-\frac{\mathrm{x}_{\mathrm{m \sigma}\left(\mathrm{t}_{0}\right)}}{\mathrm{x}_{\mathrm{m \sigma}(\mathrm{t})}}\right) \cdot \sigma_{\mathrm{cm}(\mathrm{t})} \cdot \mathrm{f}+\varepsilon_{\mathrm{cs}\left(\mathrm{t}, \mathrm{t}_{0}\right)}\right)\right.
\end{aligned}
$$

Onde as duas primeiras são as equaçőes em termos de equilíbrio; (4.97) e (4.98) são as duas equaçōes de compatibilidade de deformaçöes. Para o caso da flexão simples $\mathrm{N}$ é igual a zero $\mathbf{e}_{\mathbf{s}}$ por conseqüência deve assumir um valor tal que o produto $\mathrm{N}_{\mathrm{s}}$ resulte igual a M. 
O momento estático, $S_{c c m n}(t)$, e o momento de inércia, $S_{c c n n}(t)$, são dependentes da posição da linha neutra de tensöes para um instante de tempo $\mathbf{t}$. As incógnitas do sistema formado pelas equações (4.95) a (4.98) säo as seguintes : $\mathbf{x}_{\mathrm{m \sigma}}(\mathbf{t}), \mathbf{x}_{\mathrm{m \varepsilon}}(\boldsymbol{t}), \varepsilon_{\mathrm{cm}}(\boldsymbol{t}), \sigma_{\mathrm{cm}}(\boldsymbol{t})$ e $\mathbf{R}_{\mathrm{sm}}(\boldsymbol{t})$ que será resolvida de maneira iterativa.

Para simplificar o equacionamento será definida a função $\mathrm{g}_{3 \mathrm{~m}}($ to $)$ :

$$
g_{3 m\left(t_{0}\right)}=\frac{d^{\prime}}{x_{m \sigma\left(t_{0}\right)}}\left[g_{2 m\left(t_{0}\right)}-\varepsilon_{c m \sigma\left(t_{0}\right)}-\varepsilon_{c s\left(t, t_{0}\right)}\right]-g_{2 m\left(t_{0}\right)}
$$

Dessa forma, tem-se para a tensão no concreto:

$$
\sigma_{c m(t)}=\frac{E_{s} \cdot A_{s}^{\prime} \cdot\left(d-d^{\prime}\right) \cdot g_{3 m\left(t_{0}\right)}-N \cdot e_{s}}{E_{s} \cdot A_{s}^{\prime} \cdot\left(d-d^{\prime}\right) \cdot f \cdot\left(1-\frac{d^{\prime}}{x_{m \sigma(t)}}\right)+g_{1 m(t)}}
$$

A incógnita básica do sistema é a posição da linha neutra de tensões $\mathbf{x}_{\mathrm{m \sigma}}(t)$; a relação entre $\mathbf{R}_{\mathrm{sm}}(t)$ e $\mathbf{x}_{\mathrm{mo}}(t)$ não pode ser explicitada. Disto resulta um sistema de quatro equações com cinco incógnitas, incluindo $R_{s m}(t)$.

A solução pode ser obtida por iteraçōes conforme o roteiro de cálculo que será apresentado a seguir. É necessário uma condição suplementar para tornar possivel e determinado o sistema de equações. Para tanto calcula-se a deformação média da armadura de tração, $\varepsilon_{\mathrm{sm}}(t)$, a partir da tensão no aço para a seção fissurada, conforme será visto mais adiante. O valor de $\varepsilon_{\mathrm{sm}}(\boldsymbol{t})$ será uma condição que deve ser respeitada na resolução do sistema. 
Roteiro para Solução do Sistema - Equações (4.95) a (4.98)

1) adota-se um valor inicial para $x_{m \sigma}(t)$;

2) calculam-se $\mathbf{f}, \mathbf{g}_{2 m}\left(\mathfrak{t}_{0}\right)$ e $\mathbf{g}_{3 \mathrm{~m}}\left(\boldsymbol{t}_{0}\right)$ por meio das expressőes (4.88), (4.94) e (4.99), respectivamente;

3) calculam-se os valores de $\mathbf{S}_{\mathrm{ccmn}}(\boldsymbol{t}), \mathbf{I}_{\mathrm{ccmn}}(\boldsymbol{t}), \mathbf{g}_{1 \mathrm{~m}}(\boldsymbol{t})$ por (4.77), (4.78) e (4.93);

4) calculam-se os valores de $\sigma_{\mathrm{cm}}(\mathbf{t}), \varepsilon_{\mathrm{cm}}(\mathrm{t}), \mathrm{x}_{\mathrm{m} \varepsilon}(\mathrm{t}), \varepsilon_{\mathrm{sm}}(\mathrm{t})$, respectivamente pelas expressőes (4.90), (4.97), (4.98) e (4.83);

5) verifica-se o valor de $\varepsilon_{\mathrm{sm}}(\mathrm{t})$.

Compara-se o valor de $\varepsilon_{\mathrm{sm}}(\mathrm{t})$ obtido pelo passo (4) do roteiro acima com o valor correto já deve ser previamente calculado (sua determinaçäo será efetuada a partir da equação (4.102) do próximo item). Se os valores forem próximos (dentro de uma tolerância previamente estabelecida) considera-se que o processo convergiu e os resultados podem ser aceitos. Caso contrário recomeça-se o cálculo a partir do primeiro passo com um novo valor para $x_{m \varepsilon}(\hat{\imath})$ até que seja verificada a convergência. Quando esta ocorrer o vaior para a curvatura média será :

$$
\frac{1}{r_{m}}(t)=-\frac{\varepsilon_{s m(t)}}{x_{m \varepsilon(t)}-d}
$$

CONFIGURAÇÃO DA SEÇÃO FISSURADA. CÁLCULO DA DEFORMAÇÃO MÉDIA NA ARMADURA TRACIONADA:

Para a soluçäo do sistema descrito na seção anterior torna-se necessário conhecer a deformação média na armadura tracionada para um instante genérico $\hat{t}, \varepsilon_{s m}(\hat{t})$, rescrevendo-se a expressão (4.23) em função de $\mathbf{t}$, obtém-se a seguinte equação: 


$$
\varepsilon_{\mathrm{sm}(\mathrm{t})}=\frac{\sigma_{\mathrm{s} 2(t)}}{\mathrm{E}_{\mathrm{s}}}-\beta_{1} \cdot \beta_{2(t)} \cdot\left(\frac{\sigma_{\mathrm{sr}}}{\mathrm{E}_{\mathrm{s}}}-\varepsilon_{\mathrm{sr}}\right) \cdot \frac{\sigma_{\mathrm{sr}}}{\sigma_{\mathrm{s} 2(t)}}
$$

onde $\beta_{2(1)}$ é um coeficiente que considera a fluência do concreto devido às tensões de aderência e $\sigma_{\mathrm{s} 2(t)}$ é a tensão na armadura calculada para na seção fissurada.

Os valores de $\varepsilon_{\mathrm{sr}}$ e $\sigma_{\mathrm{sr}}$ serão os mesmos dos calculados para o instante inicial $\mathfrak{t}_{0}$, pois admite-se que a fissuração do concreto aconteceu no tempo $\mathbf{t}_{0}$.

Para a seção onde ocorreram fissuras a resultante de tração na armadura será :

$$
\mathrm{R}_{\mathrm{s}(t)}=\varepsilon_{s(t)} \cdot \mathrm{E}_{\mathrm{s}} \cdot \mathrm{A}_{\mathrm{s}}
$$

A deformação na armadura será :

$$
\varepsilon_{s(t)}=\frac{x_{\varepsilon(t)}-d}{x_{\varepsilon(t)}} \cdot \varepsilon_{c(t)}
$$

Que substituida em (4.103) resulta

$$
R_{s(t)}=\frac{x_{\varepsilon(t)}-d}{x_{\varepsilon(t)}} \cdot \varepsilon_{c(t)} \cdot E_{s} \cdot A_{s}
$$

Analogamente à configuração média, para a seção fissurada também pode ser escrito um sistema de quatro equaçőes. Ao invés dos valores médios anteriormente empregados são tomados agora os valores locais. Assim: 


$$
\begin{gathered}
-\frac{\sigma_{c(t)}}{x_{\sigma(t)}} \cdot S_{c c n(t)}+E_{s} \cdot A_{s}^{\prime} \cdot\left(1-\frac{d^{\prime}}{x_{\varepsilon(t)}}\right) \cdot \varepsilon_{c(t)}+R_{s(t)}=N \\
-\sigma_{c(t)} \cdot g_{1(t)}-A_{s}^{\prime} \cdot E_{s} \cdot\left(1-\frac{d^{\prime}}{x_{\varepsilon(t)}}\right) \cdot \varepsilon_{c(t)} \cdot\left(d-d^{\prime}\right)=N_{s} \\
\varepsilon_{c(t)}=g_{2\left(t_{0}\right)}+f \cdot \sigma_{c(t)} \\
\frac{1}{x_{\varepsilon(t)}}=\frac{1}{x_{\sigma\left(t_{0}\right)}} \cdot\left\{1-\frac{1}{\varepsilon_{c(t)}} \cdot\left[\varepsilon_{c \sigma\left(t_{0}\right)}+\left(1-\frac{x_{\sigma\left(t_{0}\right)}}{x_{\sigma(t)}}\right) \cdot \sigma_{c(t)} \cdot f+\varepsilon_{c s\left(t, t_{0}\right)}\right]\right\}
\end{gathered}
$$

As incógnitas básicas deste sistema säo $x_{\sigma}(t), x_{\varepsilon}(t), \varepsilon_{c}(t), \sigma_{c}(t)$. Para uma seção transversal de forma qualquer, o sistema deve ser resolvido por iteraçőes.

\section{Roteiro para Solução do Sistema - Equaçöes (4.106) a (4.109)}

1) adota-se um valor inicial para $x_{\sigma}(\hat{t})$;

2) calculam-se os valores de f pela expressão (4.88) e os valores de $g_{2}\left(\hat{t}_{0}\right)$ e $g_{3}\left(\hat{t}_{0}\right)$ respectivamente por:

$$
\begin{aligned}
& g_{2\left(t_{0}\right)}=\varepsilon_{c\left(t_{0}\right)}+\sigma_{c\left(t_{0}\right)} \cdot\left[\frac{\varphi_{28\left(t, t_{0}\right)}}{E_{c 28}}-f\right]+\varepsilon_{c s\left(t, t_{0}\right)} \\
& g_{3\left(t_{0}\right)}=\frac{d^{\prime}}{x_{\sigma\left(t_{0}\right)}}\left[g_{2\left(t_{0}\right)}-\varepsilon_{c m o\left(t_{0}\right)}-\varepsilon_{c s\left(t, t_{0}\right)}\right]-g_{2\left(t_{0}\right)}
\end{aligned}
$$

3) calculam-se os valores de $\mathbf{S}_{\mathbf{c c n}}(\boldsymbol{t}), \mathbf{I}_{\mathbf{c n}}(\boldsymbol{t})$ e $\mathbf{g}_{1}(\boldsymbol{t})$ pelas seguintes expressões: 


$$
\begin{aligned}
& S_{c c(t)}=\int_{-x_{\sigma(t)}}^{0} b_{\left(y_{n}\right)} \cdot d y_{n}-A_{s}^{\prime} \cdot\left[d^{\prime}-x_{\sigma(t)}\right] \\
& I_{c c(t)}=\int_{-x_{\sigma(t)}}^{0} b_{\left(y_{n}\right)} \cdot y_{n} \cdot d y_{n}-A_{s}^{\prime} \cdot\left[d^{\prime}-x_{\sigma(t)}\right]^{2} \\
& g_{l(t)}=\frac{1}{x_{\sigma(t)}} \cdot\left\{I_{\operatorname{con}(t)}-\left[d-x_{\sigma(t)}\right] \cdot S_{\operatorname{con}(t)}\right\}
\end{aligned}
$$

4) calculam-se os valores de $x_{\sigma}(t), x_{\varepsilon}(t), \varepsilon_{c}(t)$ e $\sigma_{c}$ (t) através de expressőes análogas àquelas da configuração média, assim :

$$
\sigma_{c(t)}=\frac{E_{s} \cdot A_{s}^{\prime} \cdot\left(d-d^{\prime}\right) \cdot g_{3\left(t_{e}\right)}-N \cdot e_{s}}{E_{s} \cdot A_{s}^{\prime} \cdot\left(d-d^{\prime}\right) \cdot f \cdot\left(1-\frac{d^{\prime}}{x_{\sigma(t)}}\right)+g_{1(t)}}
$$

e, $\varepsilon_{c}(\hat{t})$ e $x_{\varepsilon}(\hat{t})$ são obtidos, respectivamente, pelas expressões (4.108) e (4.109).

5) verifica-se a equaçäo (4.106)

Para que o valor adotado de $x_{\sigma}(t)$ seja a solução do sistema, todos os valores das incógnitas anteriormente calculados devem satisfazer à equaçäo (4.106), dentro de uma tolerância pré-estabelecida. Se näo for satisfeita esta condição, deve-se retomar o processo a partir do primeiro passo com um novo valor para $x_{s}(t)$ até que a convergência seja verificada. Obtida a solução do sistema, o valor de $\sigma_{\mathrm{s} 2}(\mathrm{t})$ é dado por :

$$
\sigma_{s 2(t)}=\varepsilon_{s(t)} \cdot E_{s}
$$

A partir da deformação na armadura tracionada, na configuraçäo média, $\varepsilon_{\mathrm{sm}}(t)$, calcula-se finalmente a curvatura dessa seção por :

$$
\frac{1}{r_{m}}(t)=-\frac{\varepsilon_{s m(t)}}{x_{m \varepsilon(t)}-d}=\frac{-M}{E_{c(t)} \cdot I_{m(t)}}
$$




\section{5-ANÁLISE LINEAR E NÃO-LINEAR DE ESTRUTURAS}

\section{1-GENERALIDADES}

A energia potencial total de um sistema conservativo ou seja, de comportamento elástico, pode ser expressa por duas parcelas: energia de deformaçäo (ou energia potencial dos esforços solicitantes) e energia potencial das ações externas. Pode haver também manifestações de energia associada a trechos apoiados elasticamente sobre uma base ou, ainda, apoios elásticos discretos (molas). A soma das duas principais parcelas de energia pode ser expressa pela equação abaixo:

$$
\Pi=\mathrm{U}+\mathrm{W}
$$

onde $\Pi$ é o funcional que expressa a energia total do sistema, $U$ representa a soma das energias de deformação dos vários elementos e W corresponde à energia das açőes externas.

A parcela correspondente à energia de deformação pode ser entendida como o trabalho das tensöes internas ao corpo sobre as suas respectivas componentes de deformação. Esta parcela pode ser escrita pela equação (5.2) :

$$
\mathrm{U}=\int_{\mathrm{V}} \sigma^{\mathrm{T}} \varepsilon d \mathrm{~V}
$$

Suponha-se que uma barra carregada por uma ação externa específica (ver figura 5.1) tenha sua linha elástica de deformação dada por 
uma função $\mathbf{v}=\mathbf{v}(\mathbf{x})$. $\mathrm{O}$ trabalho de cada ação externa será igual ao produto do módulo desta ação pelo respectivo deslocamento. No caso de carregamentos distribuídos, deve ser efetuada a integral no domínio.

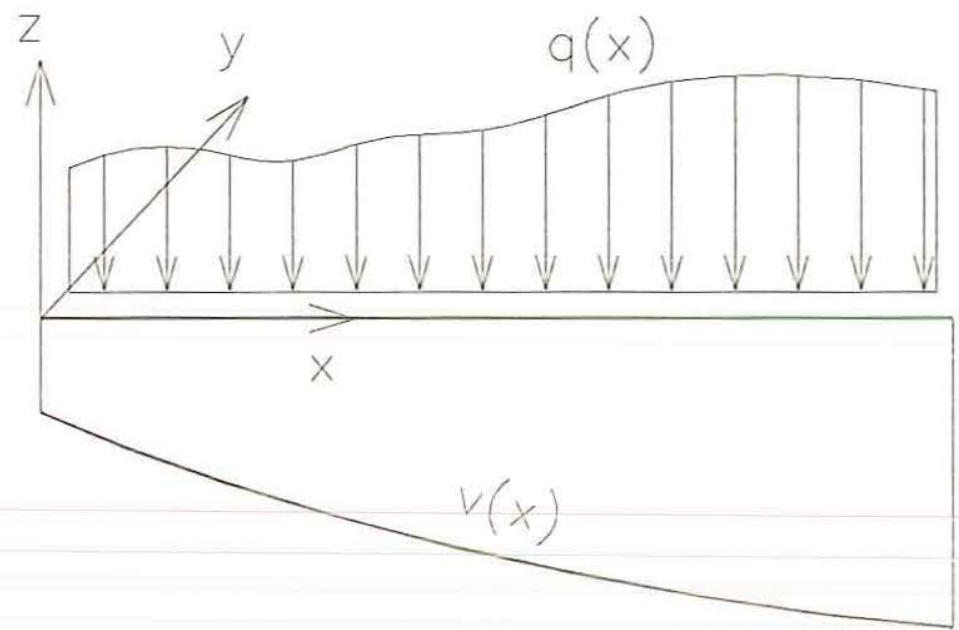

Figura 5.1 : Viga com carregamento qualquer

Dessa forma, a energia potencial externa será determinada por :

$$
w_{i}=-\int q(x) v(x) d x
$$

Que é a equação do trabalho com sinal trocado.

\subsection{1 - PRINCÍPIO DA MINIMA ENERGIA POTENCIAL}

O princípio da mínima energia potencial total consiste na aplicação do princípio dos trabalhos virtuais -PTV-afirmando que na posição de equilíbrio, ao invés dos trabalhos virtuais interno e externo serem iguais, o trabalho virtual total é nulo. Como em termos dimensionais trabalho e energia são iguais, pode-se dizer também que a variação de energia total dado pelo funcional (5.1) é nula no equilíbrio. Assim a expressão da variação de energia total para a posição de equilíbrio é escrita por : 


$$
\mathrm{d} \Pi=0 \quad \therefore \quad \frac{\mathrm{d} \Pi}{\mathrm{dv}_{\mathrm{i}}}=0
$$

onde $\mathbf{v}_{\mathbf{l}}$ expressa o deslocamento $\mathbf{i}$ do vetor de deslocamentos nodais. $A$ equação (5.4) será usada para a obtenção da matriz de rigidez e do vetor de carregamentos nodais.

\subsection{2-CASO NÄO-LINEAR}

Considere-se um material cujo comportamento seja näo-linear em termos das relações entre tensões e deformações. A partir das suas relaçőes constitutivas pode-se observar que, também para o caso não-linear; a energia interna do sistema, expressa pela integral (5.2), deve ser igual à energia potencial das ações externas. Desse modo, o funcional de energia pode ser reescrito pela seguinte expressão:

$$
\Pi=\left(U+U_{r}\right)+W
$$

onde $U_{r}$ é a parcela de energia correspondente à integral do produto das deformaçőes residuais pelas respectivas componentes de tensăo.

\section{2-ELEMENTO FINITO DE BARRA}

Considere-se um elemento de barra conforme ilustrado na figura (5.2), tendo, em cada um de seus nós, aos seguintes graus de liberdade: uma translação segundo o eixo oy , uma rotação paralela ao eixo ox e outra rotação paralela à oy. A expressão da energia de deformação passa a ser escrita somente em função das variáveis que são de interesse, admitindo-se as hipóteses da seção permanecer plana após a deformação e da proporcionalidade entre tensöes e deformaçöes. Dessa forma : 


$$
U=\frac{1}{2} \int_{\text {estr }}\left(\frac{M^{2}}{E I}+\frac{T^{2}}{G J_{t}}\right) d x
$$

Da teoria técnica da flexão, obtém-se:

$$
\begin{aligned}
& M=-E I \frac{d^{2} v}{d x^{2}} \rightarrow \rightarrow \frac{d^{2} v}{d x^{2}}=v^{\prime \prime} \\
& T=G J_{1} \frac{\partial \theta_{x}}{\partial x} \rightarrow \rightarrow \frac{\partial \theta_{x}}{\partial x}=\alpha
\end{aligned}
$$

A equação (5.9) pode ser decomposta, considerando-se os efeitos da flexão e da torção de modo independente, e reescrita na forma abaixo (supondo a seção transversal constante ao longo de um elemento) :

$$
\mathrm{U}=\mathrm{U}_{\mathrm{m}}+\mathrm{U}_{\mathrm{i}}
$$

onde :

$$
U_{m}=\frac{E I}{2} \int v_{\text {esi }} v^{\prime \prime 2} d x
$$

e

$$
\mathrm{U}_{\mathrm{T}}=\frac{\mathrm{GJ}_{\mathrm{t}}}{2} \int_{\text {est }} \alpha^{2} \mathrm{dx}
$$




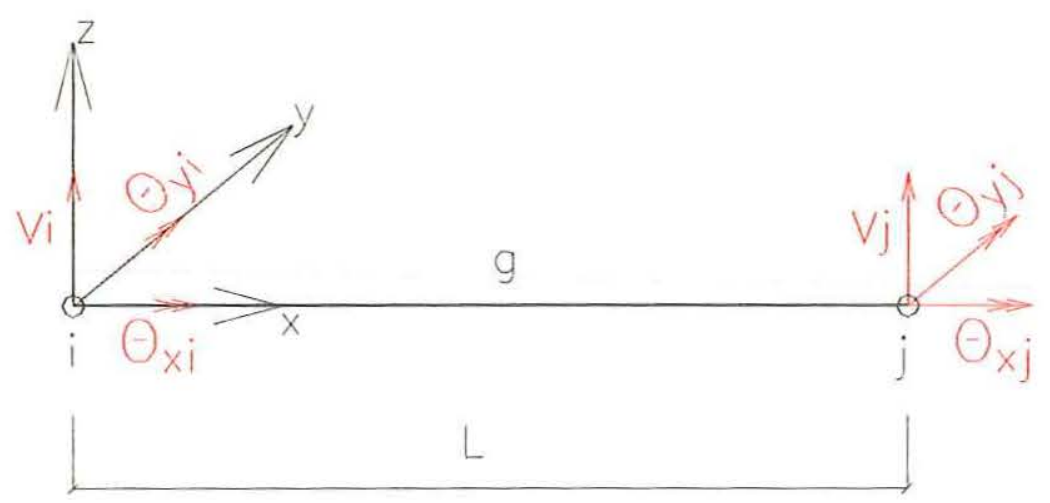

Figura 5.2 : Elemento de barra

\section{2,1-MATRIZ DE RIGIDEZ : PARCELA DA FLEXÃO}

Os deslocamentos verticais ao longo do elemento são aproximados por uma função polinomial de terceiro grau - expressão (5.12). Os valores do polinômio são conhecidos para os pontos extremos do elemento (onde $x=0 \mathrm{e}$ $x=L)$. A partir desses valores são determinados os coeficientes do polinômio.

$$
\begin{aligned}
& v=a_{1}+a_{2} x+a_{3} x^{2}+a_{4} x^{3} \\
& \theta_{y}=-\frac{d v}{d x}=-a_{2}-2 a_{3} x-3 a_{4} x^{2}
\end{aligned}
$$

Da imposição das condições de contorno, obtém-se:

$$
\left[\begin{array}{c}
v_{1} \\
\theta_{y 1} \\
v_{2} \\
\theta_{y 2}
\end{array}\right]=\left[\begin{array}{cccc}
1 & 0 & 0 & 0 \\
0 & -1 & 0 & 0 \\
1 & L & L^{2} & L^{3} \\
0 & -1 & -2 L & -3 L^{2}
\end{array}\right]\left[\begin{array}{l}
a_{1} \\
a_{2} \\
a_{3} \\
a_{4}
\end{array}\right]
$$

Simplificando a notação pode-se reescrever (5.14) e (5.12), respectivamente por: 


$$
\delta_{\mathrm{e}}=\mathrm{A} \alpha
$$

e :

$$
v=f(x)^{t} \alpha
$$

com (5.15) em (5.16) :

$$
v=f(x)^{t} A^{-1} \delta_{e}
$$

expressando a inversa da matriz $\mathbf{A}$, obtém-se :

$$
A^{-1}=\frac{1}{L^{4}}\left[\begin{array}{cccc}
\mathrm{L}^{4} & 0 & 0 & 0 \\
0 & -\mathrm{L}^{4} & 0 & 0 \\
-3 \mathrm{~L}^{2} & 2 \mathrm{~L}^{3} & 3 \mathrm{~L}^{2} & \mathrm{~L}^{3} \\
2 \mathrm{~L} & -\mathrm{L}^{2} & -2 \mathrm{~L} & -\mathrm{L}^{2}
\end{array}\right]
$$

A curvatura da seção em cada ponto ao longo do eixo do elemento pode ser obtida de maneira aproximada pelo inverso da derivada segunda do polinômio que expressa os desiocamentos. Assim :

$$
\frac{1}{i}=\beta^{t} \delta_{\mathrm{e}}
$$

onde, empregando-se as equaçōes já definidas :

$$
\beta=-\mathrm{f}^{\prime \prime} \mathrm{A}^{-1}
$$

que, efetuando as operações resulta em :

$$
\beta^{t}=\left[\begin{array}{llll}
-6 \frac{(L-2 x)}{L^{3}} & 2 \frac{(2 L-3 x)}{L^{2}} & 6 \frac{(L-2 x)}{L^{3}} & 2 \frac{(L-3 x)}{L^{2}}
\end{array}\right]
$$


Aplicando-se o princípio da mínima energia expresso na equação (5.4) obtém-se a matriz de rigidez para o elemento de barra, considerando apenas a parcela da flexão:

$$
\mathrm{K}_{\mathrm{f}}=\int_{0}^{\mathrm{L}} \beta \operatorname{EI} \beta^{\mathrm{t}} \mathrm{dx}
$$

\subsection{2 - MATRIZ DE RIGIDEZ - PARCELA DA TORÇÃO}

Para a obtenção da matriz de rigidez da parcela de energia devida à torção de um elemento de barra deve ser empregada uma função que aproxime a rotação em torno do eixo $\mathrm{OX}$. Esta função será adotada segundo uma aproximação linear conforme a equação abaixo :

$$
\theta_{x}=a_{1}+a_{2} x
$$

A partir de (5.23) e repetindo o mesmo processo empregado anteriormente para o caso da flexão, obtém-se a matriz de rigidez de um elemento de barra considerando de modo independente o efeito da torção.

A matriz de rigịdez para o elemento de barra mostrado na figura (5.3) é apresentada a seguir, já considerando a soma das parcelas relativas à torção e à flexão.

$$
\mathrm{K}=\left[\begin{array}{cccccc}
\frac{12 \mathrm{EI}}{\mathrm{L}^{3}} & 0 & \frac{-6 \mathrm{EI}}{\mathrm{L}^{2}} & \frac{-12 \mathrm{EI}}{\mathrm{L}^{3}} & 0 & \frac{-6 \mathrm{EI}}{\mathrm{L}^{2}} \\
0 & \frac{\mathrm{GJ}_{\mathrm{t}}}{\mathrm{L}} & 0 & 0 & \frac{-\mathrm{GJ}_{\mathrm{t}}}{\mathrm{L}} & 0 \\
\frac{-6 \mathrm{EI}}{\mathrm{L}^{2}} & 0 & \frac{4 \mathrm{EI}}{\mathrm{L}} & \frac{6 \mathrm{EI}}{\mathrm{L}^{2}} & 0 & \frac{2 \mathrm{EI}}{\mathrm{L}} \\
\frac{-12 \mathrm{EI}}{\mathrm{L}^{3}} & 0 & \frac{6 \mathrm{EI}}{\mathrm{L}^{2}} & \frac{12 \mathrm{EI}}{\mathrm{L}^{3}} & 0 & \frac{6 \mathrm{EI}}{\mathrm{L}^{2}} \\
0 & \frac{-\mathrm{GJ}_{\mathrm{t}}}{\mathrm{L}} & 0 & 0 & \frac{\mathrm{GJ}_{\mathrm{t}}}{\mathrm{L}} & 0 \\
\frac{-6 \mathrm{EI}}{\mathrm{L}^{2}} & 0 & \frac{2 \mathrm{EI}}{\mathrm{L}} & \frac{6 \mathrm{EI}}{\mathrm{L}^{2}} & 0 & \frac{4 \mathrm{EI}}{\mathrm{L}}
\end{array}\right]
$$


O vetor de cargas nodais equivalentes é obtido a partir da imposição da condição de mínima energia. Apresenta-se a seguir esse vetor relativo aos graus de liberdade mostrados na figura (5.2), considerando-se uma ação vertical e um momento torçor ambos uniformemente distribuídos ao longo da extensão do elemento.

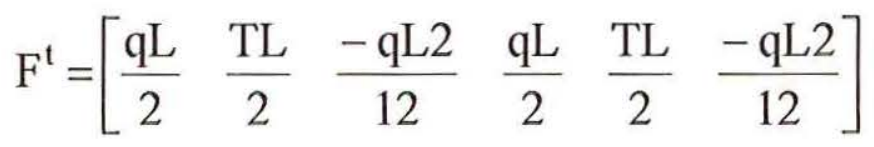

\section{3-CÁLCULO DOS RESÍDUOS DE CARREGAMENTO NO ELEMENTO}

Considere-se um elemento de barra onde existe um resíduo de momentos ao longo da sua extensão e deseja-se reaplicá-lo à estrutura em forma de esforço externo. A transformação desses resíduos em esforço externo é obtida através do emprego do Princípio dos Trabalhos Virtuais PTV. Conforme já foi citado, sabe-se que as curvaturas da seção podem ser relacionadas aos desiocamentos através da matriz $\beta$. Assim :

$$
\frac{1}{r}=\beta^{t} \varphi
$$

onde $\varphi$ são os deslocamentos virtuais.

Pode ainda ser a relação entre uma variação no campo de curvaturas e deslocamentos virtuais por :

$$
\delta \frac{1}{r}=\beta^{\prime} \delta \varphi
$$

Para um elemento de barra de comprimento L o PTV impöe que o trabalho virtual do carregamento externo $\psi_{\mathrm{e}}$ pelo deslocamento virtual

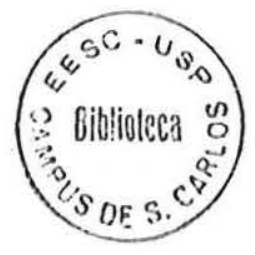


relativo $\delta \varphi$ é a igual ao trabalho virtual dos resíduos de momento pela deformação virtual $\delta \frac{1}{\mathrm{r}}$ :

$$
\Psi_{\mathrm{e}}^{\mathrm{T}} \delta \varphi=\int_{\mathrm{L}} \Delta \mathrm{M}_{0}^{\mathrm{T}} \delta \frac{1}{\mathrm{r}} \mathrm{dL}
$$

e:

$$
\Psi_{\mathrm{e}}^{\mathrm{T}} \delta \varphi=\int_{\mathrm{L}} \beta \Delta \mathrm{M}_{0}^{\mathrm{T}} \delta \varphi \mathrm{dL}
$$

Dividindo-se as equaçöes (5.28) e (5.29) por $\delta \varphi$, obtém-se o vetor de esforços residuais para o elemento e. Assim :

$$
\Psi_{\mathrm{e}}^{\mathrm{T}}=\int_{\mathrm{L}} \Delta \mathbf{M}_{0}^{\mathrm{T}} \beta \mathbf{d L}
$$

onde a matriz $\beta$ é aquela definida em (5.21) e $\Delta M_{0}$ é uma função apropriada que deve descrever a variação dos resíduos de momento ao longo do elemento finito.

\section{4-SOLUÇÃO NUMÉRICA}

\subsection{1-INTRODUÇÃO}

O emprego do método dos elementos finitos na análise linear de estruturas resulta num sistema de equações na seguinte forma :

$$
\mathrm{Ku}-\mathrm{F}=0
$$

onde u é o vetor dos deslocamentos nodais (que são os termos desconhecidos do sistema), F é o vetor dos carregamentos aplicados segundo um sistema de coordenadas globais previamente definido e $\mathrm{K}$ é a matriz de rigidez da estrutura. 


\section{Capítulo 5 : ANÁLISE LINEAR E NÄO-LINEAR DE ESTRUTURAS}

Quando a não linearidade física for considerada, os esforços internos e externos não mais estarão em equilíbrio e a matriz de rigidez da estrutura é função dos estado de deformações. A equação (5.31) passa a ser escrita por :

$$
\mathrm{K}(\mathrm{u}) \mathrm{u}-\mathrm{F}=\Psi
$$

Os métodos de resolução de sistemas näo-lineares podem ser classificados em iterativos, incrementais ou mistos. Segundo BATHE e CIMENTO (1980) uma análise nåo-linear pelo método dos elementos finitos é feita usando uma formulaçäo incremental, na qual as variáveis são atualizadas incrementalmente, correspondendo a passos de carga sucessivos. Nesse tipo de solução, é importante que as equaçöes de equilibrio sejam satisfeitas a cada passo, de forma a se assegurar precisão na resposta. Portanto deve-se usar um grande número de incrementos, o que se torna o inconveniente de tais métodos. Além disso, o equilíbrio não é rigorosamente garantido em cada passo de resolução para um incremento gerando, portanto, um erro em cada passo, e este erro é cumulativo.

Já os métodos iterativos garantem o equilíbrio na convergência, no entanto exigem um grande trabalho computacional. Os métodos mistos utilizam as vantagens dos dois métodos anteriores e seu emprego é o mais indicado. OWEN \& HINTON (1980) trazem uma completa discussäo sobre esses métodos; apresentam-se a seguir os conceitos básicos dos procedimentos incremental e iterativo, respectivamente.

\section{5,4,2-Formulação incremental}

A formulação incremental consiste em dividir o carregamento total, $F$, em incrementos de carga, $\Delta \mathbf{f}$, de modo que:

$$
\mathrm{F}=\sum_{\mathrm{i}=1}^{\mathrm{n}} \Delta \mathrm{f}_{\mathrm{i}} \quad \mathrm{c} / \quad \Delta \mathrm{f}_{\mathrm{i}}=\alpha_{\mathrm{i}} \mathrm{F}
$$


Para cada incremento calcula-se a parcela de deslocamentos correspondentes:

$$
\Delta \mathrm{u}_{\mathrm{i}}=\left[\mathrm{K}_{\mathrm{t}}\left(\mathrm{u}_{\mathrm{i}}\right)\right]^{-1} \Delta \mathrm{f}_{\mathrm{i}}
$$

O deslocamento total será:

$$
\mathrm{u}=\sum_{\mathrm{i}=1}^{\mathrm{n}} \Delta \mathrm{u}_{\mathrm{i}}
$$

com $\mathbf{n}$ sendo o número de incrementos definidos, $K_{t}\left(u_{i}\right)$ é o gradiente local da relação esforço/deslocamento para o incremento $\mathbf{i}$ e $\alpha$ um coeficiente menor que a unidade.

\section{5,4,3-Formulação iterativa : método de Newton-Raphson}

Esta formulação consiste em resolver uma equação não-linear de modo iterativo, de forma que a cada passo da iteração existe um vetor de carregamentos residuais que é resolvido pelo passo seguinte; assim sucessivamente, até que os resíduos sejam suficientemente pequenos. $\mathrm{O}$ vetor de esforços residuais para cada iteração será determinado de acordo com a equação abaixo :

$$
\Psi=\mathrm{Ku}-\mathrm{F} \neq 0
$$

ou:

$$
\Psi=\mathrm{F}-\mathrm{F}^{\text {int eno }}
$$

Com os esforços residuais $\Psi$ determina-se um acréscimo ao vetor de deslocamentos nodais da seguinte forma :

$$
\Delta \mathrm{u}_{\mathrm{i}}=\left[\mathrm{K}_{\mathrm{t}}\left(\mathrm{u}_{\mathrm{i}}\right)\right]^{-1} \Psi
$$


O vetor de deslocamentos da estrutura para a iteração 'i' será dado por :

$$
\mathrm{u}_{\mathrm{i}}=\mathrm{u}_{\mathrm{i}-1}+\Delta \mathrm{u}_{\mathrm{i}}
$$

A fórmula de recorrência para a solução de um resíduo $\Psi$ é a seguinte:

$$
\Psi_{\mathrm{i}}=\mathrm{K}_{1}^{\mathrm{i}} \Delta \mathrm{u}_{\mathrm{i}}
$$

onde $K_{t}{ }^{\prime}$ é a matriz de rigidez tangente correspondente aos deslocamentos $u_{1}$ e é dada pelo gradiente local tensão-deformação.

O procedimento de resolução prossegue até que ocorra a convergência dentro de certas tolerâncias pré estabelecidas, para isso deverão ser atendidas simultaneamente as inequações expressas por :

$$
\frac{\|\Psi\|}{\|F\|} \leq \varepsilon_{\mathrm{f}}, \mathrm{e}: \frac{\left\|\Delta \mathrm{u}_{\mathrm{i}}\right\|}{\left\|\mathrm{u}_{\mathrm{i}}\right\|} \leq \varepsilon_{\mathrm{i}}
$$

A figura (5.3) tem como objetivo ilustrar os procedimentos de resolução de sistemas de equações não lineares citados neste trabalho. 
Capítulo 5 : ANÁLISE LINEAR E NÃO-LINEAR DE ESTRUTURAS
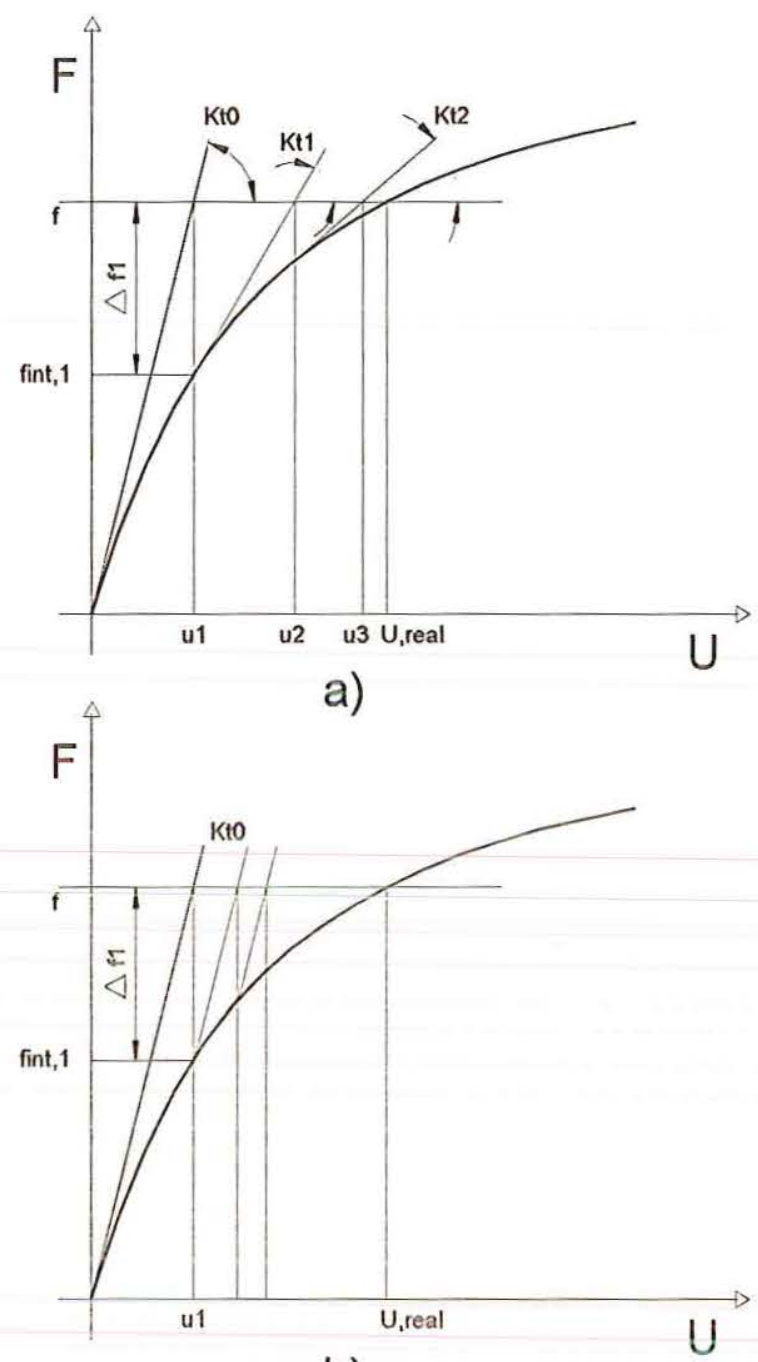

b)

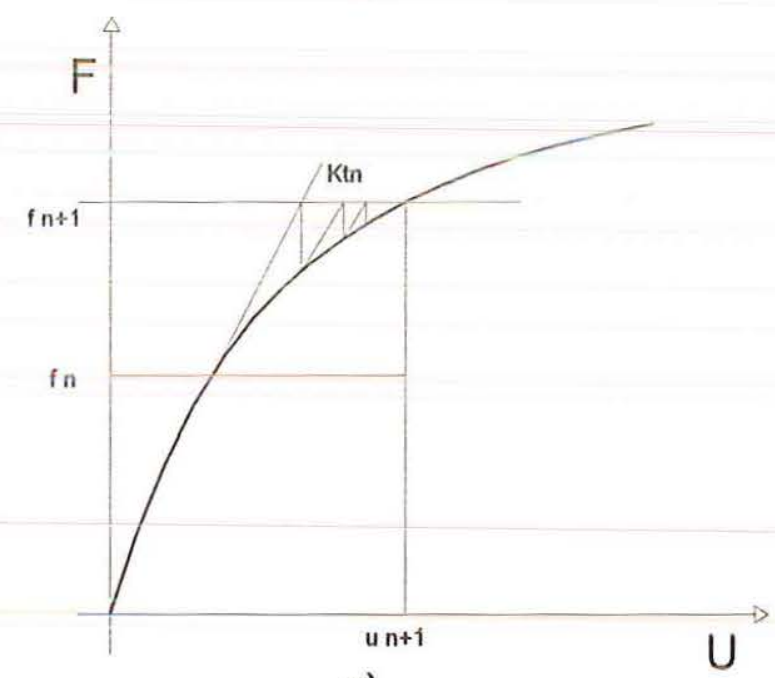

c)

Figura 5.3 - Métodos de Newton-Raphson: a) Método de Newton-Raphson puro; b) Método da Rigidez Inicial ; c) Método de Newton-Raphson Modificado ou Misto. 


\section{6-IMPLEMENTAÇÃO NUMÉRICA DE ALGORITMO PARA ANÁLISE NÃO-LINEAR DE GRELHAS}

\section{1-INTRODUÇÃO}

Neste capítulo pretende-se mostrar o desenvolvimento de um algoritmo numérico para a determinação de esforços solicitantes e deslocamentos em pavimentos de edifícios onde o sub-sistema estrutural "grelha" é empregado. As seções transversais das barras de concreto armado obedecem um critério não-linear escrito em termos da relação entre momentos e curvaturas. Foram implementados os modelos de GHALI \& FAVRE (1986) e DEBERNARDI (1983) para o concreto armado. O Método dos Elementos Finitos é empregado na discretização da estrutura.

O programa fol desenvolvido de forma a permitir simuitaneamente basicamente três tipos de análise, a saber:

- Análise de esforços e deslocamentos na estrutura considerando a nãolineridade física para o instante de aplicação do carregamento;

- Consideração da fluência do concreto e das alterações nos esforços solicitantes e deslocamentos que ocorrerão ao longo do tempo;

- Simulação de fases de carregamento, onde cada ação é considerada aplicada num instante de tempo conhecido.

Cada um desses fenômenos será tratado nesse capítulo de maneira isolada, por simplicidade. Para o cálculo das propriedades mecânicas do concreto - tais como módulo de elasticidade, resistência à compressão, resistência à tração etc..., além das deformações dependentes do tempo e 
do momento de fissuração da seção, 'e foram empregadas as recomendações do CEB-1990. Serão apresentados fluxogramas simplificados do programa no decorrer deste capítulo.

O programa permite que se trabalhe com barras de seção transversal em forma de "I " com apenas um eixo de simetria e armaduras superior e inferior. Os dados de entrada são propriedades geométricas da seção e são ilustrados na figura (6.1).

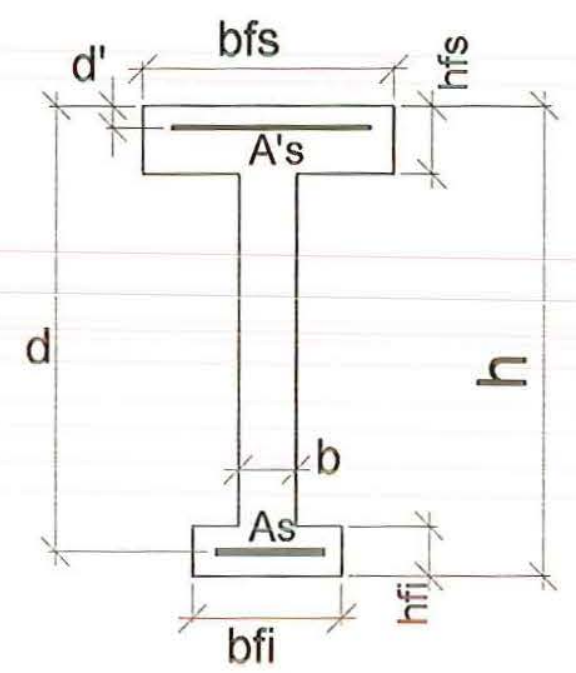

Figura 6.1 : Seção transversal típica.

\section{2-NÃO-LINEARIDADE FISICA - INSTANTE DE APLICAÇÃO} DO CARREGAMENTO

A consideração da não-linearidade física na análise de estruturas de concreto armado requer uma estratégia incremental-iterativa para sua resolução. Esse assunto foi tratado no item 5.4 deste texto sendo que no item 5.3 foi desenvolvido uma expressão, a partir da aplicação do PTV, para o cálculo do vetor de esforços residuais num elemento de barra. Pretendese agora mostrar o procedimento utilizado nos algoritmos para a determinaçäo dos resíduos, a partir da resoluçäo da expressäo (5.30) aqui repetida por comodidade. 


$$
\Psi_{\mathrm{e}}^{\mathrm{T}}=\int_{\mathrm{L}} \Delta \mathrm{M}(\mathrm{x}) \beta \mathrm{dL}
$$

Considere-se um elemento de barras conforme mostrado na figura (6.2). São conhecidos nos seus nós os valores de duas rotações segundo os eixos específicos - ox e oy - e um deslocamento vertical segundo o eixo oz. É possível conhecer, de maneira aproximada, a curvatura em cada ponto do elemento empregando-se a expressão (6.2). Assim :

$$
\frac{1}{\mathrm{r}}=\beta^{\mathrm{t}} \delta_{\mathrm{e}}
$$

onde :

$$
\beta^{t}=\left[\begin{array}{llll}
-6 \frac{(L-2 x)}{L^{3}} & 2 \frac{(2 L-3 x)}{L^{2}} & 6 \frac{(L-2 x)}{L^{3}} & 2 \frac{(L-3 x)}{L^{2}}
\end{array}\right]
$$

e :

$$
\delta_{\mathrm{e}}^{\mathrm{t}}=\left[\begin{array}{llll}
\mathrm{v}_{\mathrm{i}} & \theta_{\mathrm{xi}} & \mathrm{v}_{\mathrm{j}} & \theta_{\mathrm{xj}}
\end{array}\right]
$$

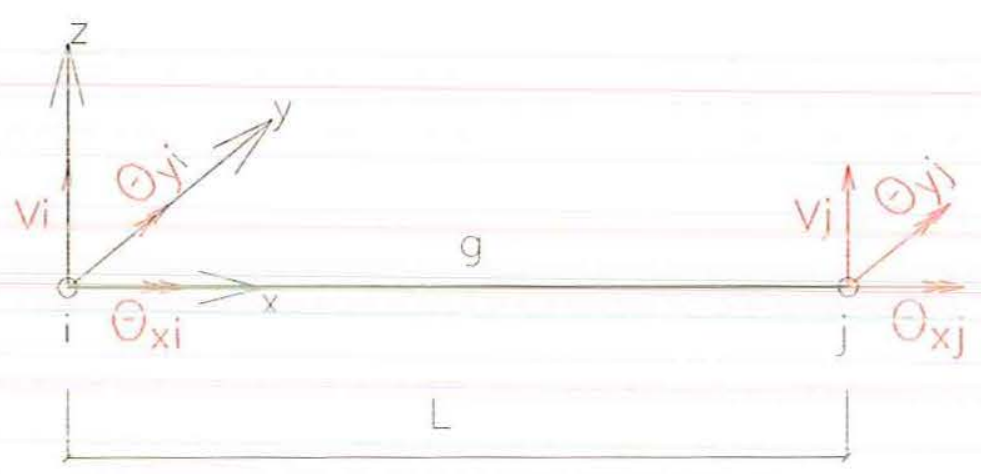

Figura 6.2 : Elemento de barra.

Como pode-se observar, a função (6.3) tem uma variação linear. Como a curvatura real varia parabolicamente ao longo do comprimento do elemento - isto para carregamentos uniformemente distribuídos - foi utilizada uma correção no valor da curvatura que é empregada somente na primeira iteraçäo de cada incremento de carga. Assim, para os nós $\mathbf{i}$ e $\mathbf{j}$ pode-se escrever a expressão (6.5). 


$$
{\frac{1}{\mathrm{r}_{\mathrm{K}, \mathrm{cor}}}}_{\mathrm{r}}=\frac{1}{\mathrm{r}}-\mathrm{cor}
$$

com:

$$
\text { cor }=\frac{\Delta \mathrm{pL}^{2}}{8 \mathrm{EI}_{\mathrm{m}}}
$$

onde $\Delta \mathrm{p}$ é o incremento de carregamento uniformemente distribuído e $\mathrm{EI}_{\mathrm{m}}$ é o módulo de deformação por flexão médio que será definido neste capítulo.

Como o problema é näo-linear e emprega-se uma estratégia incremental-iterativa, é necessário utilizar a expressão (6.2) para calcular, na verdade, incrementos de curvatura para uma seção em função dos acréscimos nos deslocamentos da estrutura que ocorrerão a cada iteração. Assim, para cada nó do elemento:

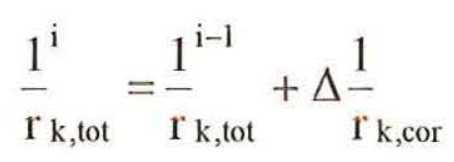

onde o índice sobrescrito $\mathrm{i}$ indica a iteração e o termo $\Delta \frac{1}{\mathrm{r}_{\mathrm{k}, \text { cor }}}$ é determinado empregando-se as expressőes (6.2) a (6.6) substituindo-se, evidentemente, os desiocamentos totais por incrementos de deslocamento. A figura (6.3) tem por objetivo esclarecer essas considerações.

Uma vez conhecido o valor da curvatura total nos nós de um elemento a partir dos seus deslocamentos nodais, determina-se, através do emprego dos modelos de DEBERNARDI ou de GHALI \& FAVRE, para o instante de aplicação do carregamento (tratado no capítulo 4), o momento correspondente à essa curvatura. $\mathrm{O}$ resíduo de momento, $\Delta \mathbb{M}_{\mathbf{k}}$, é determinado para cada nó do elemento de acordo com a expressão (6.8) onde o índice da iteração é suprimido por comodidade. Assim :

$$
\Delta \mathrm{M}_{\mathrm{k}}=\mathrm{M}_{\mathrm{k}}-\mathrm{M}_{\mathrm{r}, \mathrm{k}}
$$


onde $\mathrm{M}_{\mathrm{r}, \mathrm{k}}$ é função da seção transversal, dos seus materiais e da curvatura total. A figura (6.4) tem por objetivo mostrar a avaliação dos resíduos de momento numa seção.

Como a relação entre momento e curvatura é não-linear torna-se necessário o emprego do método da bisecção para a determinação do momento correspondente à curvatura total acumulada, uma vez que os modelos fornecem a curvatura a partir de um momento fletor conhecido.
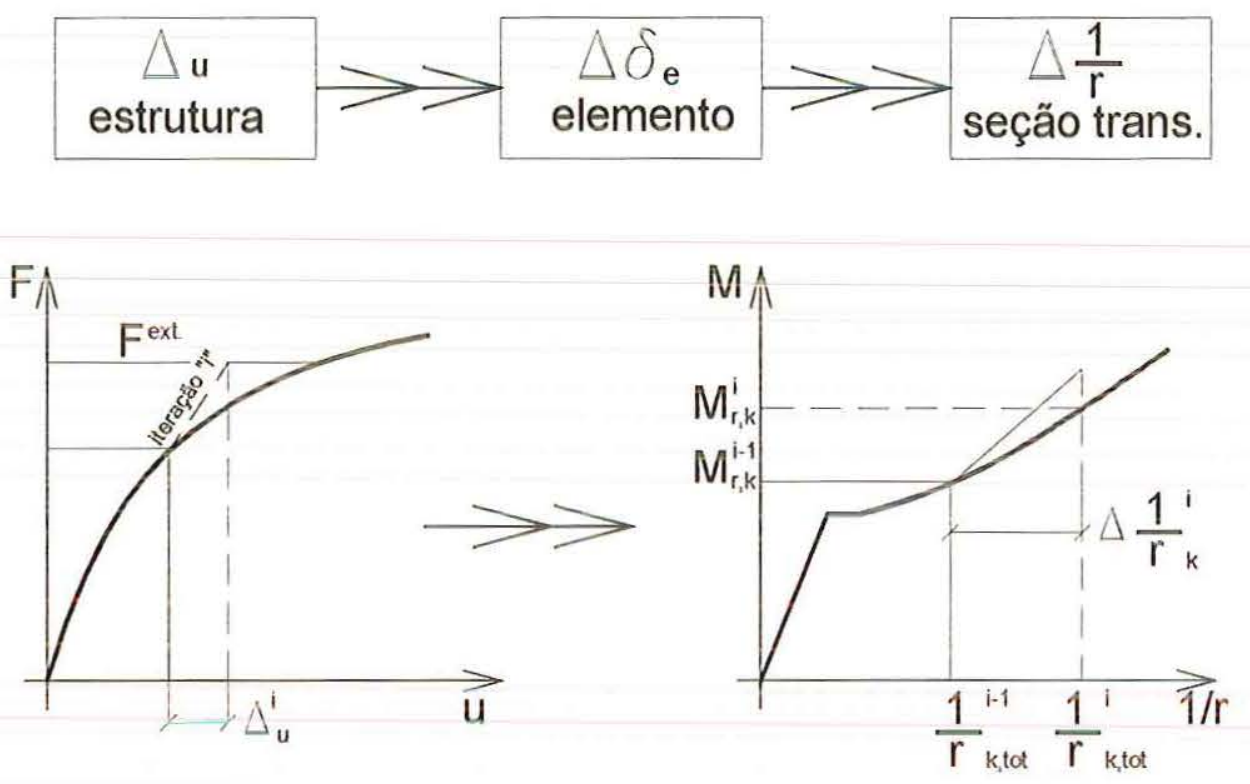

Figura 6.3: llustração do cálculo das curvaturas.

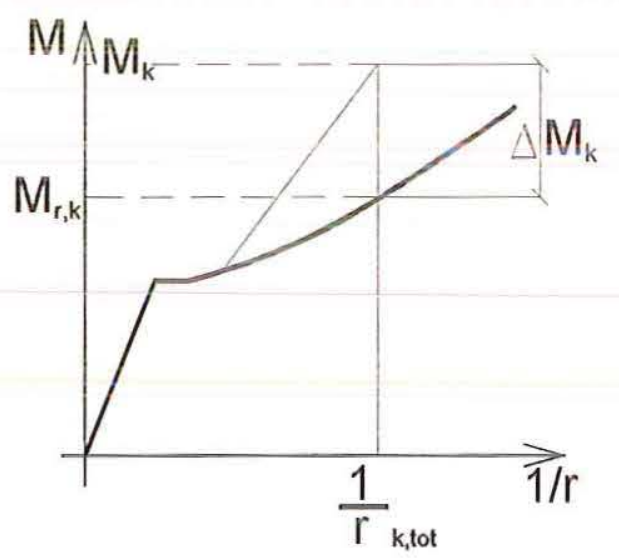

Figura 6.4: Resíduos de momento para uma seção. 
Conhecidos os resíduos de momento fletor em cada nó pode-se escrever a função $\Delta M(x)$ tendo em vista seu emprego na expressão (6.1). Emprega-se uma aproximação linear para cada resíduo; assim:

$$
\begin{aligned}
& \Delta M(x)_{i}=\Delta M_{i}-\frac{\Delta M_{i}}{L} x \\
& \Delta M(x)_{j}=\Delta M_{j}-\frac{\Delta M_{j}}{L}(L-x)
\end{aligned}
$$

Efetuando-se a integração da expressão (6.1) com o uso de (6.9) e (6.10) obtêm-se os vetores de carregamentos residuais $\psi_{\mathrm{e}}$, considerando de maneira isolada a contribuição de cada nó do elemento. Assim resulta:

$$
\Psi_{\mathrm{e}, \mathrm{i}}=\left[\begin{array}{c}
-\frac{\Delta \mathrm{M}_{\mathrm{i}}}{\mathrm{L}} \\
0 \\
\frac{\Delta \mathrm{M}_{\mathrm{i}}}{\Delta \mathrm{M}_{\mathrm{i}}} \\
\mathrm{L} \\
0
\end{array}\right]
$$$$
\Psi_{\mathrm{e}, \mathrm{j}}=\left[\begin{array}{c}
-\frac{\Delta \mathrm{M}_{\mathrm{j}}}{\mathrm{L}} \\
0 \\
0 \\
\frac{\Delta \mathrm{M}_{\mathrm{j}}}{\mathrm{L}} \\
0 \\
\Delta \mathrm{M}_{\mathrm{j}}
\end{array}\right]
$$

O vetor de resíduos totais para um elemento será a soma das parcelas (6.11) e (6.12). Os esforços residuais da estrutura serão obtidos a partir da consideração da contribuição de cada elemento.

A matriz de rigidez do elemento, para cada iteração, é determinada pela expressão (5.24) a partir do módulo de deformação por flexão "secante", relativo à rigidez média do elemento, calculado pela expressão (6.13) que é ilustrada pela figura (6.5). Assim :

$$
\mathrm{EI}_{\mathrm{m}}=\mathrm{M}_{\mathrm{r}, \mathrm{k}} / \frac{1}{\mathrm{r}_{\mathrm{k}, \text { tot }}}
$$

e: 


$$
\mathrm{K}_{\mathrm{e}}=\left[\begin{array}{cccccc}
\frac{12 \mathrm{EI}_{\mathrm{m}}}{\mathrm{L}^{3}} & 0 & \frac{-6 \mathrm{EI}_{\mathrm{m}}}{\mathrm{L}^{2}} & \frac{-12 \mathrm{EI}_{\mathrm{m}}}{\mathrm{L}^{3}} & 0 & \frac{-6 \mathrm{EI}_{\mathrm{m}}}{\mathrm{L}^{2}} \\
0 & \frac{\mathrm{GJ}_{\mathrm{t}}}{\mathrm{L}} & 0 & 0 & \frac{-\mathrm{GJ}_{\mathrm{t}}}{\mathrm{L}} & 0 \\
\frac{-6 \mathrm{EI}_{\mathrm{m}}}{\mathrm{L}^{2}} & 0 & \frac{4 \mathrm{EI}_{\mathrm{m}}}{\mathrm{L}} & \frac{6 \mathrm{EI}_{\mathrm{m}}}{\mathrm{L}^{2}} & 0 & \frac{2 \mathrm{EI} \mathrm{I}_{\mathrm{m}}}{\mathrm{L}} \\
\frac{-12 \mathrm{EI}_{\mathrm{m}}}{\mathrm{L}^{3}} & 0 & \frac{6 \mathrm{EI}_{\mathrm{m}}}{\mathrm{L}^{2}} & \frac{12 \mathrm{EI}_{\mathrm{m}}}{\mathrm{L}^{3}} & 0 & \frac{6 \mathrm{EI}_{\mathrm{m}}}{\mathrm{L}^{2}} \\
0 & \frac{-\mathrm{GJ}_{\mathrm{t}}}{\mathrm{L}} & 0 & 0 & \frac{\mathrm{GJ}_{\mathrm{t}}}{\mathrm{L}} & 0 \\
\frac{-6 \mathrm{EI}_{\mathrm{m}}}{\mathrm{L}^{2}} & 0 & \frac{2 \mathrm{EI}}{\mathrm{L}} & \frac{6 \mathrm{EI}_{\mathrm{m}}}{\mathrm{L}^{2}} & 0 & \frac{4 \mathrm{EI}}{\mathrm{L}}
\end{array}\right]
$$

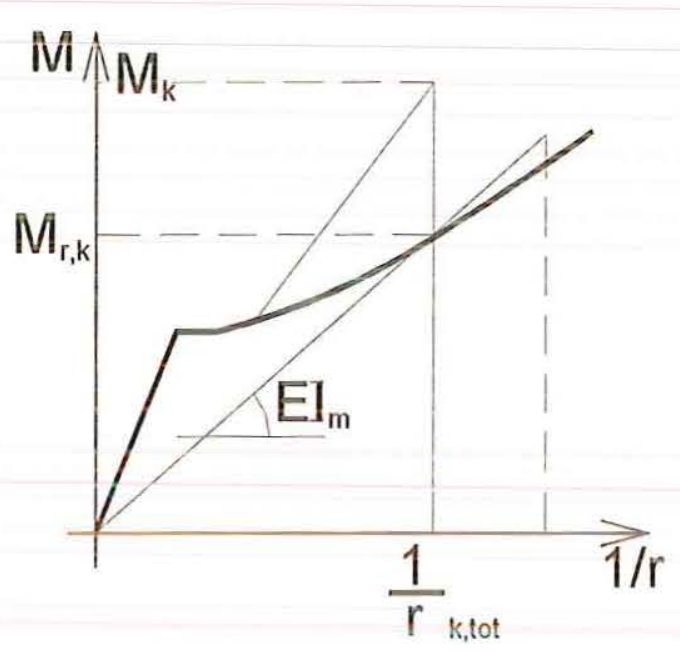

Figura 6.5: Determinação do modulo de deformação por ที่exão secante.

Com o emprego dos parâmetros definidos nesta seção procede-se a resolução da estrutura conforme mostrado no capítulo 5. Adotam-se dois critérios de convergência para o processo iterativo sendo um em termos de esforços e outro em termos de deslocamentos. Assim, empregando-se as expressões definidas em OWEN \& HINTON (1980), tem-se :

$$
\frac{\sqrt{\left[\sum_{i=1}^{n}\left(\psi_{i}^{r}\right)^{2}\right]}}{\sqrt{\left[\sum_{i=1}^{n}\left(f_{i}\right)^{2}\right]}} \times 100 \leq \text { TOL }
$$


onde o numerador indica a norma da soma dos esforços residuais, e o denominador a norma do total de forças aplicadas; TOL é o valor préestabelecido da tolerância.

Em termos de deslocamentos, obtém-se:

$$
\frac{\sqrt{\left[\sum_{i=1}^{n}\left(\Delta u_{i}^{r}\right)^{2}\right]}}{\sqrt{\left[\sum_{i=1}^{n}\left(u_{i}\right)^{2}\right]}} \times 100 \leq \text { TOL }
$$

onde $\Delta \mathbf{u}_{\mathrm{i}}^{\mathbf{r}}$ é o valor do acréscimo de deslocamentos para a iteração $r$ e $\mathbf{u}_{\mathbf{i}}$ é o deslocamento total acumulado até a iteração i.

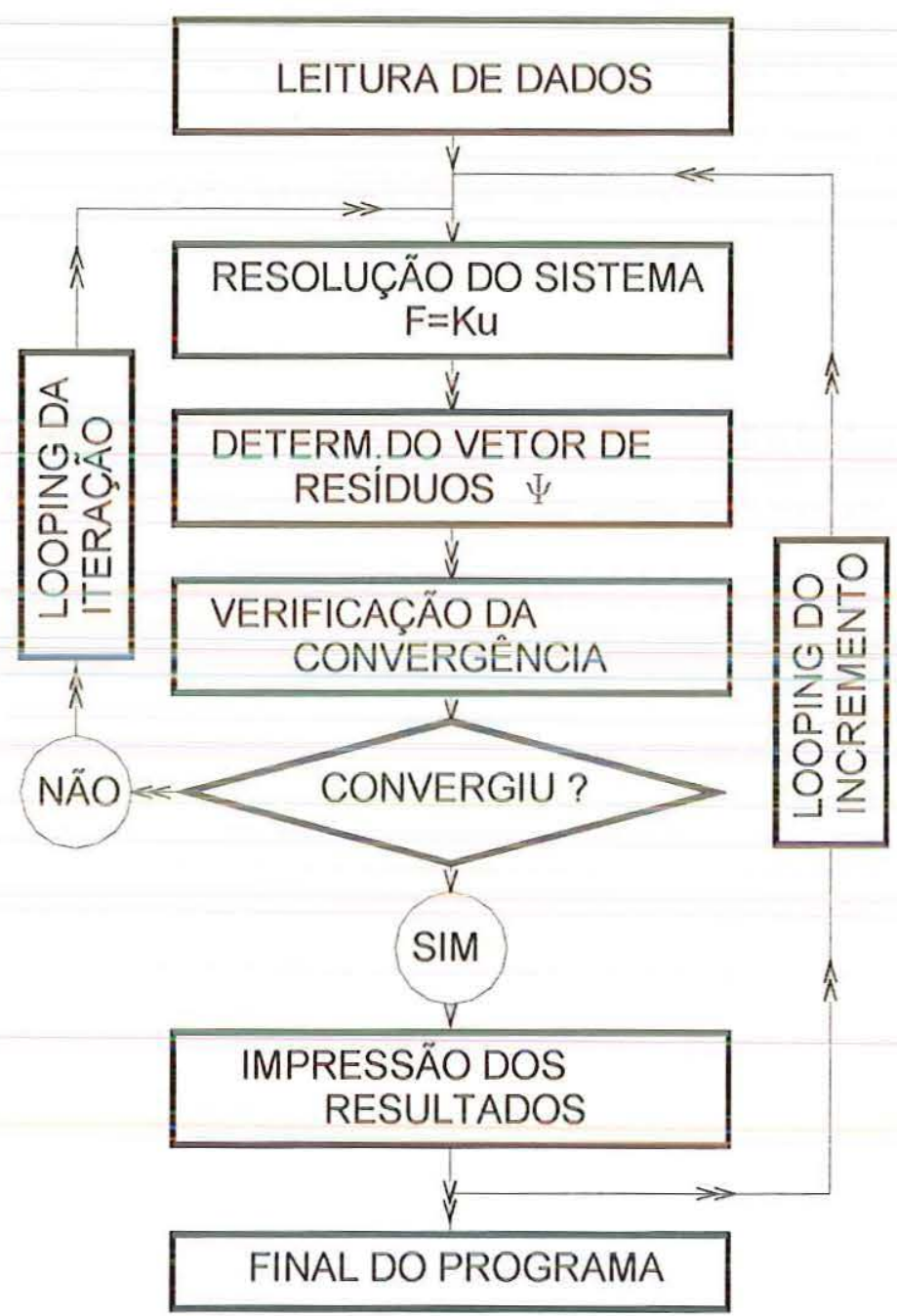

Figura 6.6: Apresentação de fluxograma de procedimento incrementaliterativo. 


\section{3-ESFORÇOS E DEFORMAÇÕES AO LONGO DO TEMPO}

A variação nos esforços solicitantes e deslocamentos que devem ocorrer na estrutura de um pavimento de edifício, entre os instantes de tempo " $t_{0}$ " e " $\mathrm{t}$ ", devido ao efeito da fluência säo considerados no programa desenvolvido através de uma estratégia incremental onde as deformaçöes visco-plásticas são reaplicadas à estrutura na forma de esforços residuais nos nós dos elementos que a constituem.

Pretende-se nesta seção mostrar, de maneira resumida, o desenvolvimento de um procedimento utilizado para a análise da fluência. Os modelos de GHALI \& FAVRE ou DEBERNADI fornecem um diagrama de curvatura $\mathrm{x}$ momento resistente para $\mathrm{o}$ instante de tempo " $\mathrm{t}$ ", além daquele para o instante "to", já tratado na seção anterior. A figura (6.8) ilustra esses dois diagramas num mesmo gráfico. Desse modo obtém-se para um momento fletor $\mathbf{M}$ as curvaturas em " $\mathbf{t}_{0}$ " e em " $\mathbf{t}$ ".

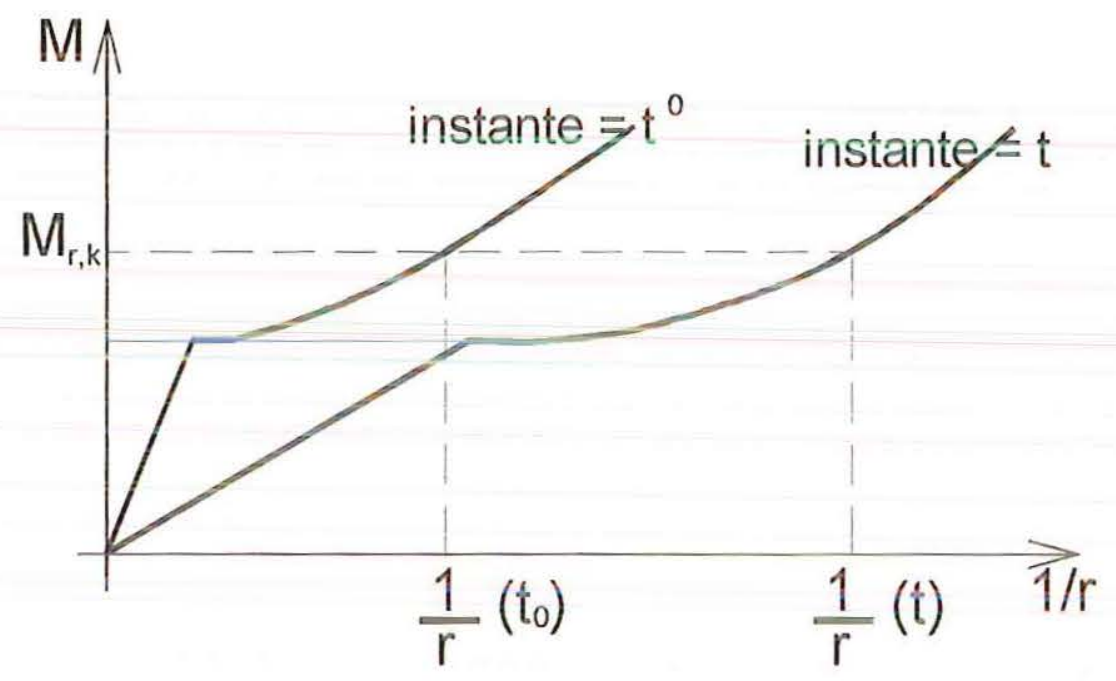

Figura 6.8 : Diagrama momento curvatura, com a consideração da f́luência.

Suponha-se uma estrutura que foi resolvida para o instante " $t_{0}$ " $e$ deseja-se a sua resolução também no instante " $t$ ". São definidos incrementos de tempo $\Delta t$ da seguinte forma: 


$$
\Delta \mathrm{t}=\frac{\left(\mathrm{t}-\mathrm{t}_{0}\right)}{\mathrm{n}}
$$

onde $\mathrm{n}$ é o número de sub-intervalos de tempo.

Para o instante de tempo " $\mathfrak{t}_{0}+\Delta \mathfrak{t}$ " determina-se, a partir dos modelos utilizados, a curvatura $\frac{1}{\mathrm{r}}\left(\mathrm{t}_{0}+\Delta \mathrm{t}\right)$, lembrando-se que $\frac{1}{\mathrm{r}}\left(\mathrm{t}_{0}\right)$ é conhecido. $\mathrm{O}$ vetor de resíduos a ser reaplicado na estrutura é determinado do mesmo modo que aquele mostrado na seção 6.2 , onde o valor de $\Delta M_{k}$ será dado por:

$$
\Delta \mathrm{M}_{\mathrm{k}}=\left(\frac{1}{\mathrm{r}}\left(\mathrm{t}_{0}+\Delta \mathrm{t}\right)-\frac{1}{\mathrm{r}}\left(\mathrm{t}_{0}\right)\right) \cdot E \mathrm{I}_{\mathrm{m}}
$$

A matriz de rigidez com a qual a estrutura deve ser resolvida é determinada de maneira análoga ao utilizado na seçäo (6.2). A curvatura real de uma seção no instante " $\mathbf{t}_{0}+\Delta \hat{t}$ " não é aquela determinada a partir das relaçöes constitutivas e deve ser calculada a partir dos deslocamentos nodais dos elementos obtidos após a resolução da estrutura, já que houve uma redistribuição nos esforços solicitantes. Para instantes de tempo diferentes de " $\mathfrak{t}_{0}+\Delta \boldsymbol{t}^{\prime}$ " procede-se da mesma maneira, sendo que a matriz de rigidez é atualizada a cada incremento.

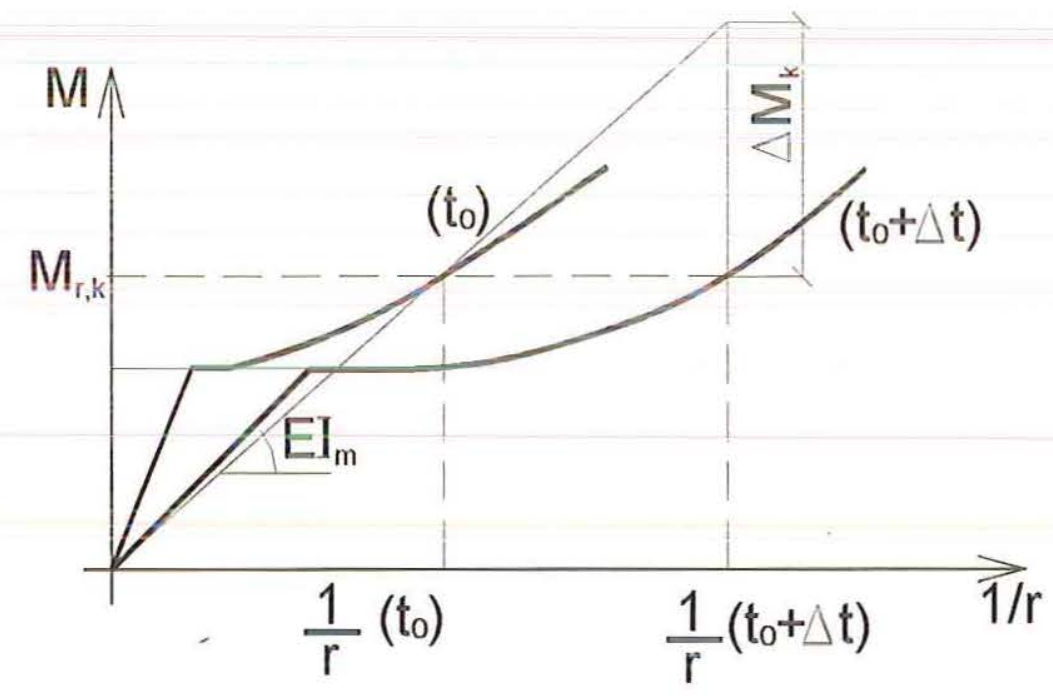

Figura 6.9: Resíduo de momento devido a fluência para o instante de tempo " $\mathrm{t}_{0}+\Delta \mathrm{t}$ ". 
É apresentado, a seguir, um fluxograma simplificado onde as deformaçőes ao longo do tempo são consideradas.

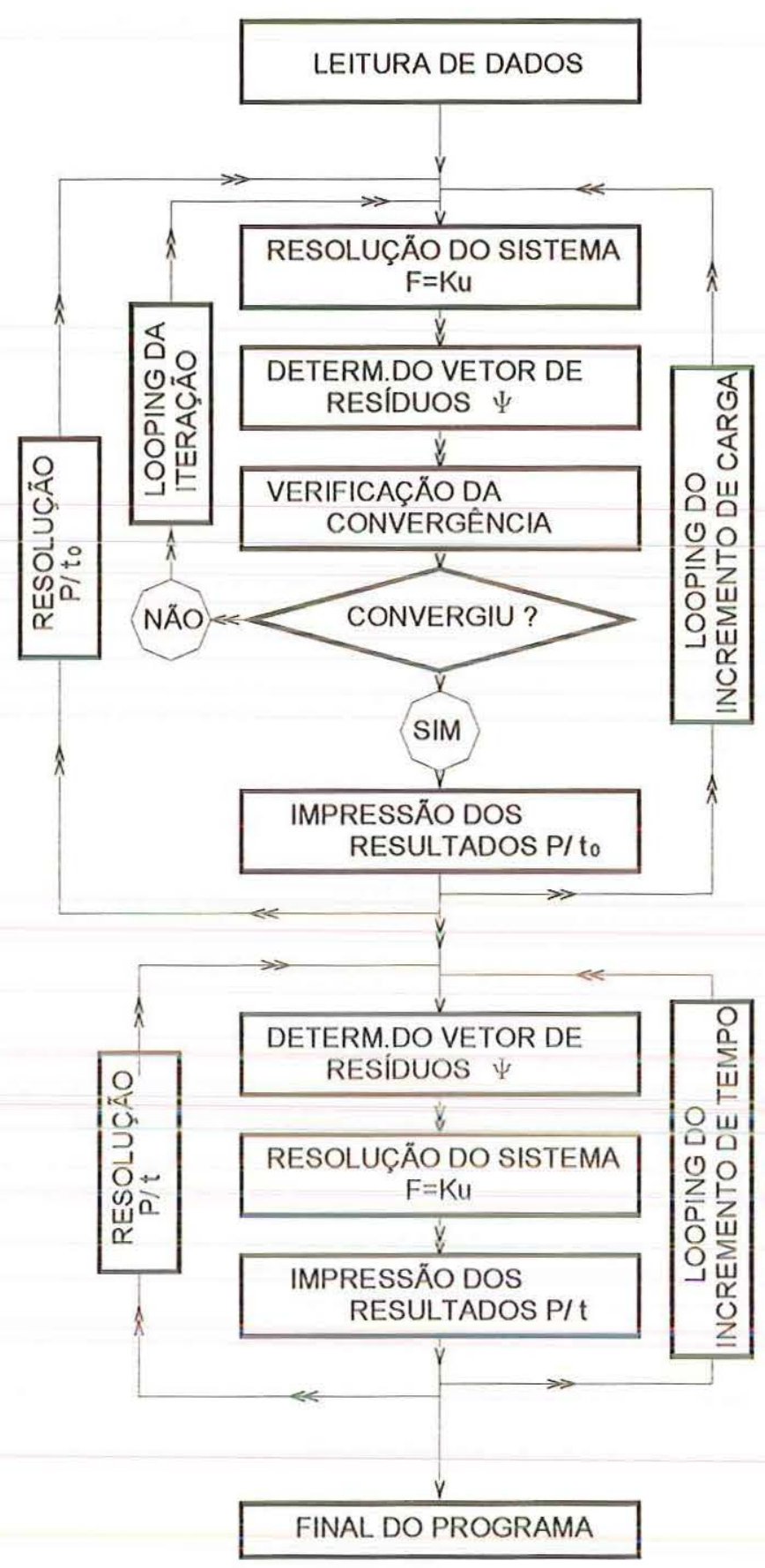

Figura 6.10: Fluxograma de procedimento incremental-iterativo para o instante de aplicação das cargas e incremental para a consideração das deformações ao longo do tempo. 


\section{4-APLICAÇÃO DE CARGAS NO INSTANTE DE TEMPO " $\imath$ ".}

O programa foi desenvolvido de modo a permitir a análise da aplicação de diversos carregamentos distintos, cada um num instante de tempo conhecido. São consideradas as perdas de rigidez que ocorreram antes da aplicação de um carregamento; provocadas por carregamentos anteriores a este. Deste modo, a matriz de rigidez da estrutura é aquela obtida a partir do módulo de deformação por flexão médio - já definido neste capítulo. A aplicação de um novo carregamento é ilustrada pela figura (6.11) relativa a uma seção transversal.

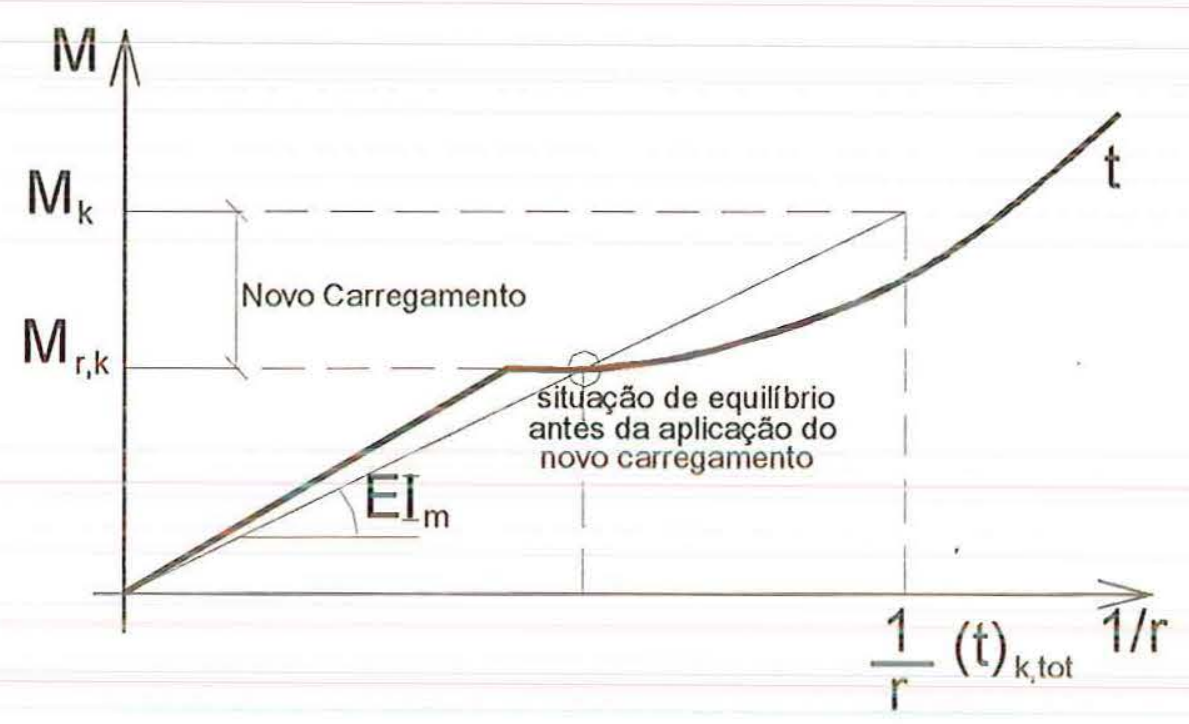

Figura 6.11 : Novo carregamento na estrutura.

O novo carregamento deve ser aplicado à estrutura em incrementos e, da mesma forma que na seção 6.2 , a nova configuração de equilíbrio será obtida através de uma estratégia incremental-iterativa utilizando o mesmo procedimento descrito naquela seção.

Os modelos de DEBERNARDI ou de GHALI \& FAVRE a serem empregados na resolução de um novo carregamento aplicado no instante de tempo " $t$ " devem considerar a fluência que ocorreu no intervalo de tempo $\left(\mathbf{t}_{0}, \mathbf{t}\right)$, visto que a estrutura sofreu alteraçöes no seu estado de deformações devidas à fluência nesse intervalo. 
O fluxograma apresentado na figura (6.10) é agora empregado para cada etapa de carregamento conforme ilustrado pela figura (6.12).

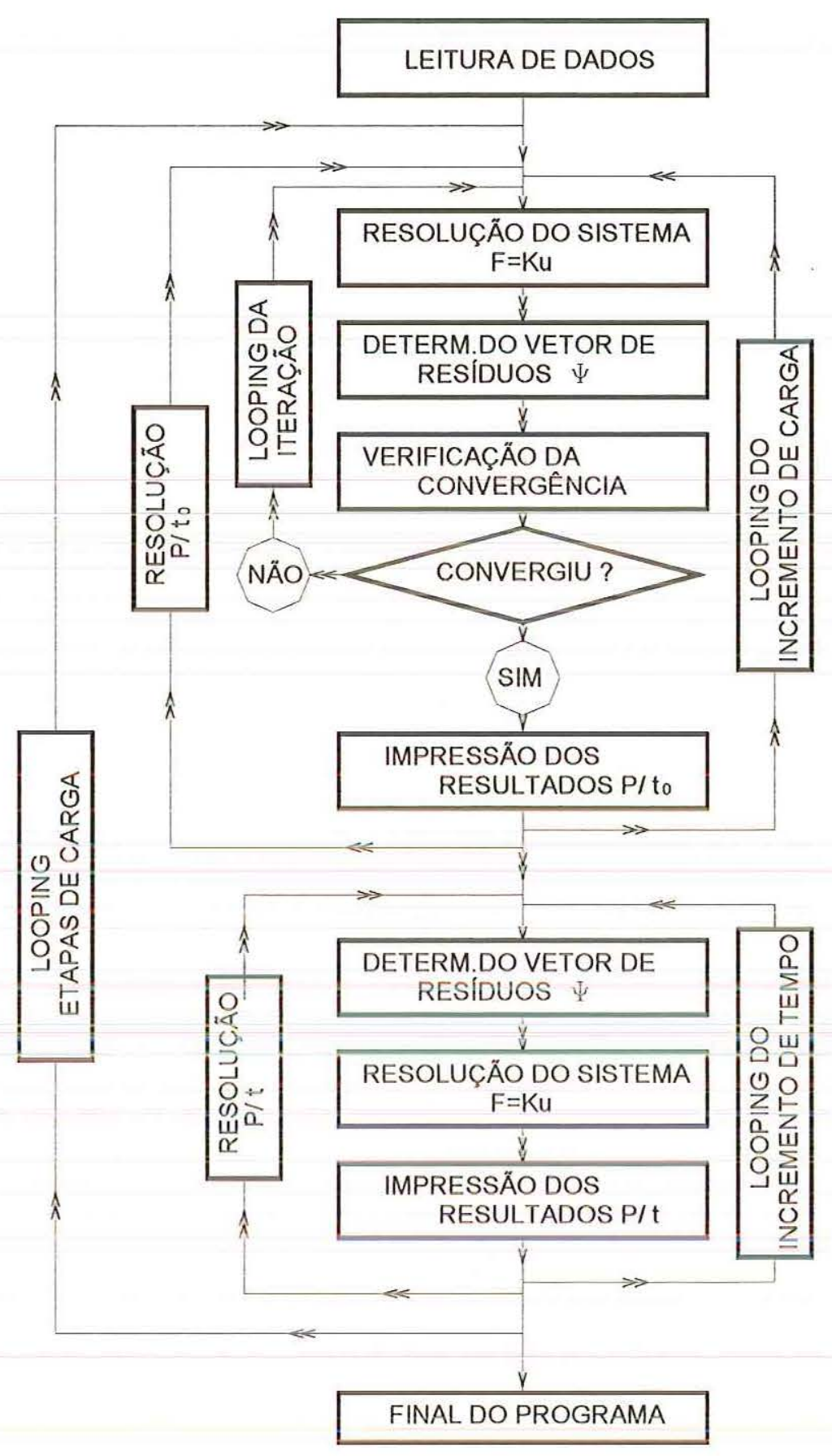

Figura 6.12: Fluxograma para análise considerando carregamentos em instantes de tempo distintos. 


\section{5-DESCARREGAMENTO}

O descarregamento foi considerado de maneira simplificada neste trabalho, desprezando a danificação da estrutura. A matriz de rigidez da estrutura, quando ocorrer o descarregamento, será determinada conforme a expressão (6.14) onde o módulo de deformação por flexão será igual ao produto do módulo elástico do concreto pela inércia calculada no estádio 1 tanto para o instante " $\mathbf{t}_{0}$ " quanto para o instante " $\mathbf{t}$ ". Assim:

$$
\mathrm{EI}_{\mathrm{m}}=\mathrm{EI}_{1}
$$

A figura (6.13) tem por objetivo ilustrar essa consideração.

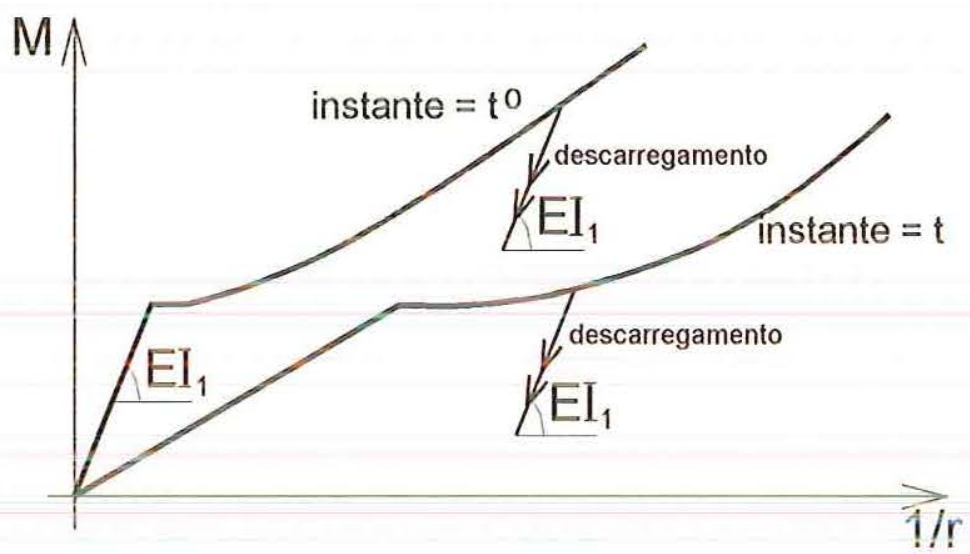

Figura 6.13: Descarregamento. 


\section{7-EXEMPLOS}

\section{1-INTRODUÇÃO}

Neste capítulo pretende-se mostrar alguns exemplos de aplicação do programa desenvolvido. Serão efetuadas comparações entre os modelos implementados visando destacar as vantagens e desvantagens de cada modelo. Procura-se também efetuar, em alguns exemplos, comparações com dados experimentais conhecidos na literatura. 
Capitulo7:EXEMPLOS

\section{2-EXEMPLOS DO BULLETIN-158 DO CEB}

\subsection{1-VIGA BI-ENGASTADA}

O "Bulletin" informativo $n^{\circ} 158$ do CEB (1990) apresenta os resultados em termos de esforços e deslocamentos para uma viga bi-engastada de concreto armado solicitada por uma ação vertical uniformemente distribuída conforme mostrado na figura (7.1). Foram consideradas as seguintes características para os materiais:

- concreto $\mathrm{f}_{\mathrm{ck}}=25 \mathrm{MPa}$;

- módulo de elasticidade longitudinal do aço igual a $200 \mathrm{Gpa}$;

- barras de aço rugosas.

O carregamento é suposto aplicado aos 28 dias. Considera-se a fluência que ocorrerá desde a aplicação da carga até um instante de tempo igual a 10000 dias, procurando-se aproximar o coeficiente de fluência calculado pelo programa com o valor empregado pelo CEB (o CEB considera $\varphi(t, t 0)=2,5$ e um coeficiente de envelhecimento do concreto igual a 0,8$)$.
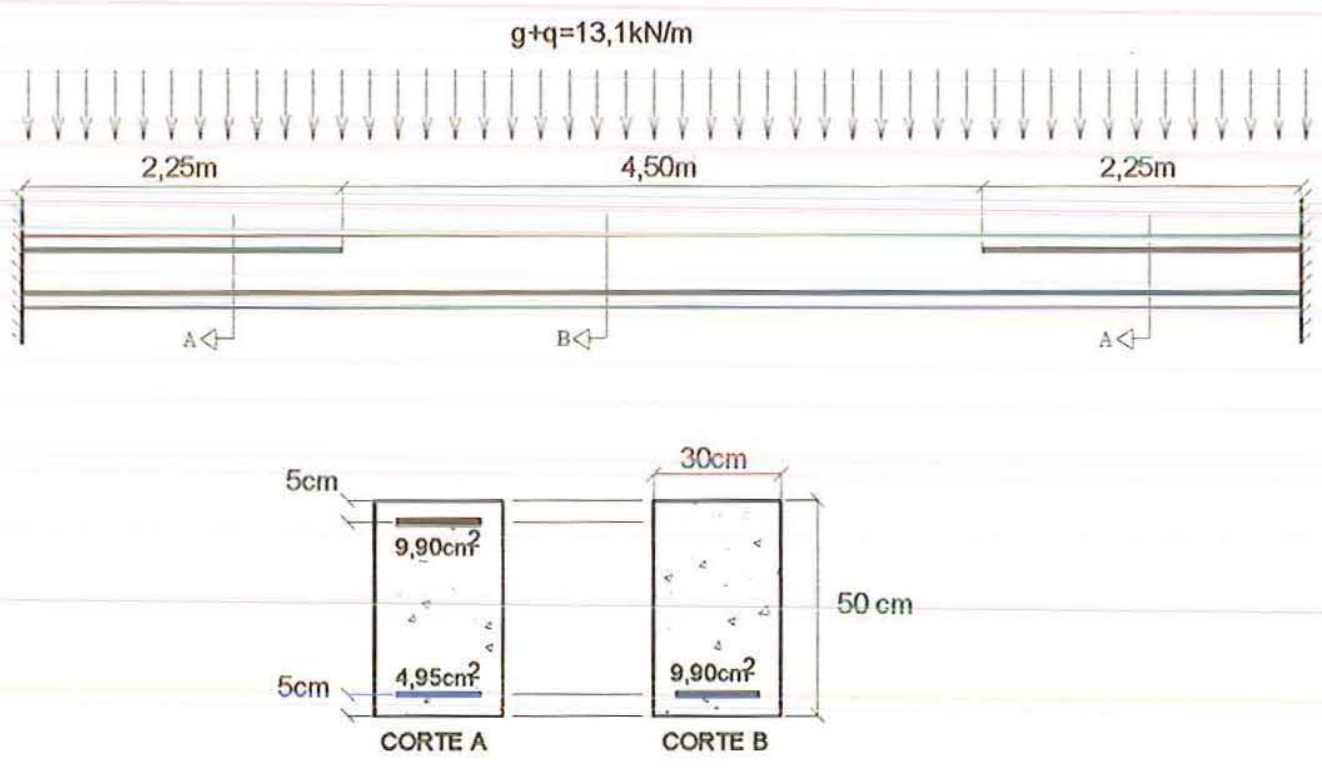

Figura 7.1: Exemplo 7.2.1- viga bi-engastada de concreto armado. 


\section{Capítulo7:EXEMPLOS}

Para a resolução do exemplo a viga foi dividida em 20 elementos finitos iguais e a carga foi aplicada do seguinte modo:

- 20 incrementos de $5 \%$;

- tolerância exigida no processo iterativo : 0,01\%;

- número máximo de iterações : 50.

Para a consideração da fluência, o intervalo de tempo dos 28 aos 10000 dias foi dividido em 100 sub-intervalos iguais. A retração não foi considerada.

Após a execução do programa os resultados obtidos foram os seguintes:

a) Diagrama de momentos fletores elásticos e após a redistribuição de esforços - para 28 e 10000 dias. Foram plotados apenas os valores de momento relativos ao modelo de Debernardi, visto que o modelo de Ghali \& Favre forneceu, para este exemplo, valores bem próximos.

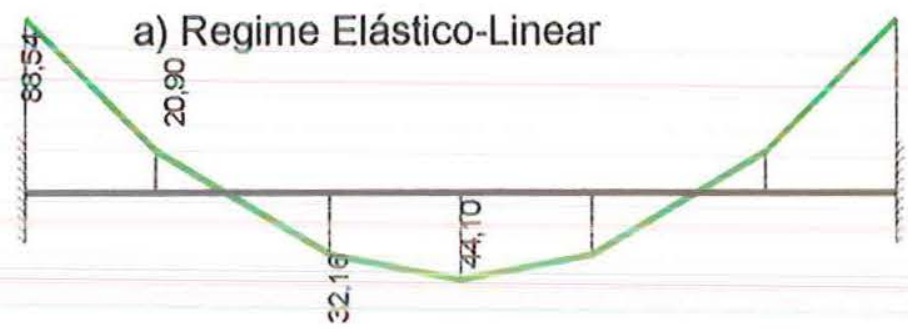

b) Redistribuição de Esforços : Método de Debernardi
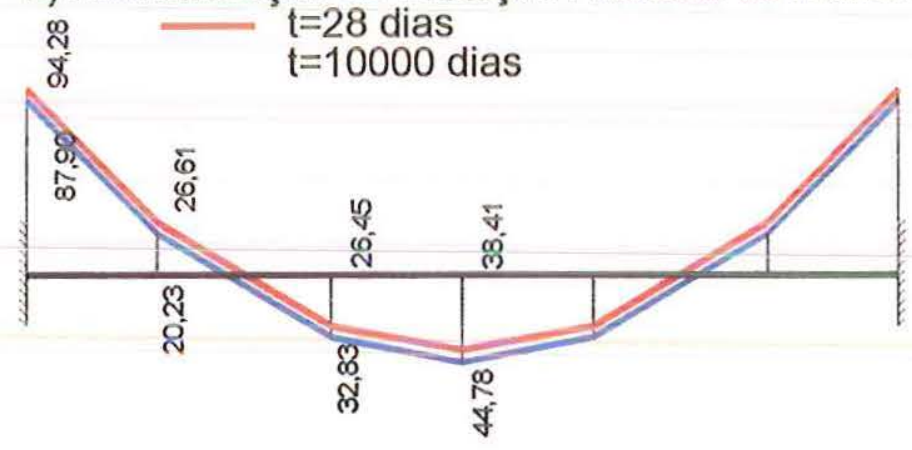

Figura 7.2: Diagrama de momentos para exemplo 7.2.1. (kN.cm) 


\section{Capítulo7:EXEMPLOS}

b) Deslocamento do ponto central da viga, para o instante $t=28$ dias, em função do percentual do carregamento externo aplicado :

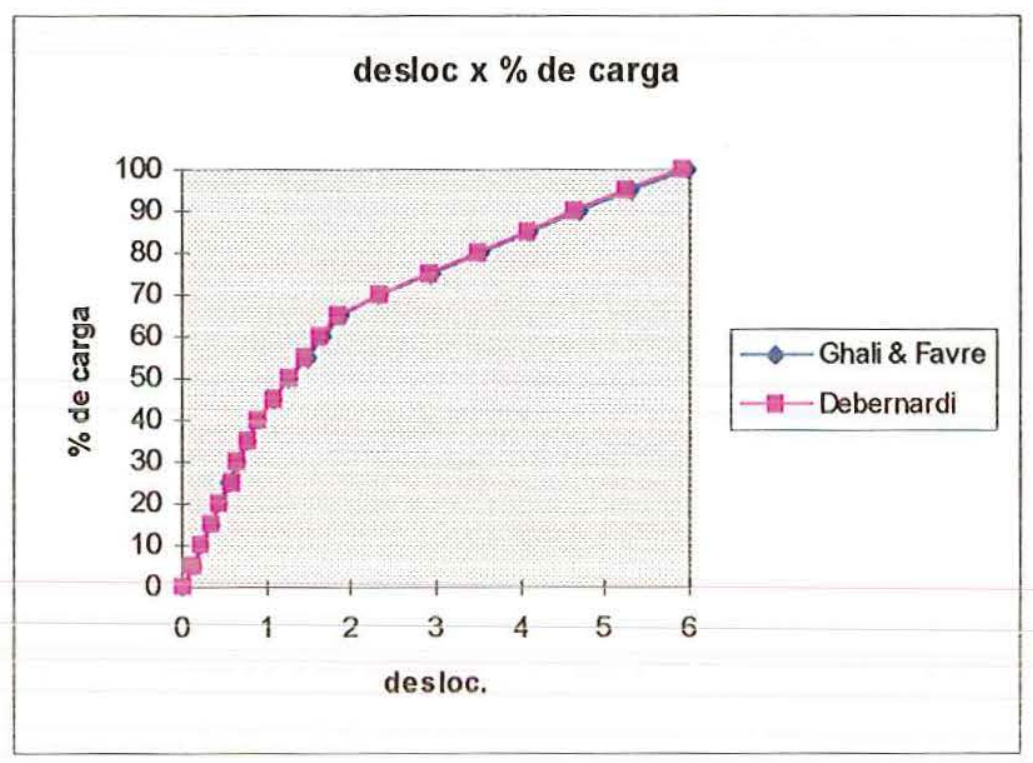

Figura 7.3 : Curva de Deslocamentos Para o Ponto Central da Viga (mm).

O deslocamento vertical do ponto central da viga, obtido através dos modelos implementados foi o seguinte :

- Debernardi : 5,97mm.

- Ghali \& Favre :5,90mm.

$\underline{\mathrm{O} \text { valor indicado pelo CEB é de aproximadamente } 6 \mathrm{~mm}}$. Alravés do gráfico da figura (7.3) pode-se perceber a evolução da fissuração da peça que começa a ocorrer com cerca de $40 \%$ do carregamento total aplicado, existindo o que aparenta ser uma transiçäo entre os comportamentos de estádios 1 e 2 para o carregamento variando de 40 a $70 \%$ do total, a partir daí a estrutura se comporta como fortemente fissurada.

c) Os valores do deslocamento do ponto central da viga, para o instante $t=10000$ são os seguintes:

- Presente trabalho - Modelo de Debernardi : 10,71 mm;

- Presente trabalho - Modelo de Ghali \& Favre : $14,71 \mathrm{~mm}$; 


\section{Capitulo7:EXEMPLOS}

- Bulletin 158 do CEB - Método exato com integração : 12,20 mm;

- Bulletin 158 do CEB - Método dos coeficientes globais : 16,40 mm;

- Bulletin 158 do CEB - Método bilinear : 16,00 mm.

Existe uma diferença entre todos os valores para o instante de tempo "t" sendo que nem os métodos sugeridos pelo próprio CEB são próximos do valor obtido por integração (CEB). Debernardi faz um tratamento da deformação lenta bastante rigoroso, por isso acredita-se que conduza a um valor mais preciso.

\section{2,2-VIGA SIMPLESMENTE APOIADA}

A finalidade deste exemplo é comparar os resultados obtidos através do programa desenvolvido com os resultados fornecidos pelo CEB para várias taxas de armadura. A viga é ilustrada na figura (7.4).

Tabela 7.1: Taxas de armadura e carregamento para a viga Fig.(7.4).

\begin{tabular}{|c|c|c|c|c|c|}
\hline$\rho(\%)$ & 0,3 & \multicolumn{3}{|c|}{0,6} & 0,9 \\
\hline$\rho^{\prime}(\%)$ & 0 & 0 & 0,15 & 0,30 & 0 \\
\hline$q(\mathrm{kN} / \mathrm{m})$ & 8,9 & 16,9 & 16,9 & 16,9 & 25,0 \\
\hline Caso & 1 & 2 & 3 & 4 & 5 \\
\hline
\end{tabular}

q

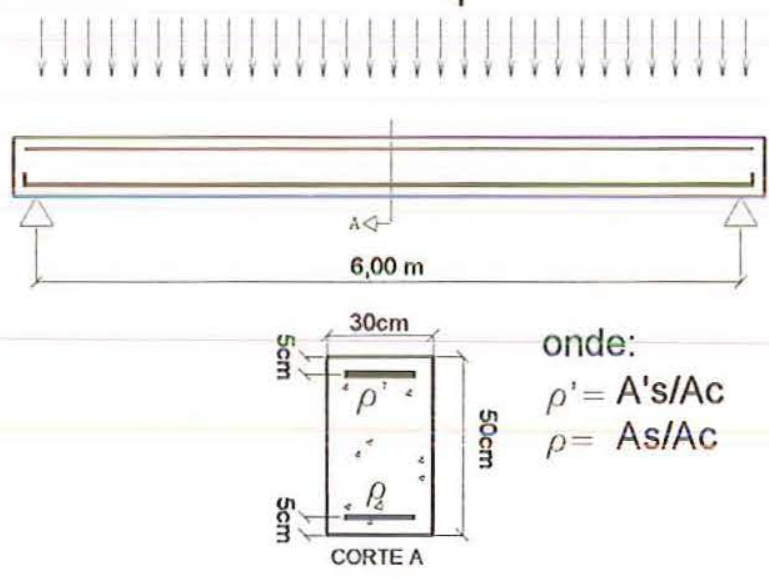

Figura 7.4 : Viga bi-apoiada do exemplo 7.2.2. 


\section{Capítulo7:EXEMPLOS}

A viga foi dividida em 20 elementos finitos iguais e a carga foi aplicada do seguinte modo:

- 20 incrementos de 5\%;

- tolerância exigida no processo iterativo : 0,01\%;

- número máximo de iterações : 50.

Para a consideração da fluência o intervalo de tempo dos 28 aos 10000 dias foi dividido em 100 sub-intervalos iguais. A retração foi desprezada.

O deslocamento do ponto médio do vão é mostrado na tabela (7.2) para o instante de aplicação do carregamento e na tabela (7.3) para $\mathrm{t}=10000$ dias.

Tabelas 7.2 e 7.3 : Deslocamento vertical do ponto médio do vão da viga do exemplo 7.2.2 para os instantes " $\hat{t}_{0}$ " $\mathrm{e}$ "t

\begin{tabular}{|c|c|c|c|c|c|}
\cline { 2 - 6 } \multicolumn{1}{c|}{} & \multicolumn{3}{c|}{ BULLETIN DO CEB } & PRESENTE & TRABALHO \\
\hline Caso & $\begin{array}{c}\text { Método } \\
\text { Exato - CEB } \\
(\mathrm{mm})\end{array}$ & $\begin{array}{c}\text { método } \\
\text { bi-linear } \\
(\mathrm{mm})\end{array}$ & $\begin{array}{c}\text { Método dos } \\
\text { coef. Globais } \\
(\mathrm{mm})\end{array}$ & $\begin{array}{c}\text { método de } \\
\text { Debernardi } \\
(\mathrm{mm})\end{array}$ & $\begin{array}{c}\text { Método de } \\
\text { Ghali \& Favre } \\
(\mathrm{mm})\end{array}$ \\
\hline 1 & 4,20 & 3,80 & 3,80 & 3,15 & 3,09 \\
\hline 2 & 10,00 & 8,20 & 8,40 & 8,90 & 8,84 \\
3 & 10,00 & 8,20 & 8,40 & 8,79 & 8,73 \\
4 & 9,90 & 8,20 & 8,40 & 8,68 & 8,63 \\
\hline 5 & 12,10 & 10,60 & 10,60 & 11,01 & 10,99 \\
\hline
\end{tabular}

\begin{tabular}{|c|c|c|c|c|c|}
\hline & \multicolumn{3}{|c|}{ BULLETIN DO CEB } & \multicolumn{2}{|c|}{ PRESENTE TRABALHO } \\
\hline Caso & $\begin{array}{c}\text { Método } \\
\text { Exato - CEB } \\
(\mathrm{mm})\end{array}$ & $\begin{array}{c}\text { Método } \\
\text { bi-linear } \\
(\mathrm{mm})\end{array}$ & $\begin{array}{l}\text { Método dos } \\
\text { coef. Globais } \\
\text { (mm) }\end{array}$ & $\begin{array}{c}\text { Método de } \\
\text { Debernardi } \\
(\mathrm{mm})\end{array}$ & $\begin{array}{c}\text { Método de } \\
\text { Ghali \& Favre } \\
(\mathrm{mm})\end{array}$ \\
\hline 1 & 10,90 & 11,20 & 11,00 & 9,25 & 9,30 \\
\hline 2 & 16,20 & 15,00 & 15,60 & 16,18 & 14,97 \\
\hline 3 & 15,50 & 14,40 & 15,00 & 15,38 & 14,29 \\
\hline 4 & 14,90 & 14,00 & 14,30 & 14,69 & 13,72 \\
\hline 5 & 19,20 & 18,50 & 18,60 & 20,20 & 18,00 \\
\hline
\end{tabular}


Pode-se mencionar, a partir da interpretação das tabelas (7.2) e (7.3) o seguinte:

- Para o instante de aplicação do carregamento os Modelos de Debernardi e Ghali \& Favre conduzem a resultados bastante próximos - praticamente não existindo diferença entre ambos; no entanto é possível destacar que para baixas taxas de armadura Ghali \& Favre resulta num erro maior em relação à Debernardi, indicando que quanto maior a taxa de armadura mais próximos são os valores.

- Para o instante de tempo $t=10000$ dias, existe uma diferença considerável entre os modelos implementados. O modelo de Ghali \& Favre resulta próximo aos modelos do CEB. A diferença de resultados entre ambos se deve ao fato de, neste trabalho, a deformação lenta ser aplicada em incrementos.

- Os resultados obtidos pelo método de Debernardi - com a consideração da fluência são bem próximos aos do CEB relativos ao método "exato".

O valor "exato" do CEB é obtido a partir da integração das curvaturas ao longo do vão, visando considerar a redistribuição de esforços. É utilizada uma estratégia iterativa. Deve-se deixar claro que o valor exato referido é uma indicação do Bulletin 158 do CEB. 
Capítulo7:EXEMPLOS

\section{7,2.3-VIGA BI-APOIADA COM SEÇÃO "T"}

Este exemplo tem como objetivo mostrar os resultados obtidos pelo programa para uma seção "T" de concreto armado. A viga é ilustrada na figura 7.5 .

$\mathrm{g}+\mathrm{q}=20.0 \mathrm{kN} / \mathrm{m}$
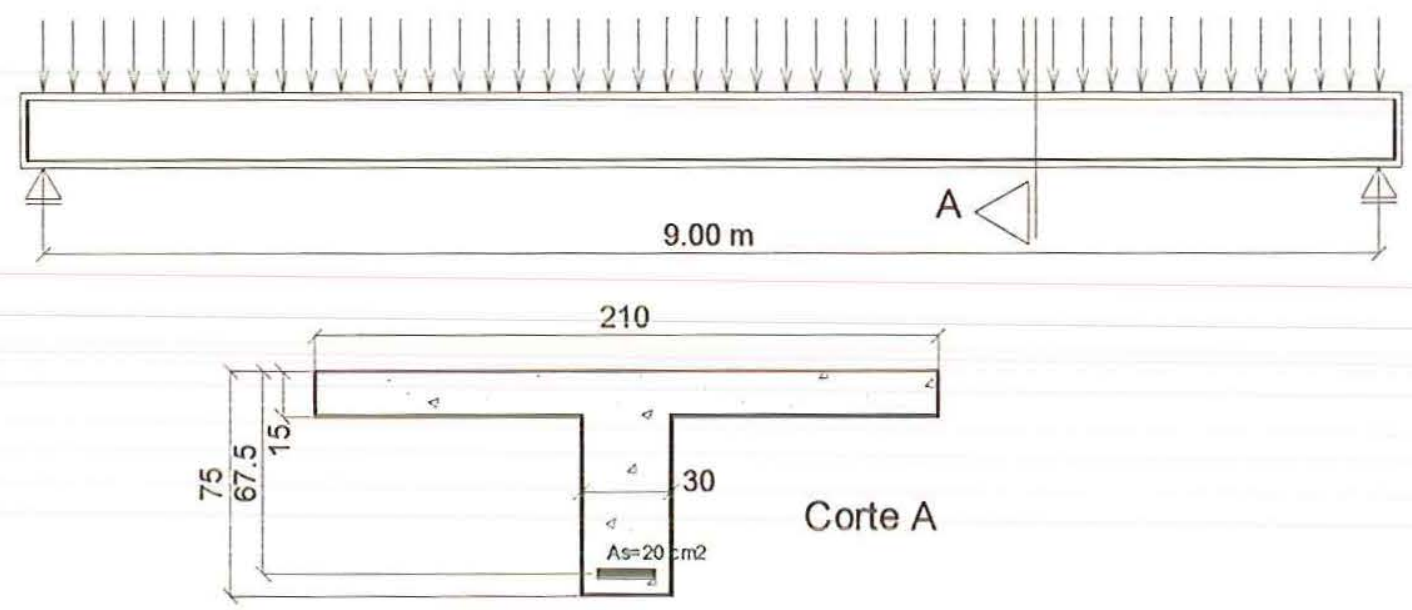

Figura 7.5: Viga do exempio 7.2 .3

Os demais dados deste exemplo são comuns aos exempios anteriores. Os resuitadios oblidos, para o deslocamento central da viga foram os seguintes:

- Modelo de Ghali \& Favre : 5,75mm para $t=28$ dias e 9,43 mm para $\mathrm{t}=10000$ dias;

- Modelo de Debernardi : $7,04 \mathrm{~mm}$ para $t=28$ dias e $12,34 \mathrm{~mm}$ para $t=10000$ dias.

O Bulletin 158 do CEB indica os valores de $6,4 \mathrm{~mm}$ para o instante de aplicação do carregamento e 13,0mm quando a fluência é considerada. Esses valores são calculados no CEB a partir da transformação da seção $T$ numa seção retangular equivalente e da aplicação do método dos coeficientes globais (ver Bulletin 158). 


\section{Capítulo7:EXEMPLOS}

Para esta viga pode-se observar que houve uma grande diferença entre os dois modelos implementados, esta se deve ao fato de Debernardi equacionar sua formulação para uma seção transversal de forma qualquer (neste trabalho, a seção transversal pode ser no máximo seçäo "I"). Neste caso, pode-se dizer que os resultados obtidos pelo modelo de Debernardi são mais precisos que os demais. A precisão para seçöes de forma qualquer constitui-se numa das grandes vantagens do modelo de Debernardi.

\section{3-COMPARAÇÃO COM DADOS EXPERIMENTAIS}

\section{7,3,1-LABORATÓRIO DE ESTRUTURAS DA EESC-USP}

ÁLVARES (1993) propôs um conjunto de três vigas que foram ensaiadas no Laboratório de Engenharia de Estruturas da EESC-USP. Segundo ÁLVARES, a resposta experimental de cada viga foi colhida de uma prova realizada com controle de carga, sendo as leituras tomadas em relógios comparadores posicionados nos apoios e no trecho central, além de extensômetros elétricos nas faces superior, inferior e na armadura tracionada. Os dados relativos às seçöes transversais das vigas säo apresentados na tabela (7.4). A carga "P" foi aplicada no ensaio até provocar a ruptura das vigas. As propriedades mecanicas dos materiais são apresentadas a seguir :

- Módulo de elasticidade do concreto : $29200 \mathrm{MPa}$;

- Módulo de elasticidade do aço : $196000 \mathrm{MPa}$.

Empregando-se a expressão do CEB-90 (7.1) para o cálculo do módulo de elasticidade médio do concreto aos 28 dias em função do $f_{\mathrm{ck}}$ pode-se determinar o valor da resistência característica do concreto à compressão. Assim com :

$$
\mathrm{E}_{\mathrm{cm}}=9500\left(\mathrm{f}_{\mathrm{ck}}+8 \mathrm{Mpa}\right)^{1 / 3}
$$

e

$$
29200=9500\left(f_{\text {ck }}+8 \mathrm{Mpa}\right)^{1 / 3}
$$


resulta $f_{c k}=21,04 \mathrm{MPa}$, que é um parâmetro necessário para a análise numérica.

Tabela 7.4 : Viga do exemplo 7.3.1

\begin{tabular}{|c|c|c|c|c|c|}
\hline Caso & As $\left(\mathrm{cm}^{2}\right)$ & $\mathrm{d}(\mathrm{cm})$ & $\mathrm{A}^{\prime} \mathbf{s}\left(\mathrm{cm}^{2}\right)$ & $\mathrm{d}^{\prime}(\mathrm{cm})$ & \\
\hline 1 & 2,4 & 27,5 & 0,2 & 2,0 & Pouco arm. \\
\hline 2 & 4,0 & 27,0 & 0,2 & 2,0 & Normal.arm. \\
\hline 3 & 5,6 & 26,0 & 0,2 & 2,0 & Muito arm. \\
\hline
\end{tabular}
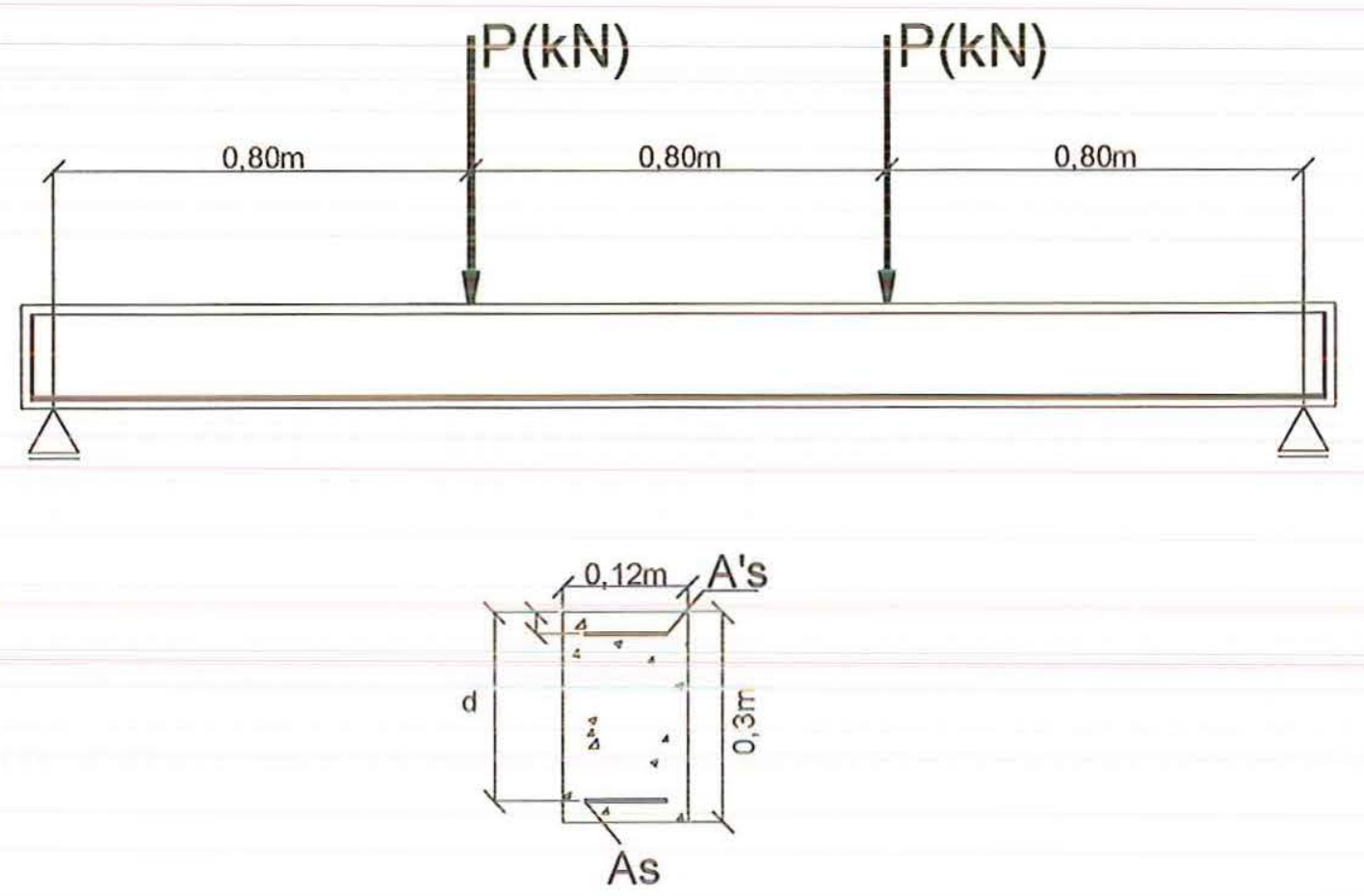

Figura 7.6 :Viga do exemplo 7.3.1 
O CEB sugere que o momento de fissuração para uma seção de concreto armado seja calculado da seguinte forma :

$$
\mathrm{M}_{\mathrm{r}}=\frac{\mathrm{f}_{\mathrm{ctm}} \mathrm{I}_{1}}{\mathrm{~h}-\mathrm{x}_{1}}
$$

O emprego da expressão (7.3) conduz a valores maiores para os deslocamentos, visto que considera uma passagem abrupta do estádio 1 para o estádio 2, desprezando a plastificação na tração. Neste exemplo, pretende-se discutir um fator de correção, "c $>=1$ ", a ser empregado na expressão (7.3), tal que :

$$
\mathrm{M}_{\mathrm{r}}=\frac{\mathrm{cf}_{\mathrm{ctm}} \mathrm{I}_{1}}{\mathrm{~h}-\mathrm{x}_{1}}
$$

Utilizou-se apenas o modelo de Ghali \& Favre que, para carregamentos instantâneos, conduz a resultados bons quando comparados ao modelo de Debernardi. As vigas foram discretizadas em 30 elementos finitos iguais e a carga foi aplicada do seguinte modo:

- 50 incrementos de $2 \%$ cada;

- tolerância exigida no processo iterativo : 0,01\%;

- número máximo de iterações : 50;

- a carga aplicada foi $\mathrm{P}=100 \mathrm{kN}$.

Os resultados obtidos sāo apresentadios a seguir e coníroniadios com aqueles obtidos nos experimentos de ÁLVARES.

Da interpretação das figuras (7.7) a (7.9) pode-se concluir o seguinte:

- O modelo de Ghali \& Favre encontra-se bastante próximo da curva inferior experimental, para açöes em serviço - cerca de $70 \%$ da carga última - para as seçöes pouco e normalmente armada;

- Para a seção muito armada, o modelo numérico só é representativo para ações inferiores a $60 \%$ da carga última;

- Acredita-se que isso se deva ao fato de näo ser considerada no modelo a plastificação da armadura.

- A plastificação da armadura também näo é contemplada no modelo de DEBERNARDI. 


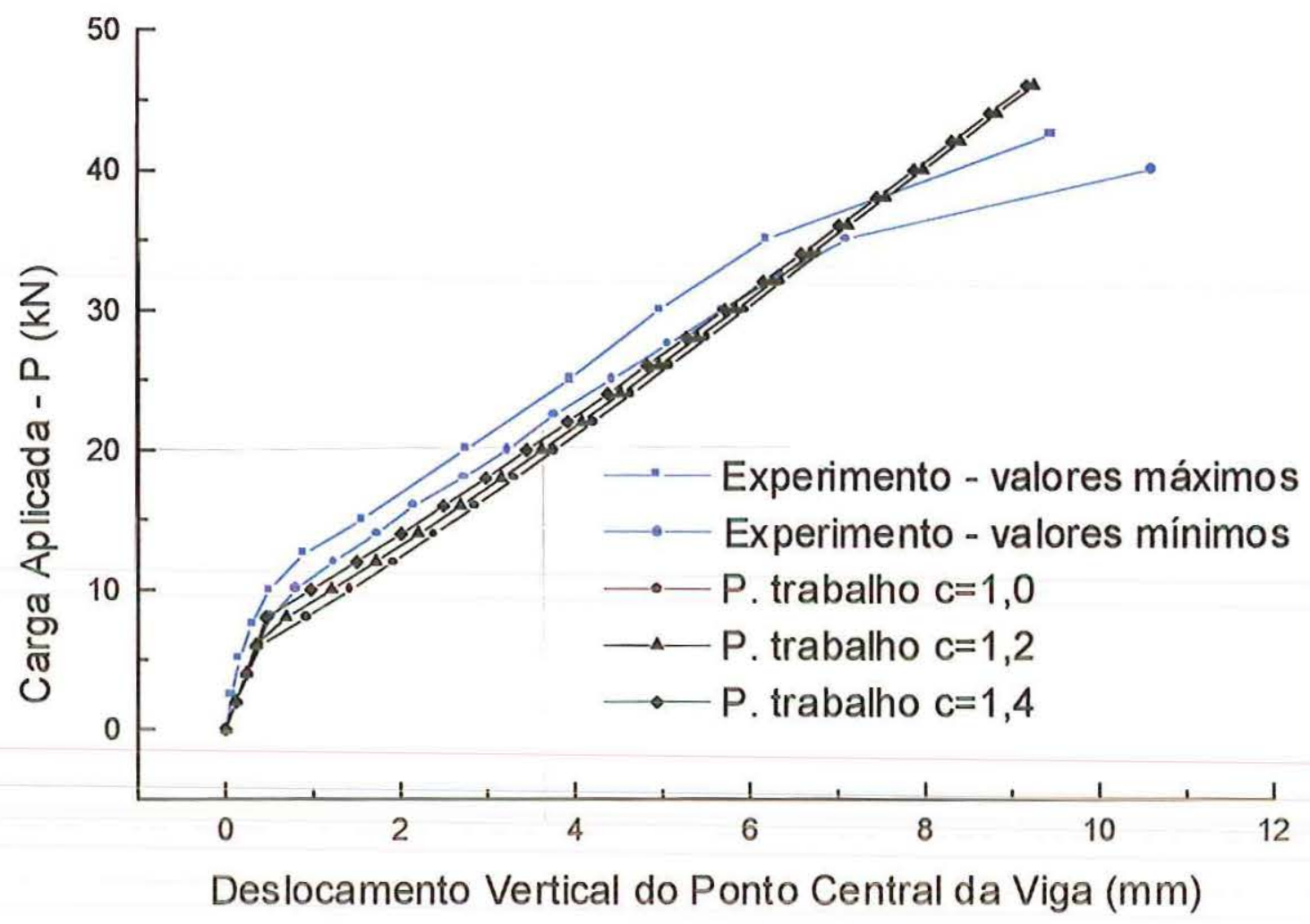

Figura 7.7: Resultados numéricos para viga pouco armada.

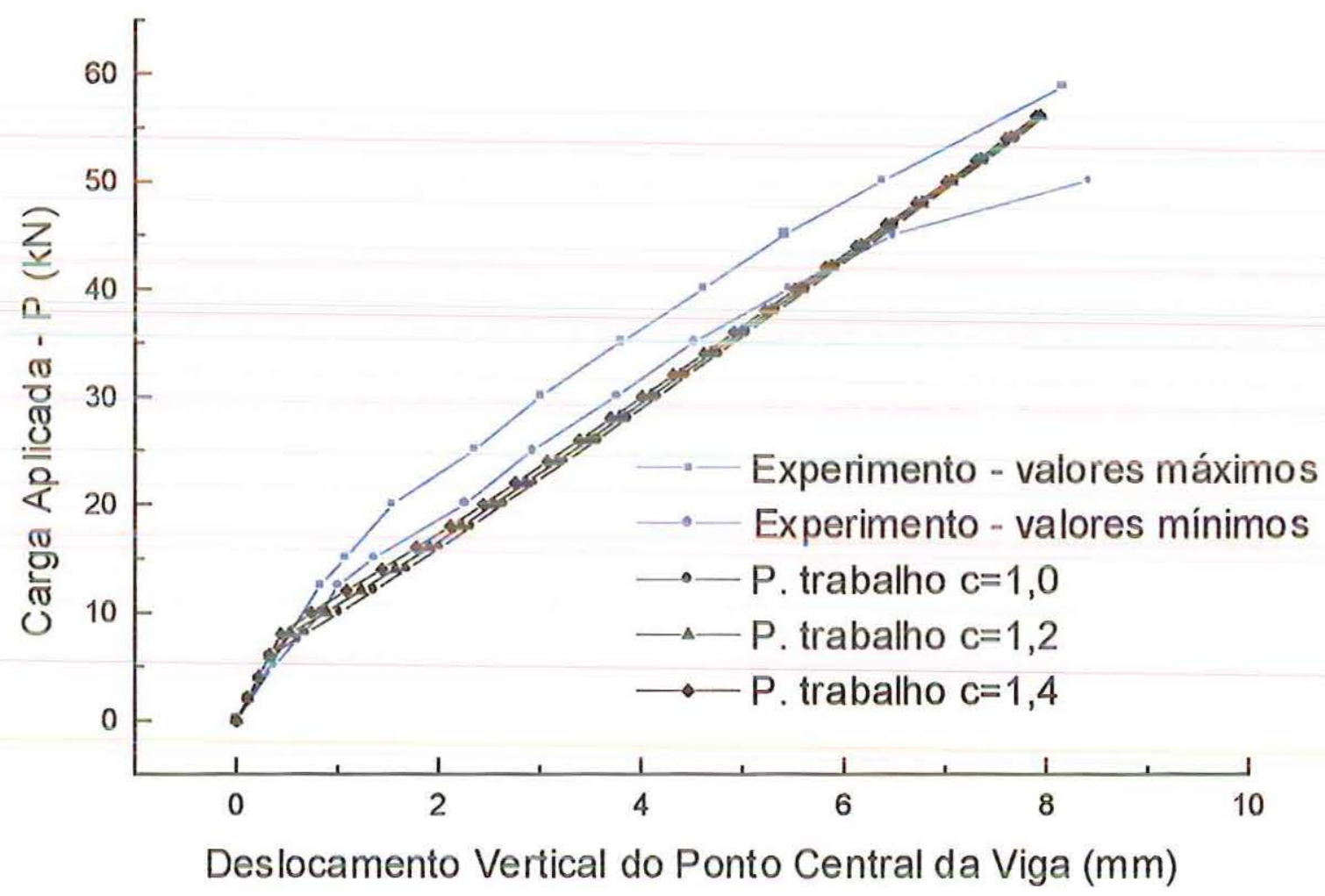

Figura 7.8: Resultados numéricos para viga normalmente armada. 


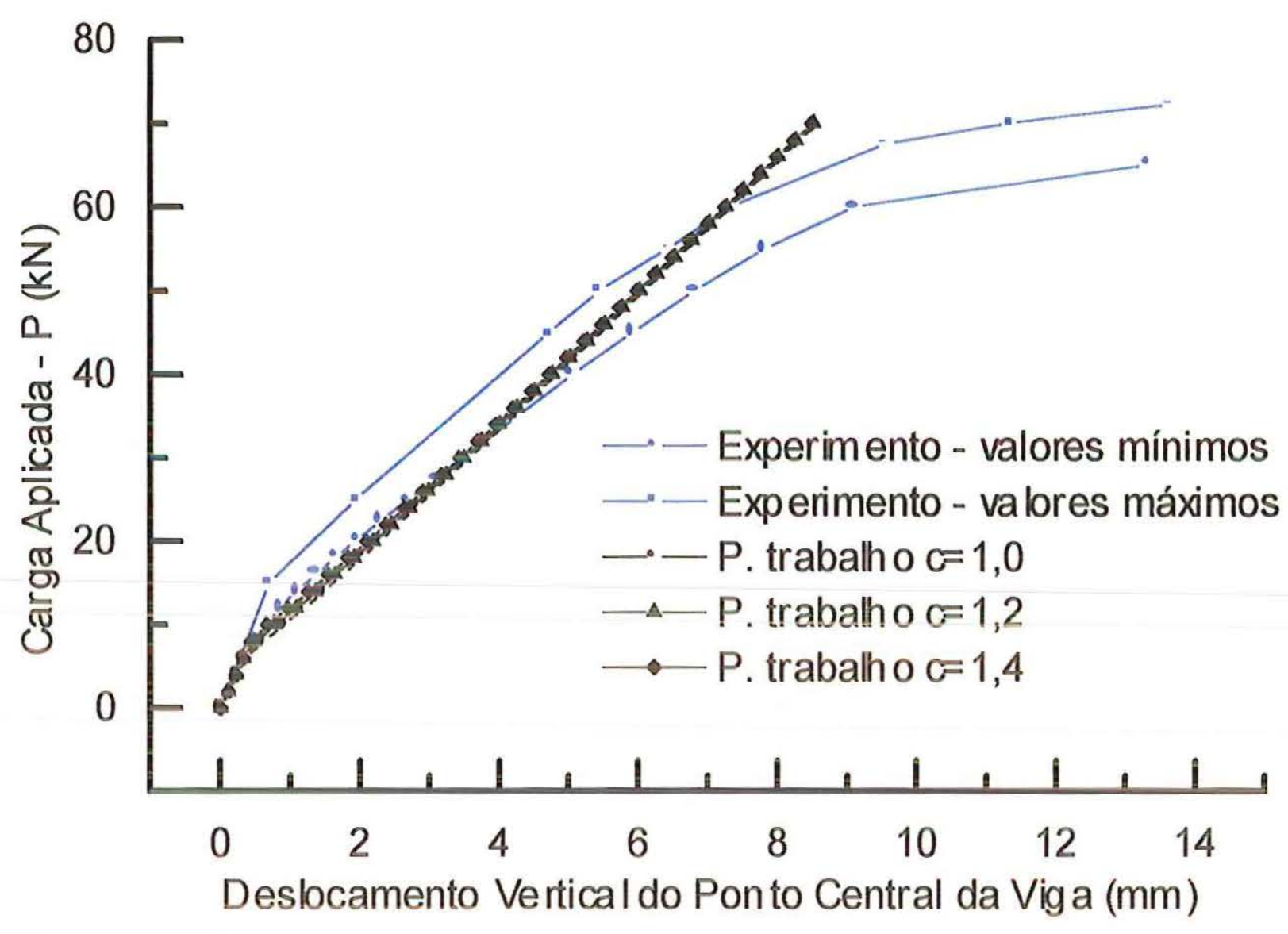

Figura 7.9: Resultados numéricos para viga muito armada.

- Valores de $\mathrm{c}=1,0$ na equação (7.4) resultam em desiocamentos muito a favor da segurança

- Pode-se observar, para este exemplo, que o emprego de um fator $c=1,4$ resulta em uma curva carga $x$ deslocamento bem próximo dos valores mínimos da curva experimental.

- Pode-se concluir, ainda, que os modelos são confiáveis para as ações de serviço nas estruturas de concreto armado. 


\section{7,3.2-ENSAIO DE BRESLER E SCORDELIS}

Este exemplo visa comparar os resultados obtidos com o programa com outros obtidos em experimentos, para esse fim, utiliza-se uma viga biapoiada de concreto armado ensaiada por BRESSER e SCORDELIS e que consta do trabalho de OLIVEIRA (1997). As características da viga ensaiada são mostradas na figura (7.10). As propriedades mecânicas dos materiais são as seguintes:

- Módulo de elasticidade longitudinal do aço igual a 195456,6 MPa;

- $E_{\mathrm{cm}}=23201,7 \mathrm{MPa}$

- $\mathrm{f}_{\mathrm{ctm}}=2,3413 \mathrm{MPa}$.

Os valores acima foram impostos na execuçäo ao programa ou seja, estas variáveis não foram calculadas a partir de $\boldsymbol{f}_{\mathrm{ck}}$.

Deve ser citado que as unidades apresentadas por OLIVEIRA eram originalmente polegadas e PSi . Estas foram convertidas para o sistema internacional de unidades, exceto no gráfico abaixo que representa o deslocamento central da viga em relação ao carregamento aplicado (este está localizado na metade do väo).

Foi imposto $c=1,5$ para efetuar uma comparação com os valores de OLIVEIRA. Com $\mathrm{c}=1,5$; o momento de fissuração calculado pelo programa desenvolvido condiz com os valores de OLIVEIRA, como pode ser observado no gráfico da figura (7.11). 
Capitulo7:EXEMPLOS

362,88 kN
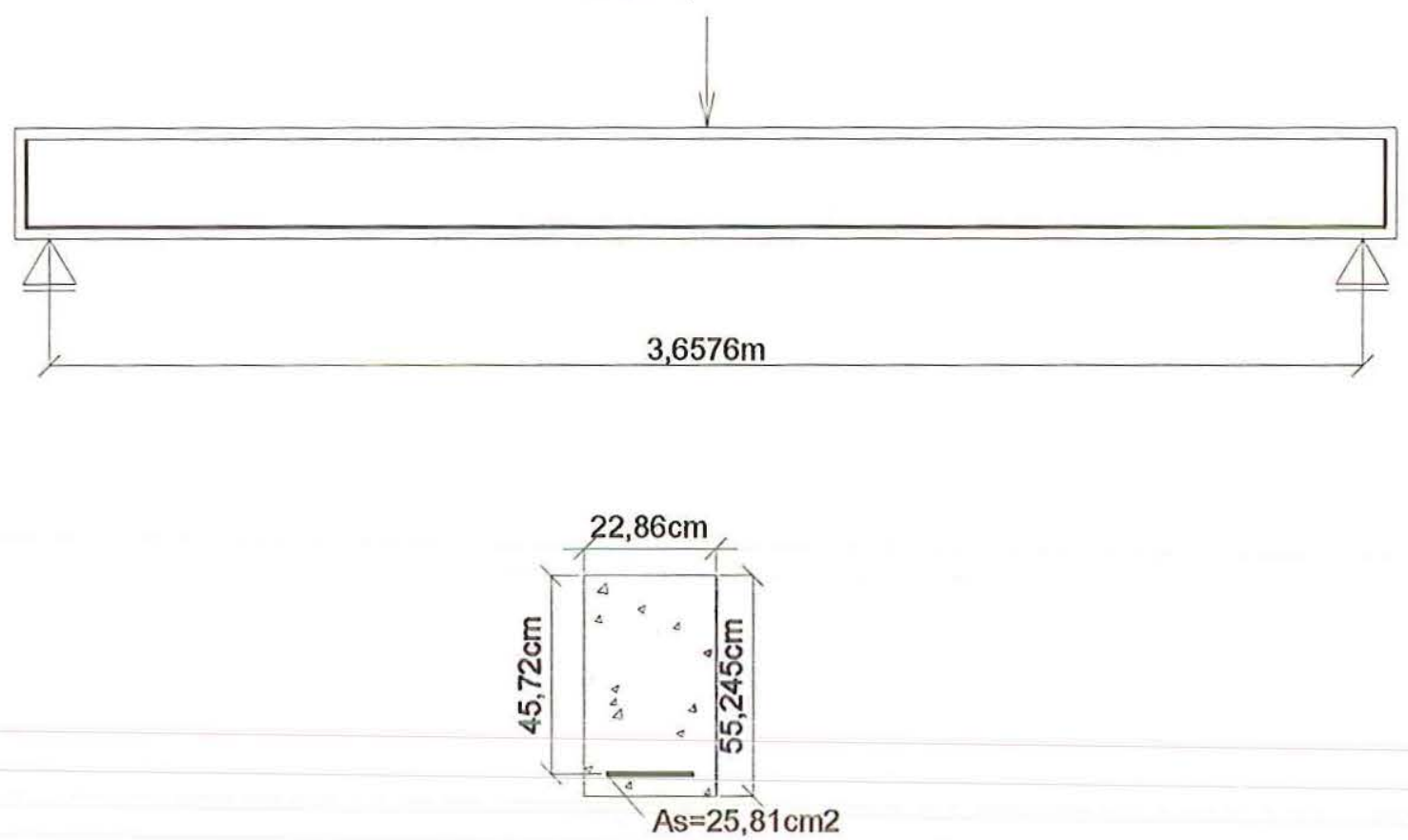

Figura 7.10 : Viga ensaiada por Bresler \& Scordelis.

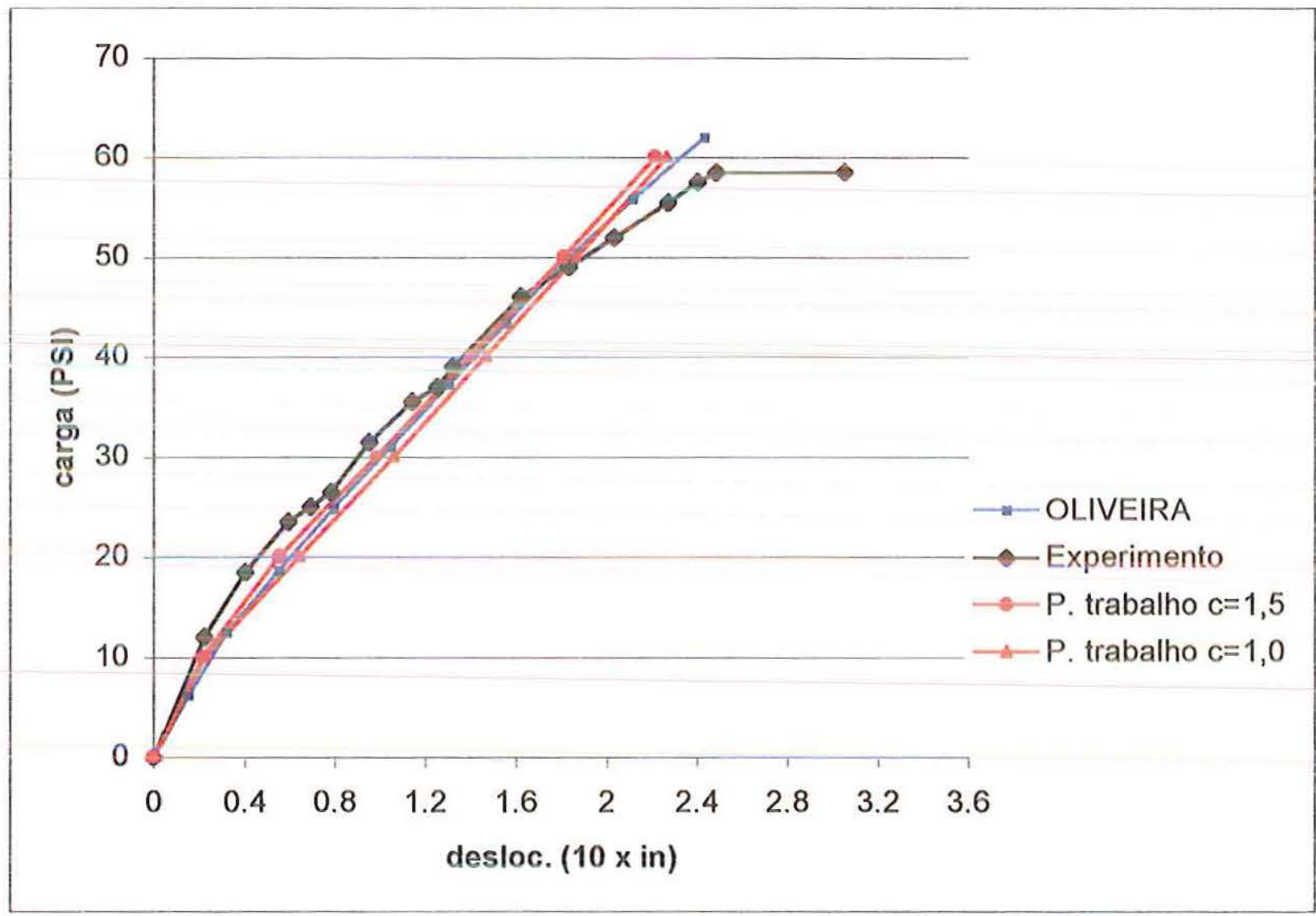

Figura 7.11 : Resultados numéricos para viga ensaiada por BRESLER \& SCORDELIS. 


\section{4-PAVIMENTOS DE EDÍFICIOS}

\subsection{1-PAVIMENTO FICTÍCIO}

Este exemplo tem como objetivo mostrar a redistribuição de esforços ao longo do tempo num pavimento de edifício fictício, figura (7.13), e ilustrar a aplicação de vários carregamentos cada um num instante de tempo. Os dados do pavimento são os seguintes :

- concreto $\mathrm{f}_{\mathrm{ck}}=25 \mathrm{MPa}$;

- módulo de elasticidade longitudinal do aço igual a 200 GPa;

- barras de aço rugosas.

- considerou-se, para o cálculo dos coeficientes de fluência que a parte da seção exposta ao ambiente corresponde a $50 \%$ do perímetro total; umidade relativa do ar de $70 \%$ e temperatura média ambiente de $20^{\circ} \mathrm{C}$.

- a inércia reduzida à torçäo foi considerada tal que resultasse um valor bem próximo de zero.

Os carregamentos são os seguintes :

- peso próprio da estrutura $\mathrm{G}=7,0 \mathrm{kN} / \mathrm{m}$, aplicado aos 14 dias após a concretagem;

- sobrecarga devida as alvenarias Q1=7,0 kN/m, aplicada aos 150 dias;

- sobrecarga devida a revestimentos $\mathrm{Q} 2=3,5 \mathrm{kN} / \mathrm{m}$, aos 300 dias.

Para a resolução do exemplo, o programa foi executado do seguinte modo :

- empregou-se o algoritmo de DEBERNARDI;

- cada carregamento foi aplicado em 4 incrementos de $25 \%$ cada;

- tolerância exigida no processo iterativo : 0,5 \%;

- número máximo de iterações : 100.

- cada intervalo de tempo foi dividido em 100 sub-intervalos para a consideração da fluência.

Os resultados obtidos, para uma viga, são apresentados a seguir. 
Capítulo7:EXEMPLOS

a) Deslocamentos ao longo da viga $\mathrm{V} 01$

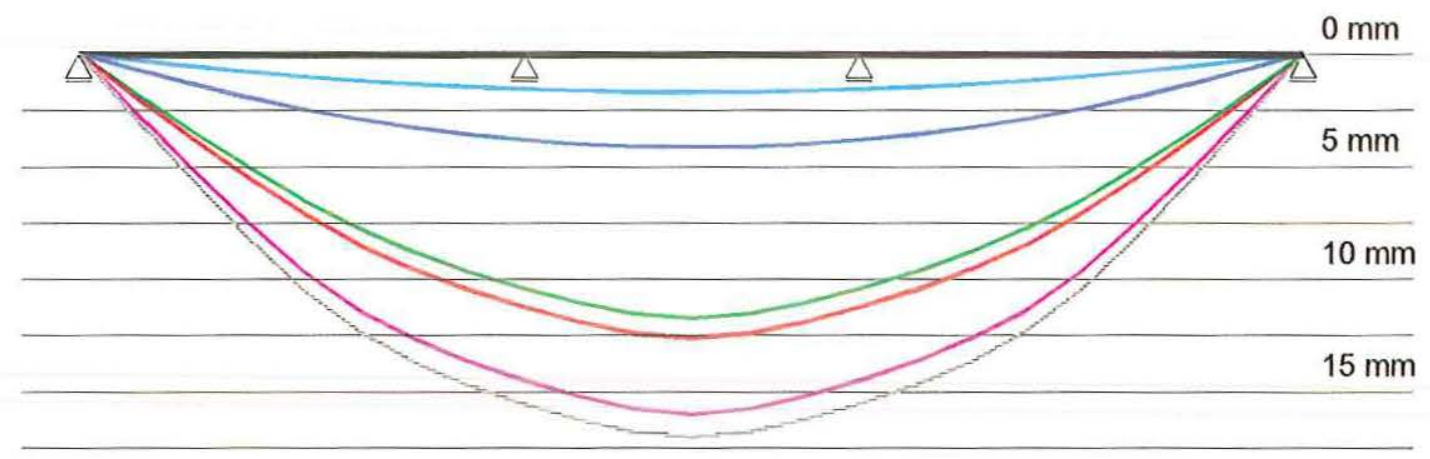

b) Diagrama de momento fletor para viga V01

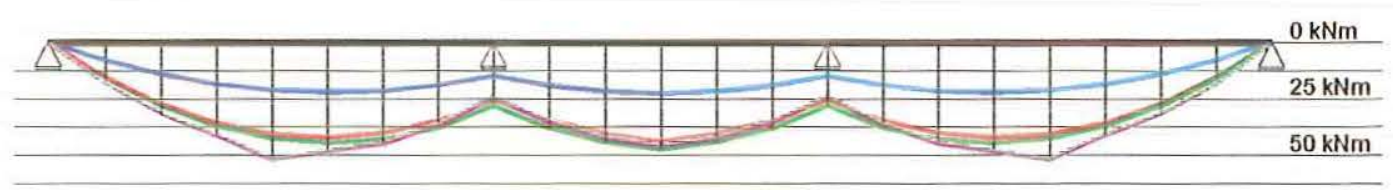

\section{Legenda :}

Aplicação de $\mathrm{G}, 14$ dias

150 dias
Aplicação de Q1, 150 dias 300 dias

Aplicação de Q2, 300 dias 1000 dias

Figura 7.12 : Resultados para viga V01.

Nesse exemplo pode-se observar que houve uma mudança bastante pequena nos esforços solicitantes ao longo da viga e que a estrutura sofre uma perda de rigidez devida à fluência. Entretanto, nesse exemplo, não está sendo considerado o ganho de resistência do concreto ao longo de seu envelhecimento. 

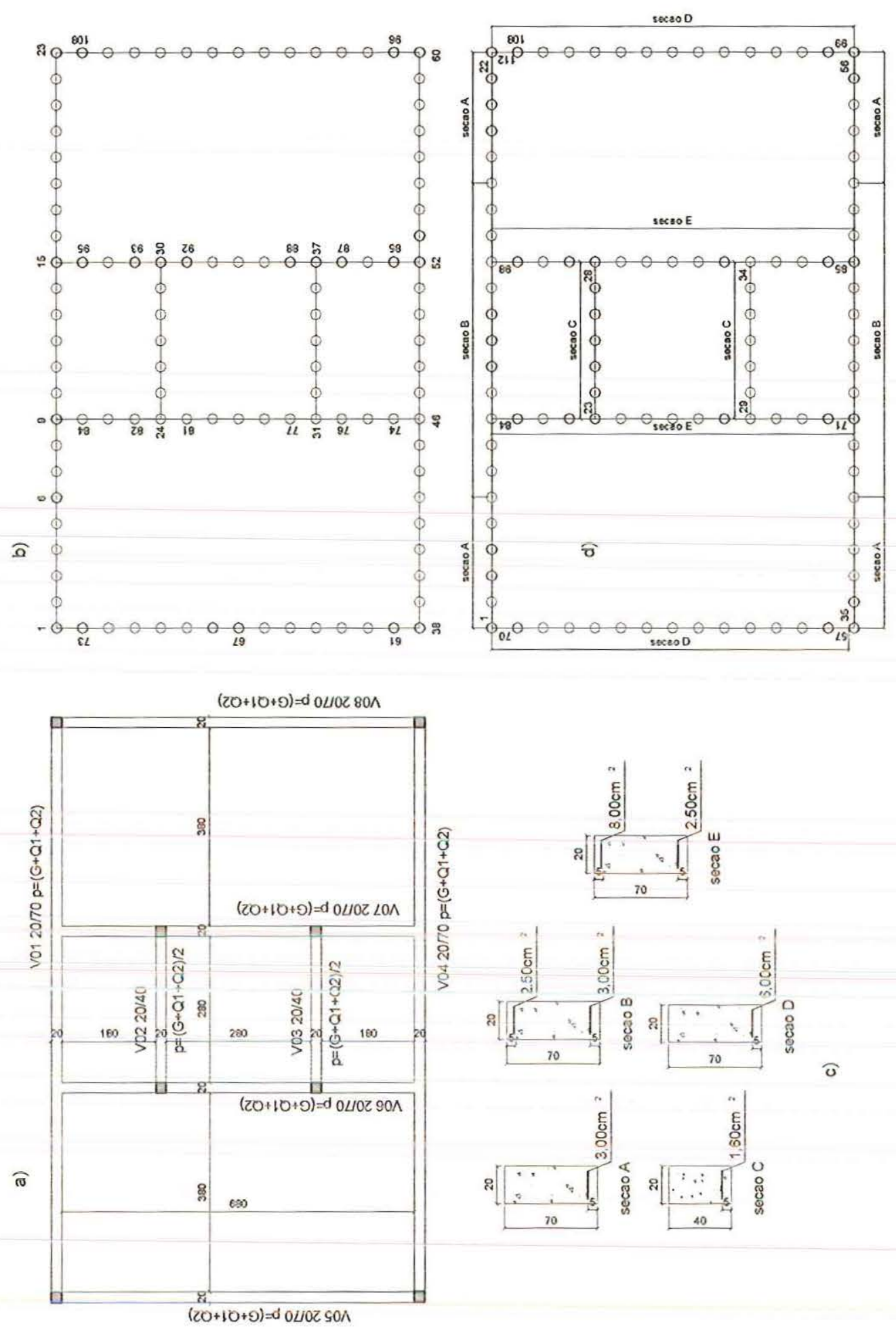

Figura 7.13 : Pavimento fictício. 


\section{7,4,2-PAVIMENTO REAL}

Esse exemplo tem como objetivo mostrar a aplicação do programa desenvolvido à uma caso prático. Analisou-se o pilotis de um edifício de alvenaria estrutural que foi construído na cidade de Brasília-DF, cujo projeto estrutural foi gentilmente cedido pela empresa TECSOF - ENGENHARIA DE ESTRUTURAS, da cidade de São Carlos. O pavimento completo é mostrado na figura (7.14).

Na discretização da estrutura foi considerada a simetria e desprezada a caixa da escada, reduzindo assim o piso do edifício ao ilustrado na figura (7.14). Os elementos finitos e nós são mostrados na figura (7.16); e os carregamentos na figura (7.17).

As coordenadas dos nós podem ser encontradas no anexo $\mathrm{C}$; a incidência dos elementos no anexo $D$ e as seçöes transversais e respectivas armaduras no anexo E. Os demais dados do pavimento são os seguintes :

- concreto $\mathrm{f}_{\mathrm{ck}}=20 \mathrm{MPa}$;

- módulo de elasticidade longitudinal do aço igual a 200 Gpa;

- barras de aço rugosas;

- considerou-se, para o cálculo dos coeficientes de fluência um perímetro exposto ao ambiente de $50 \%$ do perímetro da seção, umidade relativa do ar de $70 \%$ e temperatura média ambiente de $20^{\circ} \mathrm{C}$;

- a inércia reduzida à torção foi considerada por : $I_{t}=h b^{3} / 1200$.

- as seçöes transversais são mostradas nas tabelas em anexo.

- coordenadas dos nós e incidência dos elementos podem ser encontradas no anexo.

Para a resolução do exemplo, o programa foi executado do seguinte modo :

- empregou-se o algoritmo de DEBERNARDI;

- cada carregamento foi aplicado em 2 incrementos de $50 \%$ cada;

- tolerância exigida no processo iterativo : 0.5 \%;

- número máximo de iterações : 100; 
- consideraram-se três casos para análises : comportamento elásticolinear, comportamento não-linear em " $\mathrm{t}_{0} "=28$ dias e em " $\mathrm{t} "=1000$ dias;

- o intervalo de tempo foi dividido em 100 sub-intervalos para a consideração da fluência.

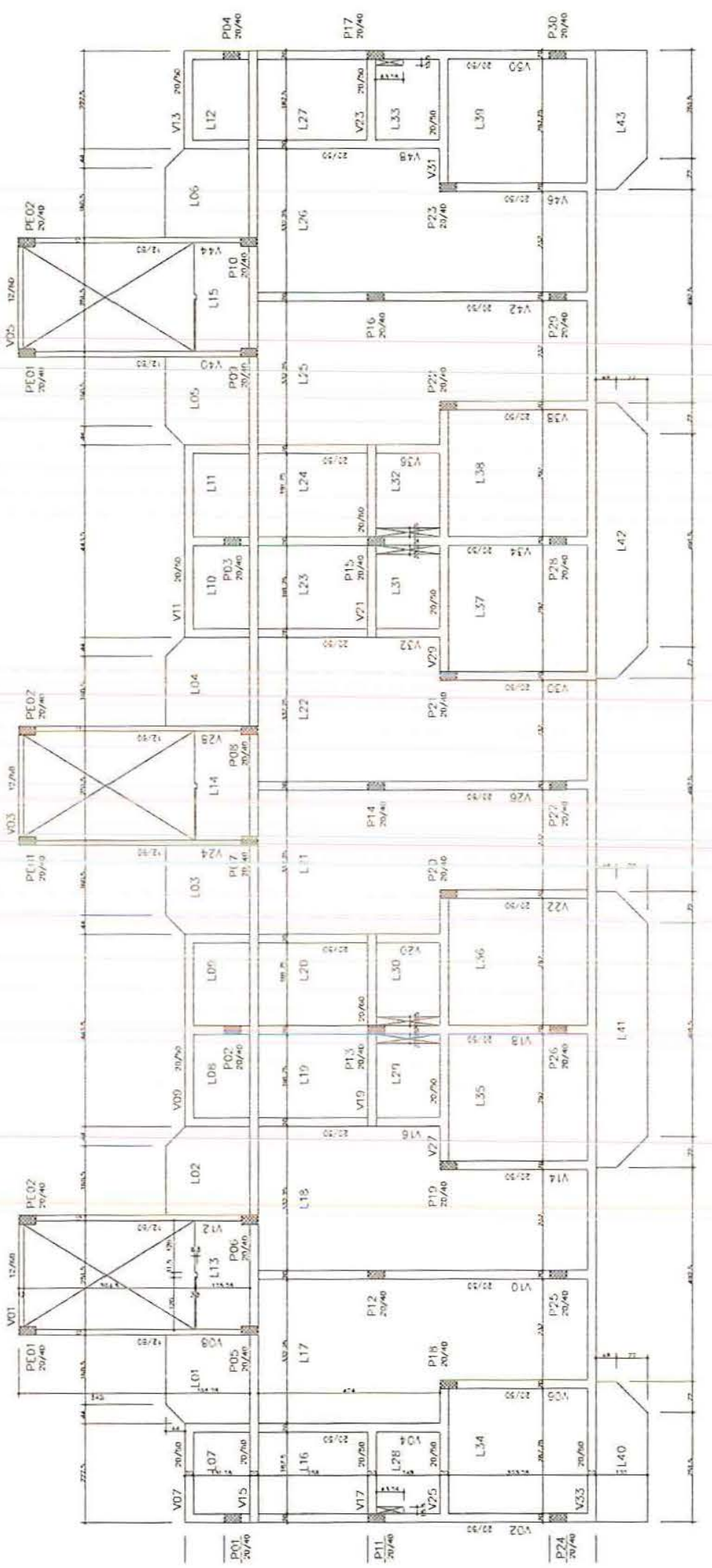

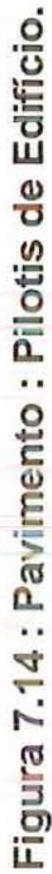




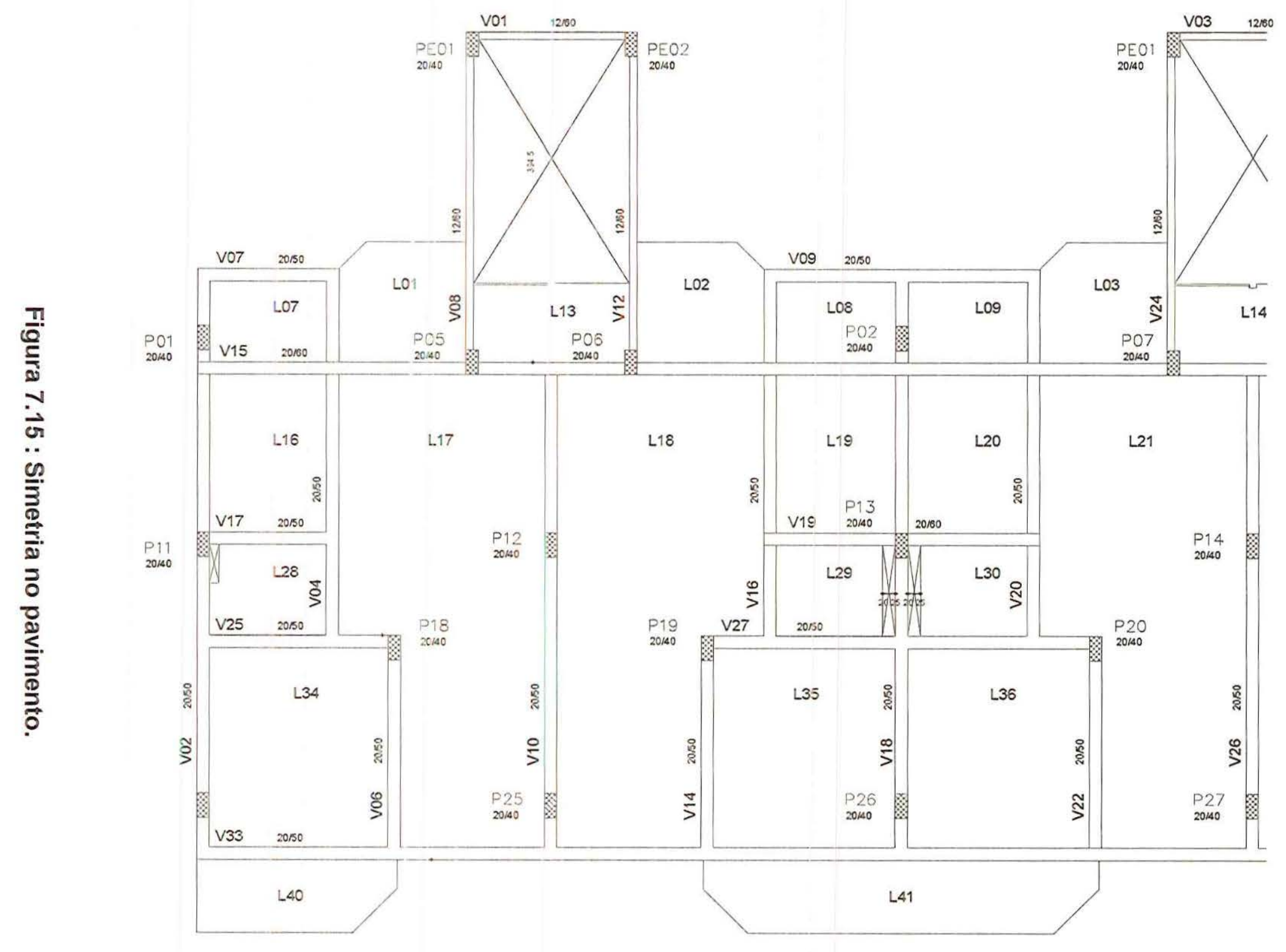

 


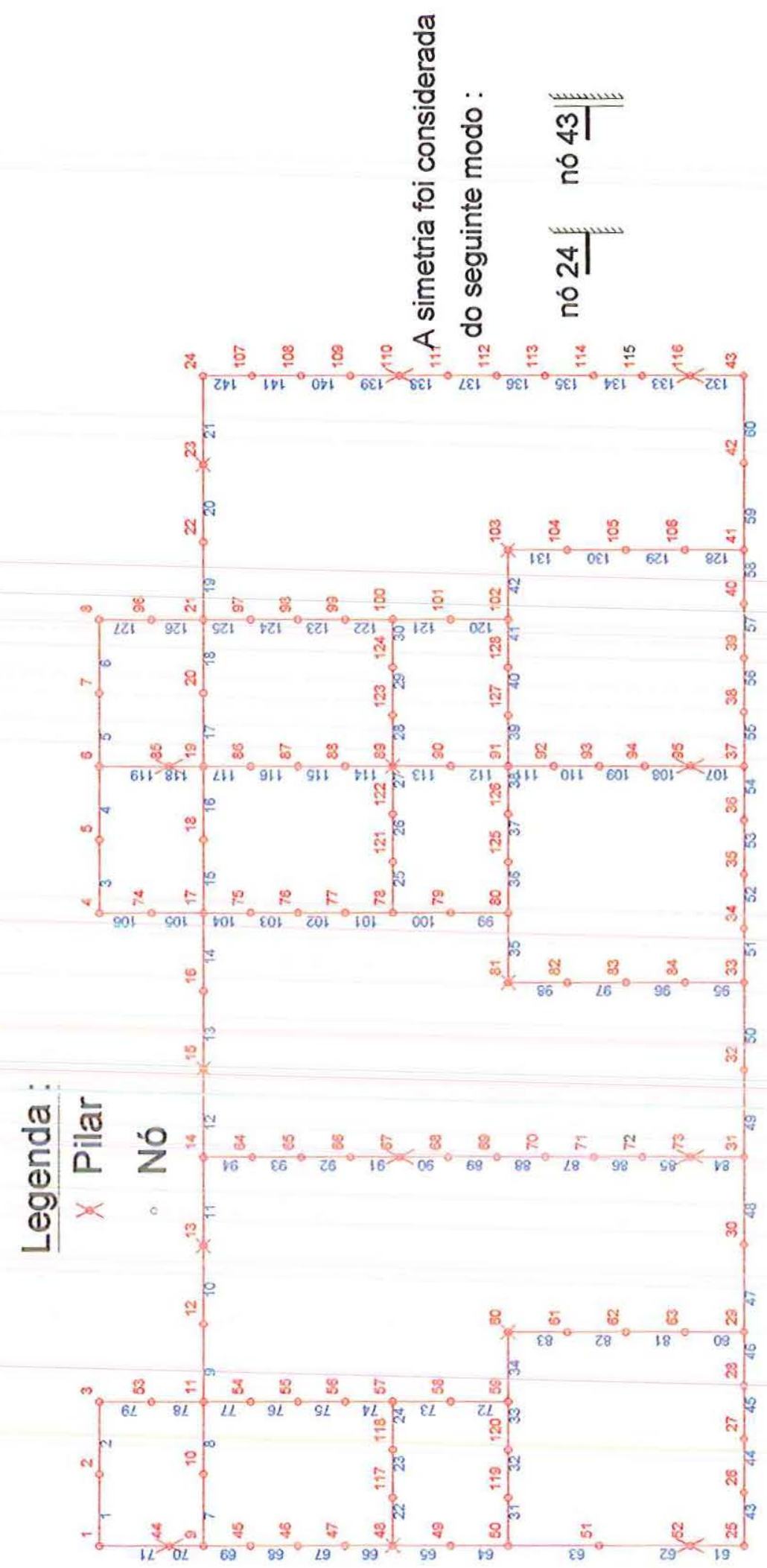

Figura 7.16 : Discretização em elementos finitos. 


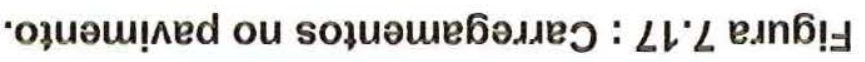

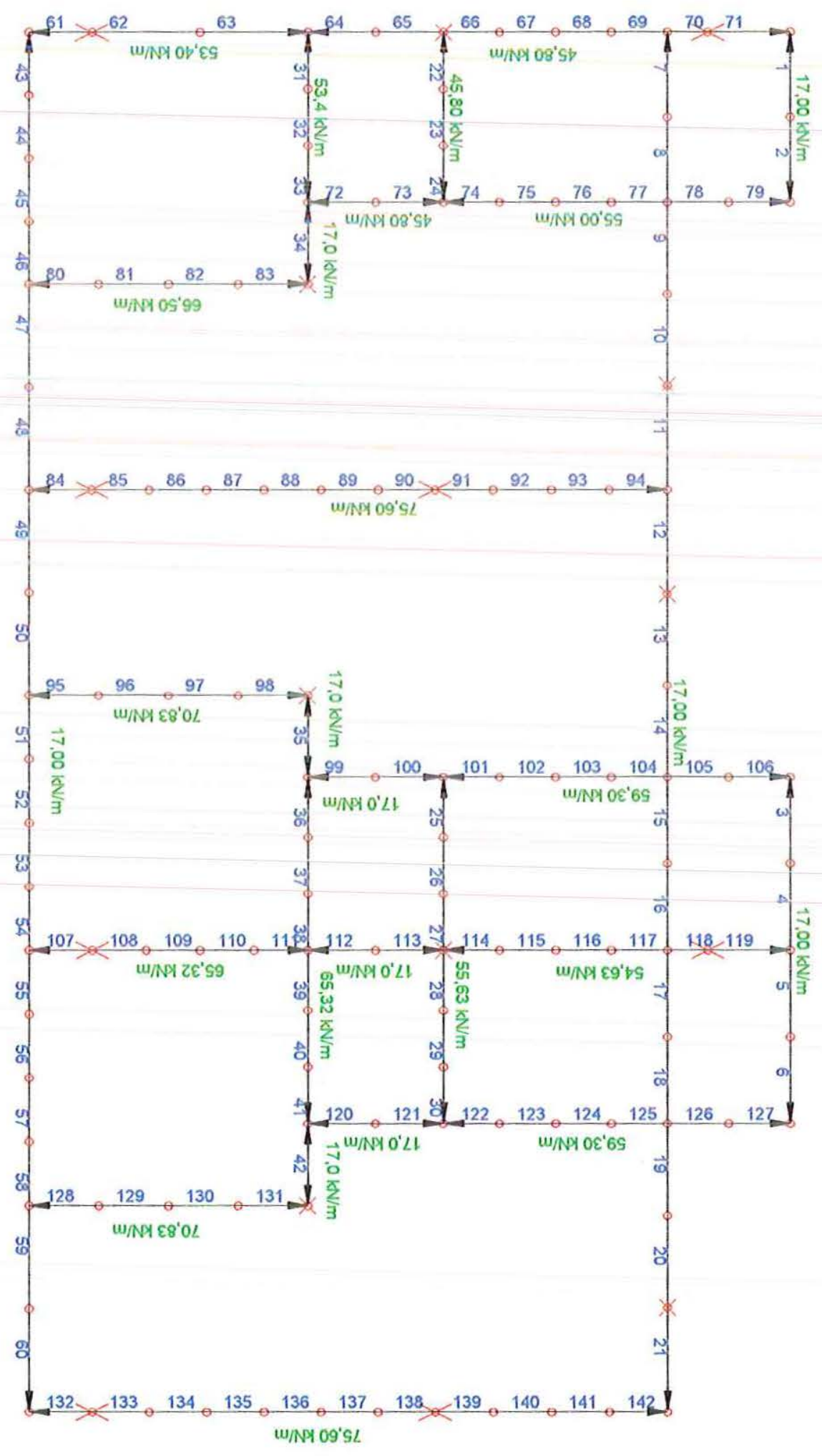


a) Diagrama de momentos para viga V10

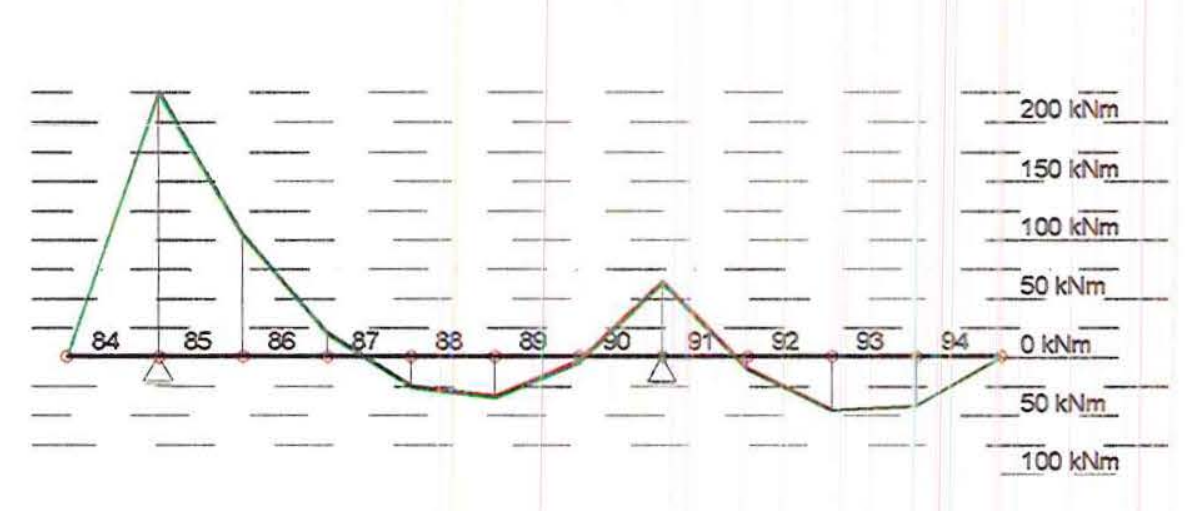

Legenda :

b) Diagrama de momentos para viga $\mathrm{V} 33$

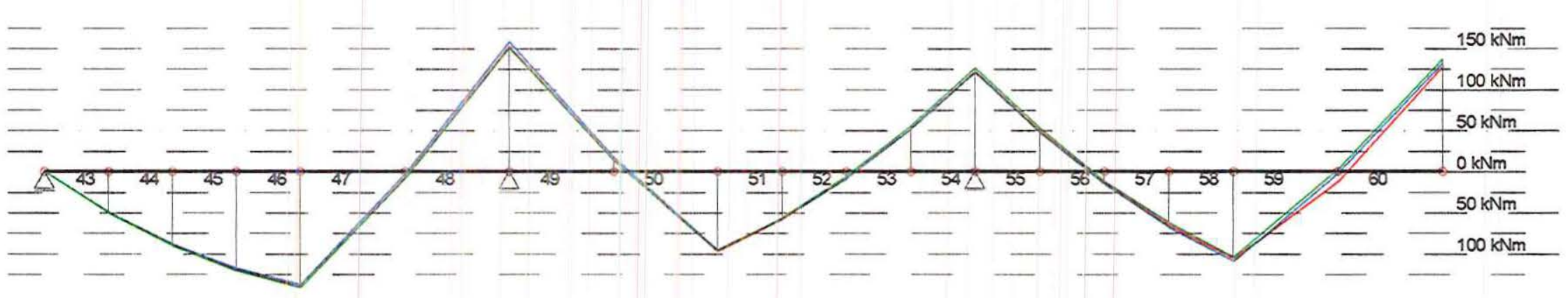

Figura 7.18: Diagramas de momento fletor - exemplo 7.4.2 
Tabela 7.5: Deslocamentos em pontos nodais.

\begin{tabular}{|c|c|c|c|}
\hline \multirow[b]{2}{*}{ Nó } & \multicolumn{3}{|c|}{$\begin{array}{l}\text { Deslocamento } \\
(\mathrm{mm})\end{array}$} \\
\hline & Elástico linear & $\begin{array}{c}\text { Debernardi } \\
28 \text { dias }\end{array}$ & $\begin{array}{c}\text { Debernardi } \\
1000 \text { dias }\end{array}$ \\
\hline 1 & 0,10 & 0,02 & $-0,23$ \\
\hline 3 & 1,25 & $-2,75$ & 0,02 \\
\hline 4 & 1,24 & 2,79 & 4,68 \\
\hline 6 & 0,30 & $-0,41$ & $-0,43$ \\
\hline 8 & 0,79 & 2,06 & 3,22 \\
\hline 11 & 2,64 & 6,33 & 10,04 \\
\hline 14 & $-0,46$ & $-1,00$ & 1,78 \\
\hline 17 & 1,37 & 3,99 & 6,04 \\
\hline 19 & 0,17 & 0,94 & 1,35 \\
\hline 21 & 1,04 & 3,44 & 4,94 \\
\hline 25 & $-0,82$ & $-2,11$ & $-2,77$ \\
\hline 29 & 5,49 & 14,28 & 23,32 \\
\hline 31 & 1,93 & 4,75 & 7,27 \\
\hline 33 & 2,96 & 9,58 & 12,56 \\
\hline 37 & 0,08 & 0,62 & 0,79 \\
\hline 41 & 2,36 & 7,10 & 10,74 \\
\hline 56 & 5,66 & 19,85 & 26,57 \\
\hline 57 & 5,59 & 19,66 & 26,44 \\
\hline 59 & 2,25 & 7,59 & 10,74 \\
\hline 78 & 2,49 & 6,83 & 10,56 \\
\hline 91 & 2,36 & 4,57 & 6,86 \\
\hline 100 & 2,36 & 6,63 & 10,14 \\
\hline 113 & 1,18 & 4,99 & 6,56 \\
\hline
\end{tabular}


Este exemplo permite uma discussão a respeito da redistribuição de momentos fletores nos elementos de barra de um pavimento de edifício; embora foram analisados os diagramas de momentos fletores apenas para duas vigas, as conclusōes podem ser generalizadas para todo o pavimento.

Pode-se observar que os esforços obtidos a partir da análise linear praticamente não sofrem redistribuição devida ao comportamento não-linear do pavimento, nem tampouco devida à fluência. Este fato se deve à armação das vigas do pavimento ter sido efetuada de maneira apropriada, ou seja, de acordo com a distribuição de momentos elástico-linear; o que vem a tranqüilizar os projetistas de estruturas de concreto armado.

Por outro lado, se não for efetuada uma armação adequada das vigas do pavimento, ocorrerá redistribuição de esforços na análise não-linear e na consideração da fluência. Para ilustrar este fato imagine-se uma viga contínua tal que exigisse a disposição de armadura longitudinal negativa sobre os seus apoios. Se o seu projetista optasse pela omissão dessas armaduras, o máximo momento fletor que seria permitido sobre tais apoios seria aquele correspondente ao momento de fissuração das respectivas seções; dessa forma este poderia ser diferente do momento obtido pela análise elástico-linear.

Outro fato que pode ser notado é relativo ao acréscimo dos desiocamentos devido à fluência. Pode-se observar que a maneira mais apropriada de analisar o comportamento estrutural ao longo da vida útil da estrutura é através do emprego de programas de análise não-linear de estruturas. Embora não foram efetuadas comparaçőes com procedimentos de normas, fica evidenciado pela análise dos deslocamentos da tabela 7.5 que o acréscimo de deslocamentos devido à fluência não é tão grande como a maioria das normas indicam 


\section{8-CONCLUSÕES}

Através da interpretação dos resultados numéricos obtidos pelo algoritmo computacional desenvolvido pode-se concluir, em relação aos modelos implementados, que para seçōes retangulares de concreto armado, o modelo simplificado de GHALI \& FAVRE para o instante de aplicação do carregamento é mais vantajoso do que o modelo de DEBERNARDI, considerado mais rigoroso do que o primeiro, cujo tempo de processamento é cerca de 50 vezes menor.

Em se tratando de elementos de concreto pouco armado, o modelo de DEBERNARDI conduziu, dentre vários exemplos analisados, a valores de deslocamentos cerca de $1,5 \%$ maiores do que os valores obtidos pelo modelo de GHALI \& FAVRE. Por outro lado, nos elementos muito armados, os valores são bem próximos para ambos os modelos; este fato se justifica pelo fato de DEBERNARD! indicar que o cálculo da deformação média da armadura tracionada deva ser feito através da interpolação entre os resultados obtidos entre os estádios 1 e 2, que é a hipótese básica do modelo de GHALI \& FAVRE.

Desejando-se uma análise estrutural onde as deformaçöes näoimediatas devam ser consideradas, o modelo de DEBERNARDI mostrou-se mais apropriado; do mesmo modo ocorre para as seçőes transversais de forma qualquer. Isto se deve ao fato deste modelo ser desenvolvido para uma seção transversal de forma qualquer e para um instante qualquer após a aplicação do carregamento.

A análise estrutural de pavimentos de edifícios de concreto armado, onde não houver grandes disparidades entre as rigidezes de cada tramo de viga, pode ser feita em regime elástico-linear para o instante de aplicação 


\section{Capitulo 8: CONCLUSÖES}

do carregamento. Observou-se que, nestes casos, quando a não-linearidade física é incorporada à análise praticamente não existe redistribuição de esforços, nem para o instante de aplicação do carregamento, nem para um instante qualquer de tempo. Portanto, os pavimentos usuais podem ser armados, de maneira coerente, para os esforços obtidos na estrutura em regime elástico-linear.

A consideração da aplicação de várias fases de carregamento no pavimento, em instantes de tempo específico, foi implementada neste trabalho de maneira simplificada e näo conduziu a bons resultados. Entretanto, para seu melhor desempenho, basta efetuar a implementação de rotina que considere o ganho de resistência do concreto ao longo do tempo; isto é bastante simples de ser incorporado ao programa desenvolvido.

Sugere-se para trabalhos futuros a implementaçäo da consideração da retração. Todas as rotinas implementadas encontram-se preparadas para a incorporação da retração; esta é atualmente uma variável cujo valor é nulo. Desse modo, basta ser implementado um elemento finito com um grau de liberdade a mais do que o atual para a consideraçäo de esforços normais que irão ocorrer devido a retração. 


\section{ANEXOS}

\section{ANEXOS}

\section{ANEXO A - FORMULAÇÃO PARA SEÇÃO "I" NO ESTÁDIO 1}

Considere-se a seção transversal de concreto armado apresentada na figura (A.1) onde todas as suas características geométricas, bem como o plano de atuação dos esforços solicitantes são mostrados. Nesta seção será inicialmente determinada uma equação, em termos daquelas características, para a determinação da posição da linha neutra no estádio 1, posteriormente será calculado o momento de inércia. A seção será homogeneizada e os espaços ocupados pela armadura serão descontados.

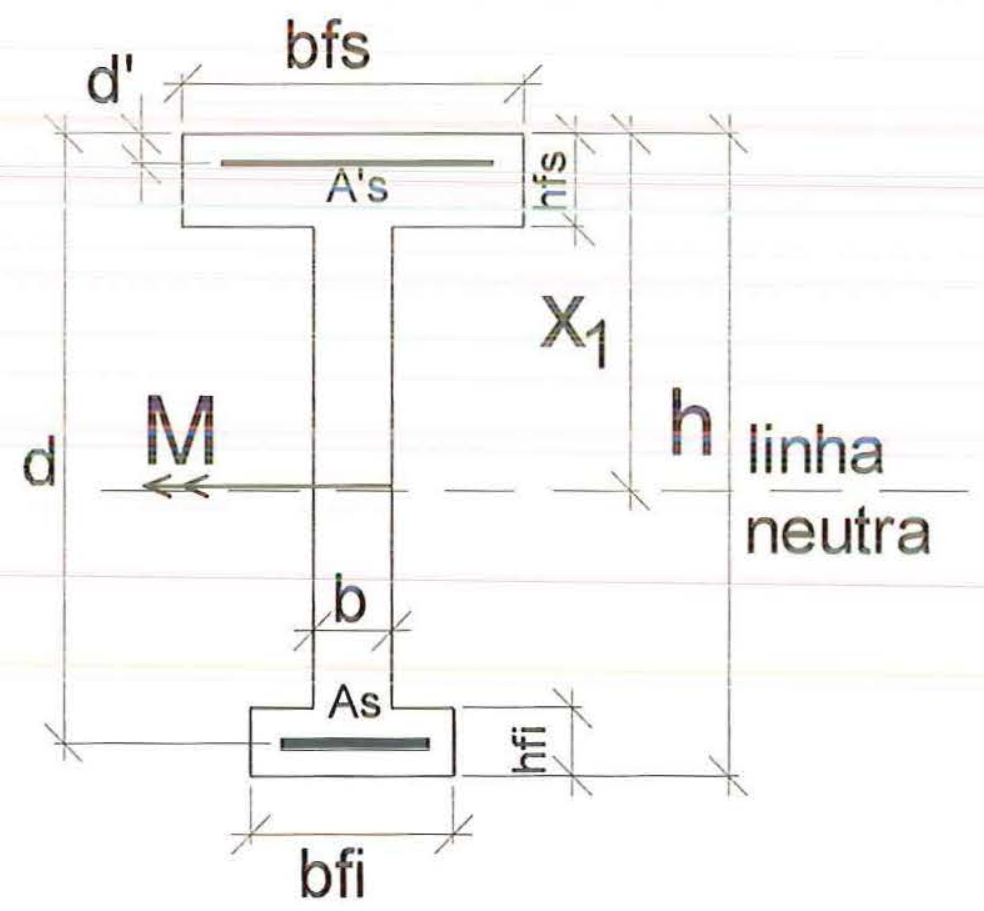

Figura A.1 : Seção em forma de "I ". 


\section{ANEXOS}

Aplicando a condição de momento estático nulo $\left(\mathbf{S}_{n, 1}=\mathbf{0}\right)$ em relação à linha neutra, $\mathrm{X}_{1}$ :

$$
\begin{aligned}
& \frac{b \cdot h^{2}}{2}+\alpha^{*} \cdot A_{s}^{\prime} \cdot\left(x_{1}-d^{\prime}\right)+\operatorname{auxs} \cdot h f s \cdot\left(x_{1}-\frac{h f s}{2}\right)+ \\
& -\frac{b \cdot\left(h-x_{1}\right)^{2}}{2}-\alpha^{*} \cdot A_{s} \cdot\left(d-x_{1}\right)-\text { auxi.hfi }\left(h-\frac{h f i}{2}-x_{1}\right)=0
\end{aligned}
$$

onde:

$$
\begin{aligned}
& \text { auxs }=\text { bfs }-\mathbf{b} \\
& \text { auxi }=\text { bfi }-\mathbf{b} \\
& \alpha^{*}=\alpha_{s}-1
\end{aligned}
$$

Isolando-se $\mathrm{X}_{1}$, a posição da linha neutra pode ser determinada pela expressão abaixo :

$$
x_{1}=\frac{\frac{b \cdot h^{2}}{2}+\alpha^{*} \cdot\left(A_{s} \cdot d+A_{s}^{\prime} \cdot d^{\prime}\right)+\frac{\operatorname{auxs}^{\prime} h s^{2}}{2}+\operatorname{auxi} \cdot\left(h f i \cdot h-\frac{h i^{2}}{2}\right)}{b \cdot h+\alpha^{*} \cdot\left(A_{s}+A_{s}^{\prime}\right)+\operatorname{auxs} \cdot h f s+\text { auxi.hfi }}
$$

O momento de inércia no estádio 1 em relação à linhha neutra será

$$
\begin{aligned}
& I_{n, 1}=\frac{b \cdot h^{3}}{12}+b \cdot h \cdot\left(\frac{h}{2}-x_{1}\right)^{2}+\alpha^{*} \cdot A_{s}^{\prime} \cdot\left(x_{1}-d^{\prime}\right)^{2}+\alpha^{*} \cdot A_{s}\left(d-x_{1}\right)^{2}+ \\
& +\frac{\text { auxs.hfs }}{12}+\text { auxs.hfs. }\left(x_{1}-\frac{h f s}{2}\right)^{2}+\frac{\text { auxi.hfi }}{12}+\text { auxi.hfi. }\left(h-\frac{h f i}{2}-x_{1}\right)^{2}
\end{aligned}
$$




\section{ANEXO B - FORMULAÇÃO PARA SEÇÃO "I" NO ESTÁDIO 2}

Serão apresentadas fórmulas práticas para a determinação da posição da linha neutra , $\mathrm{X}_{2}$, e do momento de inércia, $\mathrm{I}_{2}$, para a seção transversal apresentada na figura (A.2). Impondo-se a condiçäo de momento estático nulo em relaçäo a linha neutra resulta:

$\frac{\text { b. } x_{2}^{2}}{2}+$ auxs.hfs. $\left(x_{2}-\frac{h f s}{2}\right)^{2}+\alpha^{*} \cdot A_{s}^{\prime} \cdot\left(x_{2}-d^{\prime}\right)-\alpha_{s} \cdot A_{s} \cdot\left(d-x_{2}\right)=0$

A expressão acima é uma equação de segundo grau onde apenas uma de suas raízes tem sentido físico (pertence à seção, para flexão simples). Deve-se verificar, inicialmente, se a seção se comporta como se fosse retangular, de base igual a bís. Para esse fim é imposta esta condição, de início, e será aceita se a posição da linha neutra resultante estiver localizada acima da mesa comprimida, desse modo:

$$
\begin{aligned}
& \beta=2 \cdot\left(\alpha_{\mathrm{s}} \cdot \mathrm{A}_{\mathrm{s}}+\alpha^{*} \mathrm{~A}_{\mathrm{s}}^{\prime}\right) / \mathrm{bfs} \\
& \triangle=\beta^{2}+8 \cdot\left(\alpha_{\mathrm{s}} \cdot \mathrm{A}_{\mathrm{s}} \cdot d+\alpha^{*} \mathrm{~A}_{\mathrm{s}}^{\prime} \cdot \mathrm{d}^{\prime}\right) / \mathrm{bfs} \\
& \mathrm{X}_{2}=(-\beta+\sqrt{\Delta}) / 2
\end{aligned}
$$

O momento de inércia no estádio 2 , deste modo, será dado pela expressão abaixo, confirmada a hipótese de seçäo retangular :

$$
I_{2}=\frac{b \cdot x_{2}^{3}}{3}+\alpha^{*} \cdot A_{s}^{\prime} \cdot\left(x_{2}-d^{\prime}\right)^{2}+\alpha_{s} \cdot A_{s} \cdot\left(x_{2}-d\right)^{2}
$$

De outra forma, se $x_{2}>h f s$, a seção se comporta de maneira diferente e os cálculos devem ser refeitos, empregando-se as expressões abaixo:

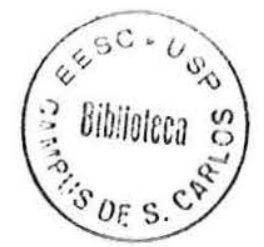




$$
\begin{aligned}
& \beta=2 \cdot\left[\text { auxs.hfs }+\left(\alpha_{s} \cdot A_{s}+\alpha^{*} \cdot A_{s}^{\prime}\right)\right] / b \\
& \Delta=\beta^{2}+8 \cdot\left(\frac{\text { auxs } \cdot h s^{2}}{2}+\alpha_{s} \cdot A_{s} \cdot d+\alpha^{*} \cdot A_{s}^{\prime} \cdot d^{\prime}\right) / b \\
& x_{2}=(-\beta+\sqrt{\Delta}) / 2
\end{aligned}
$$

O momento de inércia para o estádio 2 , em relação a linha será calculado de acordo com a seguinte fórmula :

$$
\begin{aligned}
I_{2} & =\frac{b \cdot x_{2}^{3}}{3}+\alpha_{s} \cdot A_{s} \cdot\left(d-x_{2}\right)^{2}+\alpha^{*} \cdot A_{s}^{\prime} \cdot\left(d^{\prime}-x_{2}\right)^{2}+ \\
& +\frac{\text { auxs.hfs } s^{3}}{12}+\text { auxs.hfs } \cdot\left(x_{2}-\frac{h f s}{2}\right)^{2}
\end{aligned}
$$

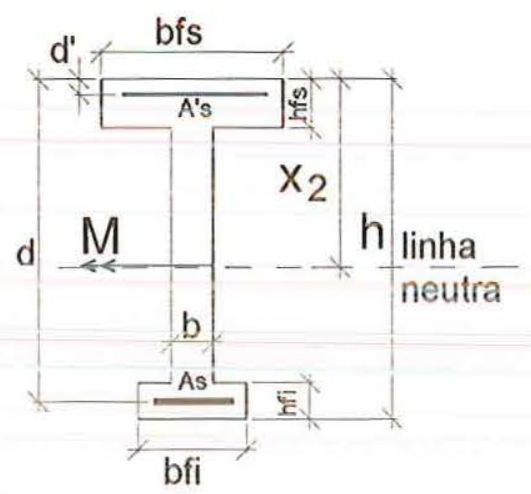

a)

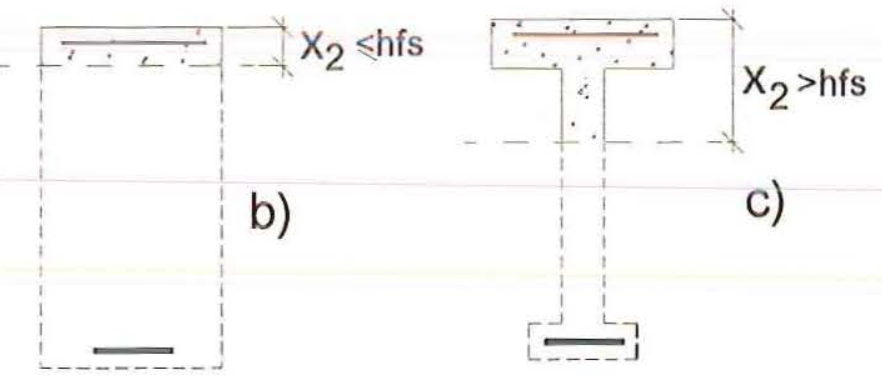

Figura A.2: Estádio 2 : a) seção transversal; b) comportamento de seção retangular; c) comportamento de seção "I" 


\section{ANEXO C - COORDENADAS DOS NÓS DO EXEMPLO 7.4.2}

Tabela A.1 : Coordenadas do exemplo 7.4.2

\begin{tabular}{|c|c|c|c|c|c|}
\hline Nó & $x(\mathrm{~cm})$ & $y(\mathrm{~cm})$ & Nó & $x(\mathrm{~cm})$ & $\mathrm{y}(\mathrm{cm})$ \\
\hline 1 & 100.00 & 1039.50 & 51 & 100.00 & 310.88 \\
\hline 2 & 203.75 & 1039.50 & 52 & 100.00 & 178.00 \\
\hline 3 & 307.50 & 1039.50 & 53 & 307.50 & 963.63 \\
\hline 4 & 1012.00 & 1039.50 & 54 & 307.50 & 818.75 \\
\hline 5 & 1117.88 & 1039.50 & 55 & 307.50 & 749.75 \\
\hline 6 & 1223.75 & 1039.50 & 56 & 307.50 & 680.75 \\
\hline 7 & 1329.63 & 1039.50 & 57 & 307.50 & 611.75 \\
\hline 8 & 1435.50 & 1039.50 & 58 & 307.50 & 527.75 \\
\hline 9 & 100.00 & 887.75 & 59 & 307.50 & 443.75 \\
\hline 10 & 203.75 & 887.75 & 60 & 407.75 & 443.75 \\
\hline 11 & 307.50 & 887.75 & 61 & 407.75 & 357.81 \\
\hline 12 & 419.75 & 887.75 & 62 & 407.75 & 271.88 \\
\hline 13 & 532.00 & 887.75 & 63 & 407.75 & 185.94 \\
\hline 14 & 659.75 & 887.75 & 64 & 659.75 & 816.25 \\
\hline 15 & 787.50 & 887.75 & 65 & 659.75 & 744.75 \\
\hline 16 & 899.75 & 887.75 & 66 & 659.75 & 673.25 \\
\hline 17 & 1012.00 & 887.75 & 67 & 659.75 & 601.75 \\
\hline 18 & 1117.88 & 887.75 & 68 & 659.75 & 531.13 \\
\hline 19 & 1223.75 & 887.75 & 69 & 659.75 & 460.50 \\
\hline 20 & 1329.63 & 887.75 & 70 & 659.75 & 389.88 \\
\hline 21 & 1435.50 & 887.75 & 71 & 659.75 & 319.25 \\
\hline 22 & 1547.75 & 887.75 & 72 & 659.75 & 248.63 \\
\hline 23 & 1660.00 & 887.75 & 73 & 659.75 & 178.00 \\
\hline 24 & 1787.75 & 887.75 & 74 & 1012.00 & 963.63 \\
\hline 25 & 100.00 & 100.00 & 75 & 1012.00 & 818.75 \\
\hline 26 & 176.94 & 100.00 & 76 & 1012.00 & 749.75 \\
\hline 27 & 253.88 & 100.00 & 77 & 1012.00 & 680.75 \\
\hline 28 & 330.81 & 100.00 & 78 & 1012.00 & 611.75 \\
\hline 29 & 407.75 & 100.00 & 79 & 1012.00 & 527.75 \\
\hline 30 & 533.75 & 100.00 & 80 & 1012.00 & 443.75 \\
\hline
\end{tabular}

\begin{tabular}{|c|c|c|}
\hline Nó & $x(\mathrm{~cm})$ & $y(\mathrm{~cm})$ \\
\hline 101 & 1435.50 & 527.75 \\
\hline 102 & 1435.50 & 443.75 \\
\hline 103 & 1535.75 & 443.75 \\
\hline 104 & 1535.75 & 357.81 \\
\hline 105 & 1535.75 & 271.88 \\
\hline 106 & 1535.75 & 185.94 \\
\hline 107 & 1787.75 & 816.25 \\
\hline 108 & 1787.75 & 744.75 \\
\hline 109 & 1787.75 & 673.25 \\
\hline 110 & 1787.75 & 601.75 \\
\hline 111 & 1787.75 & 531.13 \\
\hline 112 & 1787.75 & 460.50 \\
\hline 113 & 1787.75 & 389.88 \\
\hline 114 & 1787.75 & 319.25 \\
\hline 115 & 1787.75 & 248.63 \\
\hline 116 & 1787.75 & 178.00 \\
\hline 117 & 169.10 & 611.75 \\
\hline 118 & 238.30 & 611.75 \\
\hline 119 & 169.10 & 443.75 \\
\hline 120 & 238.30 & 443.75 \\
\hline 121 & 1085.35 & 611.75 \\
\hline 122 & 1154.55 & 611.75 \\
\hline 123 & 1297.10 & 611.75 \\
\hline 124 & 1366.30 & 611.75 \\
\hline 125 & 1085.35 & 443.75 \\
\hline 126 & 1154.50 & 443.75 \\
\hline 127 & 1297.10 & 443.75 \\
\hline 128 & 1366.30 & 443.75 \\
\hline
\end{tabular}




\section{ANEXOS}

Tabela A.1 : Coordenadas do exemplo 7.4 .2 (continuação)

\begin{tabular}{|c|c|c|c|c|c|}
\hline 31 & 659.75 & 100.00 & 81 & 911.75 & 443.75 \\
\hline 32 & 785.75 & 100.00 & 82 & 911.75 & 357.81 \\
\hline 33 & 911.75 & 100.00 & 83 & 911.75 & 271.88 \\
\hline 34 & 989.75 & 100.00 & 84 & 911.75 & 185.94 \\
\hline 35 & 1067.75 & 100.00 & 85 & 1223.75 & 937.50 \\
\hline 36 & 1145.75 & 100.00 & 86 & 1223.75 & 818.75 \\
\hline 37 & 1223.75 & 100.00 & 87 & 1223.75 & 749.75 \\
\hline 38 & 1301.75 & 100.00 & 88 & 1223.75 & 680.75 \\
\hline 39 & 1379.75 & 100.00 & 89 & 1223.75 & 611.75 \\
\hline 40 & 1457.75 & 100.00 & 90 & 1223.75 & 527.75 \\
\hline 41 & 1535.75 & 100.00 & 91 & 1223.75 & 443.75 \\
\hline 42 & 1661.75 & 100.00 & 92 & 1223.75 & 377.31 \\
\hline 43 & 1787.75 & 100.00 & 93 & 1223.75 & 310.88 \\
\hline 44 & 100.00 & 937.50 & 94 & 1223.75 & 244.44 \\
\hline 45 & 100.00 & 818.75 & 95 & 1223.75 & 178.00 \\
\hline 46 & 100.00 & 749.75 & 96 & 1435.50 & 963.63 \\
\hline 47 & 100.00 & 680.75 & 97 & 1435.50 & 818.75 \\
\hline 48 & 100.00 & 611.75 & 98 & 1435.50 & 749.75 \\
\hline 49 & 100.00 & 527.75 & 99 & 1435.50 & 680.75 \\
\hline 50 & 100.00 & 443.75 & 100 & 1435.50 & 611.75 \\
\hline
\end{tabular}


ANEXOS

ANEXO D - INCIDÊNCIA DAS BARRAS DO EXEMPLO 7.4.2

Tabela A.2 : Incidência das barras do exemplo 7.4.2

\begin{tabular}{|c|c|c|c|c|c|c|c|c|}
\hline Barra & $\begin{array}{c}\text { Nó } \\
\text { inicial }\end{array}$ & $\begin{array}{l}\text { Nó } \\
\text { final }\end{array}$ & Barra & $\begin{array}{c}\text { Nó } \\
\text { inicial }\end{array}$ & $\begin{array}{l}\text { Nó } \\
\text { final }\end{array}$ & Barra & $\begin{array}{c}\text { Nó } \\
\text { inicial }\end{array}$ & $\begin{array}{l}\text { Nó } \\
\text { final }\end{array}$ \\
\hline 1 & 1 & 2 & 51 & 33 & 34 & 101 & 78 & 77.00 \\
\hline 2 & 2 & 3 & 52 & 34 & 35 & 102 & 77 & 76 \\
\hline 3 & 4 & 5 & 53 & 35 & 36 & 103 & 76 & 75 \\
\hline 4 & 5 & 6 & 54 & 36 & 37 & 104 & 75 & 17 \\
\hline 5 & 6 & 7 & 55 & 37 & 38 & 105 & 17 & 74 \\
\hline 6 & 7 & 8 & 56 & 38 & 39 & 106 & 74 & 4 \\
\hline 7 & 9 & 10 & 57 & 39 & 40 & 107 & 37 & 95 \\
\hline 8 & 10 & 11 & 58 & 40 & 41 & 108 & 95 & 94 \\
\hline 9 & 11 & 12 & 59 & 41 & 42 & 109 & 94 & 93 \\
\hline 10 & 12 & 13 & 60 & 42 & 43 & 110 & 93 & 92 \\
\hline 11 & 13 & 14 & 61 & 25 & 52 & 111 & 92 & 91 \\
\hline 12 & 14 & 15 & 62 & 52 & 51 & 112 & 91 & 90 \\
\hline 13 & 15 & 16 & 63 & 51 & 50 & 113 & 90 & 89 \\
\hline 14 & 16 & 17 & 64 & 50 & 49 & 114 & 89 & 88 \\
\hline 15 & 17 & 18 & 65 & 49 & 48 & 115 & 88 & 87 \\
\hline 16 & 18 & 19 & 66 & 48 & 47 & 116 & 87 & 86 \\
\hline 17 & 19 & 20 & 67 & 47 & 46 & 117 & 86 & 19 \\
\hline 18 & 20 & 21 & 68 & 46 & 45 & 118 & 19 & 85 \\
\hline 19 & 21 & 22 & 69 & 45 & 9 & 119 & 85 & 6 \\
\hline 20 & 22 & 23 & 70 & 9 & 44 & 120 & 102 & 101 \\
\hline 21 & 23 & 24 & 71 & 44 & 1 & 121 & 101 & 100 \\
\hline 22 & 48 & 117 & 72 & 59 & 58 & 122 & 100 & 99 \\
\hline 23 & 117 & 118 & 73 & 58 & 57 & 123 & 99 & 98 \\
\hline 24 & 118 & 57 & 74 & 57 & 56 & 124 & 98 & 97 \\
\hline 25 & 78 & 121 & 75 & 56 & 55 & 125 & 97 & 21 \\
\hline 26 & 121 & 122 & 76 & 55 & 54 & 126 & 21 & 96 \\
\hline 27 & 122 & 89 & 77 & 54 & 11 & 127 & 96 & 8 \\
\hline 28 & 89 & 123 & 78 & 11 & 53 & 128 & 41 & 106 \\
\hline 29 & 123 & 124 & 79 & 53 & 3 & 129 & 106 & 105 \\
\hline 30 & 124 & 100 & 80 & 29 & 63 & 130 & 105 & 104 \\
\hline
\end{tabular}


ANEXOS

Tabela A.2 : Incidência das barras do exemplo 7.4 .2 (continuação)

\begin{tabular}{|c|c|c|}
\hline 31 & 50 & 119 \\
\hline 32 & 119 & 120 \\
\hline 33 & 120 & 59 \\
\hline 34 & 59 & 60 \\
\hline 35 & 81 & 80 \\
\hline 36 & 80 & 125 \\
\hline 37 & 125 & 126 \\
\hline 38 & 126 & 91 \\
\hline 39 & 91 & 127 \\
\hline 40 & 127 & 128 \\
\hline 41 & 128 & 102 \\
\hline 42 & 102 & 103 \\
\hline 43 & 25 & 26 \\
\hline 44 & 26 & 27 \\
\hline 45 & 27 & 28 \\
\hline 46 & 28 & 29 \\
\hline 47 & 29 & 30 \\
\hline 48 & 30 & 31 \\
\hline 49 & 31 & 32 \\
\hline 50 & 32 & 33 \\
\hline
\end{tabular}

\begin{tabular}{|l|l|l|}
\hline 81 & 63 & 62 \\
\hline 82 & 62 & 61 \\
\hline 83 & 61 & 60 \\
\hline 84 & 31 & 73 \\
\hline 85 & 73 & 72 \\
\hline 86 & 72 & 71 \\
\hline 87 & 71 & 70 \\
\hline 88 & 70 & 69 \\
\hline 89 & 69 & 68 \\
\hline 90 & 68 & 67 \\
\hline 91 & 67 & 66 \\
\hline 92 & 66 & 65 \\
\hline 93 & 65 & 64 \\
\hline 94 & 64 & 14 \\
\hline 95 & 33 & 84 \\
\hline 96 & 84 & 83 \\
\hline 97 & 83 & 82 \\
\hline 98 & 82 & 81 \\
\hline 99 & 80 & 79 \\
\hline 100 & 79 & 78 \\
\hline & & \\
\hline
\end{tabular}

\begin{tabular}{|c|c|c|}
\hline 131 & 104 & 103 \\
\hline 132 & 43 & 116 \\
\hline 133 & 116 & 115 \\
\hline 134 & 115 & 114 \\
\hline 135 & 114 & 113 \\
\hline 136 & 113 & 112 \\
\hline 137 & 112 & 111 \\
\hline 138 & 111 & 110 \\
\hline 139 & 110 & 109 \\
\hline 140 & 109 & 108 \\
\hline 141 & 108 & 107 \\
\hline 142 & 107 & 24 \\
\hline
\end{tabular}

ANEXO E - SEÇÕES TRANSVERSAIS E ARMIADURAS DOS ELEMENTOS DO EXEMPLO 7.4.2 
ANEXOS

Tabela A.3 : Seções transversais dos elementos.

\begin{tabular}{|c|c|c|c|c|c|c|}
\hline Elemento & $\mathrm{B}(\mathrm{cm})$ & $\mathrm{H}(\mathrm{cm})$ & $\mathrm{A}^{\prime} \mathrm{s}(\mathrm{cm} 2)$ & $\mathrm{d}^{\prime}(\mathrm{cm})$ & As (cm2) & $\mathrm{d}(\mathrm{cm})$ \\
\hline 1 & 20 & 50 & 1.6 & 3 & 1.6 & 47 \\
\hline 2 & 20 & 50 & 1.6 & 3 & 1.6 & 47 \\
\hline 3 & 20 & 50 & 2.5 & 3 & 1.6 & 47 \\
\hline 4 & 20 & 50 & 3.75 & 3 & 1.6 & 47 \\
\hline 5 & 20 & 50 & 3.75 & 3 & 1.6 & 47 \\
\hline 6 & 20 & 50 & 2.5 & 3 & 1.6 & 47 \\
\hline 7 & 20 & 60 & 2.5 & 3 & 10 & 57 \\
\hline 8 & 20 & 60 & 2.5 & 3 & 14 & 57 \\
\hline 9 & 20 & 60 & 4 & 3 & 14 & 57 \\
\hline 10 & 20 & 60 & 8 & 3 & 8.5 & 57 \\
\hline 11 & 20 & 60 & 8 & 3 & 2.5 & 57 \\
\hline 12 & 20 & 60 & 5 & 3 & 2.5 & 57 \\
\hline 13 & 20 & 60 & 5 & 3 & 6 & 57 \\
\hline 14 & 20 & 60 & 2.5 & 3 & 10 & 57 \\
\hline 15 & 20 & 60 & 4 & 3 & 10 & 57 \\
\hline 16 & 20 & 60 & 8 & 3 & 6 & 57 \\
\hline 17 & 20 & 60 & 8 & 3 & 6 & 57 \\
\hline 18 & 20 & 60 & 4 & 3 & 10 & 57 \\
\hline 19 & 20 & 60 & 2.5 & 3 & 10 & 57 \\
\hline 20 & 20 & 60 & 5 & 3 & 6 & 57 \\
\hline 21 & 20 & 60 & 5 & 3 & 4 & 57 \\
\hline 22 & 20 & 50 & 1.6 & 3 & 1.6 & 47 \\
\hline 23 & 20 & 50 & 1.6 & 3 & 1.6 & 47 \\
\hline 24 & 20 & 50 & 1.6 & 3 & 1.6 & 47 \\
\hline 25 & 20 & 60 & 6 & 3 & 2.5 & 57 \\
\hline 26 & 20 & 60 & 10 & 3 & 2.5 & 57 \\
\hline 27 & 20 & 60 & 10 & 3 & 2.5 & 57 \\
\hline 28 & 20 & 60 & 10 & 3 & 2.5 & 57 \\
\hline 29 & 20 & 60 & 10 & 3 & 2.5 & 57 \\
\hline 30 & 20 & 60 & 6 & 3 & 2.5 & 57 \\
\hline
\end{tabular}




\section{ANEXOS}

Tabela A.3 : Seções transversais dos elementos (continuação).

\begin{tabular}{|l|l|l|l|l|l|l|}
\hline 31 & 20 & 50 & 1.6 & 3 & 6 & 47 \\
\hline 32 & 20 & 50 & 1.6 & 3 & 6 & 47 \\
\hline 33 & 20 & 50 & 1.6 & 3 & 6 & 47 \\
\hline 34 & 20 & 50 & 1.6 & 3 & 6 & 47 \\
\hline 35 & 20 & 50 & 1.6 & 3 & 6 & 47 \\
\hline 36 & 20 & 50 & 1.6 & 3 & 6 & 47 \\
\hline 37 & 20 & 50 & 1.6 & 3 & 6 & 47 \\
\hline 38 & 20 & 50 & 1.6 & 3 & 4 & 47 \\
\hline 39 & 20 & 50 & 1.6 & 3 & 4 & 47 \\
\hline 40 & 20 & 50 & 1.6 & 3 & 6 & 47 \\
\hline 41 & 20 & 50 & 1.6 & 3 & 6 & 47 \\
\hline 42 & 20 & 50 & 1.6 & 3 & 6 & 47 \\
\hline 43 & 20 & 50 & 1.6 & 3 & 4 & 47 \\
\hline 44 & 20 & 50 & 0.6 & 3 & 8 & 47 \\
\hline 45 & 20 & 50 & 0.6 & 3 & 8 & 47 \\
\hline 46 & 20 & 50 & 0.6 & 3 & 8 & 47 \\
\hline 47 & 20 & 50 & 0.6 & 3 & 8 & 47 \\
\hline 48 & 20 & 50 & 8 & 3 & 4 & 47 \\
\hline 49 & 20 & 50 & 8 & 3 & 4 & 47 \\
\hline 50 & 20 & 50 & 0.6 & 3 & 6 & 47 \\
\hline 51 & 20 & 50 & 0.6 & 3 & 6 & 47 \\
\hline 52 & 20 & 50 & 0.6 & 3 & 4 & 47 \\
\hline 53 & 20 & 50 & 6 & 3 & 4 & 47 \\
\hline 54 & 20 & 50 & 6 & 3 & 4 & 47 \\
\hline 55 & 20 & 50 & 6 & 3 & 4 & 47 \\
\hline 56 & 20 & 50 & 6 & 3 & 4 & 47 \\
\hline 57 & 20 & 50 & 0.6 & 3 & 4 & 47 \\
\hline 58 & 20 & 50 & 0.6 & 3 & 8 & 47 \\
\hline 59 & 20 & 50 & 0.6 & 3 & 8 & 47 \\
\hline 60 & 20 & 50 & 6 & 3 & 4 & 47 \\
\hline
\end{tabular}


ANEXOS

Tabela A.3 : Seções transversais dos elementos (continuação).

\begin{tabular}{|c|c|c|c|c|c|c|}
\hline 61 & 20 & 50 & 3.75 & 3 & 4 & 47 \\
\hline 62 & 20 & 50 & 3.75 & 3 & 4 & 47 \\
\hline 63 & 20 & 50 & 6 & 3 & 6 & 47 \\
\hline 64 & 20 & 50 & 6 & 3 & 6 & 47 \\
\hline 65 & 20 & 50 & 6 & 3 & 4 & 47 \\
\hline 66 & 20 & 50 & 6 & 3 & 2.5 & 47 \\
\hline 67 & 20 & 50 & 6 & 3 & 2.5 & 47 \\
\hline 68 & 20 & 50 & 6 & 3 & 2.5 & 47 \\
\hline 69 & 20 & 50 & 3.75 & 3 & 2.5 & 47 \\
\hline 70 & 20 & 50 & 3.75 & 3 & 2.5 & 47 \\
\hline 71 & 20 & 50 & 3.75 & 3 & 2.5 & 47 \\
\hline 72 & 20 & 50 & 1.6 & 3 & 4 & 47 \\
\hline 73 & 20 & 50 & 1.6 & 3 & 6 & 47 \\
\hline 74 & 20 & 50 & 10 & 3 & 6 & 47 \\
\hline 75 & 20 & 50 & 10 & 3 & 4 & 47 \\
\hline 76 & 20 & 50 & 10 & 3 & 4 & 47 \\
\hline 77 & 20 & 50 & 10 & 3 & 4 & 47 \\
\hline 78 & 20 & 50 & 10 & 3 & 4 & 47 \\
\hline 79 & 20 & 50 & 10 & 3 & 4 & 47 \\
\hline 80 & 20 & 50 & 1.6 & 3 & 5 & 47 \\
\hline 81 & 20 & 50 & 1.6 & 3 & 5 & 47 \\
\hline 82 & 20 & 50 & 2.5 & 3 & 5 & 47 \\
\hline 83 & 20 & 50 & 2.5 & 3 & 2.5 & 47 \\
\hline 84 & 20 & 50 & 10 & 3 & 2.5 & 47 \\
\hline 85 & 20 & 50 & 10 & 3 & 2.5 & 47 \\
\hline 86 & 20 & 50 & 10 & 3 & 2.5 & 47 \\
\hline 87 & 20 & 50 & 10 & 3 & 3.75 & 47 \\
\hline 88 & 20 & 50 & 2.5 & 3 & 3.75 & 47 \\
\hline 89 & 20 & 50 & 5 & 3 & 2.5 & 47 \\
\hline 90 & 20 & 50 & 5 & 3 & 2.5 & 47 \\
\hline 91 & 20 & 50 & 5 & 3 & 2.5 & 47 \\
\hline 92 & 20 & 50 & 5 & 3 & 2.5 & 47 \\
\hline
\end{tabular}




\section{ANEXOS}

Tabela A.3 : Seçöes transversais dos elementos (continuação).

\begin{tabular}{|c|c|c|c|c|c|c|}
\hline 93 & 20 & 50 & 2.5 & 3 & 3.75 & 47 \\
\hline 94 & 20 & 50 & 1.6 & 3 & 3.75 & 47 \\
\hline 95 & 20 & 50 & 1.6 & 3 & 5 & 47 \\
\hline 96 & 20 & 50 & 1.6 & 3 & 5 & 47 \\
\hline 97 & 20 & 50 & 2.5 & 3 & 5 & 47 \\
\hline 98 & 20 & 50 & 2.5 & 3 & 2.5 & 47 \\
\hline 99 & 20 & 50 & 1.6 & 3 & 2.5 & 47 \\
\hline 100 & 20 & 50 & 1.6 & 3 & 3.75 & 47 \\
\hline 101 & 20 & 50 & 4 & 3 & 3.75 & 47 \\
\hline 102 & 20 & 50 & 4 & 3 & 3.75 & 47 \\
\hline 103 & 20 & 50 & 8 & 3 & 2.5 & 47 \\
\hline 104 & 20 & 50 & 8 & 3 & 2.5 & 47 \\
\hline 105 & 20 & 50 & 8 & 3 & 1 & 47 \\
\hline 106 & 20 & 50 & 8 & 3 & 1 & 47 \\
\hline 107 & 20 & 50 & 10 & 3 & 6 & 47 \\
\hline 108 & 20 & 50 & 10 & 3 & 6 & 47 \\
\hline 109 & 20 & 50 & 10 & 3 & 6 & 47 \\
\hline 110 & 20 & 50 & 10 & 3 & 14 & 47 \\
\hline 111 & 20 & 50 & 6 & 3 & 14 & 47 \\
\hline 112 & 20 & 50 & 14 & 3 & 14 & 47 \\
\hline 113 & 20 & 50 & 14 & 3 & 2.5 & 47 \\
\hline 114 & 20 & 50 & 14 & 3 & 2.5 & 47 \\
\hline 115 & 20 & 50 & 14 & 3 & 2.5 & 47 \\
\hline 116 & 20 & 50 & 24 & 3 & 2.5 & 47 \\
\hline 117 & 20 & 50 & 10 & 3 & 3.75 & 47 \\
\hline 118 & 20 & 50 & 10 & 3 & 3.75 & 47 \\
\hline 119 & 20 & 50 & 10 & 3 & 3.75 & 47 \\
\hline 120 & 20 & 50 & 1.6 & 3 & 2.5 & 47 \\
\hline 121 & 20 & 50 & 1.6 & 3 & 3.75 & 47 \\
\hline 122 & 20 & 50 & 4 & 3 & 3.75 & 47 \\
\hline 123 & 20 & 50 & 4 & 3 & 3.75 & 47 \\
\hline 124 & 20 & 50 & 8 & 3 & 2.5 & 47 \\
\hline
\end{tabular}


ANEXOS

Tabela A.3 : Seções transversais dos elementos (continuação).

\begin{tabular}{|c|c|c|c|c|c|c|}
\hline 126 & 20 & 50 & 8 & 3 & 1 & 47 \\
\hline 127 & 20 & 50 & 8 & 3 & 1 & 47 \\
\hline 128 & 20 & 50 & 1.6 & 3 & 5 & 47 \\
\hline 129 & 20 & 50 & 1.6 & 3 & 5 & 47 \\
\hline 130 & 20 & 50 & 2.5 & 3 & 5 & 47 \\
\hline 131 & 20 & 50 & 2.5 & 3 & 2.5 & 47 \\
\hline 132 & 20 & 50 & 8 & 3 & 4 & 47 \\
\hline 133 & 20 & 50 & 8 & 3 & 4 & 47 \\
\hline 134 & 20 & 50 & 8 & 3 & 4 & 47 \\
\hline 135 & 20 & 50 & 4 & 3 & 4 & 47 \\
\hline 136 & 20 & 50 & 2.5 & 3 & 4 & 47 \\
\hline 137 & 20 & 50 & 5 & 3 & 4 & 47 \\
\hline 138 & 20 & 50 & 5 & 3 & 4 & 47 \\
\hline 139 & 20 & 50 & 5 & 3 & 2.5 & 47 \\
\hline 140 & 20 & 50 & 5 & 3 & 2.5 & 47 \\
\hline 141 & 20 & 50 & 1.6 & 3 & 3.75 & 47 \\
\hline 142 & 20 & 50 & 1.6 & 3 & 3.75 & 47 \\
\hline
\end{tabular}




\section{REFERÊNCIAS BIBLIOGRÁFICAS}

ÁLVARES, M.S. (1993); Estudo de um modelo para o concreto: formulação, identificação paramétrica e aplicação do método dos elementos finitos. São Carlos. Dissertação (Mestrado) - Departamento de Engenharia de Estruturas, EESC-USP.

AMERICAN SODIETY OF CIVIL ENGINEERS (1982). State-of-the-art report on finite element analysis of reinforced concrete. New York. ASCE.

ASSOCIAÇÃO BRASILEIRA DE NORMAS TÉCNICAS (1978). NB-1 - Projeto e execução de obras de concreto armado. Rio de Janeiro. (1984). NBR 8681 - Ações e segurança nas estruturas. Rio de Janeiro.

BATHE, K. J. and CIMENTO, A. P. (1980). Some practical procedures for the soluction of nonlinear finite element equations. Computer Methods in Applied Mechanics and Engeneering. V. 22, n. 1, 59-85, April 1980.

BAZANT, Z. P. (1982). Creep and Shrinkage in Concrete Structures. Chichester, John Willey \& Sons. $2^{\mathrm{a}}$. edição.

BRESLER, B. ; SCORDELIS, A.C. (1963). Shear strenghtof reinforced concrete beams. Proc. of the American Concrete Institute, v. 60 n 1 p.51-74.

CAMARA, J. M. M. N. (1988). Comportamento em serviço das estruturas de betão armado e pré-esforçado. Tese (Doutorado). Departamento de Engenharia Civil, Universidade Técnica de Lisboa.

CHEN, W. F. (1982). Plasticity in reinforced concrete. New York. MacGraw-Hill. 
CHEN, W. F. and ZHANG, H. (1990). Structural plasticity: Theory, problems and CAE Software. Indiana, Springer-Verlag.

CILONI, A. D. (1993). Sobre o comportamento em serviço Estruturas Planas de Concreto Armado. Tese (Doutorado) - Departamento de Engenharia de Estruturas, EESC-USP.

CEB; Manual on cracking and deformations; Bulletin n 158; 1985

COMITÉ EURO-INTERNACIONAL DU BÉTON (1990). CEB-FIP Model Code 1990.

CORREA, M. R. S. (1990). Aperfeiçoamento dos modelos usualmente empregados no projeto de sistemas estruturais de edificios. Tese (Doutorado). Escola de Engenharia de São Carlos, Universidade de São Paulo.

DEBERNARDI, P. G. (1983). La Deformazione Differita in C. A. Sogette a Fessurazione: Considerazioni sui Metodi Approssimati di Caicoio. L'industria Italiana del Cemento. Roma. V. 7/8, pg. 499-510.

FUSCO, P. B. (1986). Estruturas de concreto: solicitações normais. Rio de Janeiro, Guanabara Dois. $2^{a}$.edição.

GHALI, A. and FAVRE, R. (1986). Concrete structures: stress and deformations. Chapman and Hall, $1^{\text {a }}$. edição.

LEONHARDT, FRITZ (1977). Construções de concreto - volume 1 : Princípios básicos para o dimensionamento das estruturas de concreto armado. Tradução. Rio de Janeiro, Interciência. $1^{a}$. edição.

MACHADO, C. P. (1989). Tensões, deformações e deslocamentos em estruturas de concreto armado e protendido. Dissertação de Mestrado. Escola Politécnica, Universidade de São Paulo. 
MUNAIAR NETO, J. (1994). Modelos de comportamento viscoelástico e viscoplástico na análise de estruturas planas. Dissertação de Mestrado. Escola de Engenharia de São Carlos, Universidade de São Paulo.

NEVILE, A. M. (1983). Creep of Plain and Structural Concrete. New York. London Construction Press.

OLIVEIRA, R. S. (1997). Análise de pavimentos de concreto armado com a consideração da não-linearidade física. Dissertação de Mestrado. Escola de Engenharia de São Carlos, Universidade de São Paulo.

OWEN, D. R. J. and HINTON, H. (1980). Finite Element in Plasticity : Theory and Practice. Swansea, Pineridge Press Lid.

PROENÇA, S. P. B. (1986). Noções Básicas de Reologia. São Carlos, Escola de Engenharia de São Carlos - Publicações. Publicação 045/86.

PROENÇA, S. P. B. (1996). Notas de Aula da Disciplina Análise Não-linear de Estruturas. São Carlos, Escola de Engenharia de São Carlos, Departamento de Engenharia de Estruturas.

SAVASSI, W. (1996). Introdução ao Método dos Elementos Finitos em Análise Linear de Estruturas. São Carlos, Escola de Engenharia de São Carlos Publicações. $1^{a}$. edição.

ZIENKIEWICS, O. C.; VALLIAPAN, S.; KING, I.P. (1969). Elasto-plastic solutions on engineering problems - 'initial stress', finite element aproach. Int. Joumal of Num. Methods in Engineering, V.1, p.75-100. 